\title{
Estudo da mudança estrutural fotoinduzida em filmes de vidros a base de polifosfato de antimônio
}

\author{
Fábio Simões De Vicente
}

\section{USP/IFSC/SBI}

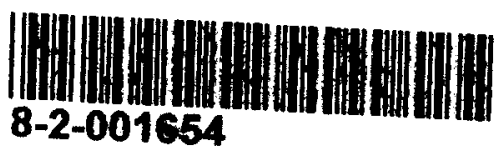

\begin{abstract}
Tese apresentada à Área Interunidades em Ciêncla e Engenharia de Materiais, da Universidade de São Paulo, para obtenção do título de Doutor em Ciências e Engenharia de Materiais.
\end{abstract}

Orientador: Prof. Dr. Máximo Siu Li 
Vicente, Fábio Simões De

"Estudo da mudança estrutural fotoinduzida em filmes de vidros a base de polifosfato de antimônio" Fábio Simões De Vicente - São Carlos, 2004

Tese (Doutorado) - Interunidades Ciência e Engenharia de Materiais da Universidade de São Paulo, 2004 - páginas: 181

Área: Ciência e Engenharia de Materiais

Orientador: Prof. Dr. Máximo Siu Li

1. Vidros fosfato, Antimônio, Filmes finos.

1. Título 


\section{Universidade de São Paulo \\ Ciência e Engenharia de Materiais}

MEMBROS DA COMISSAO JULGADORA DA TESE DE DOUTORADO DE FÁBIO SIMOES DE VICENTE APRESENTADA A AREA INTERUNIDADES CIENCIA E ENGENHARLA DE MATERIAIS, UNMERSIDADE DE SAO PAULO, EM 16/12/2004.

COMISSÃO JULGADORA:

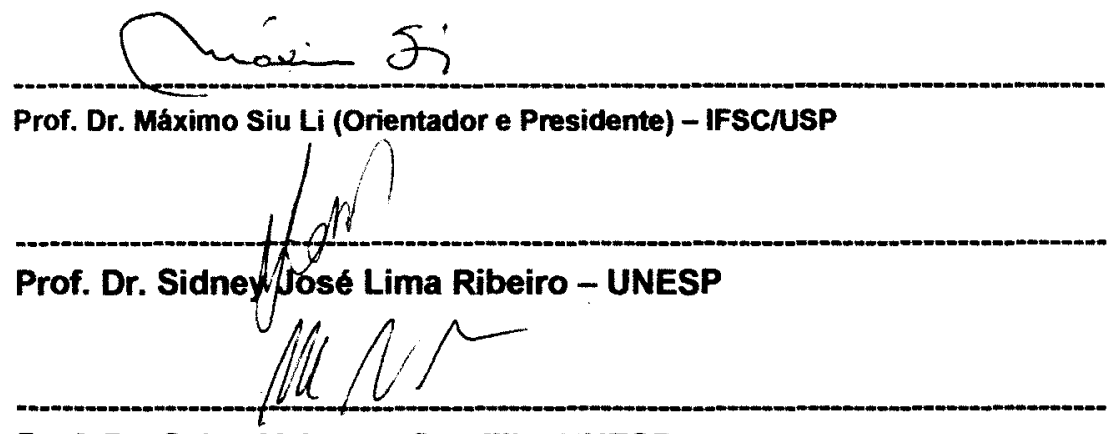

Prof. Dr. Celso Valentim Santilli - UNESP

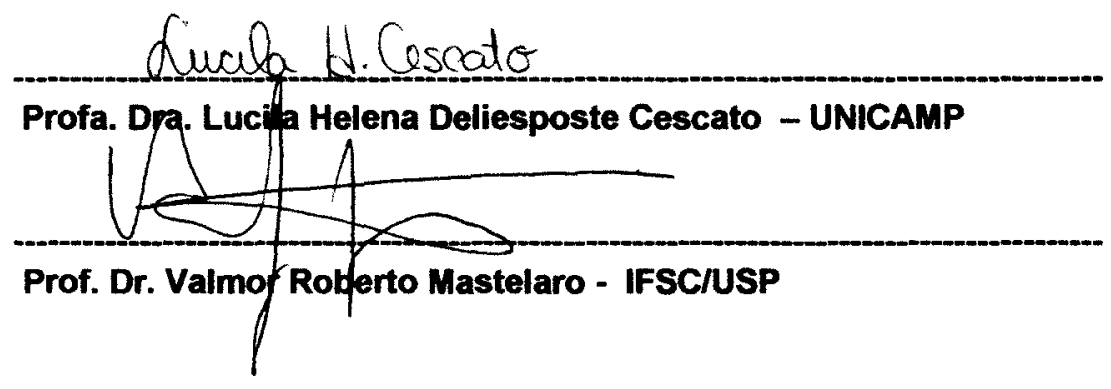


“Dedico este trabalho a esta pessoa tão especial, à minha esposa, Tatiana, pelo apoio e incentivo a cada instante nesta jornada". 
“Deus não joga dados"

Albert Einstein 


\section{AGRADECIMENTOS}

Agradeço ao Professor Máximo Siu Li pela amizade, paciência, e orientação neste trabalho e também aos Professores Valmor R. Mastelaro, Younés Messaddeq e Sidney J. L. Ribeiro pela grande colaboração nas discussões e idéias e pela disposição de seus laboratórios e por todo tipo de cooperação.

Aos companheiros de trabalho do IFSC-São Carlos, Antônio Carlos de Castro, Profa. Elisabete A. P. Rubo, Luis Humberto, Antônio Salerno Jr., Profa. Rosa M. Scalvi, e do IQ-Unesp-Araraquara, Sandra e Marcelo Nalim pelas valiosas discussões e por todo tipo de colaboração. Aos professores Tito Bonagamba e Eduardo R. de Azevedo pela colaboração e cooperação com as medidas de RMN. Também ao professor Cláudio Magon e ao amigo José Fernando de Lima pela colaboração nas medidas de RPE e nos trabalhos em conjunto. Ao Professor Manfredo Tabaknics pela colaboração com as medidas de RBS. E também ao Professor Pedro A. P. Nascente do CCDM pela colaboração com as medidas de XPS. Aos responsáveis pela linha de SXS, Flavio Vicentin e Edílson Tamura do Laboratório Nacional de Luz Síncrotron pela atenção dada durante as medidas de XANES. A Professora Lucila Cescato do IFGWUnicamp, que gentilmente nos forneceu material bibliográfico e também contribuiu com várias idéias em nossa primeira tentativa de montar um sistema para gravação de redes holográficas em filmes. Aos técnicos do Grupo de Crescimento de Cristais e Materiais Cerâmicos, Geraldo e Manoel Roncon pela dedicação nas medidas de DSC e Talystep. A todos que colaboraram direta ou indiretamente com o desenvolvimento deste trabalho.

A Fapesp pelo apoio financeiro (proc.:99/11523-5). 
I - ÍNDICE DE FIGURAS viii

II - ÍNDICE DE TABELAS......................................................................... xii

III - LISTA DE SÍMBOLOS ............................................................................... xii

IV - RESUMO ............................................................................................... xiv

V - ABSTRACT …...................................................................................... $\mathrm{xvi}$

1 INTRODUÇÃO ............................................................................................. 1

1.1 Vidros - Uma breve Introdução ....................................................................... 2

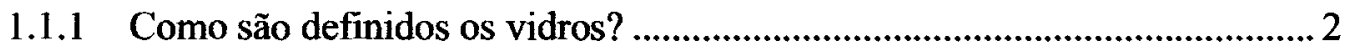

1.1.2 Formação do vidro a partir de um fundido .................................................... 6

1.2 Os Vidros Fosfatos............................................................................................. 8

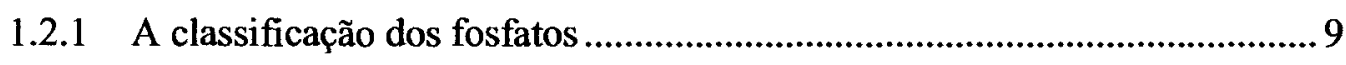

1.2.2 A formação e estrutura básica dos Vidros Fosfatos ..................................... 14

1.2.3 Vidros fosfatos modificados por óxidos metálicos ....................................... 16

1.2.4 Polarizabilidade, Despolimerização e Dispersão em vidros fosfatos ......... 19

1.3 Vidros a base de Antimônio ................................................................................. 25

1.4 Fenômenos Fotoinduzidos em vidros e filmes........................................................ 29

1.4.1 Efeitos puramente Fotoinduzidos...............................................................31

1.4.2 A relevância do efeito Foto-Térmico .............................................................. 36

1.5 Motivações para o estudo de filmes de $\left[\mathrm{Sb}\left(\mathrm{PO}_{3}\right)_{3}\right]_{n}-\mathrm{Sb}_{2} \mathrm{O}_{3} \ldots . . . . . . . . . . . . . . . . . . . . . . . . . .42$

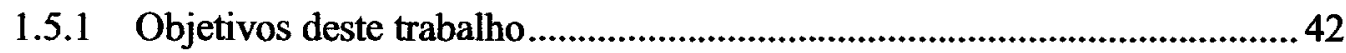

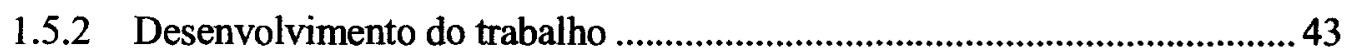

2 METODOLOGIA EXPERIMENTAL ............................................. 45

2.1 Preparação dos vidros..................................................................................................... 47

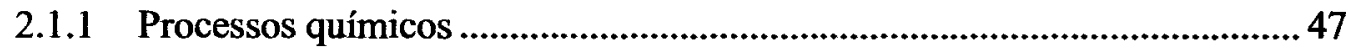

2.1.1.1 Produção do Ortofosfato de Antimônio $\mathrm{SbPO}_{4}$ …………………......47

2.1.1.2 Produção do Polifosfato de Antimônio $\left[\mathrm{Sb}\left(\mathrm{PO}_{3}\right)_{3}\right]_{n}$.......................... 48

2.1.2 Processos de fusão e recozimento .................................................................... 49

2.2 Preparação dos Filmes Finos....................................................................... 51

2.2.1 Processos de deposição de filmes ..............................................................51

2.2.2 Processos de formação dos filmes ............................................................52

2.2.3 O Sistema de Evaporação por Canhão de Elétrons......................................... 55 
2.2.4 A deposição dos filmes a partir de vidros $\left[\mathrm{Sb}\left(\mathrm{PO}_{3}\right)_{3}\right]_{\mathrm{n}}-\mathrm{Sb}_{2} \mathrm{O}_{3} \ldots \ldots \ldots \ldots \ldots . . . . .57$

2.3 Caracterização das Amostras ................................................................58

2.3.1 Técnicas de Análise Térmica .........................................................58

2.3.1.1 Calorimetria exploratória diferencial (DSC) ............................58

2.3.2 Técnicas de Análise de Superficie ....................................................60

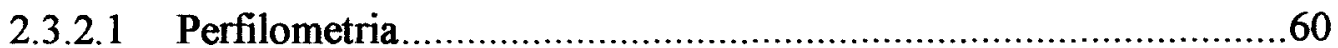

2.3.2.2 Microscopia de força atômica (AFM) …..................................60

2.3.2.3 Microscopia eletrônica de varredura (MEV) ............................61

2.3.2.4 Espectroscopia de dispersão de Raios-X (EDX/WDX) ................62

2.3.2.5 Análise de Materiais por Feixe Iônico (RBS) ............................63

2.3.2.6 Espectroscopia de Fotoelétrons excitados por Raios-X (XPS) .......65

2.3.3 Espectroscopia Óptica e Vibracional ................................................68

2.3.3.1 Espectroscopia de Absorção Óptica no UV-VIS .........................68

2.3.3.2 Espectroscopia de Absorção no infravermelho (FTIR) .................69

2.3.3.3 Espectroscopia de Emissão Óptica no UV-VIS ..........................69

2.3.4 Técnicas para determinação Estrutural ...............................................71

2.3.4.1 Difração de Raios-X (XRD) ........................................... 71

2.3.4.2 Espectroscopia de Absorção de Raios-X (XAS) .........................71

2.3.4.2.1 As técnicas de XANES e XAFS .....................................72

2.3.4.3 Ressonância Magnética Nuclear (NMR) …............................ 77

2.3.4.3.1 A técnica de MAS-NMR .............................................. 79

2.3.4.4 Ressonância Paramagnética Eletrônica (RPE)............................81

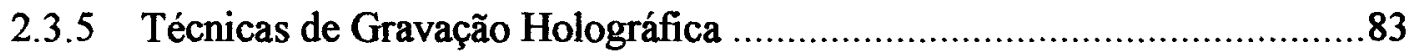

2.3.5.1 Gravação de Redes e Medidas de Eficiência .............................83

3 RESULTADOS EXPERIMENTAIS E ANÁLISE............................86

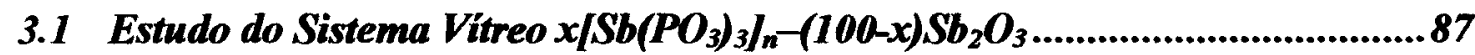

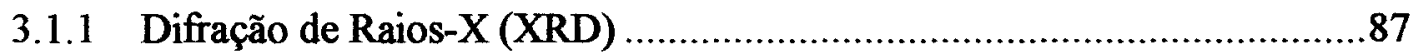

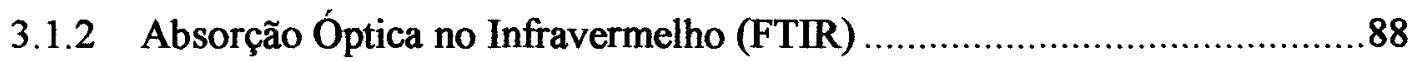

3.1.3 Calorimetria Exploratória Diferencial (DSC) ...................................89

3.1.4 Ressonância Magnética Nuclear (MAS - NMR) ................................91

3.1.5 Formação vítrea no sistema $x\left[\mathrm{Sb}\left(\mathrm{PO}_{3}\right)_{3}\right]_{\mathbf{n}}-(100-\mathrm{x}) \mathrm{Sb}_{2} \mathrm{O}_{3} \ldots \ldots \ldots \ldots \ldots \ldots . . . . . . . . . . .66$

3.1.6 Janela de Transmitância e Durabilidade Química..................................96

3.1.7 Índice de Refração e Densidade dos vidros $x\left[\mathrm{Sb}\left(\mathrm{PO}_{3}\right)_{3}\right]_{\mathrm{n}}-(100-\mathrm{x}) \mathrm{Sb}_{2} \mathrm{O}_{3} . .98$ 
3.1.8 Absorção de Raios-X próximo da Borda de Absorção (XANES) 100

3.1.8.1 XANES da borda $\mathrm{K}$ do fósforo de vidros $x\left[\mathrm{Sb}\left(\mathrm{PO}_{3}\right)_{3}\right]_{n}-(100-x)$ $\mathrm{Sb}_{2} \mathrm{O}_{3}$ 100

3.1.9 Efeito de escurecimento em vidros de $\mathrm{x}\left[\mathrm{Sb}\left(\mathrm{PO}_{3}\right)_{3}\right]_{\mathrm{n}}-(100-\mathrm{x}) \mathrm{Sb}_{2} \mathrm{O}_{3} \ldots \ldots . . .103$

3.1.9.1 XANES da borda $\mathrm{K}$ do fósforo para vidros com escurecimento.. 105

3.1.9.2 Microscopia Eletrônica de Varredura para vidros com escurecimento 106

3.2 Estudo dos Fenômenos Fotoinduzidos em Filmes de $\left[\mathrm{Sb}\left(\mathrm{PO}_{3}\right)_{3}\right]_{n}-\mathrm{Sb}_{2} \mathrm{O}_{3} \ldots . . .107$ EVOLUÇÃO DO EFEITO DE FOTOCONTRAÇÃO 108

3.2.1 Fotocontração VS. Tempo e Potência de exposição ao laser....................... 108

3.2.2 Fotocontração em função da concentração de $\left[\mathrm{Sb}\left(\mathrm{PO}_{3}\right)_{3}\right]_{\mathrm{n}}$.......................... 114

3.2.3 Fotocontração em diferentes atmosferas e no vácuo .................................. 115

3.2.4 Fotocontração em função da espessura do filme ........................................117

CARACTERIZAÇÃO DO EFEITO DE FOTOCONTRAÇÃO POR ANÁLISES QUÍMICAS. 118

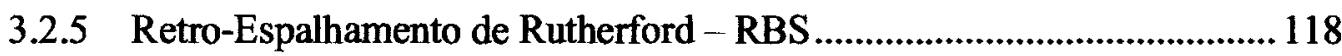

3.2.5.1 Resultados de RBS para filmes de $\left[\mathrm{Sb}\left(\mathrm{PO}_{3}\right)_{3}\right]_{n}-\mathrm{Sb}_{2} \mathrm{O}_{3} \ldots \ldots \ldots \ldots \ldots . . . . .120$

3.2.6 Análises de WDX de Filmes de $\left[\mathrm{Sb}\left(\mathrm{PO}_{3}\right)_{3}\right]_{\mathrm{n}}-\mathrm{Sb}_{2} \mathrm{O}_{3} \ldots \ldots \ldots \ldots . . . . . . . . . . . . . . . . . . . .121$

3.2.7 Análises de XPS de Filmes de $\left[\mathrm{Sb}\left(\mathrm{PO}_{3}\right)_{3}\right]_{\mathrm{n}}-\mathrm{Sb}_{2} \mathrm{O}_{3} \ldots \ldots \ldots \ldots \ldots \ldots \ldots \ldots \ldots . . . . . . . . . . . . . . . . . . . .123$

CARACTERIZAÇAOO A NÍVEL ESTRUTURAL DO EFEITO DE

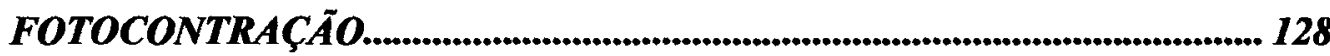

3.2.8 Absorção de Raios-X próximo da Borda de Absorção (XANES) ............ 128

3.2.8.1 XANES da borda $K$ do fósforo de filmes ........................................ 128

3.2.8.2 XANES de Filmes Tratados Termicamente .................................. 129

3.2.9 Difração de Raios-X, FTIR, e estrutura entre Vidros e Filmes.................. 137

3.2.10 Luminescência de Filmes de $\left[\mathrm{Sb}\left(\mathrm{PO}_{3}\right)_{3}\right]_{n}-\mathrm{Sb}_{2} \mathrm{O}_{3}$ dopados com $\mathrm{Cu}^{2+} \ldots 140$

3.2.11 Ressonância Paramagnética Eletrônica - RPE ...................................... 143

3.2.11.1 A técnica de RPE para análise estrutural em vidros ...................... 143

3.2.11.2 Resultados de RPE para filmes dopados com $\mathrm{Cu}^{2+}$........................ 146

MODELO PARA FOTOCONTRAÇÃO ESTRUTURAL................................ 150

3.2.12 Modelo para Fotocontração baseado em centros de defeitos ................. 150

3.3 Aplicações do Efeito de Fotocontração para Holografia ................................... 152

3.3.1 Gravação de Redes Holográficas com Espelho de Lloyd.......................... 152

3.3.2 Montagem e Cálculo do espaçamento das redes holográficas................... 152 


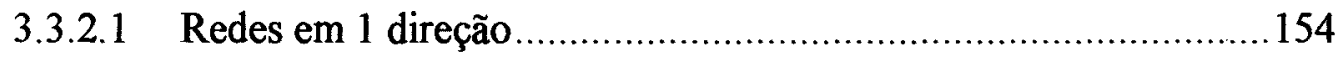

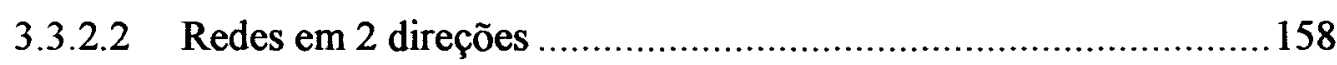

3.3.3 Medidas de Eficiência de Difração das redes ............................................ 160

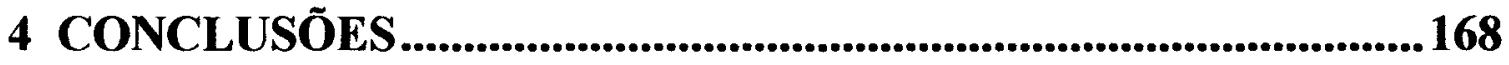

5 SUGESTÕES PARA TRABALHOS FUTUROS.............................173

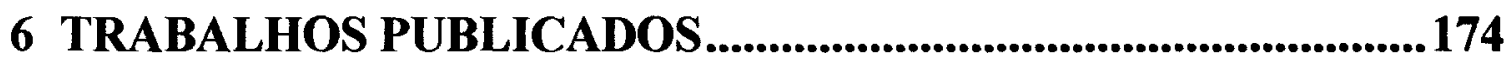

6.1 Publicações em Artigos Cientificos............................................................174

6.2 Participaç̃̃es em Congressos..........................................................................174

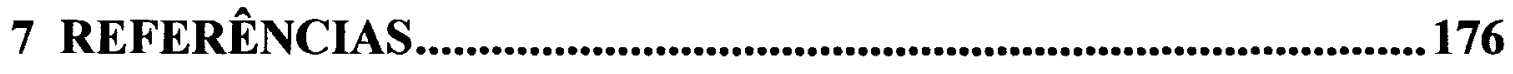




\section{I-ÍNDICE DE FIGURAS}

Figura 1-Representação bidimensional: a) do arranjo cristalino de um cristal de composição $\mathrm{A}_{2} \mathrm{O}_{3}$; b) representação da rede vítrea do mesmo composto. 3

Figura 2 - Curva Volume vs. Temperatura de resfriamento de um líquido fundido...............................................6

Figura 3 - Representação de um tetraedro $\mathrm{PO}_{4}$, onde $\mathrm{O}_{\mathrm{L}}$ são oxigênios ligantes, $\mathrm{O}_{\mathrm{NL}}$, são oxigênios não-ligantes, e $\mathrm{O}_{\mathrm{T}}$ oxigênio terminal.

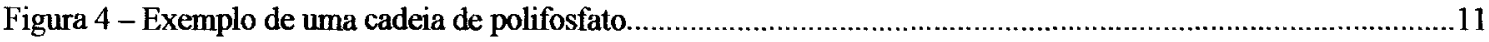

Figura 5 - Representação de cadeias de Fosfatos Lineares............................................................................11

Figura 6 - Representação de cadeias de metafosfatos (ciclofosfatos) …...........................................................12

Figura 7 - Representação de uma cadeia em 3D com composição de ultrafosfato amorfo.......................................13

Figura 8 - Estrutura básica de um vidro fosfato com $\mathrm{PO}_{4}$ conectados................................................................15

Figura 9 - Exemplos de Aplicações de vidros fosfatos modificados por metais pesados e íons terras raras................18

Figura 10 - Exemplo de ligação de cadeias de fosfatos com íons metálicos..........................................................20

Figura 11 - Ligações químicas entre cátions de metal pesado $(\mathrm{R}+)$ e grupos $\mathrm{PO}_{4} \mathrm{em}$ vidros fosfatos.......................21

Figura 12 - Configurações de sítios $\mathrm{Q}^{\mathrm{n}}$ para o grupo $\left(\mathrm{PO}_{4}\right)$ em vidros fosfato .....................................................22

Figura 13 - Modelo de despolimerização em vidros fosfato pela adição de óxidos modificadores............................22

Figura 14 - Difração de Nêutrons mostrando a distância média das ligações P-OT e P-OL na primeira esfera de coordenação do átomo de fósforo para o $\mathrm{P}_{2} \mathrm{O}_{5}$ puro e vidros fosfatos modificados.

Figura 15 - Representação do efeito de dispersão entre grupos $\mathrm{PO}_{4}$ tendo como referência o $\mathrm{P}_{2} \mathrm{O}_{5}$ puro e o aumento da concentração de um cátion modificador na estrutura...................................................................................26

Figura 16 - Representação estrutural das três formas mais comuns do óxido de antimônio, $\mathrm{Sb}_{2} \mathrm{O}_{3}, \mathrm{Sb}_{2} \mathrm{O}_{4}$ e $\mathrm{Sb}_{2} \mathrm{O}_{5} \ldots .26$

Figura 17 - Fibra óptica de silicato de antimônio com núcleo de $15 \mu \mathrm{m}$ de diâmetro, fabricada pela técnica de

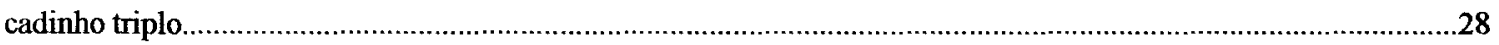

Figura 18 - Diagrama esquemático mostrando os fenômenos fotoinduzidos mais estudados em vidros.....................32

Figura 19 - Modelo dos processos de mudança estrutural e luminescência, nos fenômenos fotoinduzidos em vidros.33

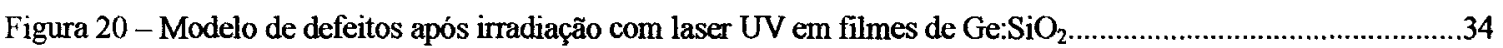

Figura 21- Distribuição radial de temperatura em um feixe de laser com perfil gaussiano de intensidade.................37

Figura 22 - Perda de enxofre na superficie de filme de $\mathrm{Sb}_{2} \mathrm{~S}_{3}$, para irradiações com laser de $\mathrm{Ar}+$ em $514 \mathrm{~nm}$ e densidade de potência de $40 \mathrm{~W} / \mathrm{cm}^{2}$.

Figura 23 - Microscopia eletrônica de um filme de $\mathrm{As}_{40} \mathrm{~S}_{30} \mathrm{Se}_{30}$ onde se observa a formação cristalito de arsenolita $\left(\mathrm{As}_{2} \mathrm{O}_{3}\right)_{2}$ após irradiação UV.

Figura 24 - Exemplo de fotopolimerização de formaldeído sobre substrato de $\mathrm{Ag}$ (111) após irradiação com laser $\mathrm{Nd}$ Y YAG (355 nm), levando em conta a componente fototérmica gerada pelo laser.

Figura 25 - Espectro de difração de Raios-X do $\mathrm{SbPO}_{4}$ produzido. As barras verticais referem-se ao espectro padrão do $\mathrm{SbPO}_{4}$ da base de dados JCPDS.

Figura 26 - Espectro de difração de Raios-X do $\left[\mathrm{Sb}\left(\mathrm{PO}_{3}\right)_{3}\right]_{n}$ produzido...

Figura 27 - Ilustração do forno tubular, cadinho de carbono vitreo, e molde de aço inox utilizados para a fusão dos vidros $x\left[\mathrm{Sb}\left(\mathrm{PO}_{3}\right)_{3}\right]_{n}-(100-x) \mathrm{Sb}_{2} \mathrm{O}_{3}$.

Figura 28 - Relevo do potencial sobre a superficie de um sólido ....................................................................54

Figura 29 - Processo da coalescência de dois núcleos, formando uma ilha ...........................................................54

Figura 30- Visão geral do sistema de evaporação.a) Câmara de evaporação, b)Eletrodos para evaporação resistiva, c) Canhão de elétrons, d) Sistema de vácuo, e) Sistema para elevação da câmara .........................................................55

Figura 31- Canhão de Elétrons: a) Vista superior, b) vista lateral ................................................................56

$$
\begin{aligned}
& \text { IFSC-USP SERVICOO DE BIBLIOTECA } \\
& \text { INFORIVACÄO }
\end{aligned}
$$


Figura 32- Curvas de Calorimetria Exploratória Diferencial mostrando as temperaturas características $\left(T_{g}, T_{x}, T_{f}\right)$ do sistema obtidas pelo método de intersecção de tangentes. .............................................................................59

Figura 33-Espectro RBS de um filme fino de $\mathrm{SiO}_{2} \mathrm{com} 300 \mathrm{~nm}$ de espessura sobre substrato de carbono..............64

Figura 34-Espectro de XPS na forma de intensidade em função da energia, para amostra metálica.........................67

Figura 35- Diagrama do arranjo experimental utilizado para medir a luminescência de filmes.................................70

Figura 36- Diagrama esquemático do decaimento do estado excitado após o efeito de absorção de raios-X. a) Fluorescência de raios-X; b) Efeito de emissão de elétron Auger e fluorescência. …..............................................73

Figura 37- Esquema ilustrativo sobre a definição de absorção de um feixe de luz que atravessa uma amostra de espessura $t$, onde absorbância é definido como $\log (\mathrm{Io} / \mathrm{I})$

Figura 38- Espectro típico de XAFS da borda K para o átomo de ferro, na forma de coeficiente de absorção $\mu(\mathrm{E})$ vs. Energia, onde as regiões de XANES e EXAFS estão indicadas. .......................................................................75

Figura 39- Espectro de XANES da borda $\mathrm{K}$ do ferro, para vários compostos......................................................76

Figura 40- Exemplo de análise para determinação da estrutura local dos átomos de fósforo em amostras de diferentes espécies de fosfatos de cálcio através de XANES na borda K do fósforo $(2149 \mathrm{eV})$............................................77

Figura 41- Ilustração da precessão de spins nucleares sobre influência de um campo magnético em RMN...............78

Figura 42- Variação da magnetização dos spins nucleares em função do tempo. b) Transformada de Fourier da

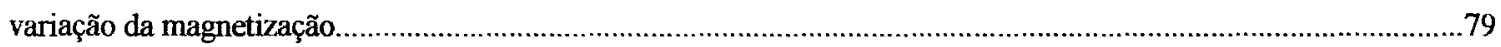

Figura 43- Representação da diferença de energia entre dois estados de spin eletrônicos gerados por aplicação de campo magnético $\mathrm{B}_{0}$.

Figura 44- Montagem do espelho de Lloyd para gravação de redes holográficas e medidas de eficiência de difração em tempo real em filmes.

Figura 45- Difratograma de Raios-X mostrando a evolução na estrutura do vidro em função da variação (em moles \%) da composição no sistema $x\left[\mathrm{Sb}\left(\mathrm{PO}_{3}\right)_{3}\right]_{n}-(100-x) \mathrm{Sb}_{2} \mathrm{O}_{3},(5 \leq x \leq 40)$.

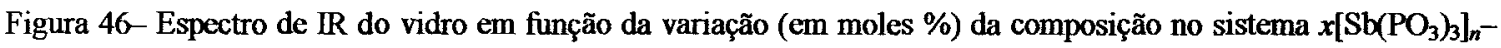
$(100-x) \mathrm{Sb}_{2} \mathrm{O}_{3}$. $(5 \leq x \leq 40)$..

Figura 47-Curvas de DSC para o sistema vitreo $x\left[\mathrm{Sb}\left(\mathrm{PO}_{3}\right)_{3}\right]_{n}-(100-x) \mathrm{Sb}_{2} \mathrm{O}_{3}(5 \leq x \leq 40) \ldots$ .89

Figura 48 - Evolução da Temp. de Transição Vitrea $\left(\mathrm{T}_{\mathrm{g}}\right)$ e do parâmetro de estabilidade térmica $\left(\mathrm{T}_{\mathrm{x}}-\mathrm{T}_{\mathrm{g}}\right)$ para 0 sistema $\left[\mathrm{Sb}\left(\mathrm{PO}_{3}\right)_{3}\right]_{n}-\mathrm{Sb}_{2} \mathrm{O}_{3}$ em função do aumento de polifosfato de antimônio.

Figura 49 - Comparação dos espectros de $\mathrm{RMN}$ do sistema vitreo $\left[\mathrm{Sb}\left(\mathrm{PO}_{3}\right)_{3}\right]_{n}-\mathrm{Sb}_{2} \mathrm{O}_{3}$ com $\mathrm{SbPO}_{4}$ e $\left[\mathrm{Sb}\left(\mathrm{PO}_{3}\right)_{3}\right]_{n} \ldots . .92$

Figura 50 - Espectro de $\mathrm{RMN}$ para o sistema vítreo $x\left[\mathrm{Sb}\left(\mathrm{PO}_{3}\right)_{3}\right]_{n}-(100-x) \mathrm{Sb}_{2} \mathrm{O}_{3}(5 \leq x \leq 40)$. Os picos marcados por asterisco representam o crescimento da fase cristalina no vidro.

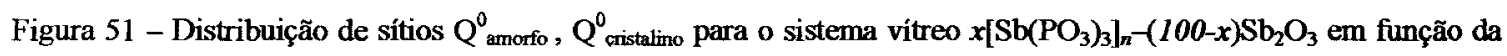
composição ( $x$, em moles \%), determinados a partir dos espectros de deslocamento químico do ${ }^{31} \mathrm{P}$.........................95

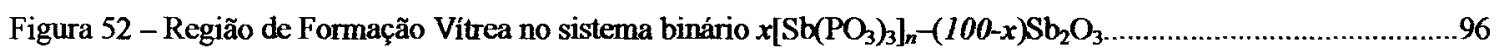

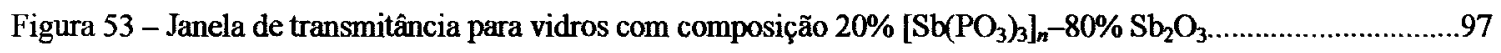

Figura 54 - Taxa de dissolução (durabilidade química) dos vidros $x\left[\mathrm{Sb}\left(\mathrm{PO}_{3}\right)_{3}\right]_{n}-(100-x) \mathrm{Sb}_{2} \mathrm{O}_{3} \ldots \ldots \ldots \ldots \ldots \ldots \ldots \ldots \ldots . . . . . . . . . . . . . .77$

Figura 55 - Comportamento de parâmetros como: a) Densidade; b)Índice de refração; c) Massa molar normalizada da composição, para vidros $x\left[\mathrm{Sb}\left(\mathrm{PO}_{3}\right)_{3}\right]_{n}-(100-x) \mathrm{Sb}_{2} \mathrm{O}_{3}$ em função da concentração de formador vítreo, $x$.................. 98

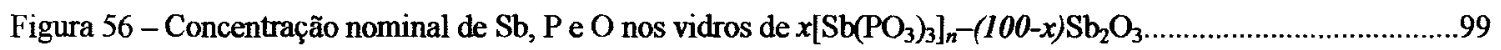

Figura 57 - Espectro XANES da borda $\mathrm{K}$ do fósforo para vidros $x\left[\mathrm{Sb}\left(\mathrm{PO}_{3}\right)_{3}\right]_{n}-(100-x) \mathrm{Sb}_{2} \mathrm{O}_{3}(5 \leq x \leq 20) \ldots \ldots \ldots \ldots . . . .100$

Figura 58 - Espectro XANES da borda $\mathrm{K}$ do fósforo para vidros $x\left[\mathrm{Sb}\left(\mathrm{PO}_{3}\right)_{3}\right]_{n}-(100-x) \mathrm{Sb}_{2} \mathrm{O}_{3}(20 \leq x \leq 40) \ldots \ldots \ldots . . .101$

Figura 59 - Espectros de Referência de XANES da borda $\mathrm{K}$ do fósforo para diferentes matrizes...........................102

Figura 60 - Imagens de vidros produzidos: A) vidros fundidos a temperatura normal, B) vidros com diferentes intensidades de escurecimento controlado pela temperatura de fusão. 
Figura 61- Deslocamento da borda de absorção óptica para vidros $20 \%\left[\mathrm{Sb}\left(\mathrm{PO}_{3}\right)_{3}\right]_{n}-80 \% \mathrm{Sb}_{2} \mathrm{O}_{3}$ com efeito de escurecimento. 104

Figura 62 - Espectro de XANES da borda $\mathrm{K}$ do fósforo para vidros $20 \%\left[\mathrm{Sb}\left(\mathrm{PO}_{3}\right)_{3}\right]_{n}-80 \% \mathrm{Sb}_{2} \mathrm{O}_{3}$ a diferentes temperaturas de fusão. 105

Figura 63 - MEV de vidros $20 \%\left[\mathrm{Sb}\left(\mathrm{PO}_{3}\right)_{3}\right]_{n}-80 \% \mathrm{Sb}_{2} \mathrm{O}_{3}$ com escurecimento. A região escura representa a matriz vítrea e as partículas claras são $100 \%$ antimônio metálico. .106

Figura 64 - Deslocamento da borda de absorção óptica em filmes $20 \%\left[\mathrm{Sb}\left(\mathrm{PO}_{3}\right)_{3}\right]_{n}-80 \% \mathrm{Sb}_{2} \mathrm{O}_{3}$ irradiados com 100 $\mathrm{mW}$ em diferentes comprimentos de onda (fotoclareamento) e filme tratado termicamente (fotoescurecimento)..... 108 Figura 65 - a) Fotocontração em filme de 3,5 $\mu \mathrm{m}$ irradiado com laser UV sem a utilização de máscara, b) Fotocontração no filme irradiado com a utilização de máscara retangular. c) Perfil da espessura do filme medida por perfilometria. (filme de $20 \%\left[\mathrm{Sb}\left(\mathrm{PO}_{3}\right)_{3}\right]_{n}-80 \% \mathrm{Sb}_{2} \mathrm{O}_{3}$; irradiação: $5 \mathrm{~W} / \mathrm{cm}^{2}, 1$ hora).

Figura 66 - Perfil da fotocontração provocada por laser na superficie de um filme de $20 \%\left[\mathrm{Sb}\left(\mathrm{PO}_{3}\right)_{3}\right]_{n}-80 \%$ $\mathrm{Sb}_{2} \mathrm{O}_{3}$, (espessura: $1,0 \mu \mathrm{m}$ ) exposto a $100 \mathrm{~mW}$ de $U V\left(5 \mathrm{~W} / \mathrm{cm}^{2}\right)$ por 4 horas.

Figura 67 - Máscaras com furos circulares de aproximadamente $0,8 \mathrm{~mm}$ de diâmetro em lâmina de metal utilizadas no processo de irradiação de filmes com laser UV

Figura 68 - Imagens de fotocontração em filmes de 20\% $\left[\mathrm{Sb}\left(\mathrm{PO}_{3}\right)_{3}\right]_{n}-80 \% \mathrm{Sb}_{2} \mathrm{O}_{3}$ (espessura:1,0 $\mu \mathrm{m}$ ) expostos a 5 W/ $\mathrm{cm}^{2}$ de UV por 4 horas. A) e B) microscopia óptica; C) AFM ; D) Perfilometria.

Figura 69 - Fotocontração em função do tempo de irradiação em filmes de $20 \%\left[\mathrm{Sb}\left(\mathrm{PO}_{3}\right)_{3}\right]_{n}-80 \% \mathrm{Sb}_{2} \mathrm{O}_{3}$ (espessura: $0,8 \mu \mathrm{m})$ expostos a $5 \mathrm{~W} / \mathrm{cm}^{2}$ de UV $(100 \mathrm{~mW})$

Figura 70 - Fotocontração em um filme de $20 \%\left[\mathrm{Sb}\left(\mathrm{PO}_{3}\right)_{3}\right]_{n}-80 \% \mathrm{Sb}_{2} \mathrm{O}_{3}$ (espessura:0,8 $\mu \mathrm{m}$ ), a) em função do tempo de exposição, b) em função da potência de irradiação UV.

Figura 71 - Fotocontração em filmes de $x\left[\mathrm{Sb}\left(\mathrm{PO}_{3}\right)_{3}\right]_{n}-(100-x) \mathrm{Sb}_{2} \mathrm{O}_{3}$ irradiado por 4 horas com $100 \mathrm{~mW}\left(5,0 \mathrm{~W} / \mathrm{cm}^{2}\right)$, em função da concentração de formador vítreo $\left[\mathrm{Sb}\left(\mathrm{PO}_{3}\right)_{3}\right]_{n}$ 114

Figura 72 - Fotocontração em função da atmosfera em filmes de 20\% $\left[\mathrm{Sb}\left(\mathrm{PO}_{3}\right)_{3}\right]_{n}-80 \% \mathrm{Sb}_{2} \mathrm{O}_{3}$ (espessura:1,0 $\mu \mathrm{m}$ ) irradiados com laser UV por 4 horas. a) $100 \mathrm{~mW}\left(5,0 \mathrm{~W} / \mathrm{cm}^{2}\right)$, b) $300 \mathrm{~mW}\left(15 \mathrm{~W} / \mathrm{cm}^{2}\right)$

Figura 73- Comportamento da fotocontração em função da espessura para filmes $20 \%\left[\mathrm{Sb}\left(\mathrm{PO}_{3}\right)_{3}\right]_{n}-80 \% \mathrm{Sb}_{2} \mathrm{O}_{3}$, irradiados com laser UV (100 $\mathrm{mW} / 4$ horas).

Figura 74 - Simulação do espectro de RBS para amostra composta por Sb, P, e O com (a) 1000 ângstrons e (b) com 10000 ângstrons de espessura.

Figura 75 - Espectros de RBS obtido para os filmes de $20 \%\left[\mathrm{Sb}\left(\mathrm{PO}_{3}\right)_{3}\right]_{n}-80 \% \mathrm{Sb}_{2} \mathrm{O}_{3}$ (espessura:5 $\mu \mathrm{m}$ ) não irradiado e irradiado com $5 \mathrm{~W} / \mathrm{cm}^{2}$ durante 6 horas. As linhas sólidas representam a simulação obtida pelo software RUMP....120 Figura 76 - Medida obtida por WDX, da composição de $\mathrm{Sb}$, P e $\mathrm{O}$ em filme de $20 \%\left[\mathrm{Sb}\left(\mathrm{PO}_{3}\right)_{3}\right]_{n}-80 \% \mathrm{Sb}_{2} \mathrm{O}_{3}$ (espessura:5 $\mu \mathrm{m}$ ), irradiado com diferentes tempos de exposição ao laser UV com $5 \mathrm{~W} / \mathrm{cm}^{2}(100 \mathrm{~mW}) \ldots \ldots \ldots \ldots \ldots . . .121$

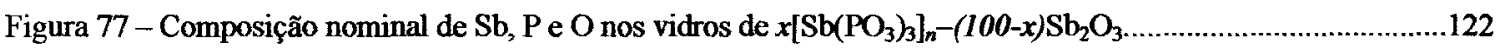
Figura 78 - Comparação da evolução da fotocontração com a perda de fósforo causada pela irradiação de Filmes de $20 \%\left[\mathrm{Sb}\left(\mathrm{PO}_{3}\right)_{3}\right]_{n}-80 \% \mathrm{Sb}_{2} \mathrm{O}_{3} \mathrm{com} 5 \mathrm{~W} / \mathrm{cm}^{2}(100 \mathrm{~mW})$ de laser $\mathrm{UV}$ 123

Figura 79 - Espectros de XPS das linhas do $\mathrm{Sb}(3 \mathrm{~d})$ e $\mathrm{O}(1 \mathrm{~s})$ para filmes de $20 \%$ [Sb( $\left.\left.\mathrm{PO}_{3}\right)_{3}\right]_{n}-80 \% 2 \mathrm{Sb}_{2} \mathrm{O}_{3}$ (espessura:5 $\mu \mathrm{m}$ ). a) filme não irradiado; b) filme após irradiação com laser UV (6 horas com $5 \mathrm{~W} / \mathrm{cm}^{2}$ ). 126 Figura 80 - Espectros de XPS das linhas do $\mathrm{P}(2 \mathrm{p})$ e $\mathrm{C}(\mathrm{ls})$ para filmes de $20 \%\left[\mathrm{Sb}\left(\mathrm{PO}_{3}\right)_{3}\right]_{n}-80 \% 20 \mathrm{Sb}_{2} \mathrm{O}_{3}$ (espessura:5 $\mu \mathrm{m}$ ). a) filme não irradiado; b) filme após irradiação com laser UV (6 horas com $5 \mathrm{~W} / \mathrm{cm}^{2}$ ). 127

Figura 81 - Espectro de XANES da borda $\mathrm{K}$ do fósforo para filmes de $20 \%$ [ $\left.\mathrm{Sb}\left(\mathrm{PO}_{3}\right)_{3}\right]_{n}-80 \% \mathrm{Sb}_{2} \mathrm{O}_{3}$ 128 Figura 82 - Espectro de XANES da borda $\mathrm{K}$ do fósforo para filmes com composição $20 \%\left[\mathrm{Sb}\left(\mathrm{PO}_{3}\right)_{3}\right]_{n}-80 \% \mathrm{Sb}_{2} \mathrm{O}_{3}$; Comparação entre filmes irradiados, tratados termicamente e vidro .130 
Figura 83 - Espectro de XANES da borda $\mathrm{K}$ do fósforo para Filmes de $20 \%\left[\mathrm{Sb}\left(\mathrm{PO}_{3}\right)_{3}\right]_{n}-80 \% \mathrm{Sb}_{2} \mathrm{O}_{3}$ (FNIR), (FIRlh e FIR4h) e (FNIRT1 e FNIRT2). (irradiação com $100 \mathrm{~mW}$ de laser UV $\left(5,0 \mathrm{~W} / \mathrm{cm}^{2}\right)$ ).

Figura 84-Espectro de XANES da borda $\mathrm{L} 3$ do antimônio para Filmes de $20 \%\left[\mathrm{Sb}\left(\mathrm{PO}_{3}\right)_{3}\right]_{n}-80 \% \mathrm{Sb}_{2} \mathrm{O}_{3} \ldots \ldots \ldots \ldots . . . . .133$ Figura 85 - Espectro de XANES da borda $\mathrm{K}$ do fósforo para Filmes de $20 \%$ [ $\left.\mathrm{Sb}\left(\mathrm{PO}_{3}\right)_{3}\right]_{n}-80 \% \mathrm{Sb}_{2} \mathrm{O}_{3}$ (FNIR), (FIR1h), (FIR1hT1 e FIR1hT2) e (FNIRT2). (irradiação com $100 \mathrm{~mW}$ de laser UV $\left(5,0 \mathrm{~W} / \mathrm{cm}^{2}\right)$ )

Figura 86 - XANES da borda K do fósforo para Filmes de $20 \%\left[\mathrm{Sb}\left(\mathrm{PO}_{3}\right)_{3}\right]_{n}-80 \% \mathrm{Sb}_{2} \mathrm{O}_{3}$ (FNIR), (FIR4h), (FIR4hT1, FIR4hT2 e FIR4hT3) e (FNIRT2).

Figura 87 - XANES (linha branca) de filmes de $20 \%\left[\mathrm{Sb}\left(\mathrm{PO}_{3}\right)_{3}\right]_{n}-80 \% \mathrm{Sb}_{2} \mathrm{O}_{3}$ (FNIR), (FIRlh) e (FIR4h); tratamentos térmicos $\mathrm{T} 0, \mathrm{~T} 1, \mathrm{~T} 2 \mathrm{e} \mathrm{T} 3$

Figura 88 - Espectros de difração de raios-X para filmes não-irradiados, irradiados com UV e vidro do sistema $20 \%$ $\left[\mathrm{Sb}\left(\mathrm{PO}_{3}\right)_{3}\right]_{n}-80 \% \mathrm{Sb}_{2} \mathrm{O}_{3}$, mostrando o FSDP que representa o pré-pico relativo a vazios intersticiais ao redor de unidades estruturais em materiais amorfos.

Figura 89 - Espectro de IR de filmes $20 \%\left[\mathrm{Sb}\left(\mathrm{PO}_{3}\right)_{3}\right]_{n}-80 \% \mathrm{Sb}_{2} \mathrm{O}_{3}$ não-irradiados e irradiados com UV. a) Região de

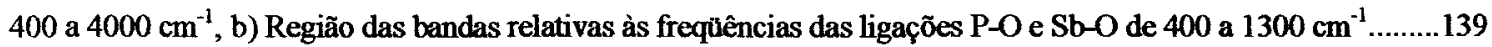

Figura 90 - Luminescência de filmes de $20 \%\left[\mathrm{Sb}\left(\mathrm{PO}_{3}\right)_{3}\right]_{n}-80 \% \mathrm{Sb}_{2} \mathrm{O}_{3} \mathrm{com} 2 \%$ de CuO..................................141

Figura 91 - Deconvolução com duas bandas gaussianas dos espectros de luminescência de filmes de $20 \%$

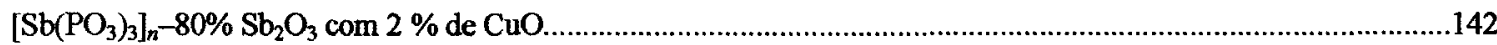

Figura 92 - Diagrama de energia do $\mathrm{Cu}^{2+}$ em campo cristalino octaédrico com distorção estrutural em vidros........144 Figura 93 - Perspectiva de complexos octaédricos distorcidos ao longo do eixo z, proposto a partir do diagrama de energia do $\mathrm{Cu}^{2+}$ em vidros óxidos . .144

Figura 94 - Diagrama de energia do $\mathrm{Cu}^{2+} \mathrm{em}$ campo cristalino em vidros fosfato: (a) tetraedro puro, (b) com distorção Tetragonal e (c) com distorção Rômbica.....................................................................................................145 Figura 95 - Espectro de RPE do $\mathrm{Cu}^{2+}$ em 3 simetrias distintas em diferentes composiçðes em vidros fosfato..........145 Figura 96 - Espectro de RPE para o vidro $\left[\mathrm{Sb}\left(\mathrm{PO}_{3}\right)_{3}\right]_{n}-\mathrm{Sb}_{2} \mathrm{O}_{3} \mathrm{com} 2 \%$ de $\mathrm{CuO}$................................................146 Figura 97 - Estrutura a curto alcance para os vidros de $\left[\mathrm{Sb}\left(\mathrm{PO}_{3}\right)_{3}\right]_{n}-\mathrm{Sb}_{2} \mathrm{O}_{3}$ mostrando um átomo de $\mathrm{Sb}$ em sítio octaédrico cercado por seis tetraedros $\mathrm{PO}_{4}$

Figura 98-Espectros de RPE obtidos para composição $20 \%\left[\mathrm{Sb}\left(\mathrm{PO}_{3}\right)_{3}\right]_{n}-80 \% \mathrm{Sb}_{2} \mathrm{O}_{3} \operatorname{com~} 2 \%$ de Cu${ }^{2+}$, (a) vidro, (b) Filme não-irradiado, (c) Filme irradiado com UV.

Figura 99 - Espectros de RPE obtidos a $10 \mathrm{~K}$ para Filme não-irradiado e Filme irradiado com laser UV (composição $20 \%\left[\mathrm{Sb}\left(\mathrm{PO}_{3}\right)_{3}\right]_{n}-80 \% \mathrm{Sb}_{2} \mathrm{O}_{3} \mathrm{com} 2 \%$ de $\mathrm{Cu}^{2+}$ ); a) ESEEM 2 pulsos, b) ESEEM 3 pulsos 148

Figura 100 - Esquema ilustrativo do efeito de fotopolimerização de centros deficientes em oxigênio, $\left(\mathrm{PO}_{3}\right)^{+}$, pela reação com $\mathrm{O}^{2-}$ após irradiação com $\mathrm{UV}$ e formação de cadeias de $\left(\mathrm{PO}_{3}\right)_{n}$, em filmes de $\left[\mathrm{Sb}\left(\mathrm{PO}_{3}\right)_{3}\right]_{n}-\mathrm{Sb}_{2} \mathrm{O}_{3} \ldots \ldots \ldots . . .150$ Figura 101 - Modelo para o Efeito de Fotocontração estrutural com irradiação UV, baseado em centros de defeitos deficientes em oxigênio e vazios estruturais na estrutura vítrea 151

Figura 102 - Descrição da formação do padrão de interferência baseado no Espelho de Lloyd em função da dimensões mensuráveis.

Figura 103 - Projeção por triangulação das dimensões mensuráveis derivadas do Espelho de Lloyd. 153

Figura 104 - Imagem de AFM de uma amostra padrão com $1 \mu \mathrm{m}$ de espaçamento .154

Figura 105 - Imagens de AFM do relevo de redes holográficas gravadas com diferentes periodos após exposição ao laser $U V$; a) $\Lambda \approx 600 \mathrm{~nm}$, b) $\Lambda \approx 6,2 \mu \mathrm{m}$, c) $\Lambda \approx 20 \mu \mathrm{m}$, d) $\Lambda \approx 19 \mu \mathrm{m}$.

Figura 106 - Imagens de AFM do perfil de redes holográficas, mostrando as dimensões da amplitude e do período das ranhuras em filmes de $20 \%\left[\mathrm{Sb}\left(\mathrm{PO}_{3}\right)_{3}\right]_{n}-80 \% \mathrm{Sb}_{2} \mathrm{O}_{3} \mathrm{com} 1,7 \mu \mathrm{m}$ de espessura, após exposição ao laser UV.....156 Figura 107 - Imagem de AFM mostrando detalhes das redes gravadas com ranhuras em duas direçoes em filme de $20 \%\left[\mathrm{Sb}\left(\mathrm{PO}_{3}\right)_{3}\right]_{n}-80 \% \mathrm{Sb}_{2} \mathrm{O}_{3}$ (exposição 1,0 hora, UV com 100mW) .158 
Figura 108 - Imagem de AFM do perfil de amplitude e período da rede nas duas direções de gravação, para rede em duas direç̃̃es em filme de $20 \%\left[\mathrm{Sb}\left(\mathrm{PO}_{3}\right)_{3}\right]_{n}-80 \% \mathrm{Sb}_{2} \mathrm{O}_{3}$ (exposição de 1,0 hora ao laser UV com $100 \mathrm{~mW}$ ).

Figura 109 - Difração do laser durante a gravação das redes em filmes de $20 \%\left[\mathrm{Sb}\left(\mathrm{PO}_{3}\right)_{3}\right]_{n}-80 \% \mathrm{Sb}_{2} \mathrm{O}_{3}$ de $1,7 \mu \mathrm{m}$ de espessura mostrando até a $3^{a}$ ordem de difração (negativo e imagem real).

Figura 110 - Curvas de eficiência de difração em rede gravada em filme de $20 \%\left[\mathrm{Sb}\left(\mathrm{PO}_{3}\right)_{3}\right]_{n}-80 \% \mathrm{Sb}_{2} \mathrm{O}_{3}$ de $1,7 \mu \mathrm{m}$ de espessura para potências de 50 a $600 \mathrm{~mW}\left(2,5\right.$ a $\left.30 \mathrm{~W} / \mathrm{cm}^{2}\right)$ e tempo de exposição de $\sim 1$ hora.

Figura 111 - Curvas de eficiência de difração em rede gravada em filme de $20 \%\left[\mathrm{Sb}\left(\mathrm{PO}_{3}\right)_{3}\right]_{n}-80 \% \mathrm{Sb}_{2} \mathrm{O}_{3}$ de $1,7 \mu \mathrm{m}$ de espessura para potências de 50 a $600 \mathrm{~mW}\left(2,5\right.$ a $\left.30 \mathrm{~W} / \mathrm{cm}^{2}\right)$ e tempo de exposição de $\sim 10$ minutos.

Figura 112 - Eficiência de difração de filmes $20 \%\left[\mathrm{Sb}\left(\mathrm{PO}_{3}\right)_{3}\right]_{n}-80 \% \mathrm{Sb}_{2} \mathrm{O}_{3}$. a) Rede de Relevo após 1 hora de exposição ao laser UV; b) Rede de Fotoclareamento após 1 hora de exposição ao laser UV

Figura 113 - Representação de Q vs. $\Lambda$ para três espessuras de holograma. As setas indicam no gráfico o valor máximo para $Q$, obtido considerando $\mathrm{d}=1,0 \mu \mathrm{m}, \lambda=350,7 \mathrm{~nm}, \mathrm{e} \mathbf{n} \approx 2,0$. .164

Figura 114 - Alteração no índice de refração no filme $20 \%\left[\mathrm{Sb}\left(\mathrm{PO}_{3}\right)_{3}\right]_{n}-80 \% \mathrm{Sb}_{2} \mathrm{O}_{3}$ irradiado com $50 \mathrm{~mW}$ (2.5 W/ $/ \mathrm{cm}^{2}$ ) por diferentes períodos. a) 1, b) 5 , c) 10, d) 15, e) 20 , e f) 30 minutos, respectivamente. 166

\section{II-ÍNDICE DE TABELAS}

Tabela 1 - Definições sobre vidros encontradas em livros-texto publicados no ano de 1990 4

Tabela 2 - Características e Aplicações de vidros fosfatos modificados por cátions metálicos. 17

Tabela 3 - Composições e temperaturas características do sistema $x\left[\mathrm{Sb}\left(\mathrm{PO}_{3}\right)_{3}\right]_{n}-(100-x) \mathrm{Sb}_{2} \mathrm{O}_{3}$.

Tabela 4 - Resultados de XPS para filmes de 20\% $\left[\mathrm{Sb}\left(\mathrm{PO}_{3}\right)_{3}\right]_{n}-80 \% 20 \mathrm{Sb}_{2} \mathrm{O}_{3}$ (espessura:5 $\mu \mathrm{m}$ ) antes e após irradiação com laser UV. 124

Tabela 5 - Seqüência e notação de amostras de filmes de $20 \%\left[\mathrm{Sb}\left(\mathrm{PO}_{3}\right)_{3}\right]_{n}-80 \% \mathrm{Sb}_{2} \mathrm{O}_{3}(0,8 \mu \mathrm{m}$ de espessura) preparados para medidas de XANES.

Tabela 6 - Classificação dos domínios de rede em função da modulação de profundidade, $\mu$ 165

\section{III-LISTA DE SÍMBOLOS}

T

$\mathrm{T}_{\mathrm{g}}$

$T_{x}$

$T_{f}$

$\mathrm{T}_{\mathrm{L}}$

${ }^{\circ} \mathrm{C}$

$\pi$

$\mathrm{O}_{\mathrm{T}}$

$\mathrm{O}_{\mathrm{L}}$

$\mathrm{O}_{\mathrm{NL}}$

3D
Temperatura.

Temperatura de transição vítrea.

Temperatura de início de cristalização.

Temperatura de fusão.

Temperatura de líquido.

graus centígrados.

relativo a ligação pi.

oxigênio terminal.

oxigênio ligante.

oxigênio não ligante.

tridimensional. 
$\lambda$

$\mathrm{W} / \mathrm{cm}^{2}$

$\mathrm{mW}$

$\mu \mathrm{m}$

$\alpha$

$\mu(\mathrm{E})$

Z

$\rho$

I

$\mathrm{I}_{0}$

$\eta$

$I_{d}$

$I_{t}$

$\theta$

$\mu$

$\mathrm{h}$

$\Lambda$

Q

$\phi$

v

$\mathrm{ge}_{\mathrm{e}}$

$\mu_{\mathrm{B}}$

B

$\mathrm{K}_{\alpha}, \mathrm{K}_{\boldsymbol{\beta}}$

$\mathrm{L}_{\boldsymbol{\alpha}}, \mathrm{L}_{\boldsymbol{\beta}}$

$\mathrm{eV}$ angstrôn.

definição de grupo fosfato que faz $i$ ligações com $P$ vizinhos.

comprimento de onda.

densidade de potência em watts por centímetro quadrado.

potência em miliWatts.

micrômetro.

definição para coeficiente de absorção óptica.

coeficiente de absorção linear no caso de raios-X.

número atômico de um elemento.

densidade de um elemento.

intensidade.

intensidade inicial.

definição para eficiência de difração de redes holográficas.

intensidade de feixe de luz difratado em primeira ordem.

intensidade de feixe de luz transmitida pela amostra.

ângulo.

modulação de profundidade de uma rede senoidal.

profundidade em uma rede senoidal.

espaçamento entre ranhuras de uma rede de difração.

fator de Klein para distinção entre hologramas.

amplitude de modulação de fase da luz em uma rede de difração.

freqüência.

fator Zeeman.

Magnéton de Bohr.

Campo magnético.

emissão de raios- $X$ de um átomo devido ao decaimento eletrônico da camada $L \rightarrow K$, e $M \rightarrow K$, respectivamente.

emissão de raios- $X$ de um átomo devido ao decaimento eletrônico da camada $M \rightarrow L, e N \rightarrow L$, respectivamente.

elétron-volt. 
O objetivo deste trabalho é o estudo das Mudanças Estruturais Fotoinduzidas em filmes do sistema vítreo $\left[\mathrm{Sb}\left(\mathrm{PO}_{3}\right)_{3}\right]_{n}-\mathrm{Sb}_{2} \mathrm{O}_{3}$ bem como a produção e caracterização do sistema vítreo em questão. Vidros de $x\left[\mathrm{Sb}\left(\mathrm{PO}_{3}\right)_{3}\right]_{n}-(100-x) \mathrm{Sb}_{2} \mathrm{O}_{3}(5 \leq x \leq 40)$ foram produzidos pela fusão dos precursores $\mathrm{Sb}_{2} \mathrm{O}_{3}$ e $\left[\mathrm{Sb}\left(\mathrm{PO}_{3}\right)_{3}\right]_{n}$ a $900{ }^{\circ} \mathrm{C}$ em cadinhos de carbono vítreo e em seguida vertidos e resfriados rapidamente em moldes de aço inox. Dessa forma foi possível obter vidros homogêneos e estáveis com dimensões de $1,0 \times 1,0 \times 0,5 \mathrm{~cm}^{3}$. A caracterização do sistema vítreo e parâmetros como região de formação vítrea e temperaturas características foram obtidos por meio de técnicas como DSC, Difração de Raios-X, FTIR, e MAS-NMR. A região de formação vítrea neste sistema ocorre para composições entre $10 \leq x \leq 25$ sendo que para $x=5, x=30$, e $x=$ 35 forma-se um vidro com pequena fração de microcristalinidade que apresenta coloração amarelada sendo visualmente transparente, já para $x=40$ forma-se um vidro com maior fração de microcristalinidade e totalmente opaco. Este sistema vitreo possui interessantes propriedades como larga janela de transmitância $(\sim 0,4$ a $8 \mu \mathrm{m})$, alto índice de refração $(n \sim 2,0)$, baixa temperatura de fusão $\left(T_{\mathbf{f}} \sim 900^{\circ} \mathrm{C}\right)$ e baixa temperatura de transição vítrea, $\left(\mathrm{T}_{\mathrm{g}} \sim 300^{\circ} \mathrm{C}\right)$.

Filmes de $x\left[\mathrm{Sb}\left(\mathrm{PO}_{3}\right)_{3}\right]_{n}-(100-x) \mathrm{Sb}_{2} \mathrm{O}_{3}$ foram produzidos por evaporação térmica dos vidros através de canhão de elétrons (EB-PVD) em um sistema não comercial de evaporação desenvolvido em nosso laboratório, onde conseguimos produzir de maneira eficiente e com boa qualidade óptica filmes de até $10 \mu \mathrm{m}$ de espessura. Estes filmes apresentam um atípico fenômeno de fotocontração em torno de $8 \%$ da espessura do filme, acompanhado de fotoclareamento após irradiação com laser UV em $350,7 \mathrm{~nm}$. Além da caracterização a nível macroscópico do fenômeno de fotocontração (comportamento em função da potência e tempo de irradiação com laser UV) nossa atenção ficou voltada para o estudo desse efeito a nível estrutural, através de técnicas como Difração de Raios-X, XANES, FTIR, RPE, RBS e Holografia Óptica. Além da ampla caracterização mostramos a possibilidade de aplicação do material para holografia ou armazenamento óptico, redes de difração, e matrizes de microlentes.

$O$ efeito de fotocontração nos filmes foi notado devido ao fotoclareamento observado visualmente após a exposição ao UV e foi confirmado por medidas de perfilometria da região exposta ao UV. O efeito de fotoclareamento (simultâneo a 
fotocontração da superficie) ocorre gerando deslocamento de $\sim 30 \mathrm{~nm}$ do bandgap $(3,58$ $\mathrm{eV}, 347 \mathrm{~nm})$ para maiores energias $(4,01 \mathrm{eV}, 310 \mathrm{~nm})$. Também observamos um pequeno deslocamento do bandgap para irradiações com $\lambda=482$ e $460 \mathrm{~nm}$. A fotocontração evolui não linearmente com o tempo e potência de irradiação. Depende também do tempo de exposição e da potência do laser, tendendo a saturação após 4 horas de exposição a $5 \mathrm{~W} / \mathrm{cm}^{2}(100 \mathrm{~mW})$ ou 2 horas de exposição a $15 \mathrm{~W} / \mathrm{cm}^{2}(300$ mw). $O$ efeito de fotocontração tem forte dependência com a concentração de polifosfato de antimônio na composição dos filmes do sistema vítreo $x\left[\mathrm{Sb}\left(\mathrm{PO}_{3}\right)_{3}\right]_{n}$ $(100-x) \mathrm{Sb}_{2} \mathrm{O}_{3}$. Filmes de $1,0 \mu \mathrm{m}$ de espessura irradiados com $100 \mathrm{~mW}\left(5,0 \mathrm{~W} / \mathrm{cm}^{2}\right)$ por 4 horas (região de saturação) apresentam fotocontração $(-\Delta \mathrm{V} / \mathrm{V})$ de até $8,0 \%$ da espessura do filme (para $x=25)$ quando irradiados com laser UV ( $\lambda=350 \mathrm{~nm}$ )/ Para $x=10$ a contração é menor que $2,0 \%$, e para concentrações de polifosfato acima de 25 $\%$ efeito é diminuído drasticamente. A atmosfera na qual o filme é irradiado tem grande

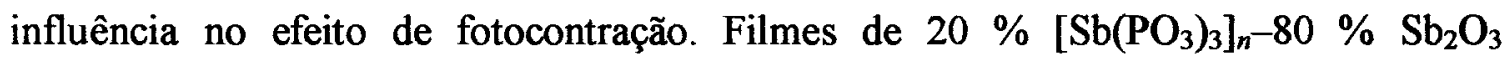
(espessura:1,0 $\mu \mathrm{m}$ ) irradiado com laser UV por 4 horas a $100 \mathrm{~mW}\left(5,0 \mathrm{~W} / \mathrm{cm}^{2}\right)$ apresentaram fotocontração $(-\Delta \mathrm{V} / \mathrm{V})$ de $\sim 8 \%(\sim 50 \%$ maior $)$ em atmosfera de $\mathrm{O}_{2}, 5 \%$ no ar, e menor que $2 \%$ para o vácuo, $\mathrm{N}_{2}$ e He.

Apesar de se partir da evaporação dos vidros para produção dos filmes, a principal diferença de estrutura entre vidro e filme é que estes últimos apresentam estrutura com grande número de vazios intersticiais ao redor de unidades estruturais, $o$ que não ocorre para os vidros. Nossos resultados mostraram efetivamente que o efeito de fotocontração em filmes irradiados com UV está relacionado com mudanças de estrutura de grupos fosfatos e efeitos fototérmicos cooperativos. Na parte de aplicações gravamos redes holográficas de relevo nos filmes estudados. Utilizando uma montagem tipo espelho de Lloyd para holografia foi possivel gravar redes com período de $600 \mathrm{~nm}$ até $20 \mu \mathrm{m}$ e medimos a eficiência de difração em tempo real utilizando um feixe de prova de laser He-Ne. As redes gravadas em filmes de filmes de $20 \%\left[\mathrm{Sb}\left(\mathrm{PO}_{3}\right)_{3}\right]_{n}-80 \%$ $\mathrm{Sb}_{2} \mathrm{O}_{3}$ com período de $20 \mu \mathrm{m}$ de espessura apresentam eficiência de difração de 3 a 10,5 $\%$ para aproximadamente 1 hora de gravação e potencia variando de 50 a $600 \mathrm{~mW}(2,5$ a $30 \mathrm{~W} / \mathrm{cm}^{2}$ ), respectivamente. 
The aim of this work is the study of the Photoinduced Structural Changes (PSC) in films of the $\left[\mathrm{Sb}\left(\mathrm{PO}_{3}\right)_{3}\right]_{n}-\mathrm{Sb}_{2} \mathrm{O}_{3}$ glassy system, as well as the production and characterization of the glassy system. The glass samples $x\left[\mathrm{Sb}\left(\mathrm{PO}_{3}\right)_{3}\right]_{n}-(100-x) \mathrm{Sb}_{2} \mathrm{O}_{3}(5$ $\leq x \leq 40$ ) were produced by the melt-quenching technique of suitable quantities of the precursors $\mathrm{Sb}_{2} \mathrm{O}_{3}$ and $\left[\mathrm{Sb}\left(\mathrm{PO}_{3}\right)_{3}\right]_{n}$, fused at $900{ }^{\circ} \mathrm{C}$ in glassy carbon crucibles and verted into stainless steel moulds. Homogeneous and stable glass plates of $1.0 \times 1.0 \times 0.5 \mathrm{~cm}^{3}$ were obtained. The characterization of the glass system and the obtaining of parameters such as the glass forming region and characteristic temperatures were possible through DSC, X-ray Diffraction, FTIR and MAS-NMR techniques. The studied glass system possess remarkable properties such as broad transmittance window (from 0.4 to 8.0 $\mu \mathrm{m})$, high index of refraction $(\mathrm{n} \sim 2.0)$, low melting temperature $\left(\mathrm{T}_{\mathrm{f}} \sim 900^{\circ} \mathrm{C}\right)$ and low glass transition temperature $\left(\mathrm{T}_{\mathrm{g}} \sim 300^{\circ} \mathrm{C}\right)$. The films were produced by electron beam physical vapor deposition (EB-PVD) of the glasses, in a non-commercial evaporation system developed in our laboratory, where is possible to produce high quality films with thickness of up to $10 \mu \mathrm{m}$. The films samples presented an atypical photocontraction behavior that consists of a decrease of up to $10 \%$ in the thickness, accompanied of photobleaching after UV irradiation using a $350.7 \mathrm{~nm}$ laser line. Besides the macroscopic characterization of the photocontraction effect (behavior as function of the UV laser power density and irradiation time), our attention was focused on the study of the effect at structural level using techniques such as X-ray diffraction, XANES, FTIR, EPR, RBS and Optical Holography. In addition to the wide characterization we shown in this work the possibilities of application of this material for optical storage and holography, diffraction gratings, micro-lens array. 


\section{INTRODUCÃO}




\subsection{Vidros - Uma breve Introdução}

\subsubsection{Como são definidos os vidros?}

Os materiais vítreos têm uma característica extremamente interessante: seja qual for a nossa necessidade, quase sempre temos a possibilidade de vir a utilizá-los nos mais diferentes contextos. Quando pensamos em vidros, lembramos de uma substância sólida e frágil, encontrada em janelas, copos, etc. Porém para a ciência há uma definição diferente da qual denominamos para este tipo de material: "vidro" é um material sólido com uma estrutura interna amorfa, ou seja, significa que os átomos estão arranjados de forma irregular.

$\mathrm{Na}$ teoria qualquer composição química fundida pode formar um vidro, uma vez que a mistura fundida possa ser resfriada suficientemente rápido de forma que os átomos não tenham tempo de se organizar na forma de um padrão ou cristais. A Figura 1-a) ilustra a representação bidimensional de um arranjo cristalino simétrico e periódico de um cristal de composição $\mathrm{A}_{2} \mathrm{O}_{3}$, enquanto a Figura 1-b) representa a rede do vidro para o mesmo composto, onde fica caracterizada a ausência de simetria e periodicidade. Nas definições modernas de vidro identificamos o uso freqüente das expressões sólido não-cristalino, sólido amorfo, material vítreo (ou simplesmente vidro). Tais expressões são usualmente utilizadas como sinônimas.

Do ponto de vista básico, os primeiros estudos sobre vidros foram realizados por Michael Faraday, em 1830, o qual definiu vidros como sendo materiais "mais aparentados a uma solução de diferentes substâncias do que um composto em si". Inicialmente, as definições de vidro basearam-se no conceito de viscosidade de sólidos, tendo em vista que, até então, os vidros eram preparados unicamente por fusão/ resfriamento. Segundo o critério de viscosidade, um sólido é um material rígido que não escoa quando submetido a forças moderadas. 

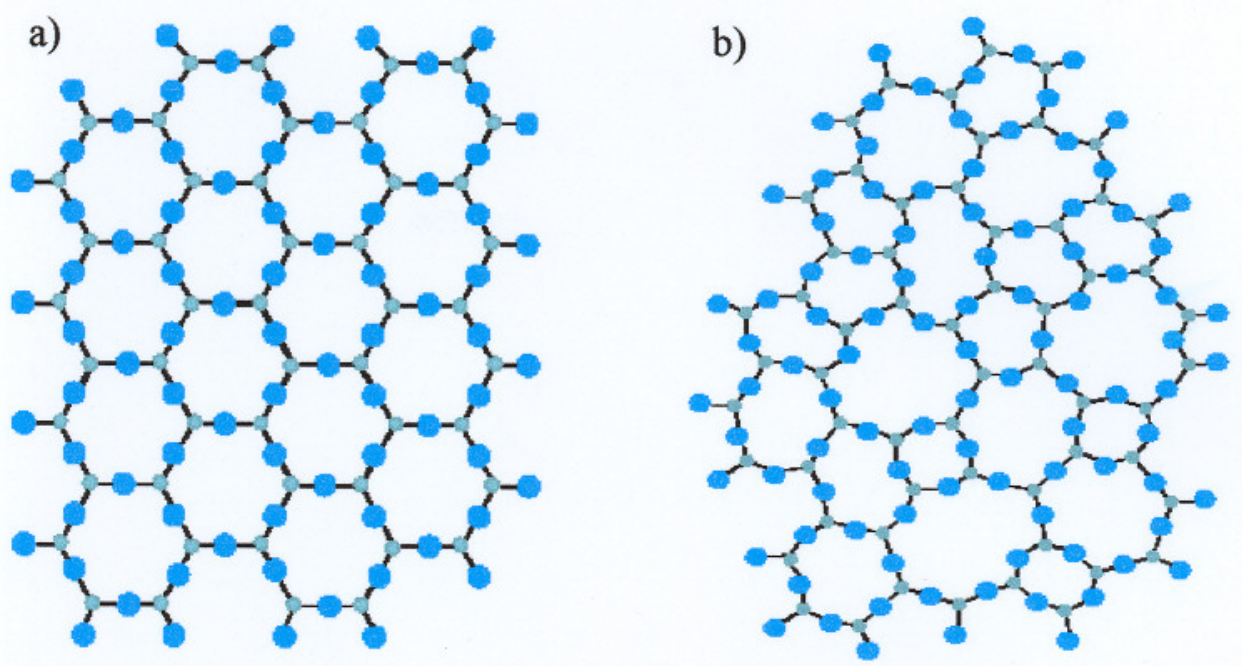

Figura 1 - Representação bidimensional: a) do arranjo cristalino simétrico e periódico de um cristal de composição $\mathrm{A}_{2} \mathrm{O}_{3}$; b) representação da rede do vidro do mesmo composto, na qual fica caracterizada a ausência de simetria e periodicidade.

Quantitativamente, um sólido pode ser definido como um material com viscosidade maior do que $10^{15} \mathrm{P}$ (poises). Com base nesse conceito, definiu-se vidro como "um material formado pelo resfriamento do estado líquido normal (ou fundido), o qual exibe mudanças contínuas em qualquer temperatura, tornando-se mais ou menos rígido através de um progressivo aumento da viscosidade, acompanhado da redução da temperatura do fundido". Tal definição poderia ser assim resumida: "vidro é um produto inorgânico fundido que atinge por resfriamento uma condição rígida, sem que ocorra cristalização".

Em 1932, Zachariasen [1] publicou o famoso artigo The Atomic Arrangement in Glass ( $O$ Arranjo Atômico em Vidros), e afirmava que "deve ser francamente admitido que não conhecemos praticamente nada sobre o arranjo atômico dos vidros". A base estrutural para a formação de vidros por fusão/resfriamento foi firmada por Zachariasen, que propôs que "o arranjo atômico em vidros era caracterizado por uma rede tridimensional estendida, a qual apresentava ausência de simetria e periodicidade" e que "as forças interatômicas eram comparáveis àquelas do cristal correspondente". Ainda segundo o pesquisador, a presença ou ausência de periodicidade e simetria em uma rede tridimensional seria o fator de diferenciação entre um cristal e um vidro.

No entanto relativamente a estas últimas definições, poderíamos fazer algumas importantes indagações, cujas respostas surgiram com o próprio processo de evolução do conhecimento científico: Vidros são obtidos somente a partir de compostos 
inorgânicos? A fusão dos componentes é necessária para a formação de um vidro? Um material sólido com estrutura interna amorfa pode ser chamado de vidro?

Para as três últimas perguntas temos uma única resposta: não. As respostas dadas a estas indagações deixaram clara a necessidade de se adequar continuamente à definição de vidros. Assim, novas e diferentes definições têm surgido nos livros-texto e na literatura científica. A Tabela 1 traz, de maneira resumida, algumas das definições utilizadas. Tradicionalmente, a maioria dos vidros é formada por compostos inorgânicos, porém, atualmente, os vidros metálicos e os vidros orgânicos são bastante conhecidos. É importante salientar que a natureza química do material não pode ser usada como critério para definir vidro. Como comentamos de passagem, os vidros podem ser formados, além do método de fusão dos componentes, por um grande número de processos: deposição química de vapor, pirólise, irradiação de nêutrons e processo sol-gel, entre outros.

Tabela 1 - Definições sobre vidros encontradas em livros-texto publicados no ano de 1990.

\begin{tabular}{|c|c|c|}
\hline Autor & Ano & Definição \\
\hline Elliott & [1990] & $\begin{array}{l}\text { "Vidros são materiais amorfos que não possuem ordem } \\
\text { translacional a longo alcance (periodicidade), caracteristica de } \\
\text { um cristal. Os termos amorfo e sólido não-cristalino são } \\
\text { sinônimos nesta definição. Um vidro é um sólido amorfo que } \\
\text { exibe uma transição vitrea" }\end{array}$ \\
\hline Zarzycki & [1991] & $\begin{array}{l}\text { "Um vidro é um sólido não-cristalino exibindo o fenômeno de } \\
\text { transiçấo vitrea" }\end{array}$ \\
\hline Doremus & [1994] & $\begin{array}{l}\text { "Vidro é um sólido amorfo. Um material é amorfo quando não } \\
\text { tem ordem à longa distância, isto é, quando não há uma } \\
\text { regularidade no arranjo dos constituintes moleculares, em uma } \\
\text { escala maior do que algumas vezes o tamanho desses grupos. Não } \\
\text { é feita distinção entre as palavras vitreo e amorfo" }\end{array}$ \\
\hline Varshneya & [1994] & $\begin{array}{l}\text { "Vidro é um sólido que tem estrutura de um líquido, um sólido } \\
\text { "não-cristalino" ou simplesmente um sólido amorfo, } \\
\text { considerando a característica de amorfo como descrição da } \\
\text { desordem atômica, evidenciada por difração de raios- } X "\end{array}$ \\
\hline Shelby & [1997] & $\begin{array}{l}\text { "Vidro é um sólido amorfo com completa ausência de ordem a } \\
\text { longo alcance e periodicidade, exibindo uma região de transição } \\
\text { vitrea. Qualquer material, seja inorgânico, orgânico ou metal, } \\
\text { formando por qualquer técnica, que exiba um fenômeno de } \\
\text { transição vitrea é um vidro" }\end{array}$ \\
\hline
\end{tabular}


Em 1995, Gupta [2] publicou o artigo denominado Non-Crystalline Solids: Glasses and Amorphous Solids (Sólidos Não-Cristalinos: Vidros e Sólidos Amorfos), no qual mostra que cada uma dessas expressões implica num conceito específico e, portanto, não podem ser tomadas como sinônimas. De acordo com Gupta, um sólido não-cristalino pode ser dividido, do ponto de vista termodinâmico, em duas classes distintas: vidros e sólidos amorfos. Sólidos não-cristalinos seriam todos aqueles materiais que apresentassem uma rede tridimensional estendida e aleatória, isto é, com ausência de simetria e periodicidade translacional.

Considerando-se o aspecto termodinâmico, um sólido não-cristalino seria um vidro quando este apresentasse o fenômeno de transição vítrea ${ }^{i}$. Conseqüentemente, sólidos amorfos seriam sólidos não-cristalinos que não exibissem a transição vítrea. Segundo Gupta, as definições resumidas na Tabela 1 apresentariam uma imprecisão, na medida em que consideram como vidros os sólidos amorfos. Os vidros e os sólidos amorfos seriam duas classes distintas de materiais não-cristalinos, uma vez que apresentam diferenças tanto do ponto de vista topológico como do termodinâmico.

Feitas estas considerações, o que, afinal, seria um vidro? Como resposta, poderíamos dizer que "um vidro é um sólido não-cristalino, portanto, com ausência de simetria e periodicidade translacional, que exibe o fenômeno de transição vitrea, podendo ser obtido a partir de qualquer material inorgânico, orgânico ou metálico e formado através de qualquer técnica de preparação".

\footnotetext{
i A temperatura de transição vítrea, $T_{g}$ é uma temperatura caracteristica para os vidros, definindo a passagem do estado vitreo para o viscoelástico, através da chamada relaxação estrutural. Os conceitos de estado vítreo e viscoelástico vêm da Reologia, que estuda propriedades associadas à fluidez. O termo viscoelástico descreve o comportamento de um corpo que responde elasticamente a uma força aplicada, sem apresentar uma deformação permanente. Adicionalmente, tal resposta elástica não é instantânea, devido a um componente significativo de viscosidade. Em contrapartida, o comportamento vítreo está associado a um corpo que não pode ser deformado nem permanentemente nem elasticamente, sendo mais propenso a absorver a energia e dissipá-la, quebrando-se. Quando se aquece um vidro acima da $\mathrm{Tg}_{\circ}$ o comportamento viscoelástico tem início, devido à possibilidade das cadeias escoarem umas em relação às outras, dentro do vidro. Sendo assim, quando uma força é aplicada as cadeias se movimentam, mas a atração que existe entre as mesmas as faz retornar elasticamente à situação inicial, com uma velocidade baixa devido à elevada viscosidade. Diz-se, neste caso, que ocorre um aumento na chamada entropia configuracional do sistema, o que significa que, à medida que as unidades formadoras do vidro adquirem a capacidade de escoamento, estas podem ser encontradas em um número cada vez maior de diferentes arranjos relativos.
} 


\subsubsection{Formação do vidro a partir de um fundido}

Os vidros convencionais são produzidos tradicionalmente através do método de fusão/resfriamento. Este método envolve a fusão de uma mistura dos materiais de partida, em geral a altas temperaturas, seguida do resfriamento rápido do fundido. Quando as matérias-primas de um vidro se encontram fundidas, suas estruturas guardam grandes semelhanças com aquelas de um líquido. Contudo, à medida que ocorre o resfriamento, o arranjo estrutural interno do material fundido pode trilhar diferentes caminhos, de acordo com a taxa de resfriamento utilizada. Como mostra a Figura 2, um parâmetro conveniente para lançar alguma luz sobre o que ocorre internamente durante tal processo, é a variação do volume.

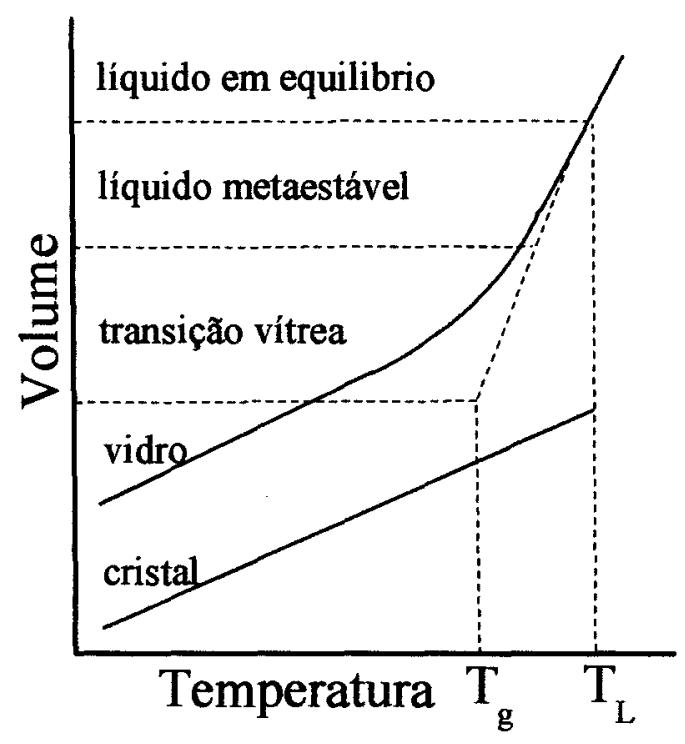

Figura 2 - Mudança de volume durante o resfriamento de um liquido fundido. Se o aparecimento de cristais ocorrer, o volume diminuirá de maneira brusca na temperatura $T_{L}$. Por outro lado, na ausência de cristalização, o líquido permanecerá em equilíbrio metaestável até atingir a $T_{g}$, quando os rearranjos estruturais passarão a ser cinéticamente impedidos. Contudo, o volume abaixo da $T_{g}$ continuará a diminuir, como conseqüência das menores amplitudes de vibração dos átomos em torno de suas posições fixas [3].

Quando se fala em diferentes arranjos internos, equivale dizer que existem várias maneiras de se empacotar as unidades formadoras, incorporando quantidades maiores ou menores de espaços vazios, segundo as orientações relativas das unidades. Para melhor compreensão, basta que se imagine a diferença entre os modos ordenado e desordenado de se empilhar um conjunto de objetos quaisquer. Um empilhamento 
organizado representa um melhor aproveitamento do espaço fazendo com que o conjunto todo "caiba" tranqüilamente no mesmo, dentro de uma caixa, por exemplo. Por outro lado, se todos os objetos forem dispostos ao acaso, alguns fatalmente ficarão de fora, devido a um excesso de espaço ocioso. Analogamente, como pode ser verificado a partir da Figura 2, o arranjo cristalino que um fundido pode assumir, após o resfriamento, apresenta um volume menor do que o estado vítreo. Ao ser resfriado abaixo de sua temperatura de líquido $\left(\mathrm{T}_{\mathrm{L}}\right)$, um fundido atravessa uma região de equilíbrio metaestável, ou seja, uma situação de equilíbrio termodinâmico inicial, o qual pode ceder frente a pequenas perturbações podendo, por exemplo, cristalizar-se.

Durante o processo de cristalização, faz-se necessário um certo tempo para que as pequenas unidades se orientem, até atingirem as posições adequadas para formar o cristal. É por isto que um resfriamento rápido faz com que as unidades percam a mobilidade antes de se ordenarem. Se a cristalização não ocorrer, o líquido permanecerá no estado de equilíbrio metaestável, abaixo de $\mathrm{T}_{\mathrm{L}}$. Como já mencionado, conforme a temperatura diminui, aproxima-se de uma condição em que a mobilidade, em nível atômico, dentro do líquido, torna-se bastante reduzida e os átomos fixam-se em suas posições. Tal fenômeno ocorre em uma faixa de temperaturas que é denominada transição vítrea. Por definição, o ponto de interseção das linhas extrapoladas, que definem a região metaestável e a região de vidro, é o parâmetro conhecido como $T_{\mathfrak{g}}$ (temperatura de transição vítrea). A $T_{g}$ é, mais rigorosamente, o intervalo de temperaturas em que tem início a chamada relaxação estrutural, quando algumas propriedades como viscosidade, capacidade calorifica e expansão térmica começam a manifestar um comportamento diferente do padrão verificado até então. A relaxação estrutural ocorre em consequiência do desimpedimento dos movimentos das cadeias umas em relação às outras (movimento translacional). Reiterando: quando um vidro é formado a partir de um fundido, o processo envolve a homogeneização dos componentes acima de $T_{L}$, e o resfriamento abaixo de $T_{g}$. A velocidade de resfriamento deve ser suficientemente elevada para que não se forme uma quantidade significativa de cristais, uma vez que o vidro completamente não-cristalino é uma situação ideal. No outro extremo, temos o cristal ideal. A velocidade de resfriamento necessária depende das cinéticas de nucleação e crescimento. 


\subsection{Os Vidros Fosfatos}

Vidros fosfatos com baixa dispersão óptica e índices de refração relativamente altos (comparado com vidros ópticos silicatos) foram desenvolvidos para elementos ópticos acromáticos há aproximadamente 100 anos atrás por Schott e co-autores [27]. $\mathrm{O}$ subseqüente interesse em vidros fosfatos alcalinos terrosos surgiu devido à grande transparência no UV, novamente quando comparados com vidros silicatos. No entanto, a baixa durabilidade química desses novos vidros ópticos limitou suas aplicações e desencorajou (temporariamente) desenvolvimentos futuros [4]. Após 1950, o interesse em fosfatos alcalinos amorfos foi estimulado por seu uso em uma variedade de aplicações industriais, incluindo agentes sequestrantes para tratamento de água e dispersantes para processamento de argila e manufatura de pigmentos [5].

Através do estudo de tais materiais, Van Wazer [5] estabeleceu a base do presente conhecimento sobre a natureza dos vidros fosfatos. Ao mesmo tempo, Kordes e co-autores $[6,7]$ re-examinaram os vidros fosfatos alcalinos terrosos, incluindo as composições transparentes ao UV, e notaram algumas tendências "anômalas" em suas propriedades as quais sugeriram apresentar uma dependência composicional para o número de coordenação de cátions metálicos como o $\mathrm{Zn}^{2+}$.

Com o advento dos laseres de estado sólido em meados de 1960, surgiu uma nova fase na pesquisa de vidros fosfatos. Certas composições têm grande seção de choque de emissão estimulada para íons terras raras e baixo coeficiente termo-óptico, sendo materiais adequados particularmente para aplicações em laseres de alta potência, tais como vidros fosfatos dopados com $\mathrm{Nd}^{3+}$ [8]. Mais recentemente os vidros fosfatos têm sido desenvolvidos para uma variedade de aplicações especiais. Composições de aluminofosfatos alcalinos têm temperaturas de transição vitrea abaixo de $400^{\circ} \mathrm{C}$ e coeficientes de expansão térmica maior que $150 \times 10^{-7} \mathrm{C}^{-1} \mathrm{e}$, portanto são utilizados para selagem herméticos [9]. Composições a base de fosfato de zinco são quimicamente duráveis e apresentam temperaturas de processamento abaixo de $400^{\circ} \mathrm{C}$, podendo ser formados com polímeros de altas temperaturas para produzir compósitos orgânicoinorgânico incomuns [10]. A durabilidade química e baixa temperatura de processamento de vidros a base de fosfato de ferro levaram a utilização destes como matrizes para lixo nuclear [11]. 
Vidros fosfatos e vitrocerâmicas biocompatíveis a base de cálcio têm apresentado grande impacto em aplicações médicas, sendo utilizados como implantes para recuperação óssea ou como vidros solúveis produzidos na forma de fibras flexíveis muito finas portadoras de células sadias encapsuladas, utilizadas em implantes temporários para recuperação de tecidos musculares [12]. Fosfato de lítio amorfo e vidros fosfato oxinitritos tem rápida condutividade iônica fazendo destes grandes candidatos para eletrólitos de estado sólido $[13,14]$. As propriedades que tornam os vidros fosfatos candidatos para muitas aplicações em diferentes áreas estão diretamente relacionadas com suas estruturas a nível molecular, sendo que importantes estudos nessa área incluem os trabalhos de Van Wazer [5], Abe [15] e Martin [16].

\subsubsection{A classificação dos fosfatos}

Devido às numerosas aplicações, os fosfatos têm sido extensivamente estudados durante as últimas décadas, com os maiores avanços entre 1940 e 1950 [17-19], quando a natureza linear, flexível, e polidispersa, com possibilidades de alto grau de polimerização entre grupos fosfatos $\left(\mathrm{PO}_{4}\right)^{-3}$ foi reconhecida.

Fosfatos são definidos como compostos que contém ligações $\mathbf{P}-\mathrm{O}$, ou seja, ligações entre átomos de oxigênios $(\mathrm{O})$ e fósforos $(\mathrm{P})$, e o termo fosfato se refere ao composto no qual o átomo de fósforo é tetraedricamente coordenado por quatro oxigênios. Portanto, as unidades básicas formadoras de fosfatos cristalinos ou amorfos são os tetraedros $\mathrm{PO}_{4}$, que são resultantes da formação de orbitais híbridos $\mathrm{sp}^{3}$ através de quatro dos cinco elétrons externos do átomo de fósforo $\left(3 \mathrm{~s}^{2} 3 \mathrm{p}^{3}\right)$. O quinto elétron externo do fósforo é promovido a um orbital $3 \mathrm{~d}$ onde é formada uma ligação $\pi(\mathrm{P}=0)$ com elétrons $2 \mathrm{p}$ de um oxigênio terminal $\left(\mathrm{O}_{\mathrm{T}}\right.$ ) (Figura 3). Estes tetraedros $\mathrm{PO}_{4}$ se conectam entre si por meio de ligações covalentes entre oxigênios e fósforos, formando várias espécies de ânions fosfatos. Um tetraedro $\mathrm{PO}_{4}$ é conectado ao restante da estrutura por compartilhamento de no máximo três de seus vértices. Os oxigênios de um grupo $\mathrm{PO}_{4}$ são definidos como Oxigênios Terminais $\left(\mathrm{O}_{\mathrm{T}}\right.$, fazem ligação $\pi$ ou $\left.\mathrm{P}=0\right)$, Oxigênios Ligantes $\left(\mathrm{O}_{\mathrm{L}}\right.$, fazem ponte P-O-P conectando os tetraedros), e Oxigênios Não-Ligantes $\left(\mathrm{O}_{\mathrm{NL}}\right.$, fazem ligação $\mathrm{O}-\mathrm{M}^{+}$com qualquer cátion que não o fósforo) como mostra a Figura 3. 
Os primeiros dados sobre a estrutura do $\mathrm{P}_{2} \mathrm{O}_{5}$ reportam a ligação $\mathrm{P}-\mathrm{O}$ com 1,62 Å de comprimento, com ângulos de $130^{\circ}$ para a ligação P-O-P e $102^{\circ}$ para a ligação O$\mathrm{P}-\mathrm{O}$ [20]. Porém atualmente um recente trabalho mostrou que a quarta ligação $\mathrm{P}=\mathrm{O}_{\mathrm{T}}$, do fósforo com o oxigênio terminal é um pouco menor $(1,44 \AA)$ do que as outras três ligações $(1,58 \AA)$ como conseqüência do forte caráter $\pi$ da ligação [21].

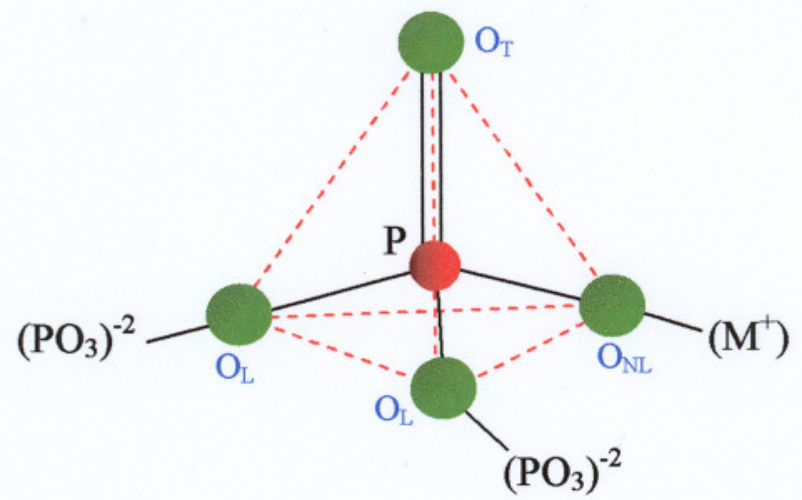

Figura 3 - Representação de um tetraedro $\mathrm{PO}_{4}$, onde $\mathrm{O}_{\mathrm{L}}$ são oxigênios ligantes, $\mathrm{O}_{\mathrm{NL}}$ são oxigênios não-ligantes, e $\mathrm{O}_{\mathrm{T}}$ oxigênio terminal; $\left(\mathrm{M}^{+}\right)$representação de cátion metálico.

No início do século dezenove as observações de que o ácido fosfórico e seus sais poderiam ser transformados em varias outras formas levaram Graham a sua histórica classificação de fosfatos em três tipos: ortofosfatos, pirofosfatos e metafosfatos [22].

Ortofosfatos são compostos contendo íons $\mathrm{PO}_{4}{ }^{-3}$ discretos. Já os pirofosfatos e metafosfatos são conhecidos como fosfatos condensados, os quais são formados pela condensação repetida (polimerização) de unidades tetraédricas $\left[\mathrm{PO}_{4}\right]$. Isto resulta em cadeias tridimensionais de tetraedros $\mathrm{PO}_{4}$, sendo que cada tetraedro faz ligação com o próximo, compartilhando o átomo de oxigênio de um ou dois vértices. $\mathrm{O}$ Difosfato (pirofosfato), $\mathrm{P}_{2} \mathrm{O}_{7}{ }^{-4}$, é o ânion fosfato condensado mais simples, formado pela condensação de dois ânions ortofosfatos. O termo metafosfato se refere a ânions com estrutura cíclica que possuem composição exata $\left(\mathrm{PO}_{3}\right)_{n}{ }^{-n}$. A Figura 4 mostra um exemplo de fragmento de cadeia de polifosfato e a ligação entre grupos $\mathrm{PO}_{4}$ pelo compartilhamento do átomo de oxigênio de um dos vértices do tetraedro.

Devido a vasta aplicação, os fosfatos condensados foram assunto de muitas investigações e controvérsias por quase um século [22]. Estes compostos são divididos em três grandes categorias: polifosfatos lineares, metafosfatos (ciclofosfatos), e ultrafosfatos (estruturas em 3D). 


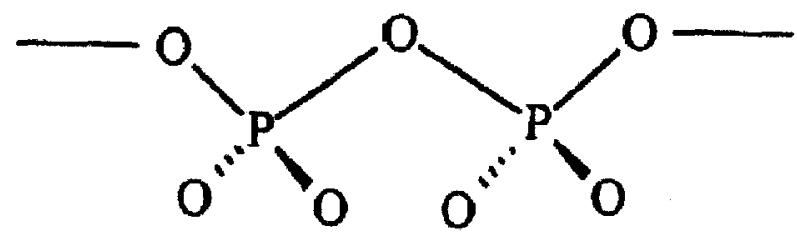

Figura 4 - Exemplo de uma cadeia de polifosfato.

\subsubsection{Polifosfatos Lineares}

A unidade básica de formação de um polifosfato é o íon ortofosfato $\left(\mathrm{PO}_{4}\right)^{-3} \mathrm{e}$ este pode ser considerado o primeiro membro da série de formação da cadeia com o die trifosfato sendo o segundo e terceiro membros, respectivamente. Estequiométricamente, as cadeias de polifosfatos têm composição $\left[\left(\mathrm{PO}_{3}\right)_{n-1} \mathrm{PO}_{4}\right]^{-(n+2)}, \mathrm{e}$ uma cadeia é composta basicamente de $n$ unidades intermediárias - $\left[\left(\mathrm{PO}_{3}\right)^{-1}\right]$ - e duas unidades $-\left[\left(\mathrm{PO}_{3}\right)^{-2}\right]$ terminais. A Figura 5 mostra alguns exemplos de polifosfatos. Variedades de cadeias com comprimentos intermediários $(n=10 \sim 50)$, onde $n$ é o número de grupos $\mathrm{PO}_{3}$, podem ser encontradas em vidros fosfatos comerciais. Em vidros específicos preparados em laboratório o número de grupos $\mathrm{PO}_{3}$ pode variar de 3 a 3000 unidades em uma cadeia [23].<smiles>O=P([O-])([O-])[O-]</smiles>

fosfato

(ortofosfato)<smiles></smiles><smiles>O=P([O-])([O-])OP(=O)([O-])OP(=O)([O-])[O-]</smiles>

trifosfato

(tripolifosfato)<smiles>CC(C)(COP(=O)([O-])[O-])OP(=O)([O-])[O-]</smiles>

(polifosfato)

Figura 5 - Representação de cadeias de Fosfatos Lineares. 
Os polifosfatos de cadeia longa geraram confusão no passado, pois eram originalmente chamados de metafosfatos, que é o nome usado para compostos com estrutura de anéis. Quando o numero de unidades, n, no polímero se torna muito grande, a fórmula de uma cadeia de polifosfato $\left[\left(\mathrm{PO}_{3}\right)_{n-1} \mathrm{PO}_{4}\right]^{(n+2)}$ se torna indistinguível da fórmula de um metafosfato, que é um composto com estrutura de anel com formula $\left(\mathrm{PO}_{3}\right)_{n}^{-n}$.

\subsubsection{Ciclofosfatos (Metafosfatos)}

Os ciclofosfatos formam a familia de compostos com cadeias na forma de anéis. A Figura 6 mostra alguns exemplos de ciclofosfatos. Cada ânion em forma de anel tem composição exata $\left(\mathrm{PO}_{3}\right)_{n}{ }^{-n}$ onde o índice estequiométrico, $n$, em princípio pode ter qualquer valor. A definição "metafosfato" (ou metafosfato cíclico) ainda é muito usada mesmo que segundo a IUPAC (International Union of Pure and Apllied Chemistry) o termo "ciclo" deva ser utilizado para indicar cadeias em forma de anéis. Contrariamente aos polifosfatos com cadeias longas, os ciclofosfatos apresentam menor interesse científico. Não há evidência da existência dos primeiro e segundo membros formadores de cadeias de ciclofosfatos, ex: monometafosfato isolado $\left(\mathrm{PO}_{3}{ }^{-}\right)$ou o dimetafosfato, sendo que este último envolveria o compartilhamento de dois vértices de um único tetraedro $\mathrm{PO}_{4}$ e causaria considerável tensão na estrutura. Em contraste, os grupos trimetafosfato e tetra-metafosfato são bem conhecidos.<smiles>O=P1([O-])OP(=O)([O-])OP(=O)([O-])O1</smiles>

Trimetafosfato (ciclotrifosfato)

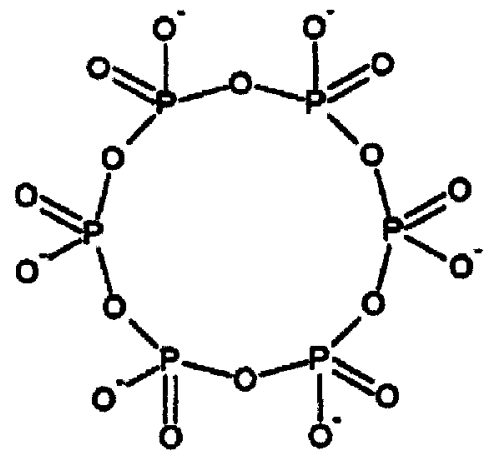

Hexametafosfato (ciclohexafosfato)

Figura 6 - Representação de cadeias de metafosfatos (ciclofosfatos). 


\subsubsection{Ultrafosfatos}

Por definição os ultrafosfatos são cadeias que conectam entre si através do compartilhamento de até três oxigênios de vértices de um único tetraedro $\left(\mathrm{PO}_{4}\right)$, formando estruturas 3D (Figura 7) sem nenhuma simetria linear ou cíclica como foi citado anteriormente no caso de polifosfatos e metafosfatos.

No caso de vidros fosfato a estrutura pode ser classificada através da razão oxigênio/fósforo na estrutura, que relaciona o número de ligações através de oxigênios que compartilham vértices entre tetraedros $\mathrm{PO}_{4}$. Nesse caso os Ultrafosfatos $(\mathrm{O} / \mathrm{P}<3)$ tem sua estrutura conectada por tetraedros que compartilham até três oxigênios com outros tetraedros vizinhos (ex.: $\mathrm{P}_{2} \mathrm{O}_{5}$ ). À medida que o comprimento das cadeias de um composto fosfato diminui a razão O/P aumenta, como é o caso dos Metafosfatos $(\mathrm{O} / \mathrm{P}=3)$ e Polifosfatos $(\mathrm{O} / \mathrm{P}>3)[24]$.

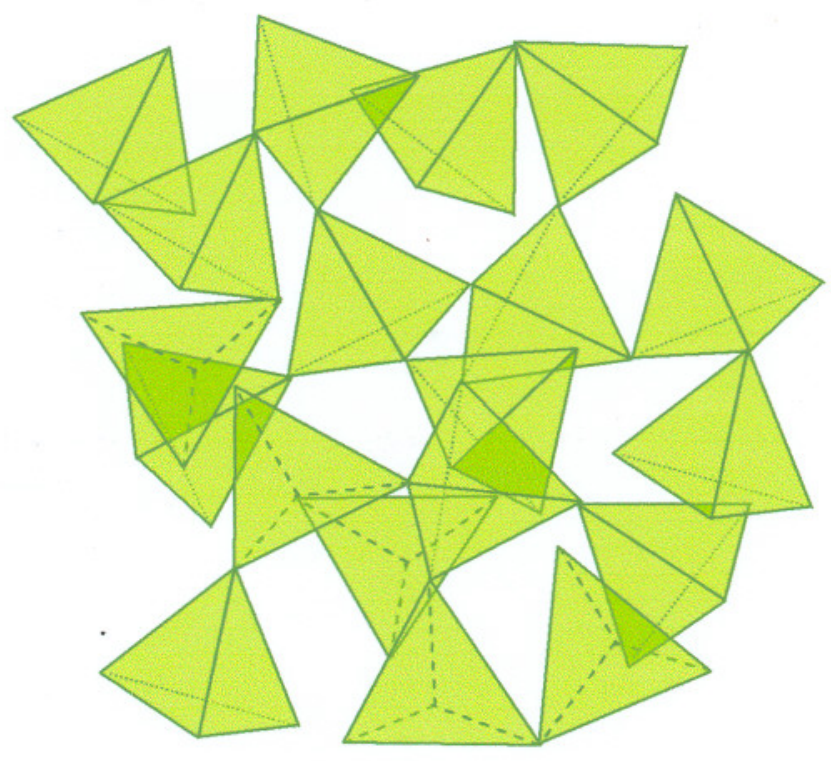

Figura 7 - Representação de uma cadeia em 3D com composição de ultrafosfato amorfo. Cada tetraedro representa um grupo $\mathrm{PO}_{4}$. 


\subsubsection{A formação e estrutura básica dos Vidros Fosfatos}

\subsubsection{Formação Vítrea a partir do $\mathrm{P}_{2} \mathrm{O}_{5}$}

Os fosfatos puros quando fundidos tem naturalmente grande capacidade de formação vítrea se resfriados rapidamente, devido à estrutura randômica distorcida formada pelos tetraedros de fósforo conectados entre si $[1,25]$. Podemos citar o caso do $\mathrm{P}_{2} \mathrm{O}_{5}$, que pode ser obtido pela decomposição do $\mathrm{NH}_{4} \mathrm{H}_{2} \mathrm{PO}_{4}$ (fosfato de amônia dibásico) por fusão a $500^{\circ} \mathrm{C}$. Após alguns minutos de fusão, a amônia e água são liberadas, e o fundido restante quando vertido num molde frio produz um vidro fosfato muito transparente. No momento que o vidro fundido está sendo esfriado, os átomos de fósforo e oxigênio se arranjam em tetraedros $\mathrm{PO}_{4}$ formando estruturas poliméricas que dependem da composição, ou seja, neste caso da razão O/P na mistura. Cada tetraedro $\mathrm{PO}_{4}$ pode se ligar simultaneamente com no máximo outros três tetraedros através de ligações P-O-P por compartilhamento de vértices. Este exemplo é ilustrado na Figura 8-a.

No entanto os vidros fosfatos puros são pouco estáveis quanto ao ataque químico causado pela água, que degrada o vidro. Para se produzir vidros fosfatos mais estáveis (menos higroscópicos), basicamente o $\mathrm{P}_{2} \mathrm{O}_{5}$ anidro é fundido juntamente com outras substâncias acima de $1000^{\circ} \mathrm{C}$ para se produzir uma mistura, que sendo rapidamente resfriada produz um vidro. Metais e óxidos metálicos são geralmente compostos incorporados nos vidros fosfatos, pois estes se conectam a estrutura polimérica através de ligações covalentes, como mostra a Figura 8-b.

\subsubsection{Formadores e Modificadores de rede}

Os materiais constituintes de um vidro podem ser divididos em cinco categorias, tomando-se por base o papel que desempenham no processo: formador, fundente, agente modificador, agente de cor e agente de refino. Cabe salientar que o mesmo composto pode ser classificado em diferentes categorias quando utilizado para diferentes propósitos. A alumina $\left(\mathrm{Al}_{2} \mathrm{O}_{3}\right)$, por exemplo, atua como agente formador em vidros aluminatos, mas é considerado um agente modificador na maioria dos vidros silicatos. 
Pela grande facilidade dos fosfatos formarem vidros quando puros e também quando misturados com uma vasta gama de óxidos metálicos, estes primeiros são denominados de formadores vítreos. Já os óxidos que são adicionados aos vidros fosfatos são denominados modificadores por não possuírem capacidade de formação vítrea. Os óxidos metálicos (ou modificadores) conferem aos vidros fosfatos diferentes propriedades estruturais e ópticas que podem ser controladas a partir das composições e do tipo de óxido incorporado, produzindo vidros com as propriedades desejadas.

Os modificadores podem ser adicionados para despolimerizar a estrutura, quebrando as ligações entre tetraedros $\mathrm{PO}_{4}$ e conectando-se entre eles. A despolimerização da estrutura dos vidros fosfatos por um íon metálico afeta muitos parâmetros, como por exemplo, a solubilidade do vidro e temperatura de transição vítrea. Além disso, a adição de cátions modificadores a rede dos vidros fosfatos resulta em materiais com grande variedade de aplicações, como materiais bioativos, sensores, vidros selantes para metais, dispositivos opto-eletrônicos, matrizes laser e condutores iônicos de estado sólido.
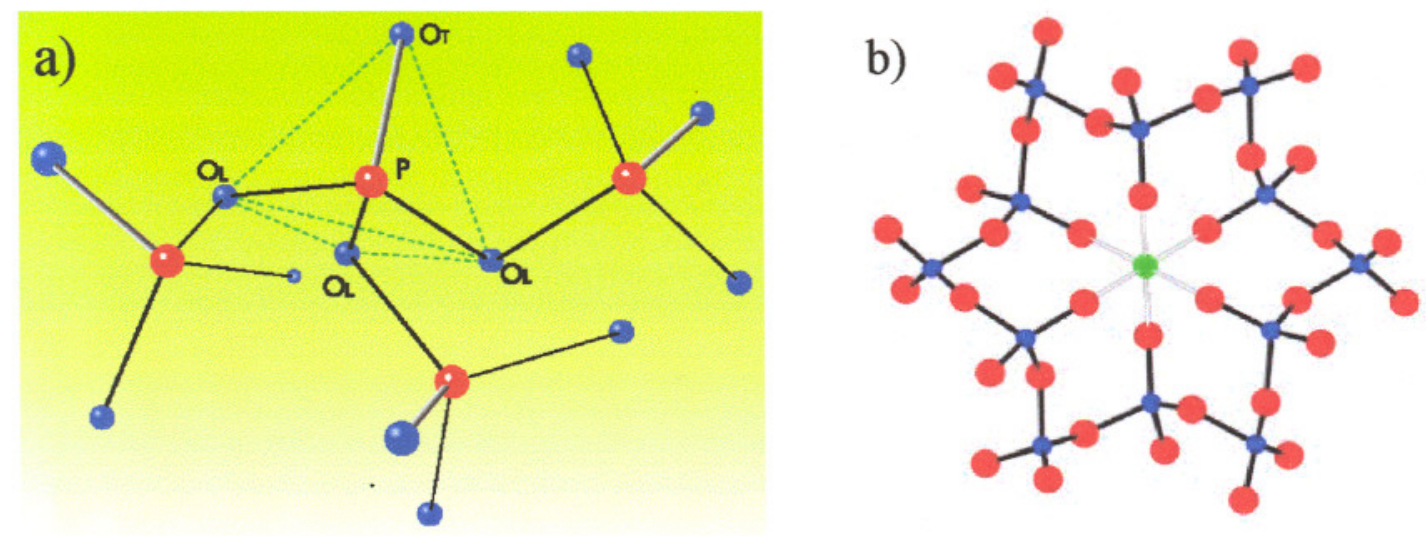

Figura 8 - a) Estrutura básica de um vidro fosfato com $\mathrm{PO}_{4}$ conectados. (vermelho $=$ fósforo, azul = oxigênio); b) Vidro fosfato com íon metálico incorporado. (azul = fósforo, vermelho = oxigênio, verde $=$ sódio). 


\subsubsection{Vidros fosfatos modificados por óxidos metálicos}

A capacidade de fosfatos formarem complexos com íons metálicos é reconhecida há mais de um século. Logo após a descoberta dos vários tipos de fosfatos foi verificado que algumas cadeias de fosfatos tinham a propriedade de prevenir a precipitação ou de dissolver precipitados de metais alcalinos terrosos [26]. A formação de complexos por associação iônica forte ou por ligação covalente entre metais e fosfatos tem sido motivo de extensa pesquisa, tanto na interpretação das mudanças químicas em fosfatos como principalmente no estudo de vidros fosfatos modificados pela adição de óxidos metálicos, formando sistemas vítreos com novas propriedades para aplicação em diversas áreas [27].

A influência da modificação de vidros fosfato por cátions metálicos depende principalmente do estado de oxidação, raio iônico, e das propriedades elétricas e magnéticas do cátion incorporado, refletindo em enormes alterações nas propriedades químicas e estruturais do sistema vítreo resultante. Além da modificação da estrutura polimérica formada pelas cadeias de $\mathrm{PO}_{4}$, os cátions metálicos podem promover ou ativar certas reações como a nucleação de grãos cristalinos ou luminescência. Estes fenômenos complexos implicam em inúmeras oportunidades para o desenvolvimento de novos materiais vítreos para aplicações tecnológicas, através da compreensão das origens fisicas e químicas de tais comportamentos.

Recentemente, a importância tecnológica de vitrocerâmicas e vidros fosfatos modificados por óxidos metálicos tem sido mais amplamente reconhecida. A Tabela 2 lista algumas áreas de interesse de aplicações potenciais para vidros fosfato modificados por cátions metálicos. A Figura 9 ilustra alguns exemplos práticos dessas aplicações. 
Tabela 2 - Características e Aplicações de vidros fosfatos modificados por cátions metálicos.

\begin{tabular}{|c|c|c|}
\hline Propriedades & Características & Aplicações potenciais \\
\hline Composição & $\begin{array}{l}\text { Oferecem vasta região de } \\
\text { formação vítrea, com } \\
\text { possibilidade de manipulação da } \\
\text { estrutura polimérica }\end{array}$ & $\begin{array}{l}\text { Fibras de vidros metafosfatos } \\
\text { com cadeias orientadas. Ligas } \\
\text { vidro-polímero moldáveis por } \\
\text { injeção }\end{array}$ \\
\hline Temperatura de preparação & $\begin{array}{l}\text { Vidros Sn-Pb-F-P-O: } \mathrm{T}_{\mathrm{g}} 100^{\circ} \mathrm{C} \\
\text { Vidros Pb-In-P-O: } \mathrm{T}_{\mathrm{f}}=900^{\circ} \mathrm{C}, \\
\mathrm{T}_{\mathrm{g}}=436^{\circ}, \mathrm{T}_{\mathrm{a}}=459^{\circ} \mathrm{C}\end{array}$ & $\begin{array}{l}\text { Lentes moldáveis e elementos } \\
\text { ópticos em geral }\end{array}$ \\
\hline Durabilidade química & $\begin{array}{l}\text { Vidros fosfato com baixa } \\
\text { durabilidade química, porém } \\
\text { podem ser melhorados pela } \\
\text { incorporação de óxidos } \\
\text { modificadores }\end{array}$ & $\begin{array}{l}\text { Meio para armazenamento de } \\
\text { lixo nuclear pela incorporação } \\
\text { de óxidos de urânio }\end{array}$ \\
\hline Expansão térmica & $\begin{array}{l}\text { Vidros com alta concentração de } \\
\text { metais alcalino-terrosos c/ coef. } \\
\text { exp. térmica: } 10-20 \times 10^{-6}{ }^{\circ} \mathrm{C}^{-1}\end{array}$ & Selantes vidro-metal \\
\hline Condutividade Elétrica & $\begin{array}{l}\text { Vidros condutores iônicos rápidos } \\
\mathrm{AgI}-\mathrm{Ag}_{2} \mathrm{O}-\mathrm{P}_{2} \mathrm{O}_{5}: 10^{-3}-10^{-2} \\
\text { /ohm/cm }\end{array}$ & $\begin{array}{l}\text { Materiais para eletrólitos } \\
\text { sólidos para células de } \\
\text { combustivel }\end{array}$ \\
\hline Qualidade óptica & $\begin{array}{l}\text { Alto índice de refração, } 1.75 \text { - } \\
1.91 \mathrm{p} / \text { vidros } \mathrm{Pb}-\mathrm{In}-\mathrm{P}-\mathrm{O}, \mathrm{Pb}-\mathrm{Sc} \text { - } \\
\mathrm{P}-\mathrm{O} \text {, e } \mathrm{Pb}-\mathrm{In}-\mathrm{Al}-\mathrm{P}-\mathrm{O} \text { com baixa } \\
\text { dispersão }\end{array}$ & Aplicações Ópticas \\
\hline Transparência no UV & $\begin{array}{l}\text { Excitações de alta energia dos } \\
\text { orbitais ligantes e não ligantes } \\
\text { dos oxigênios leva a alta } \\
\text { transparência no UV }\end{array}$ & $\begin{array}{l}\text { Fibras ópticas para } \\
\text { comunicação banda larga }\end{array}$ \\
\hline Emissão estimulada & $\begin{array}{l}\text { Linhas estreitas de emissão, } \\
\text { eficiência quântica alta, } \\
\text { homogeneidade espectral alta, } \\
\text { fotocromismo e termocromismo }\end{array}$ & $\begin{array}{l}\text { Laseres de alta potência, } \\
\text { Coletores de energia solar, } \\
\text { Vidros sensíveis à luz e calor }\end{array}$ \\
\hline Química Superficial & $\begin{array}{l}\text { Superficie hidrolisada não } \\
\text { higroscópica }\end{array}$ & $\begin{array}{l}\text { Lentes e janelas para } \\
\text { aplicações marítimas }\end{array}$ \\
\hline Nucleação e cristalização & $\begin{array}{l}\text { Formação de microestrutura } \\
\text { controlada em vitrocerâmicas }\end{array}$ & $\begin{array}{l}\text { Vitrocerâmicas de } \mathrm{BPO}_{4} \\
\text { preenchida com hidrogênio }\end{array}$ \\
\hline Biocompatibilidade & $\begin{array}{l}\text { Capacidade de ligação com ossos } \\
\text { "in vivo" pela formação vítrea de } \\
\text { superficies rica em Ca-P }\end{array}$ & Biovidros e Biocerâmicas \\
\hline
\end{tabular}

Temperatura de transição vítrea $\left(\mathrm{T}_{\mathrm{g}}\right)$, Temperatura de fusão $\left(\mathrm{T}_{\mathrm{f}}\right)$, Temperatura de amolecimento ( $\left.\mathrm{T}_{\mathrm{a}}\right)$ 


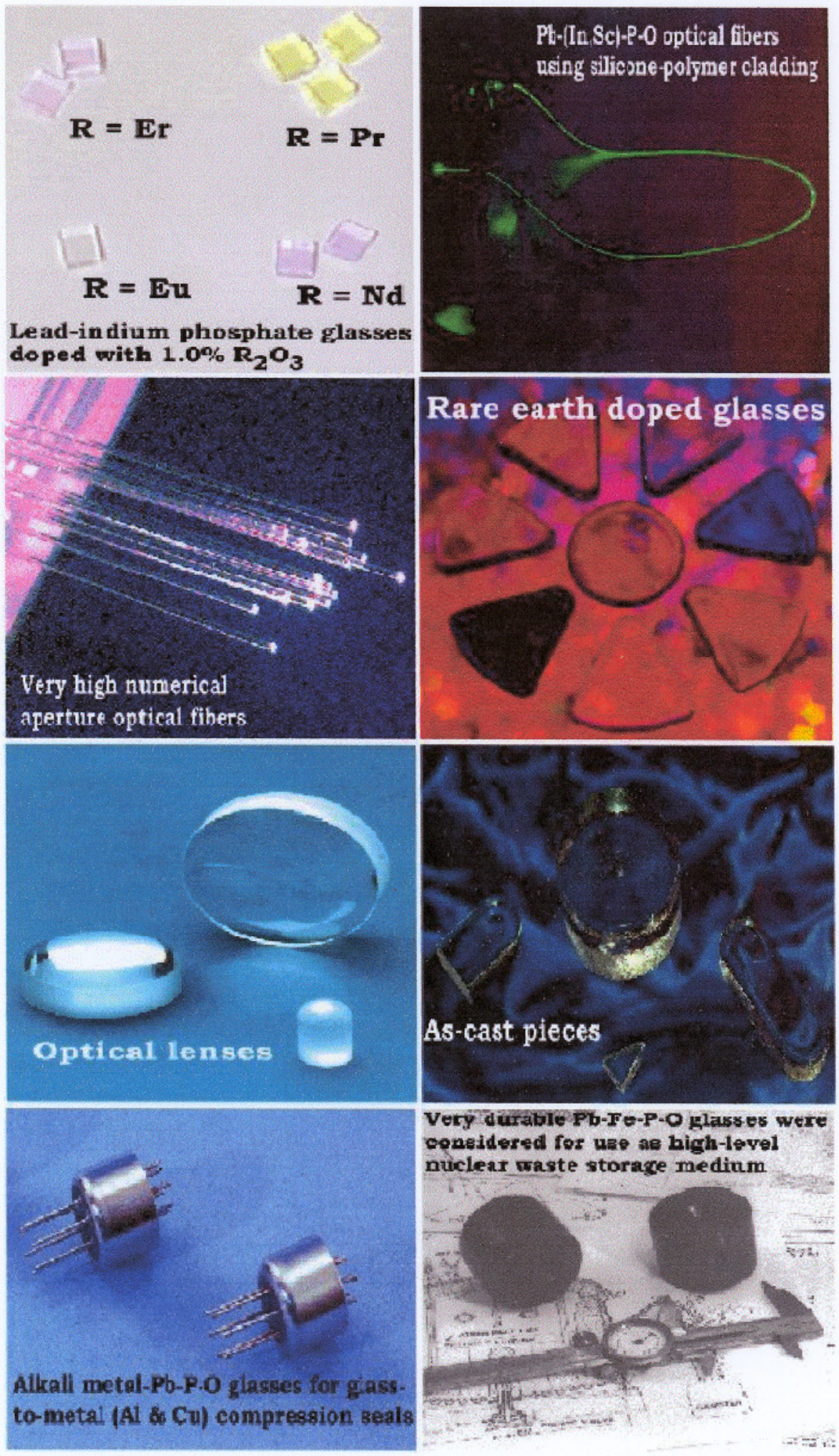

Figura 9 - Exemplos de Aplicações de vidros fosfatos modificados por metais pesados e íons terras raras (ex. $\mathrm{Pb}, \mathrm{In}, \mathrm{Sc}, \mathrm{Fe}){ }^{\text {ii }}$.

${ }^{i i}$ B. C. Sales and L. A. Boatner, Oak Ridge National Laboratory 
Como citado anteriormente, as propriedades químicas e estruturais de vidros fosfatos modificados a partir da associação com um determinado cátion dependem diretamente das características fisico-químicas de tal cátion modificador e principalmente do grau de polarização, despolimerização, e dispersão gerada na estrutura do vidro. Esses efeitos são discutidos a seguir.

\subsubsection{Polarizabilidade, Despolimerização e Dispersão em vidros fosfatos}

Com a crescente possibilidade de produção de vidros fosfatos com inúmeras propriedades determinadas pela introdução de diferentes cátions modificadores, bem como o grande interesse no estudo das alterações estruturais induzidas em vidros, é necessário um enfoque mais detalhado a nível atômico e/ou molecular para melhor compreensão da evolução da estrutura dos vidros fosfatos modificados. Dessa forma vamos descrever a seguir os efeitos de polarizabilidade, despolimerização, e dispersão dos grupos $\mathrm{PO}_{4}$, gerados a partir da adição de um cátion modificador em sistemas vítreos a base de fosfatos. Ambos efeitos estão relacionados com alterações tanto na configuração dos orbitais moleculares de grupos $\mathrm{PO}_{4}$, como também na estrutura molecular de mais longo alcance no vidro.

\subsubsection{O efeito de Polarizabilidade catiônica}

Como mencionado anteriormente, na maioria dos materiais o tetraedro $\mathrm{PO}_{4}$ aparece como elemento estrutural estável, cuja estrutura interna é determinada pela hibridização $\mathrm{sp}^{3}$ de quatro dos cinco elétrons de valência. $O$ quinto elétron de valência do fósforo popula um orbital $3 \mathrm{~d}$ onde é formada uma ligação $\pi$ com um oxigênio terminal $\left(\mathrm{O}_{\mathrm{T}}\right)$ (ver Figura 3). Dessa forma o tetraedro $\mathrm{PO}_{4}$ é conectado ao restante da estrutura vítrea por compartilhamento de no máximo três de seus vértices.

A adição de um óxido modificador induz uma alteração na estrutura do vidro de forma que a ligação $\pi$ se torna delocalizada em todas as conexões $\mathrm{P}=\mathrm{O}_{\mathrm{T}}$ de um tetraedro. Isso é devido ao efeito de polarização das nuvens eletrônicas, gerado pela carga positiva 
do cátion modificador. A delocalização da ligação $\pi$ nos tetraedros $\mathrm{PO}_{4}$ do vidro causa variações no comprimento de tais ligações, afetando propriedades do vidro como: índice de refração, e propriedades ópticas não-lineares, etc. A forma na qual um cátion se conecta a estrutura de um vidro fosfato pelo compartilhamento de elétrons de oxigênios ligantes dos vértices dos tetraedros $\mathrm{PO}_{4}$ é ilustrada na Figura 10.

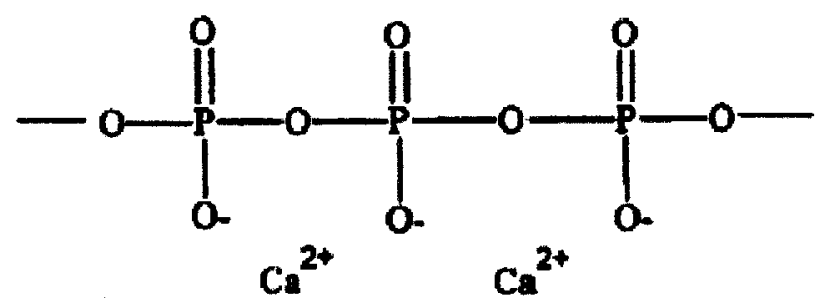

Figura 10 - Exemplo de ligação de cadeias de fosfatos com íons metálicos

Por exemplo, os cátions $\mathrm{P}^{5+}, \mathrm{B}^{3+} \mathrm{e} \mathrm{Si}^{4+}$ possuem polarizabilidade extremamente baixa $\left(0,021,0,002,0,033 \AA^{3}\right.$, respectivamente), e alta carga positiva. Estes possuem força de campo muito grande e afetam fortemente a densidade de carga eletrônica dos íons óxidos da vizinhança. Dessa forma vidros contendo alta concentração de formadores vítreos clássicos como $\mathrm{P}_{2} \mathrm{O}_{5}, \quad \mathrm{~B}_{2} \mathrm{O}_{3}$ e $\mathrm{SiO}_{2}$ apresentam, baixa polarizabilidade e baixo índice de refração. Entre os vidros convencionais, os germanatos possuem maior índice de refração. $\mathrm{O}$ ín $\mathrm{Ge}^{4+}$ possui polarizabilidade igual a $0.137 \AA^{3}$ [28], maior do que o $\mathrm{P}^{5+}, \mathrm{B}^{3+} \mathrm{e} \mathrm{Si}^{4+}$. Este fator diminui a influência do cátion sobre a carga da nuvem eletrônica, o que está relacionado com o aumento da polarizabilidade eletrônica média. Em contraste, a força de campo de íons $\mathrm{Te}^{4+}, \mathrm{Sb}^{3+}$, $\mathrm{Bi}^{3+} \mathrm{e}^{2+}$ é muito pequena. Estes cátions possuem polarizabilidade muito alta $(1,595$, $1,111,1,508$ e $3,623 \AA^{3}$, respectivamente) e também apresentam um par de elétrons livres na camada de valência, os quais são fortemente polarizáveis [29]. Dessa forma vidros fosfatos, boratos e silicatos contendo grande quantidade de $\mathrm{Sb}_{2} \mathrm{O}_{3}, \mathrm{Bi}_{2} \mathrm{O}_{3}$ ou $\mathrm{PbO}$ apresentam alta polarizabilidade do íon óxido e alto índice de refração

Outro efeito gerado pela adição de cátions modificadores em vidros fosfato é o efeito de despolimerização estrutural, discutido a seguir. 
1.2.4.2 A Despolimerização estrutural e a nomenclatura $Q^{i}$ em fosfatos

Quando falamos da incorporação de óxidos modificadores em vidros fosfatos, devemos destacar a despolimerização da estrutura do vidro, ou seja, a quebra das cadeias de tetraedros $\mathrm{PO}_{4}$ conectados entre si através de ligações P-O-P.

Um grupo $\mathrm{PO}_{4}$ pode se ligar com $0,1,2$ ou até 3 grupos fosfatos simultaneamente no vidro, dependendo do número de oxigênios ligantes disponíveis na estrutura. $\mathrm{O}$ oxigênio ligante $\left(\mathrm{O}_{\mathrm{L}}\right)$ é definido como aquele que conecta dois átomos de $\mathrm{P}$, de grupos $\mathrm{PO}_{4}$ vizinhos. $\mathrm{O}$ número de $\mathrm{O}_{\mathrm{L}}$ (oxigênios ligantes) e $\mathrm{O}_{\mathrm{NL}}$ (oxigênios nãoligantes) em cada $\mathrm{PO}_{4}$ depende da quantidade e da carga dos cátions modificadores de rede incorporados na estrutura do vidro. Dessa forma, a despolimerização em vidros fosfatos é estudada com base na variação do número de oxigênios ligantes e não ligantes na estrutura. Quanto maior a carga e a quantidade de cátions modificadores no vidro, menor a quantidade de $\mathrm{O}_{\mathrm{L}}$, pois cada cátion fará ligação com um ou mais oxigênios dos ions $\mathrm{PO}_{4}$, quebrando a estrutura polimérica formada pelos fosfatos. Esse efeito pode ser visualizado na Figura 11.
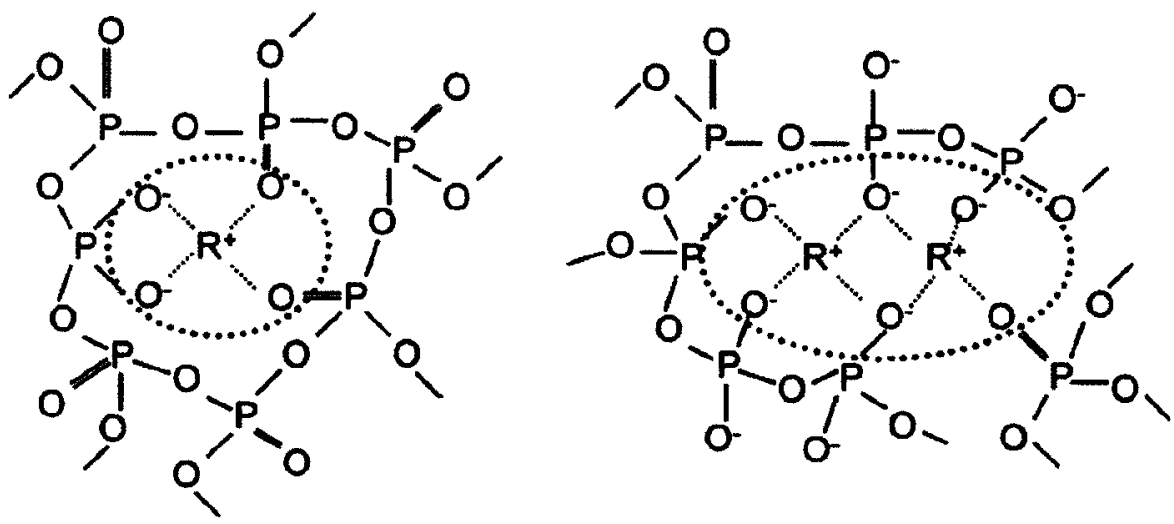

Figura 11 - Representação esquemática das ligações químicas entre cátions de metal pesado $\left(\mathrm{R}^{+}\right)$e grupos $\mathrm{PO}_{4} \mathrm{em}$ vidros fosfatos.

Para o estudo da configuração de grupos $\mathrm{PO}_{4}$ em vidros fosfato utiliza-se a terminologia $\mathrm{Q}^{\mathrm{i}}$ para definir o tipo de configuração do tetraedro $\mathrm{PO}_{4}$ na estrutura, onde $\mathrm{Q}^{3}$ seria o grupo fosfato que possui três oxigênios ligantes e $\mathrm{Q}^{0}$ o grupo fosfato isolado que não possui nenhum oxigênio ligante. As configurações $Q^{i}$ para grupos $\mathrm{PO}_{4}$ podem ser melhor compreendidas através da Figura 12, onde as ligações em azul representam os oxigênios ligantes de cada grupo. 
<smiles>CCOP(=O)(OC)OC</smiles>

$Q^{3}$<smiles>CC(C)OP(=O)([O-])OC(C)C</smiles>

$Q^{2}$<smiles>CCOP(=O)([O-])O</smiles>

$Q^{1}$

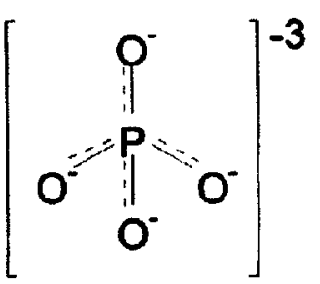

$Q^{0}$

Figura 12 - Possíveis configurações de sítios $Q^{i}$ para o grupo $\left(\mathrm{PO}_{4}\right)$ em vidros fosfato. As ligações em azul identificam os oxigênios ligantes de cada grupo $\mathrm{PO}_{4}$.

Muitas propriedades dos vidros fosfatos são investigadas baseado na quantidade de grupos $Q^{i}$ na estrutura. Os vidros fosfato podem ser feitos com uma variedade de estruturas, desde redes completamente conectadas por tetraedros $\mathrm{Q}^{3}\left(\mathrm{P}_{2} \mathrm{O}_{5}\right.$ amorfo) ou cadeias poliméricas de polifosfatos $Q^{2}$ até vidros baseados em ânions pequenos com composição piro $\left(\mathrm{Q}^{1}\right)$ ou ortofosfato $\left(\mathrm{Q}^{0}\right)$, dependendo da razão $\mathrm{O} / \mathrm{P}$ determinada pela composição vítrea. Um exemplo de como a introdução de óxidos metálicos $\left(M^{+}\right)$altera a polimerização da rede de fosfatos e por conseqüência a fração de tetraedros $Q^{i}$ na estrutura do vidro é apresentado na Figura 13.

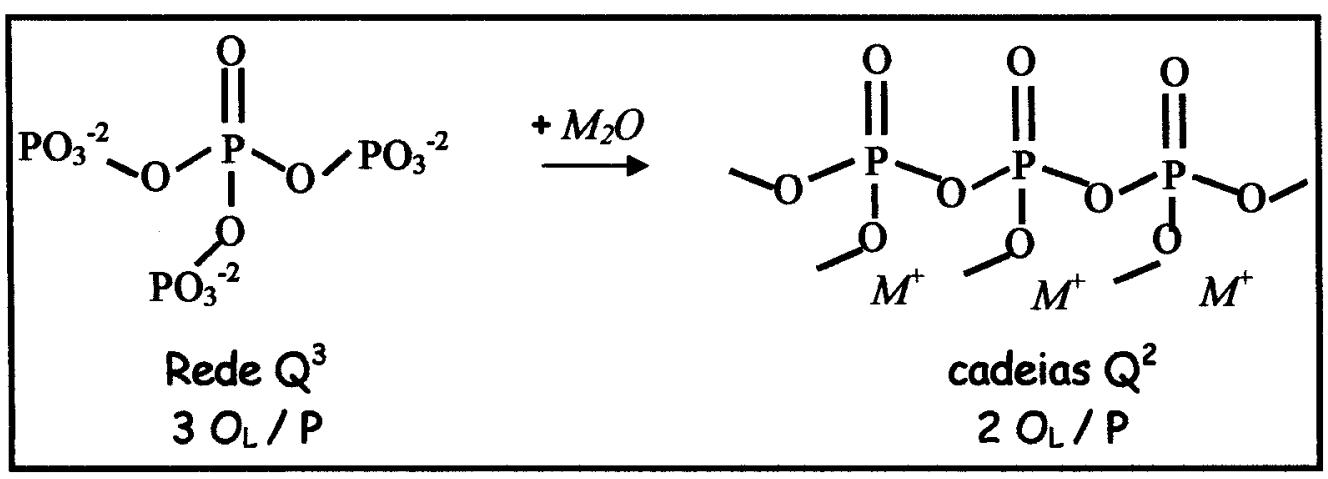

Figura 13 - Modelo de despolimerização estrutural em vidros fosfato pela adição de óxidos modificadores na estrutura.

Um exemplo de despolimerização estrutural investigado pela técnica de Difração de nêutrons para o $\mathrm{P}_{2} \mathrm{O}_{5}$ puro e uma série de vidros fosfatos modificados por $\mathrm{PbO}$ e $\mathrm{ZnO}$ é mostrado na Figura 14. Através desta técnica é possível analisar a variação da distância média e as quantidades relativas das ligações $\mathrm{P}-\mathrm{O}_{\mathrm{T}}$ e $\mathrm{P}-\mathrm{O}_{\mathrm{L}}$ na primeira esfera de coordenação do átomo de fósforo na estrutura de vidros fosfatos em função da quantidade de óxido modificador adicionado. 
A mudança na fração de $\mathrm{O}_{\mathrm{T}}$ e $\mathrm{O}_{\mathrm{L}}$ no vidro é nítida pelas alterações das áreas dos picos, uma vez que o forte caráter $\pi$ das ligações $\mathrm{P}=\mathrm{O}_{\mathrm{T}}$ faz com que estas sejam mais curtas do que as ligações das pontes $\mathrm{P}-\mathrm{O}_{\mathrm{L}}-\mathrm{P}$. A diminuição na área do pico relacionado com a ligação $\mathrm{P}-\mathrm{O}_{\mathrm{L}}$ (a partir do $\mathrm{P}_{2} \mathrm{O}_{5}$ puro) mostra claramente o efeito de despolimerização causado pela adição de um óxido ao vidro, onde ocorre a quebra das pontes $\mathrm{P}-\mathrm{O}_{\mathrm{L}}-\mathrm{P}$. Outro fato importante é notar que o comprimento das ligações $\mathrm{P}=\mathrm{O}_{\mathrm{T}}$ aumenta, devido ao efeito de polarização causada pelo cátion sobre as nuvens eletrônicas do grupo $\mathrm{PO}_{4}$, diminuindo o caráter $\pi$ da ligação do $\mathrm{P}$ com o $\mathrm{O}_{\mathrm{T}}$.

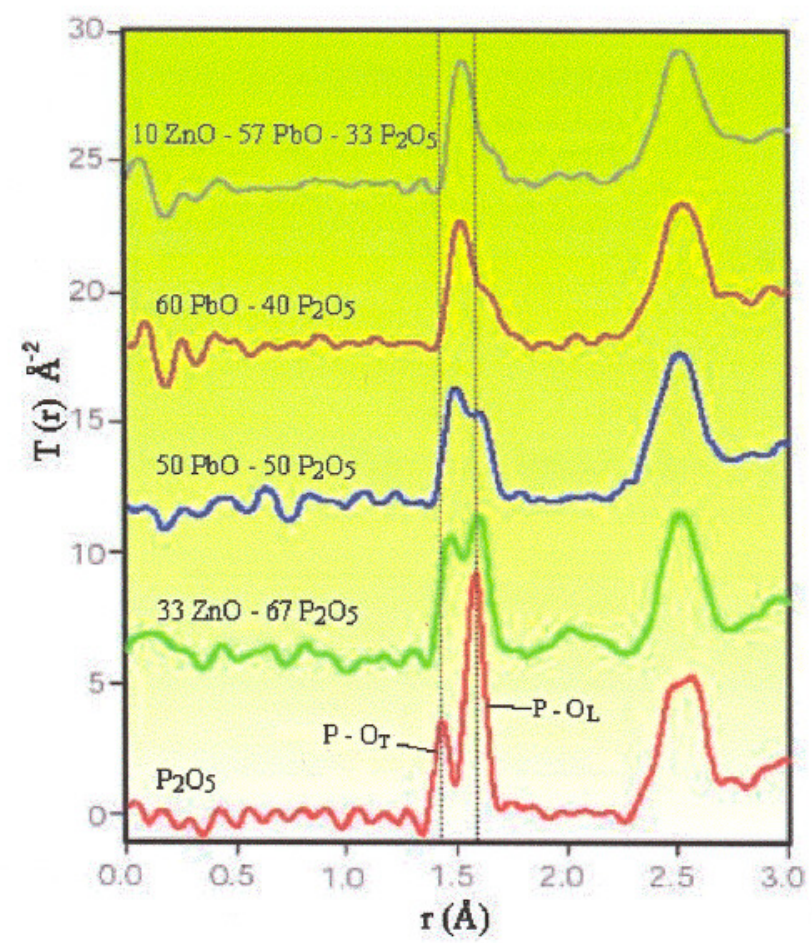

Figura 14 - Espectro de Difração de Nêutrons mostrando a distância média e as quantidades relativas das ligações $\mathrm{P}-\mathrm{O}_{\mathrm{T}}$ e $\mathrm{P}-\mathrm{O}_{\mathrm{L}}$ na primeira esfera de coordenação do átomo de fósforo para o $\mathrm{P}_{2} \mathrm{O}_{5}$ puro e uma série de vidros fosfatos modificados por $\mathrm{PbO}$ e $\mathrm{ZnO}$ [30].

\subsubsection{O efeito de Dispersão Estrutural}

A dispersão estrutural em fosfatos está relacionada com a distância média entre os grupos $\mathrm{PO}_{4}$ num vidro e a conectividade entre esses grupos e o número de cátions por fósforo presentes na estrutura. A técnica de Magic Angle Spinning-Nuclear Magnetic Resonance (MAS-NMR) é muito utilizada para o estudo de vidros fosfatos, mais especificamente devido à sensibilidade ao núcleo do ${ }^{31} \mathrm{P}$ presente nos fosfatos [31]. 
Mudanças estruturais tanto na dispersão como no tipo de configuração $Q^{i}$ de um tetraedro $\mathrm{PO}_{4}$ podem ser detectadas por MAS-NMR, devido a mudanças de ligação nos oxigênios que coordenam um fósforo como também na distância média entre núcleos de fósforos vizinhos, causando um significativo deslocamento nos espetros de NMR.

A Figura 15 mostra a representação do efeito de dispersão estrutural devido a adição de um cátion modificador. No $\mathrm{P}_{2} \mathrm{O}_{5}$ os tetraedros $\mathrm{PO}_{4}$ (círculos vermelhos) estão conectados entre si pelo compartilhamento de até três átomos de oxigênio para formar uma rede tridimensional. Pelo aumento da incorporação de cátions na estrutura (círculos azuis) a conectividade dos tetraedros se transforma de uma rede tridimensional (ultrafosfatos) para cadeias cíclicas (metafosfatos) ou lineares (polifosfatos), até a formação de dímeros e grupos $\mathrm{PO}_{4}$ isolados (ortofosfatos). A dispersão também está ligada ao efeito de despolimerização, porém a dispersão indica o afastamento (distância média) entre os grupos $\mathrm{PO}_{4}$ que pode ocorrer, por exemplo, pela adição de um cátion com grande raio iônico. Dessa forma a dispersão pode variar para uma mesma composição onde haja incorporação de cátions com mesma carga, porem com raios iônicos muito diferentes.

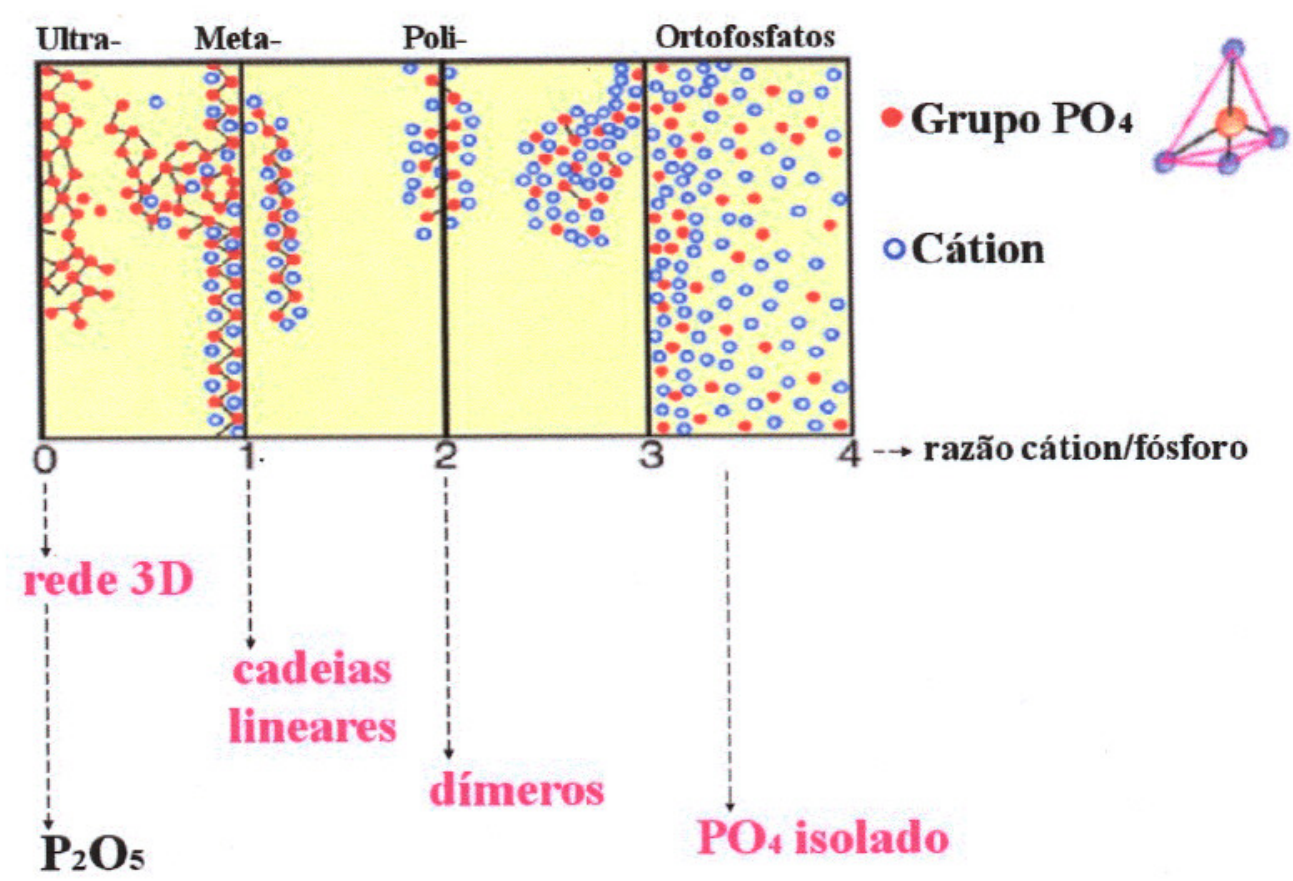

Figura 15 - Representação do efeito de dispersão entre grupos $\mathrm{PO}_{4}$ tendo como referência o $\mathrm{P}_{2} \mathrm{O}_{5}$ puro e o aumento da concentração de um cátion modificador na estrutura. 
As propriedades dos vidros são drasticamente alteradas pela adição de um modificador de rede ao sistema. A evolução da ordem de longo alcance bem como dos efeitos de despolimerização e dispersão em vidros com composições de ultrafosfatos com estrutura 3D, até cadeias de polifosfatos e dímeros de fosfatos têm sido estudadas por difração de nêutrons e espalhamento inelástico. Tais técnicas fornecem importantes informações a respeito da estrutura e das dinâmicas de um sistema vítreo ou cristalino à nível atômico [30].

A distribuição de comprimentos de cadeias em vidros fosfatos é mais precisamente determinada por análise de cromatografia de alta performance para líquidos, onde os vidros são dissolvidos na forma de soluções [32]. Tal técnica pode determinar quantitativamente fosfatos com comprimentos de cadeias de até 30 tetraedros.

\subsection{Vidros a base de Antimônio}

O antimônio é um elemento interessante por que como centro de coordenação exibe um comportamento estrutural imprevisível devido à presença de um par de elétrons livres polarizáveis quimicamente ativos [33]. Os derivativos de antimônio são importantes não apenas por causa de suas propriedades químicas, mas também devido a serem extensivamente empregados de várias formas como: reagentes analíticos [34], aditivos lubrificantes (para melhorar as propriedades antidesgaste a altas pressões de lubrificantes) [35], atividades catalíticas [36], etc.

Poucos dados encontram-se na literatura sobre os vidros a base de antimônio e a possibilidade de formação vítrea a partir do óxido de antimônio, $\mathrm{Sb}_{2} \mathrm{O}_{3}$ foi indicada por Zachariansen em 1932 [1] e os primeiros testes foram realizados por Kordes [37] em 1939. Quando fundido isoladamente o $\mathrm{Sb}_{2} \mathrm{O}_{3}$ é um fraco formador vítreo, tendendo a devitrificação durante o resfriamento, a menos que seja resfriado muito rapidamente. Porém, o óxido de antimônio é capaz de formar facilmente vidros muito estáveis quando outros óxidos formadores de rede clássicos $\left(\mathrm{P}_{2} \mathrm{O}_{5}, \mathrm{SiO}_{2}, \mathrm{~B}_{2} \mathrm{O}_{3}\right)$ são adicionados ao fundido em concentrações menores que 5 moles \% $[38,39]$.Até hoje a capacidade vitrificante do $\mathrm{Sb}_{2} \mathrm{O}_{3}$ é objeto de diversos trabalhos, porém ainda existem controvérsias sobre sua capacidade de formar vidros. 
Antigamente o óxido de antimônio era usado como uma espécie de tampão eletrônico para controlar o estado de oxidação de macro-componentes fundidos e para a otimização do crescimento de cristais em vitrocerâmicas [40]. Na indústria de vidros refratários, o antimônio é adicionado na forma de partículas metálicas na forma coloidal sólida para colorimento e para elevar a resistência térmica de chapas transparentes para o infravermelho de fogões. Esta propriedade é aproveitada para evitar o choque térmico nas cerâmicas industriais e vidros nos quais a resistência do material aumenta $15 \%$ após a adição dos compostos de antimônio na quantidade de $10 \%$ (vol.) [41].

De um modo geral, fala-se de óxido de antimônio, mas é necessário levar em conta que na realidade existe uma série quase contínua de óxidos desse elemento $\left(\mathrm{Sb}_{2} \mathrm{O}_{3}, \mathrm{Sb}_{2} \mathrm{O}_{5}, \mathrm{Sb}_{5} \mathrm{O}_{7}, \mathrm{Sb}_{8} \mathrm{O}_{11}\right.$, etc.). A mesma observação é valida com relação aos numerosos sulfetos e oxi-sulfetos de antimônio, de fórmula geral $\mathrm{Sb}_{n} \mathrm{O}_{\mathrm{m}} \mathrm{S}_{1}$. A Figura 16 mostra a representação estrutural das três formas mais comuns do óxido de antimônio, $\mathrm{Sb}_{2} \mathrm{O}_{3}, \mathrm{Sb}_{2} \mathrm{O}_{4}$ e $\mathrm{Sb}_{2} \mathrm{O}_{5}$.
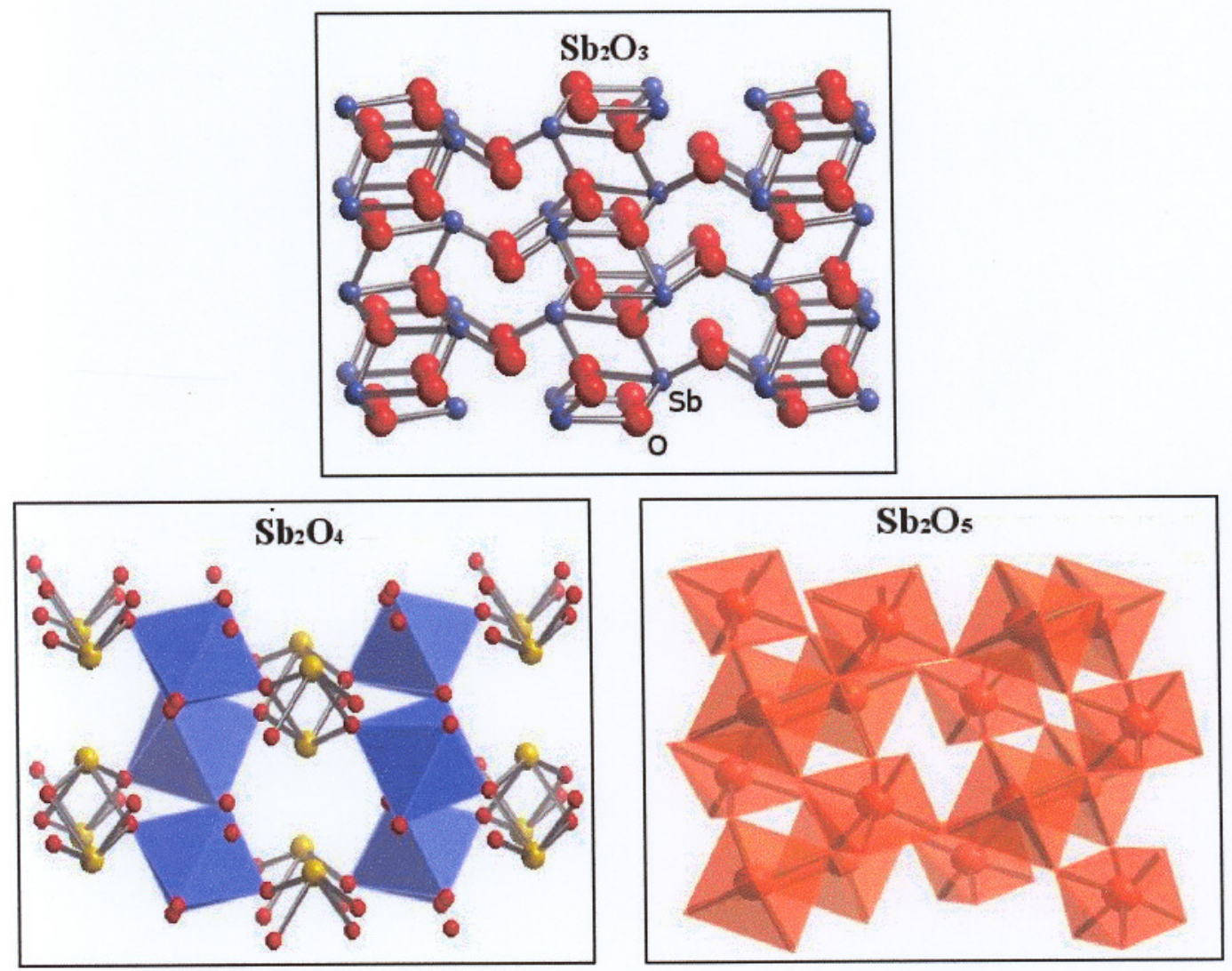

Figura 16 - Representação estrutural das três formas mais comuns do óxido de antimônio, $\mathrm{Sb}_{2} \mathrm{O}_{3}, \mathrm{Sb}_{2} \mathrm{O}_{4} \mathrm{e} \mathrm{Sb}_{2} \mathrm{O}_{5}$. 
Na década de 80, o antimônio começou a ser mais usado criteriosamente, isto é, visando os previsíveis efeitos estruturais e físico-químicos como resultado da sua incorporação nos vidros. Foi mostrado que seus óxidos (assim como sulfetos) podem desempenhar papel de formadores de rede nos vidros contendo cátions alcalinos e alcalinos terrosos. Este comportamento fez-se compreensível só depois do estudo dos espectros de fluorescência de raios- $\mathrm{X}$ nos quais foi comprovado que apesar de ter sido incorporado na forma de $\mathrm{Sb}(\mathrm{III})$ o elemento está presente em estados de oxidação tanto trivalente como pentavalente, ou seja, existe um formador de macro-rede aniônica que é o $\mathrm{Sb}(\mathrm{V})$ e os cátions compensadores de carga que são $\mathrm{M}(\mathrm{I})$ e $\mathrm{Sb}(\mathrm{III})$, ( $\mathrm{M}=$ metais alcalinos). Outras composições vítreas à base de antimônio foram estudadas, entre elas vidros à base de $\mathrm{Sb}_{2} \mathrm{~S}_{3}$ [42]. Eles apresentam alta transparência no infravermelho (até 10 $\mu \mathrm{m})$, representando assim materiais com potenciais de aplicações em dispositivos ópticos.

Vidros óxidos de metais pesados têm sido largamente estudados devido a suas propriedades ópticas específicas, tais como estendida transmitância no infravermelho e maior índice de refração comparado com outros vidros [43-49]. Vidros a base de antimônio têm atraído grande interesse recentemente, devido a apresentar propriedades ópticas não-lineares e magnéticas [50,51], e também devido à condutividade reportada para o sistema vítreo $\mathrm{Sb}_{2} \mathrm{O}_{3}-\mathrm{P}_{2} \mathrm{O}_{5}$ [52]. Sendo de interesse científico, vidros contendo antimônio são também de grande interesse tecnológico. Vidros binários de antimônio borato com alta concentração de $\mathrm{Sb}^{3+}$ foram considerados recentemente como materiais importantes para aplicações em óptica não-linear, devido a grande susceptibilidade óptica não-linear de terceira ordem [53].

Vidros silicatos de antimônio foram identificados no passado como vidros potenciais para núcleo de baixa perda em guias de onda [54]. Atualmente vidros silicatos de antimônio são usados para produzir fibras ópticas de baixa perda com alta qualidade, as quais podem acomodar altos níveis de terras raras para espectroscopia no infravermelho. Como exemplo em aplicação óptica podemos citar os resultados em vidros $\mathrm{Sb}_{2} \mathrm{O}_{3}-\mathrm{SiO}_{2}$ utilizados na produção de fibras ópticas com qualidade comparável a vidros teluretos otimizados [55] (Figura 17). 


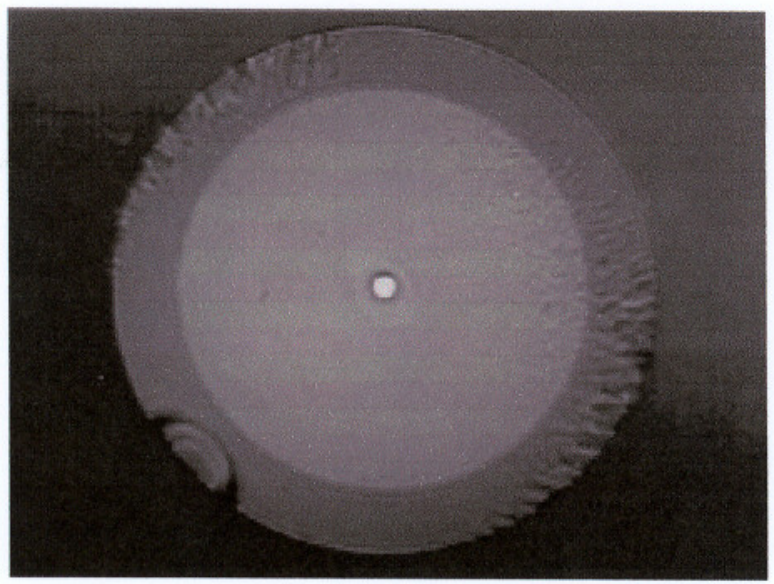

Figura 17 - Fibra óptica de silicato de antimônio com núcleo de $15 \mu \mathrm{m}$ de diâmetro, fabricada pela técnica de cadinho triplo [55].

As interessantes propriedades conferidas pelo $\mathrm{Sb}^{3+}$ em sistemas vítreos contendo terras raras foram identificadas como sendo independentes do segundo óxido presente no vidro, e, portanto é de grande interesse o estudo de diversos sistemas vítreos contendo $\mathrm{Sb}_{2} \mathrm{O}_{3}$. Em contraste, a maioria dos vidros a base de antimônio apresenta alta tendência a devitrificação e tem variação local de composição como microcristalinidade, o que causa forte espalhamento de luz. Por outro lado, vidros fosfatos modificados por óxidos metálicos são muito estáveis contra a cristalização e oferecem possibilidade de faixa de composições extremamente grandes, além de propriedades com grande aplicação como fibras ópticas de banda larga, vidros sensíveis a luz e calor, e efeitos ópticos não-lineares [56-60].

Portanto, a preparação de vidros mistos, agrupando as propriedades físicoquímicas do óxido de antimônio e vidros fosfatos em um único sistema é muito interessante, não só do ponto de vista científico, mas também para a pesquisa e produção de novos materiais com larga aplicação. 


\subsection{Fenômenos Fotoinduzidos em vidros e filmes}

A crescente necessidade da miniaturização de dispositivos tem estimulado o estudo e manipulação dos materiais na forma de filmes buscando a interpretação dos mecanismos básicos de crescimento, estudando a morfologia e estrutura de filmes amorfos, mono e policristalinos, bem como suas propriedades ópticas e elétricas. Recentemente estudos têm sido direcionados para os Fenômenos Fotoinduzidos em materiais dispostos em finas camadas com diversas aplicações como filtros, guias de onda, películas absorvedoras, e filmes sensíveis à luz para diferentes comprimentos de onda como os utilizados em CDs e DVDs.

Nesta mesma linha, nos últimos anos tem sido crescente a pesquisa de novos materiais adequados para armazenamento óptico e holografia, onde vidros e filmes amorfos produzidos por evaporação a partir de diversos sistemas vítreos têm mostrado grande potencial aplicativo nesta área [61]. Diversos efeitos fotoinduzidos foram observados em calcogenetos sendo muito mais intensos quando induzidos em filmes preparados por evaporação a vácuo, já em vidros e pós do mesmo sistema tais efeitos apresentam intensidades relativamente menores [62].

Desde a descoberta do fenômeno de cristalização induzida pela luz por Feinleib et al. [63], vários fenômenos fotoinduzidos já foram estudados em vidros calcogenetos quando expostos a luz com energia próxima ao bandgap [64,65]. Entre os sistemas vitreos mais estudados até agora que apresentam efeitos fotoinduzidos podemos citar principalmente os vidros à base de $\mathrm{Ga}, \mathrm{Ge}, \mathrm{As}, \mathrm{Se}, \mathrm{Te}, \mathrm{S}$.

$\mathrm{Na}$ ultima década novas descobertas mostraram um grande leque de efeitos fotoinduzidos em filmes amorfos e vidros de metais pesados associados sulfetos e selenetos de $\mathrm{As}, \mathrm{Ge}$ e $\mathrm{Sb}$, e.g. $\mathrm{GeS}, \mathrm{As}_{2} \mathrm{~S}_{3}$ e $\mathrm{Sb}_{2} \mathrm{~S}_{3}$. Estes vidros apresentam muitas propriedades ópticas interessantes devido ao alto índice de refração $(\sim 1,75-2,5)$, alta não-linearidade óptica e foto-sensibilidade incomum. Exposição à luz com energia próxima ao bandgap produz uma variedade de fenômenos com grande utilidade para a fotônica como: mudanças ópticas (fotoescurecimento, fotorefração), mudanças estruturais (variações na densidade, fotoexpansão, fotocontração), mecânicas (propriedades reológicas), ou químicas (fotodissolução), etc. 
Dos muitos fenômenos fotoinduzidos descobertos em vidros [66,67], a fotocontração, quantitativamente estudada por Salminen et al. [68] tem atraído maior interesse em relação ao armazenamento óptico e holografia nestes materiais.

Salminen et al., demonstraram que os vidros a base de $\mathrm{As}_{2} \mathrm{~S}_{3}$ expostos à luz visível com energia correspondente menor que do bandgap $\left(\mathrm{E}_{\text {bandgap }}=2,39 \mathrm{eV}\right)$, a temperatura ambiente sofrem uma contração de até $20 \%$ em relação à espessura do filme depositado, que desaparece uma vez que o vidro é reaquecido ao redor da temperatura de transição vítrea. As contrações são atribuídas à quebra de ligações S-S com subseqüente ligação com a rede de As-S, podendo ocorrer cristalização na região exposta ao laser, sendo que os vidros calcogenetos podem transicionar reversivelmente entre os estados amorfo e cristalino através de fotoexcitação $[61,69]$.

Arun et al. [70-72] mostraram que a fotoexcitação com energias correspondente à luz visível $\left(488,0\right.$ e $514,5 \mathrm{~nm}$ ), gera o efeito de fotoescurecimento em filmes de $\mathrm{Sb}_{2} \mathrm{~S}_{3}$ pois a região iluminada fica com coloração mais escura do que a coloração amarelada do filme, e este efeito é atribuído à variação na concentração de enxofre. Em conseqüência do efeito de fotoescurecimento o bandgap também muda na região iluminada, deslocando-se para menores energias em relação à menor concentração de enxofre $[68,70]$. Observou-se recentemente em composições vítreas à base de $\mathrm{Sb}_{2} \mathrm{O}_{3}$, o aparecimento de pontos pretos nas regiões expostas à luz ultravioleta de um laser de $\mathrm{Ar}^{+}$ de baixa potência, e este processo também é associado ao efeito de fotoescurecimento induzidos pela luz com energia próxima ao bandgap [73].

Novos testes realizados por nós mostram que a fotoexcitação com laser de $\mathrm{Kr}^{+}$ com energia próxima ao bandgap (UV, $\lambda=350 \mathrm{~nm}$ ), em filmes amorfos com composição vítrea de $30\left[\mathrm{Sb}\left(\mathrm{PO}_{3}\right)_{3}\right]_{n}-70 \mathrm{Sb}_{2} \mathrm{O}_{3}$ (em \% molar) causa fotocontração e a região iluminada fica visivelmente transparente em relação à cor amarelada original do filme [74]. Este resultado pode estar sugerindo que na região iluminada esteja ocorrendo algum tipo de mudança estrutural, alterando o bandgap para diferentes energias como reportado também para outros materiais $[68,71]$.

Os fenômenos fotoinduzidos têm sido investigados em vidros e filmes devido à aplicabilidade direta de tais propriedades em dispositivos. A seguir damos exemplo de alguns dos principais fenômenos fotoinduzidos e uma breve descrição dos efeitos envolvidos nesses processos. 


\subsubsection{Efeitos puramente Fotoinduzidos}

Considerações tecnológicas recentes têm motivado o estudo de processos fotoinduzidos. No passado os processos fotoinduzidos concentraram-se principalmente na foto-eletroquímica [75] e reações catalíticas [76]. Atualmente, os efeitos fotoinduzidos têm sido estendidos para o processamento de materiais eletrônicos $\mathrm{e}$ fotônicos [77]. As vantagens deste processamento "com luz" têm estimulado o interesse no estudo da eficiência de processos induzidos por laser como: foto-litografia, fotooxidação, dopagem de semicondutores e foto-nitretação [78-80].

Dessa forma, os laseres apresentam uma importante e expansível função na produção e processamento de materiais. Fótons incidentes podem induzir excitações como par elétron-buraco [81], plasmons [82] e fônons superficiais [83] os quais, dependendo do material, tem mostrado criar novos efeitos fotoinduzidos em superficies. Apesar de uma variedade de fenômenos terem sido descobertos, o entendimento dos mecanismos ainda é amplamente especulativo, pois as variações estruturais envolvem processos complexos.

A aplicação de efeitos fotoinduzidos que ocorrem em vidros para a optoeletrônica é baseada no fato destes materiais apresentarem capacidade específica de mudança de propriedades físico-químicas pela influência de fatores externos, especificamente, pela absorção de luz durante fotoexposição. Tais mudanças refletem alterações diretas nas propriedades ópticas destes materiais.

Os Fenômenos Fotoinduzidos podem se separados em dois grupos principais: $\mathbf{O}$ primeiro grupo dos Efeitos puramente Fotoinduzidos, que leva em conta apenas as Mudanças diretas geradas pela luz sobre o material. O segundo grupo é relativo a efeitos que ocorrem com menos freqüência, mas não podem ser desconsiderados, pois estão relacionados com os Efeitos Fototérmicos que levam em conta as Mudanças indiretas geradas pela componente térmica induzida pela absorção da luz no material.

Os Efeitos puramente Fotoinduzidos se classificam em cinco categorias, tais como: mudanças ópticas (fotoescurecimento, fotoclareamento, fotorefração), mudanças estruturais (variações na densidade, fotoexpansão, fotocontração), mudanças mecânicas (alteração nas propriedades reológicas, e.g. deformação fluxo de massa), mudanças elétricas (fotocondução), e mudanças quimicas (fotoadsorção, fotodesorção, fotodissolução). Os Efeitos Fototérmicos envolvem fenômenos que inclusive podem 
gerar mudanças similares às observadas em um efeito fotoinduzido puro (e.g., mudanças ópticas ou estruturais), mas envolvem também mudanças que caracterizam um efeito térmico como: evaporação, cristalização, fusão, adsorção, desorção, etc. A Figura 18 apresenta um diagrama esquemático com principais grupos de fenômenos fotoinduzidos estudados em materiais.

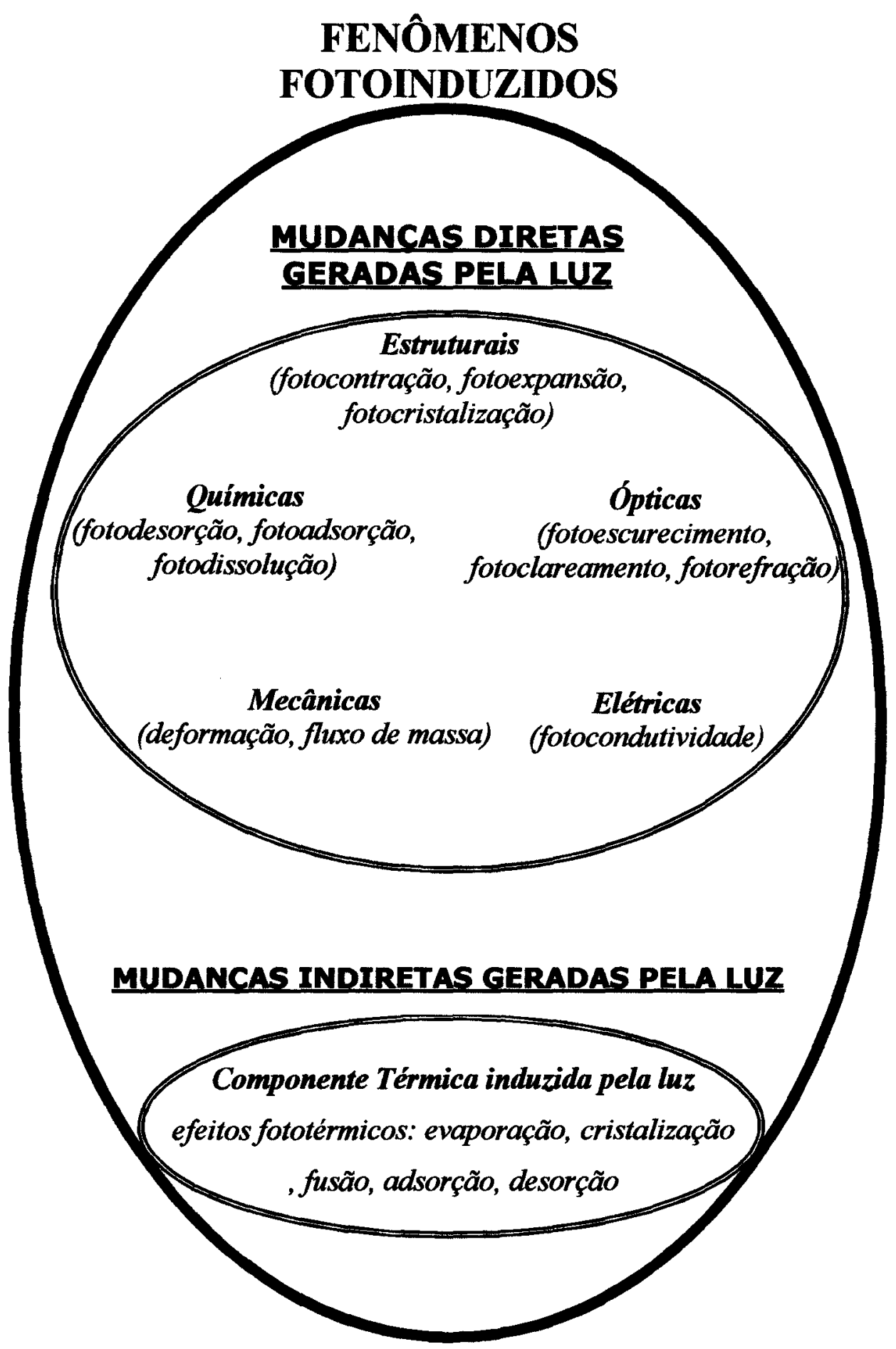

Figura 18 - Diagrama esquemático mostrando os grupos de fenômenos fotoinduzidos mais estudados em vidros. 
Os fenômenos fotoinduzidos geram mudanças que podem ser reversiveis ou irreversiveis sobre o material irradiado. As mudanças reversíveis retornam depois de determinado tempo ao seu estado original quando o material deixa de ser irradiado, ou com um tratamento térmico adequado. Já as mudanças irreversíveis permanecem no material mesmo quando este é submetido a um tratamento térmico. Alguns modelos são propostos na tentativa de explicar os mecanismos envolvidos nestes fenômenos, como mostra a Figura 19. Este modelo, proposto por Harada et al. [84] para estrutura de um vidro, leva em conta a formação de pares elétron-buraco e posterior quebra e formação de novas ligações estáveis gerando mudanças irreversíveis, e também a criação de defeitos com formação de ligações instáveis causando mudanças reversíveis. Outros efeitos como luminescência de centros de defeitos podem ocorrer simultaneamente com os efeitos fotoinduzidos.

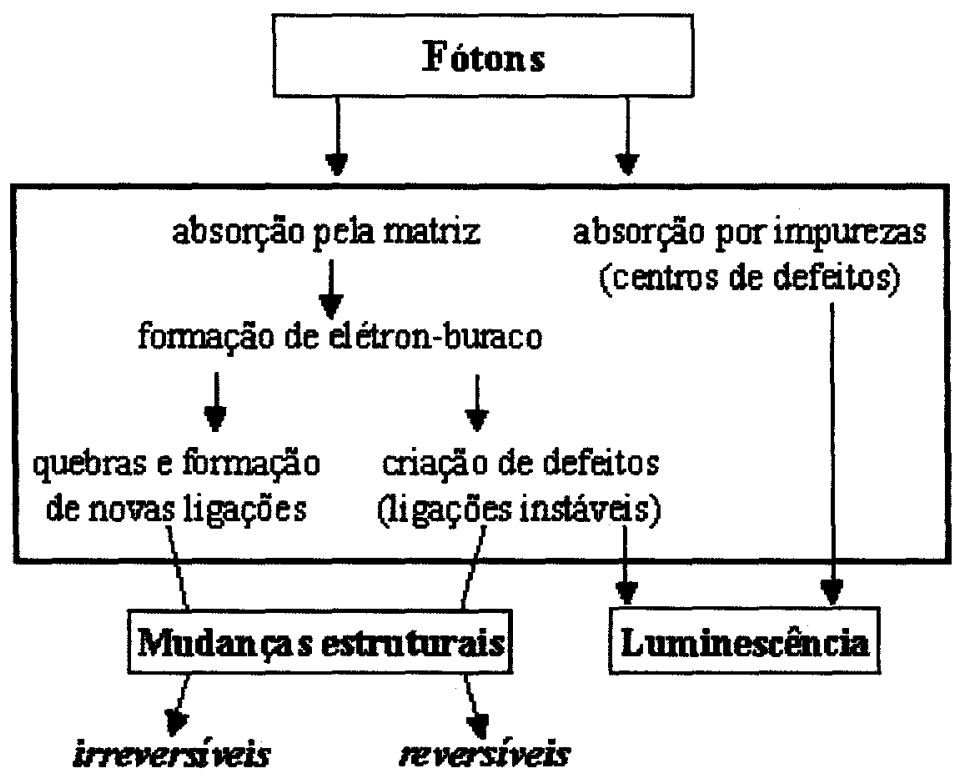

Figura 19 - Modelo dos processos de mudança estrutural e luminescência, envolvidos nos fenômenos fotoinduzidos em vidros, proposto por Harada et al. [84].

Outro modelo, também baseado na formação de centros de defeitos é proposto por Potter et al. [85] para filmes de $\mathrm{Ge}: \mathrm{SiO}_{2}$, onde ligações (Ge-) instáveis isoladas são convertidas em espécies diamagnéticas ( $\mathrm{p} /$ baixa temp. de deposição) e centros deficientes em oxigênio (oxigen deficient center, ODC) são convertidos em centros eletrônicos (GeE') (p/ alta temp. de deposição) após irradiação com laser UV (248 nm). Potter observou também para este material que os efeitos fotoinduzidos são potencializados quando o material é irradiado em atmosfera de oxigênio (devido aos 
centros deficientes em oxigênio) e que o tipo de fenômeno fotoinduzido envolvido pode ser controlado com a temperatura do substrato durante a produção do filme. A Figura 20 ilustra o modelo proposto por Potter, indicando mudanças fotoinduzidas nos filmes de $\mathrm{Ge}: \mathrm{SiO}_{2}$ com a irradiação UV, para filmes com diferentes temperaturas de deposição.

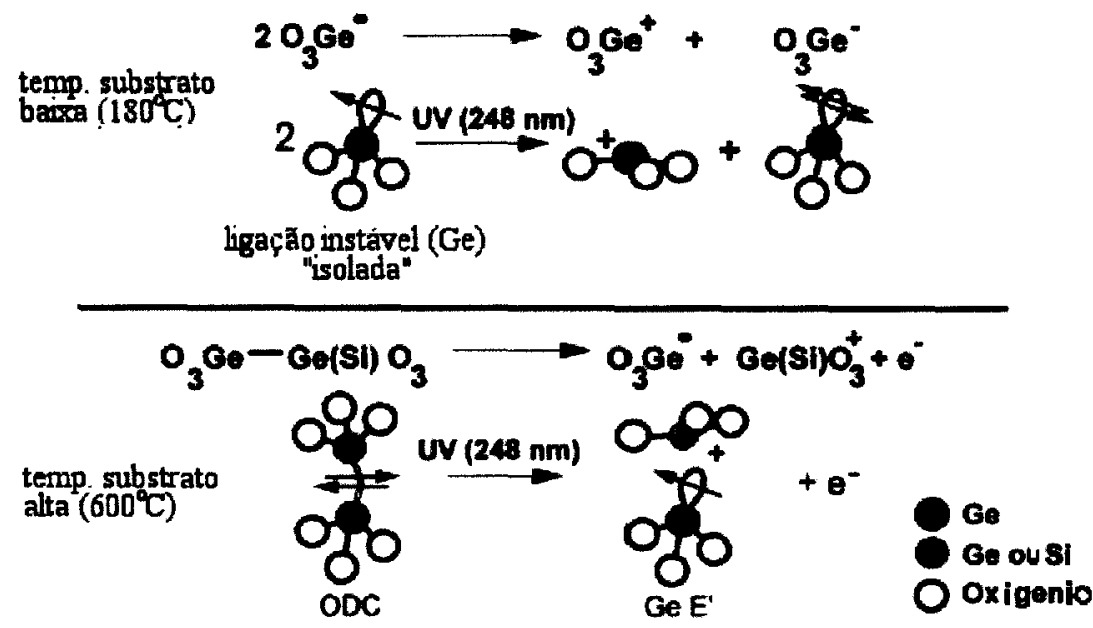

Figura 20 - Modelo de defeitos após irradiação com laser UV em filmes de $\mathrm{Ge}: \mathrm{SiO}_{2}$ depositados com temperatura de substrato de $180^{\circ} \mathrm{C}$ e $600^{\circ} \mathrm{C}$. No primeiro caso ligações (Ge-) instáveis são convertidas em espécies diamagnéticas. No segundo caso centros deficientes em oxigênio (oxigen deficient center, ODC) são convertidos em centros eletrônicos (GeE') [85].

Mudanças estruturais fotoinduzidas em vidros associados a antimônio podem estar associada a dois fatos:

1) $0 \mathrm{Sb}^{3+}$ possui um par de elétrons livres (LP-lone pair) fortemente polarizável, com caráter $p$ não ligado na parte superior da banda de valência [86]; 2) As ligações químicas devido ao par de elétrons livres do $\mathrm{Sb}^{3+}$ podem ser de dois tipos: uma ligação forte covalente intramolecular (também chamada de ligação primária) e uma ligação fraca intermolecular do tipo Van der Waals (ligação secundária) [87].

Para tentar explicar as variações fotoinduzidas, S.R. Elliot [62] propôs um modelo unificado válido para todos os fenômenos fotoinduzidos. Neste modelo, assume-se que as interações fracas intermoleculares atrativas seriam parcialmente vulneráveis a excitação óptica. Em particular seja pela criação de um buraco no orbital $p-\pi$ do par de elétrons livres em um átomo de $\mathrm{Sb}^{3+}$ através da excitação eletrônica seguida da absorção de um fóton, ou a promoção de um elétron por absorção de um fóton dentro de um estado não ligado associado com um átomo vizinho, ambos casos criando a possibilidade de quebra e/ou surgimento de novas ligações 
As mudanças irreversíveis ocorrem invariavelmente em filmes que são estruturalmente instáveis, tais como aqueles preparados por evaporação, particularmente quando depositados em ângulos oblíquos; tais filmes exibem uma morfologia de crescimento colunar pronunciado que consiste de alta concentração de lacunas. As variações irreversíveis nestes materiais são associadas com o colapso fotoinduzido destas estruturas dispostas em lacunas, junto com a ruptura de espécies moleculares do filme e originárias da fase de vapor.

Os efeitos reversíveis são geralmente menores que os correspondentes irreversíveis e também ocorrem em filmes depositados por evaporação e tratados termicamente ou em vidros resfriados rapidamente; presumidamente estas variações reversíveis que ocorrem em filmes são geralmente obscurecidas pelas maiores variações irreversíveis que são induzidas simultaneamente. Em muitos casos os filmes possuem estrutura diferente do vidro originário e sofrem uma mudança estrutural irreversível denominada fotopolimerização em resposta a iluminação no bandgap.

Os detalhes da geração da componente térmica induzida pela luz em relação aos efeitos fotoinduzidos nos materiais será discutida na seção a seguir (1.4.2). 


\subsubsection{A relevância do efeito Foto-Térmico}

\subsubsection{Distribuição Radial de Temperatura num feixe laser}

$\mathrm{Na}$ última década a interpretação de efeitos fototérmicos e suas causas foi motivo de muita controvérsia na pesquisa científica. Alguns autores consideravam que os efeitos térmicos induzidos por irradiação seriam irrelevantes para os materiais vítreos, com utilização de densidades de potência consideradas relativamente baixas (1$10 \mathrm{~W} / \mathrm{cm}^{2}$ ), sugerindo que a variação de temperatura no material irradiado não ultrapassaria $50{ }^{\circ} \mathrm{C}$ para esta faixa de potência [88], e que as mudanças termoinduzidas só teriam início acima de $100^{\circ} \mathrm{C}[89]$.

No entanto, recentes trabalhos em filmes a base de sulfeto de antimônio $\left(\mathrm{Sb}_{2} \mathrm{~S}_{3}\right)$ mostraram que a componente térmica induzida pela luz é bastante significante, podendo gerar um aumento de temperatura próximo de $300{ }^{\circ} \mathrm{C}$ após irradiação com laser continuo de $514 \mathrm{~nm}$ com potência de 136 a $200 \mathrm{~mW}$ focalizado em $600 \mu \mathrm{m}$ de diâmetro [70-72]. Outro trabalho mostrou a possibilidade de gravação óptica em filmes amorfos de Ge-Sb-Te e In-Sb-Te, através de fusão e cristalização superficial com pulsos de laser focalizado com diâmetro de $1 \mu \mathrm{m}$, onde temperatura de até $1000{ }^{\circ} \mathrm{C}$ foi obtida com pulsos de laser de curta duração (100 ns) [90].

Especificamente a distribuição radial de temperatura num feixe de laser contínuo foi calculada por Arun et al. [72] para filmes de $\mathrm{Sb}_{2} \mathrm{~S}_{3}$, baseado no alto coeficiente de absorção óptica desse material $\left(\sim 10^{4}\right)$ e na distribuição gaussiana de intensidade no feixe do laser. Dessa forma foi verificado que para a faixa de potência utilizada $(\sim 136$ a $200 \mathrm{~mW}$ ) o aumento de temperatura causado pelo laser pode atingir valores próximos a $300{ }^{\circ} \mathrm{C}$ em diâmetros de aproximadamente $100 \mu \mathrm{m}$ ao redor do centro do feixe laser e caindo a valores desprezíveis para diâmetros maiores que $600 \mu \mathrm{m}$, como mostra a Figura 21. 


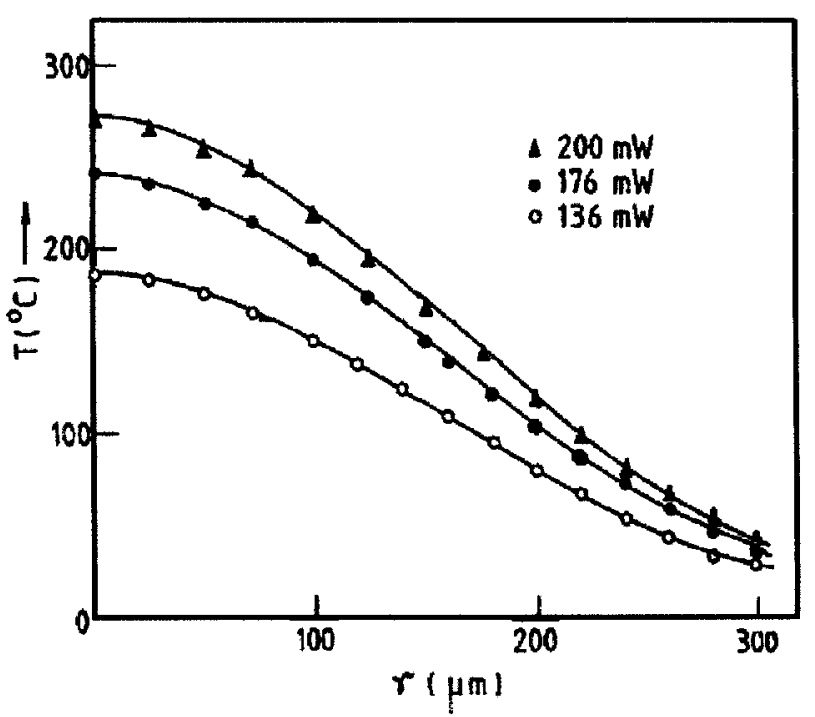

Figura 21 - Distribuição radial de temperatura em um feixe de laser com perfil gaussiano de intensidade [72].

Outro resultado interessante é a perda de enxofre induzida pela componente fototérmica da irradiação laser em filmes de $\mathrm{Sb}_{2} \mathrm{~S}_{3}$ (Figura 22), levando a uma diminuição de até $40 \%$ na concentração de enxofre na superficie do filme, para irradiações com laser de $\mathrm{Ar}^{+}(514 \mathrm{~nm})$ e densidade de potência de $40 \mathrm{~W} / \mathrm{cm}^{2}$ [71]. Popescu et al. [91] se refere ao efeito de perda de enxofre como fotosublimação, observada em filmes de GeAsS irradiados com densidade de potência de $5 \mathrm{~W} / \mathrm{cm}^{2}$ de UV com lâmpada de mercúrio.

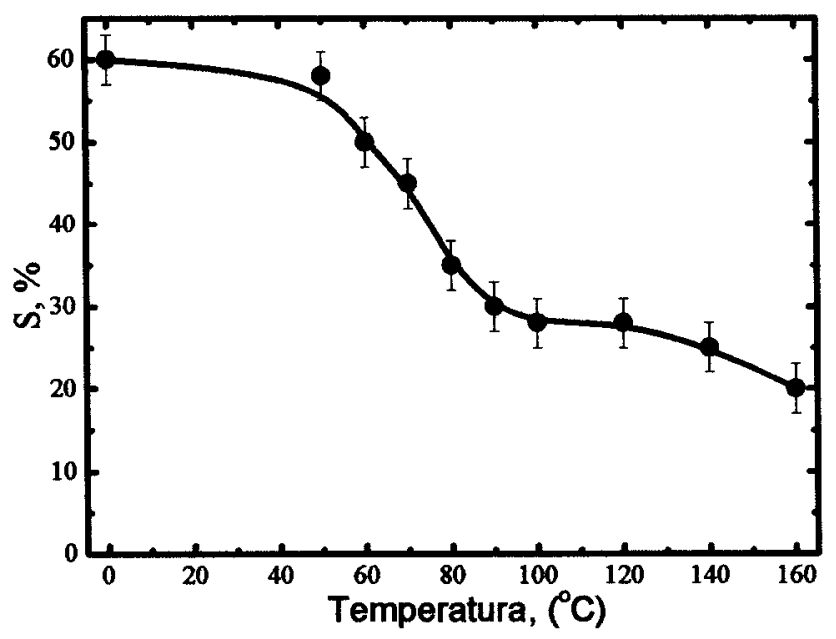

Figura 22 - Perda de enxofre na superficie de filme de $\mathrm{Sb}_{2} \mathrm{~S}_{3}$, para irradiações com laser de $\mathrm{Ar}^{+}$ em $514 \mathrm{~nm}$ e densidade de potência de $40 \mathrm{~W} / \mathrm{cm}^{2}$ [71]. 
Também em recente trabalho publicado por E. Márquez et al. [92] na mesma linha de estudo de componente térmica induzida por irradiação, é mostrada a possibilidade de cristalização devido ao efeito fototérmico com irradiação UV em filmes de $\mathrm{As}_{40} \mathrm{~S}_{30} \mathrm{Se}_{30}$, onde são formado micro-cristalitos de $\mathrm{As}_{2} \mathrm{O}_{2}$ devido à absorção de oxigênio atmosférico, como ilustra a Figura 23.

\section{Efeito de Fotocristalização}

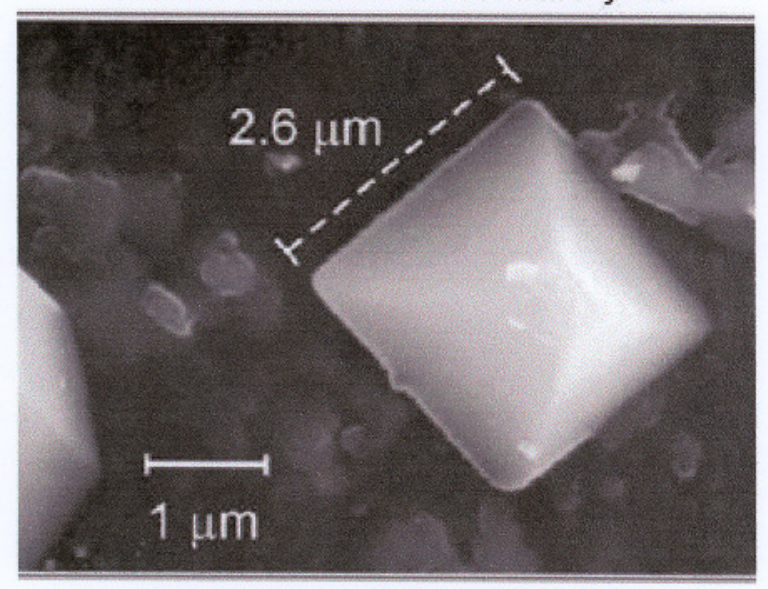

Micro-cristalito de $\mathrm{As}_{2} \mathrm{O}_{3}$

Figura 23 - Imagem de microscopia eletrônica de varredura da superficie de um filme de $\mathrm{As}_{40} \mathrm{~S}_{30} \mathrm{Se}_{30}$ onde se observa a formação de um cristalito de arsenolita $\left(\mathrm{As}_{2} \mathrm{O}_{3}\right)$, após irradiação UV por 3 horas com uma lâmpada de mercúrio gerando $40 \mathrm{~mW} / \mathrm{cm}^{2}$ [92].

Para a caracterização de um efeito fotoinduzido é necessário primeiro determinar quando a mudança fotoinduzida é resultado de um mecanismo térmico (fototérmico) ou não térmico (efeito puramente fotoinduzido), pois os dois tipos de fenômenos podem ocorrer simultaneamente. Desorção e adsorção térmica induzida por laser (laser-induced thermal desorption/adsorption, LITD/A) são exemplos de efeito fotoinduzido envolvendo efeitos puramente fotoinduzidos (ex.: fotopolimerização) e componente térmica (ex.: fotodesorção) induzida pela absorção de fótons [93,94]. A Figura 24 mostra um exemplo de fotopolimerização de formaldeído sobre substrato de $\mathrm{Ag}$ (111) após irradiação com laser Nd:YAG $(355 \mathrm{~nm})$, levando em conta a componente fototérmica causando fotodesorção molecular do material [95]. 


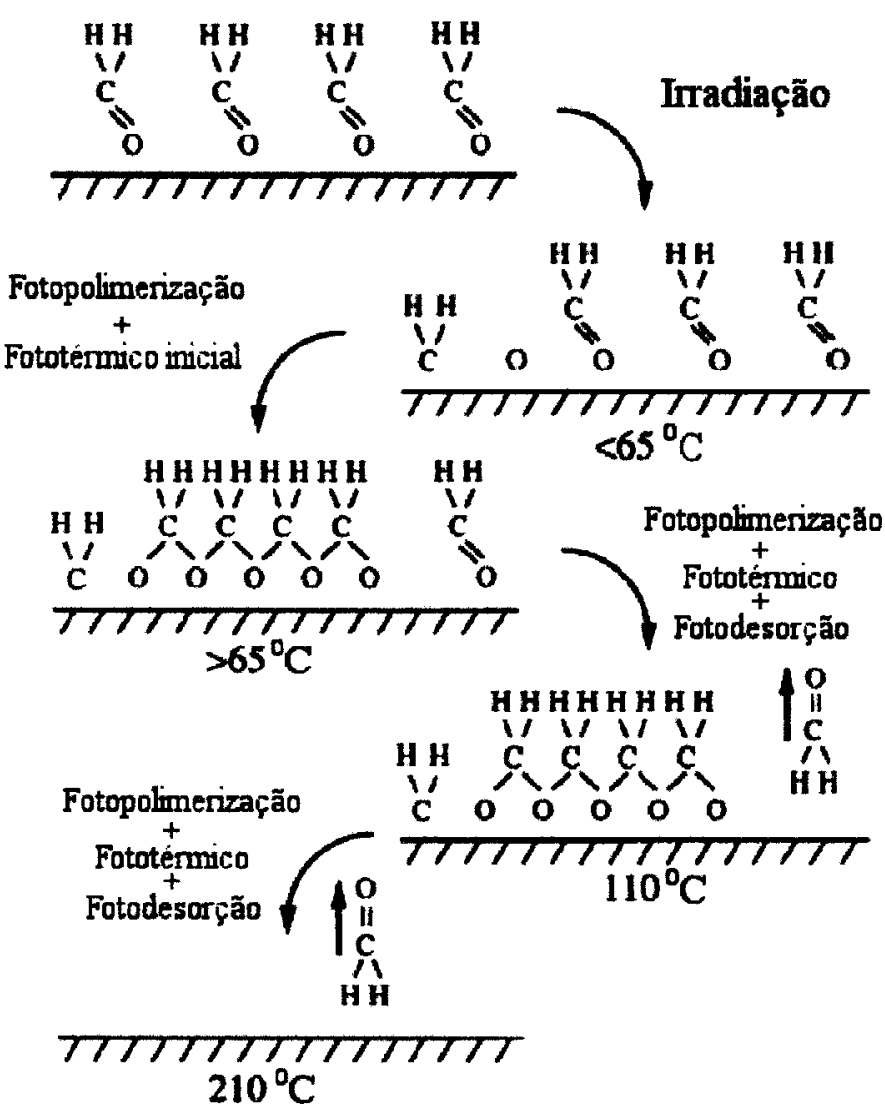

Figura 24 - Exemplo de fotopolimerização de formaldeído sobre substrato de Ag (111) após irradiação com laser Nd:YAG $(355 \mathrm{~nm})$, levando em conta a componente fototérmica gerada pelo laser [95].

\subsubsection{Mecanismos causadores de efeitos fototérmicos}

A resposta de materiais dielétricos quanto à irradiação com luz e os mecanismos que envolvem a geração de efeitos fototérmicos podem ser classificados como mecanismos intrínsecos e extrínsecos. Os mecanismos intrínsecos são relacionados com efeitos que ocorrem em materiais ultrapuros e os mecanismos extrínsecos são associados com os efeitos devido à presença de impurezas ou defeitos no material [96].

Mudanças geradas devido ao aquecimento por absorção de fótons em materiais dielétricos iniciam com a geração de elétrons livres. Se a energia do bandgap é maior que a energia dos fótons incidentes, este efeito é potencializado, pois um processo de absorção multifótons se inicia onde os elétrons são bombeados ou ionizados da banda de valência para a banda de condução [97]. Através deste processo, dois mecanismos intrínsecos podem acontecer e devem ser levados em conta na produção de grande 
quantidade de elétrons necessários para causar dano ao material: (1) Absorção multifóton continuada, e (2) multiplicação do efeito por um processo de avalanche. No segundo mecanismo, os elétrons da banda de condução são acelerados pelo campo eletromagnético da luz até que atingem energia maior que a necessária para produzir ionização e conseqüentemente podem transferir este excesso de energia aos elétrons de valência que serão bombeados para a banda de condução. Dessa forma, um processo de multiplicação tipo avalanche se desenvolve durante a absorção de fótons.

A energia absorvida pelos elétrons da banda de condução pode ser transferida para a rede e o aquecimento se inicia [98]. A transferência da energia para a rede pode ocorrer por acoplamento elétron-fônon (modelo de aquecimento de portador livre), e se esse for o mecanismo de transferência, um elétron na banda de condução pode absorver mais do que um fóton. A possibilidade de polarização de rede observada em haletos alcalinos levou a proposta de outro mecanismo no qual os elétrons da banda de condução são fortemente ligados aos fônons, e, portanto, a energia ganha por um elétron na absorção de um fóton é imediatamente liberada para a rede (modelo de aquecimento de polaron) [99]. O modelo de polaron exclui a possibilidade de absorção de fótons por elétrons que não estejam no topo da banda de condução, e, portanto exclui a possibilidade de mecanismo de avalanche para excitação de elétrons.

Experimentos de fotoacústica para análise de quebra de ligações químicas em cristais de $\mathrm{NaCl}$ ultrapuro irradiados com pulsos de laser em $532 \mathrm{~nm}$ demonstraram que excitação eletrônica da banda de valência para a banda de condução por absorção de quatro fótons é um processo que ocorre primariamente [100-102]. Foi também observado que elétrons da banda de condução podem interagir com fótons e aumentar sua energia posteriormente por absorção intrabanda. Este efeito também é observado em metais e semicondutores onde a densidade eletrônica na banda de condução é suficientemente alta.

O dano causado em materiais dielétricos devido ao aquecimento gerado por absorção de fótons é potencializado devido à presença de impurezas ou defeitos. Esses mecanismos são denominados extrínsecos.

Dessa forma os mecanismos de geração de calor ocorrem por irradiação de luz com densidades de potência muito menor do que o necessário observado para substancias ultrapuras, como já mencionado acima. A geração de defeitos de diferentes naturezas através de irradiação laser altera o acoplamento entre fótons e material à medida que a irradiação progride. Além disso, os mecanismos de absorção de luz se 
tornam predominantes em materiais que não são quimicamente ultrapuros devido à presença de imperfeições estruturais e químicas.

Existem vários tipos de fatores extrínsecos que afetam a absorção de radiação laser em materiais com bandgap largo: (1) efeito de superficies externas e interfaces, (2) preexistência de defeitos estruturais, (3) geração de defeitos pela irradiação laser, e (4) tipo de atmosfera de irradiação.

Absorção de luz significantemente alta pode ocorrer em superficies externas devido à existência de inomogeneidade [103], imperfeições topológicas [104] e impurezas químicas [101]. Por exemplo, o limite mínimo de potência laser necessário para causar quebra de ligações em uma superficie com ranhuras de dimensões menores que o comprimento de onda da luz é necessariamente menor do que o limite mínimo de potência para causar o mesmo efeito em materiais sólidos com superfície sem imperfeições. A razão para este efeito é que a intensidade do campo elétrico próximo as bordas de uma ranhura com tal dimensão é muito maior relativamente a uma superficie plana. $\mathrm{O}$ aumento na intensidade do campo elétrico devido a imperfeições com dimensões menores que o comprimento de onda da luz incidente pode ser estimado sendo da ordem de $\mathrm{n}^{2}$, onde $\mathrm{n}$ é o índice de refração do material, podendo chegar a efeitos com intensidade de 4 ordens de grandeza [104].

Nessa linha podemos incluir a observação de fenômenos fotoinduzidos com intensidade muito maior em filmes do que em vidros de mesma composição, como já citado anteriormente (seção 1.4). Isso se dá devido não só a imperfeições topológicas nos filmes devido ao próprio processo de deposição, mas também devido à de formação de grãos, que geralmente podem ser da ordem de dezenas de nanômetros em filmes preparados por técnicas tradicionais de deposição. 


\subsection{Motivações para o estudo de filmes de $\left[\mathrm{Sb}\left(\mathrm{PO}_{3}\right)_{3}\right]_{n} \rightarrow \mathrm{Sb}_{2} \mathrm{O}_{3}$}

A crescente necessidade da miniaturização de dispositivos tem estimulado o estudo e manipulação dos materiais na forma de filmes buscando a interpretação dos mecanismos básicos de crescimento, estudando a morfologia e estrutura de filmes amorfos, mono e policristalinos. Com o avanço na busca de dispositivos integrados, a pesquisa desenvolvida atualmente na área de Fenômenos Fotoinduzidos têm sido direcionada principalmente para o estudo dos materiais fotossensíveis dispostos em finas camadas, visando aplicações especificamente para as áreas de óptica, fotônica e eletrônica.

O avanço nessa área se iniciou através do estudo de semicondutores amorfos a base de calcogenetos e posteriormente em semicondutores e materiais amorfos a base de metais pesados, como é o caso de filmes de $\mathrm{Sb}_{2} \mathrm{~S}_{3}$ que exibem uma grande variedade de fenômenos fotoinduzidos como discutido anteriormente. A partir dos anos 90 grande parte do trabalho foi devotada ao estudo de fenômenos fotoinduzidos em diversos sistemas vítreos. Além disso, sistemas vítreos combinados com metais pesados exibem grande capacidade de formação vitrea com excelentes propriedades ópticas, como é o caso de vidros a base de fosfatos de antimônio, que foram extensivamente estudados atualmente [105]. Por outro lado, vidros fosfatos modificados por metais pesados são muito estáveis contra a cristalização e oferecem possibilidade de faixa de composições extremamente grandes, além de gerar melhorias em determinadas propriedades pela incorporação de um metal pesado (e.g., aumento da durabilidade química e índice de refração), fazendo destes materiais potenciais candidatos para aplicação nas áreas de óptica e fotônica.

\subsubsection{Objetivos deste trabalho}

Os estudos de fenômenos fotoinduzidos em filmes do sistema vítreo $x\left[\mathrm{Sb}\left(\mathrm{PO}_{3}\right)_{3}\right]_{n}-(100-x) \mathrm{Sb}_{2} \mathrm{O}_{3}$ são inexistentes e esta foi considerada a primeira etapa para motivação deste trabalho. Todas as propriedades citadas anteriormente e principalmente as propriedades fotoinduzidas observadas inicialmente para este material nos levou a ter como objetivo principal o estudo dos fenômenos fotoinduzidos em filmes deste sistema vítreo, partindo da produção e caracterização dos vidros $x\left[\mathrm{Sb}\left(\mathrm{PO}_{3}\right)_{3}\right]_{n}-(100-x) \mathrm{Sb}_{2} \mathrm{O}_{3} \mathrm{e}$ 
também da produção e caracterização de filmes depositados por evaporação térmica dos vidros.

\subsubsection{Desenvolvimento do trabalho}

Podemos dividir o desenvolvimento deste trabalho em 3 etapas principais, descritas a seguir:

1- Para caracterização térmica, caracterização óptica e estrutural das composições vítreas no sistema $x\left[\mathrm{Sb}\left(\mathrm{PO}_{3}\right)_{3}\right]_{n}-(100-x) \mathrm{Sb}_{2} \mathrm{O}_{3}$, variando a concentração de formador vítreo $\left[\mathrm{Sb}\left(\mathrm{PO}_{3}\right)_{3}\right]_{n}$ utilizamos as seguintes técnicas:

- Caracterização Óptica (absorção UV-VIS e IR), Caracterização Térmica (Calorimetria exploratória diferencial, DSC), e Caracterização Estrutural (Difração de Raios-X, XRD; Estrutura próximo à borda de Absorção de Raios$\mathrm{X}$, XANES; e Ressonância Magnética Nuclear do núcleo ${ }^{31} \mathrm{P}$, MAS-NMR).

2- Para o estudo dos filmes produzidos por evaporação térmica dos vidros, utilizamos basicamente as mesmas técnicas descritas acima, e também técnicas adicionais para caracterização morfológica, química e estrutural como:

- Perfilometria, Microscopia de Força Atômica (AFM), Análise química por dispersão de comprimento de onda de Raios-X (WDX), Retroespalhamento de Rutherford (RBS), Espectroscopia de fotoelétrons excitados por Raios-X (XPS), medidas de Índice de Refração por elipsometria, e Eficiência de Difração em tempo real para redes holográficas gravadas.

- Ressonância Paramagnética eletrônica, (RPE) e Luminescência em filmes dopados com $\mathrm{Cu}^{2+}$, utilizando o cobre como sonda estrutural.

3- Desta forma o trabalho desenvolvido visa mostrar os aspectos fenomenológicos dos efeitos fotoinduzidos em filmes em função de parâmetros como:

- Efeito de fotocontração/fotoclareamento nos filmes por irradiação com laser em diferentes comprimentos de onda p/ diferentes potências e tempos de exposição, diferentes atmosferas durante a irradiação, e em função da composição vítrea $\mathrm{e}$ espessura do filme. 
- Verificação da reversibilidade ou não do processo de fotocontração através de tratamentos térmicos.

- Produção e caracterização de redes holográficas com diferentes periodos nos filmes.

A produção e caracterização dos vidros e filmes a base de $\left[\mathrm{Sb}\left(\mathrm{PO}_{3}\right)_{3}\right]_{n}$ bem como as montagens e técnicas utilizadas neste trabalho são descritas detalhadamente no capítulo Metodologia Experimental apresentado à seguir. 


\section{Metodologia Experimental}

Uma vez que os objetivos deste trabalho consistem principalmente na observação dos fenômenos fotoinduzidos no sistema $\left[\mathrm{Sb}\left(\mathrm{PO}_{3}\right)_{3}\right]_{n}-\mathrm{Sb}_{2} \mathrm{O}_{3}$, procurando saber a origem dos prováveis processos envolvidos, propusemos a utilização de diversas técnicas citadas anteriormente para uma análise óptica, química e morfológica/estrutural , objetivando a observação do comportamento das alterações induzidas por luz no material como:

- Mudança de estrutura antes e após ação da luz no material

- Alterações ópticas e químicas induzidas pela ação da radiação

- Contribuição de efeitos fototérmicos

- Reversibilidade do efeito fotoinduzido

- Possibilidades de aplicação do material

Para a produção e caracterização das amostras (vidros e filmes) utilizadas neste trabalho foi necessário o uso de diversos equipamentos, montagens experimentais e diferentes técnicas de processamento e medidas. Este capítulo descreve os processos de produção de amostras e montagens experimentais realizadas no laboratório, e também dá uma noção básica sobre as técnicas e o funcionamento dos equipamentos utilizados na caracterização das amostras. 


\subsection{Preparação dos vidros}

A preparação dos vidros pode ser dividida em duas etapas envolvendo a produção dos precursores e o processo de fusão/recozimento dos vidros. Os precursores preparados foram o polifosfato de antimônio ([ $\left.\left.\mathrm{SbPO}_{3}\right)_{3}\right]_{n}$ ) usado na produção do sistema vítreo estudado e o ortofosfato de antimônio $\left(\mathrm{SbPO}_{4}\right)$ utilizado como referência em medidas de absorção de raios-X e infravermelho. Os detalhes de preparação dos precursores e dos vidros são apresentados a seguir.

\subsubsection{Processos quimicos}

\subsubsection{Produção do Ortofosfato de Antimônio $\mathrm{SbPO}_{4}$}

Inicialmente preparamos o $\mathrm{SbPO}_{4}$ partindo-se da mistura estequiométrica de $1 \mathrm{H}_{3} \mathrm{PO}_{4}$ : $1 \mathrm{SbCl}_{3}$, porém neste procedimento observamos a formação de ortofosfato em fase cristalina menos definida (Figura 25-a) com aparecimento de picos não pertencentes ao ortofosfato. Desta forma a preparação do $\mathrm{SbPO}_{4}$ foi aprimorada utilizando-se a mistura de $20 \mathrm{H}_{3} \mathrm{PO}_{4}+1 \mathrm{SbCl}_{3}$, a partir da qual conseguimos um pó cristalino com uma única fase de $\mathrm{SbPO}_{4}$ (Figura 25-b), de acordo com a reação (1):

$$
1 \mathrm{SbCl}_{3}+20 \mathrm{H}_{3} \mathrm{PO}_{4}=3 \mathrm{HCl}+1 \mathrm{SbPO}_{4}+\text { Excesso de } \mathrm{H}_{3} \mathrm{PO}_{4}
$$

$\mathrm{O} \mathrm{SbCl}{ }_{3}$ foi dissolvido diretamente em $\mathrm{H}_{3} \mathrm{PO}_{4}$ concentrado e a reação ocorreu durante quatro dias em constante agitação, em um béquer plástico. Após a reação retiramos o excesso de ácido e lavamos o precipitado até se obter $\mathrm{pH} 7,0$. Finalmente o pó de $\mathrm{SbPO}_{4}$ foi seco em estufa por $4 \mathrm{~h}$ a temperatura de $180^{\circ} \mathrm{C}$ e tratamento térmico em forno por $2 \mathrm{~h}$ a $250^{\circ} \mathrm{C}$ e $24 \mathrm{~h}$ a $450^{\circ} \mathrm{C}$ para eliminar a água residual e aumentar a cristalinidade do pó. A fase e cristalinidade do material obtido pelas duas reações já descritas foram verificadas por difração de Raios-X como mostra a Figura 25. 


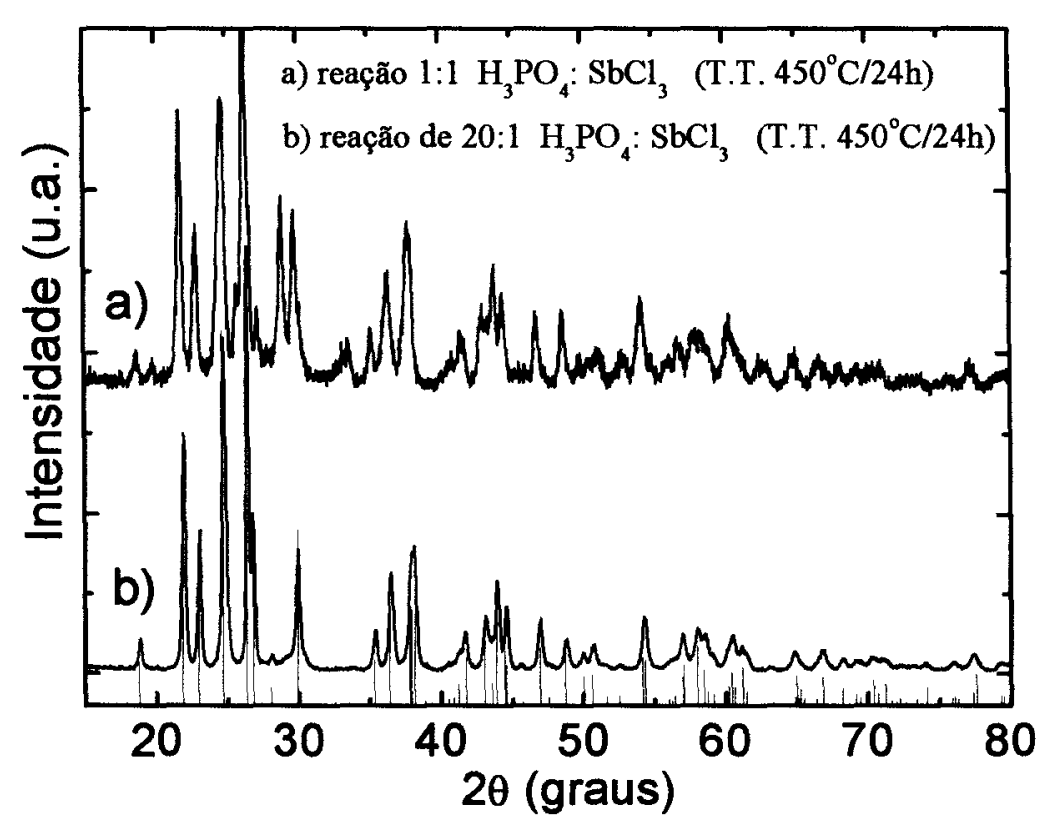

Figura 25 - Espectro de difração de Raios-X do $\mathrm{SbPO}_{4}$ produzido. a) a partir de $1: 1 \mathrm{H}_{3} \mathrm{PO}_{4}$ : $\mathrm{SbCl}_{3}$, b) a partir de 20:1 $\mathrm{H}_{3} \mathrm{PO}_{4}: \mathrm{SbCl}_{3}$, com tratamento térmico de $450{ }^{\circ} \mathrm{C}$ por $24 \mathrm{~h}$ respectivamente. As barras verticais referem-se ao espectro padrão do $\mathrm{SbPO}_{4}$ da base de dados JCPDS.

Como se observa no espectro de difração de Raios-X, $0 \mathrm{SbPO}_{4}$ produzido com alta concentração de $\mathrm{H}_{3} \mathrm{PO}_{4}$ apresenta picos de difração muito bem definidos e uma única fase que confere com o padrão de raios-X obtido pelo JCPDS, ao contrario do observado no espectro do $\mathrm{SbPO}_{4}$ produzido a partir de quantidades estequiométricas dos reagentes.

\subsubsection{Produção do Polifosfato de Antimônio $\left[\mathrm{Sb}\left(\mathrm{PO}_{3}\right)_{3}\right]_{n}$}

Nesta etapa iniciamos a produção do Polifosfato de Antimônio, $\left[\mathrm{Sb}\left(\mathrm{PO}_{3}\right)_{3}\right]_{n}, \mathrm{o}$ qual foi utilizado na produção do sistema vítreo a base de polifosfato e óxido de antimônio. Este precursor pode também ser obtido com o tratamento térmico a $900{ }^{\circ} \mathrm{C}$ do ortofosfato de antimônio, $\mathrm{SbPO}_{4}$. Porém, outro processo mais simples para obtenção do polifosfato foi realizado através da reação (2) descrita a seguir:

$$
6 \mathrm{NH}_{4} \mathrm{H}_{2} \mathrm{PO}_{4}+\mathrm{Sb}_{2} \mathrm{O}_{3}=2 \mathrm{Sb}\left(\mathrm{PO}_{3}\right)_{3}+6 \mathrm{NH}_{3}+9 \mathrm{H}_{2} \mathrm{O}
$$


O $\mathrm{NH}_{4} \mathrm{H}_{2} \mathrm{PO}_{4}$ (analytical grade, Acros 99\%) foi pulverizado com o $\mathrm{Sb}_{2} \mathrm{O}_{3}$ (spectral grade, Acros 99+\%) em almofariz de ágata e colocado em um cadinho de carbono vitreo para tratamento térmico a $200{ }^{\circ} \mathrm{C}$ por 2 horas e $500{ }^{\circ} \mathrm{C}$ por 10 horas. Após a eliminação da amônia e água, obtivemos um liquido transparente a $500{ }^{\circ} \mathrm{C}$. Subindo-se a temperatura até $700{ }^{\circ} \mathrm{Co}\left[\mathrm{Sb}\left(\mathrm{PO}_{3}\right)_{3}\right]_{n}$ foi vertido sobre um molde aço inox. O $\left[\mathrm{Sb}\left(\mathrm{PO}_{3}\right)_{3}\right]_{n}$ puro é um vidro visualmente transparente e altamente higroscópico e deve ser imediatamente utilizado após a preparação, ou armazenado em atmosfera de $\mathrm{N}_{2}$. A estrutura do Polifosfato produzido foi verificada por difração de Raios-X como mostra a Figura 26.

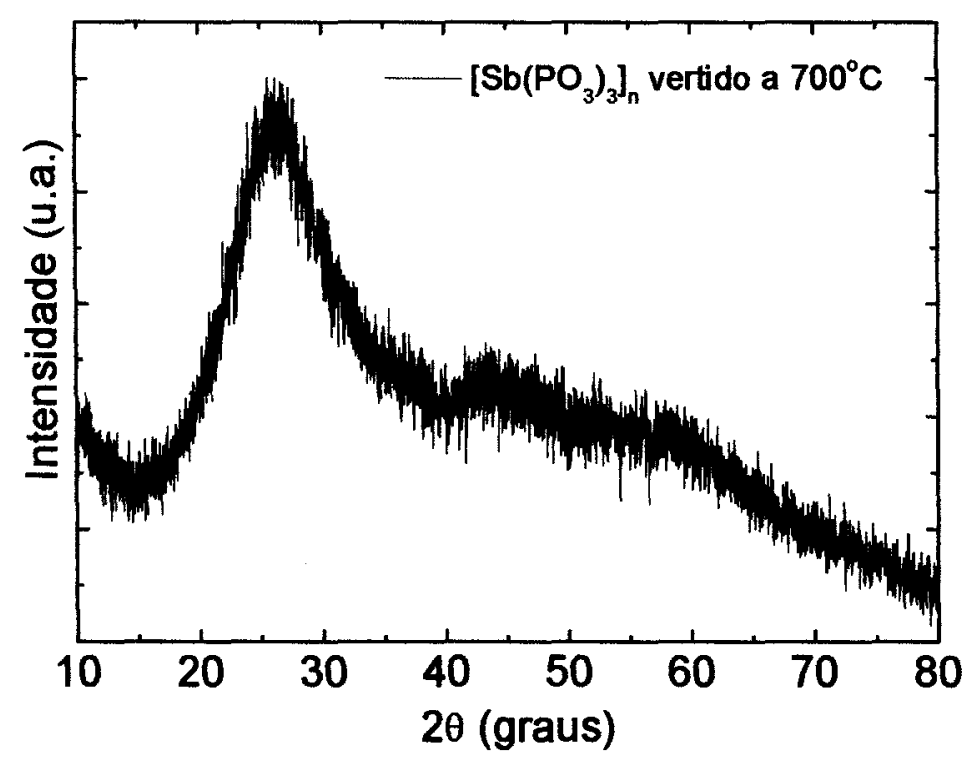

Figura 26 - Espectro de difração de Raios-X do $\left[\mathrm{Sb}\left(\mathrm{PO}_{3}\right)_{3}\right]_{n}$ produzido.

Como se observa pelo espectro acima o Polifosfato de Antimônio apresenta estrutura amorfa como esperado para este precursor com estrutura polimérica [58].

\subsubsection{Processos de fusão e recozimento}

Os vidros do sistema $x\left[\mathrm{Sb}\left(\mathrm{PO}_{3}\right)_{3}\right]_{n}-(100-x) \mathrm{Sb}_{2} \mathrm{O}_{3}$ foram preparados para concentrações de polifosfato de antimônio variando entre $5 \geq x \leq 40$. No caso deste sistema binário o precursor $\left[\mathrm{Sb}\left(\mathrm{PO}_{3}\right)_{3}\right]_{n}$ atua como formador de rede e o óxido de antimônio $\left(\mathrm{Sb}_{2} \mathrm{O}_{3}\right)$ atua como modificador de rede. 
Após a pesagem dos materiais as quantidades estequiométricas de $\left[\mathrm{Sb}\left(\mathrm{PO}_{3}\right)_{3}\right]_{n} \mathrm{e}$ $\mathrm{Sb}_{2} \mathrm{O}_{3}$ foram colocadas em um cadinho de carbono vítreo e fundidos a $900^{\circ} \mathrm{C}$. Para a fusão utilizamos um forno tubular com capacidade para operar até $1100^{\circ} \mathrm{C}$, construído em nosso laboratório composto por um suporte tubular de alumina onde foi enrolada uma resistência espiral de Kanthal para $1100{ }^{\circ} \mathrm{C}$. A Figura 27 mostra o forno, os cadinhos, e os moldes utilizados para a produção dos vidros.

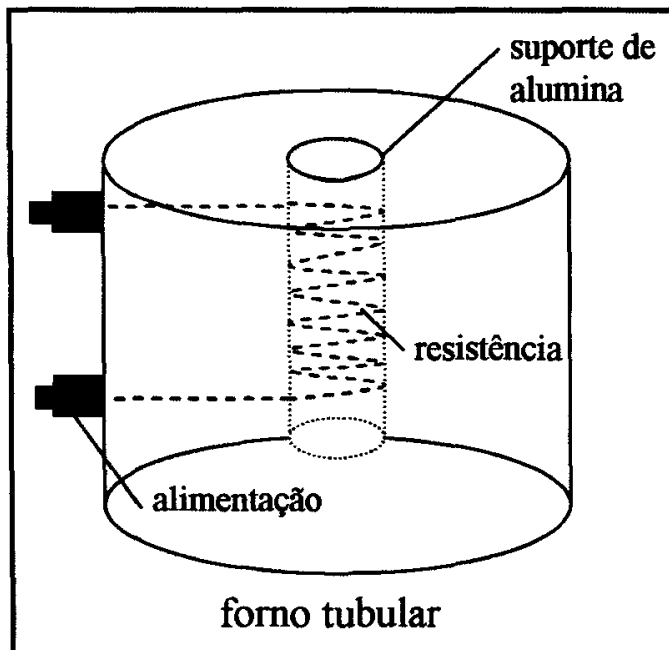

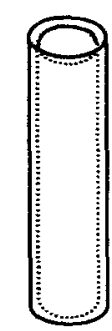

cadinho de carbono vítreo

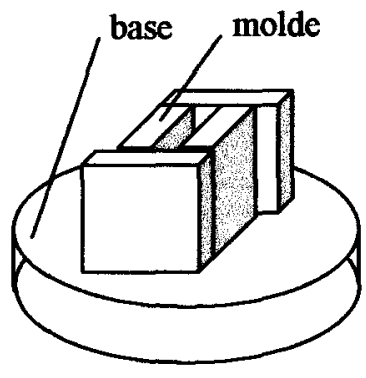

molde de aço inox

Figura 27 - Ilustração do forno tubular, cadinho de carbono vítreo, e molde de aço inox utilizados para a fusão dos vidros $x\left[\mathrm{Sb}\left(\mathrm{PO}_{3}\right)_{3}\right]_{n}-(100-x) \mathrm{Sb}_{2} \mathrm{O}_{3}$.

A mistura depois de fundida a $900{ }^{\circ} \mathrm{C}$ permanecia 30 minutos nesta temperatura para homogeneização, sendo vertida em moldes de aço inox pré-aquecido a $300{ }^{\circ} \mathrm{C}$. Logo em seguida os vidros eram levados a tratamento térmico a $250^{\circ} \mathrm{C}$ por 8 horas para eliminação completa de tensões. Placas de vidro com dimensões de $10 \times 10 \times 4 \mathrm{~mm}^{3}$, livres de trincas ou incrustações foram obtidas. A preparação óptica consistiu de lapidação com lixas 600 e 1200 e o polimento óptico foi feito sobre pano para polimento metalográfico utilizando pasta de alumina de $1 \mu \mathrm{m}$ até $0,05 \mu \mathrm{m}$. 


\subsection{Preparação dos Filmes Finos}

Neste trabalho utilizamos a técnica de evaporação por canhão de elétrons para a deposição dos filmes, partindo da evaporação de vidros precursores $\left[\mathrm{Sb}\left(\mathrm{PO}_{3}\right)_{3}\right]_{n}-\mathrm{Sb}_{2} \mathrm{O}_{3}$. Para a produção de filmes nosso laboratório possui uma evaporadora composta por um canhão de elétrons e também três pares de eletrodos para evaporação resistiva, além de acessórios tais como janelas para incidência de radiação sobre o filme durante a evaporação, medidor de espessura e dispositivos para aquecimento e medida de temperatura do substrato.

\subsubsection{Processos de deposição de filmes}

Os métodos mais utilizados para obtenção de filmes classificam-se em processos físicos (Physical Vapor Deposition - PVD) e processos químicos (Chemical Vapor Deposition - CVD). A técnica de Evaporação por canhão de elétrons é considerada um processo físico de deposição (PVD) que permite a evaporação de grande variedade de materiais que possuam desde pontos de fusão mais baixos até materiais com altíssimos pontos de fusão, com grande controle sobre o processo de deposição.

Neste método os elétrons emitidos por um filamento aquecido são acelerados sobre a amostra, utilizando-se de uma grande diferença de potencial entre o filamento e um cátodo. $O$ direcionamento e focalização do feixe de elétrons sobre o material a ser evaporado (material alvo) são determinados por um campo magnético, que faz com que os elétrons emitidos pelo filamento percorram uma trajetória circular convergente, atingindo o material alvo e causando aquecimento e vaporização do mesmo. As principais vantagens deste método são o controle da taxa de evaporação e conseqüentemente o controle de propriedades estruturais do filme, além de altas taxas que se pode obter para diferentes materiais favorecendo a rápida deposição de filmes mais espessos. Uma introdução mais detalhada ao estudo das diferentes técnicas de produção de filmes pode ser encontrada nas referências 106 à 108 . 


\subsubsection{Processos de formação dos filmes}

Como nosso trabalho trata da produção de filmes por evaporação térmica (PVD) temos que entender com mais detalhes os processos de formação e crescimento dos filmes a partir da deposição de um material vaporizado sobre um substrato. Na produção de filmes por PVD o processo de deposição obedece quatro estágios básicos:

1. Transformação do material a ser depositado por evaporação ou sublimação no estado gasoso.

2. Transferência de átomos (ou moléculas) da fonte de evaporação para o substrato.

3. Deposição dessas partículas sobre o substrato.

4. Rearranjo das partículas ou modificações de suas ligações sobre a superficie do substrato.

Durante a formação do filme outros processos podem ocorrer devido à acomodação térmica dos átomos ou moléculas sobre o substrato, dentre estes podemos citar: a) a difusão de átomos ou moléculas sobre a superficie do substrato; b) a formação de núcleos; c) o crescimento dos núcleos formando ilhas; d) coalescência de ilhas; e) crescimento do filme contínuo. $O$ processo de nucleação sobre o substrato inicia-se com a colisão das moléculas ou átomos do material evaporado sobre o substrato. Após a colisão as partículas podem ser adsorvidas pelo substrato ou podem ser adsorvidas e reevaporar num tempo $t_{A}$ (tempo de adsorção), além de poderem sofrer colisão elástica com o substrato. $O$ tempo de adsorção $t_{A}$ é dado por (3):

$$
t_{A}=\frac{1}{v} \exp \left(\frac{Q_{d e s}}{k T_{f s}}\right)
$$

onde $v$ é a freqüência de vibração da rede do substrato, $k$ a constante de Boltzmann, $Q_{d e s}$ a energia de desorção da partícula sobre um dado substrato e $T_{f s}$ é a temperatura da partícula, que geralmente está entre a temperatura da fonte de evaporação e a temperatura do substrato [108]. As partículas do material evaporado se chocam com o substrato com uma energia média de $3 k T_{f_{s}} / 2$, e a perda de energia de uma partícula que colidiu com o substrato é dada pelo coeficiente de acomodação $c_{a}(4)$ :

$$
c_{a}=\frac{E_{f}-E_{f s}}{E_{f}-E_{s}}=\frac{T_{f}-T_{f s}}{T_{f}-T_{s}}
$$


onde $T_{\mathrm{f}}$ é a temperatura da fonte de evaporação e $T_{s}$ a temperatura do substrato. Como a $T_{f s}$ é sempre maior que a temperatura do substrato, o valor do coeficiente $c_{\mathrm{a}}$ está entre 0 e 1 . O valor 0 corresponde ao caso de reflexão elástica onde a partícula bate no substrato e sai com a mesma temperatura, e o valor 1 corresponde a total acomodação, quando a partícula perde toda a energia "excessiva" e seu estado de energia é dado pela temperatura do substrato.

Valores entre estes extremos caracterizam as partículas que atingem o substrato e demoram um certo tempo para perder a energia de excesso, podendo re-evaporar. $\mathrm{O}$ tempo decorrido para que a partícula perca sua energia de excesso e acomode termicamente com o substrato é o tempo de adsorção $\left(t_{A}\right)$ e esta energia é dissipada pelo substrato frio dentro de um ou dois períodos de vibração da rede $\left(10^{12}-10^{14} \mathrm{~Hz}\right)$, ou seja, o tempo de adsorção $t_{A}$ é da ordem de $10^{-12}-10^{-14}$ segundos para a maioria dos substratos [106]. Nesse período a partícula move-se sobre a superficie podendo encontrar outra e formar um par, diminuindo ainda mais a probabilidade de reevaporação, e assim o processo de condensação se inicia pela formação de pequenos núcleos. A concentração $\left(N_{a d}\right)$ de partículas adsorvidas pela superficie do substrato é dada por:

$$
N_{a d}=\frac{R}{v} \exp \left(\frac{Q_{d e s}}{k T_{f s}}\right)=R t_{A}
$$

, onde $R$ é a taxa de evaporação. As altas taxas de evaporação favorecem a adsorção de núcleos e seu crescimento, e no caso dos vidros conseguimos taxas de até $100 \AA$ seg. (2.2.4). Neste caso o número de partículas adsorvidas pelo substrato é maior que o número de partículas re-evaporando, pois para o caso de evaporação de nossos vidros $c_{a}$ está em torno de $0,8-0,9$ considerando $T_{f} \approx 700^{\circ} \mathrm{C}$ e $\mathrm{T}_{\mathrm{fs}} \approx 200^{\circ} \mathrm{C}$, para temperatura do substrato $T_{s} \approx 50^{\circ} \mathrm{C}$. Freqüentemente a nucleação $\mathrm{e}$ o crescimento ocorrem simultaneamente durante a formação do filme, sendo que o crescimento dos núcleos é tridimensional, mas o crescimento paralelo ao substrato é maior, devido aos rápidos processos de difusão sobre a superficie do substrato. Durante o processo de difusão pela superficie, a partícula percorre uma distância média, $\bar{d}$, a partir do ponto de incidência. Esta distância média é dada por:

$$
\bar{d}=\sqrt{2 D_{d i f} t_{A}}
$$

, onde $D_{\text {dif }}$ é o coeficiente de difusão superficial, que depende do material evaporado e do tipo de substrato. A energia de ligação sobre a superfície do substrato não é a mesma 
em cada ponto, e a partícula adsorvida tende a ocupar o estado de mínima energia. $O$ relevo de potencial de uma superficie sólida é mostrado na Figura 28.

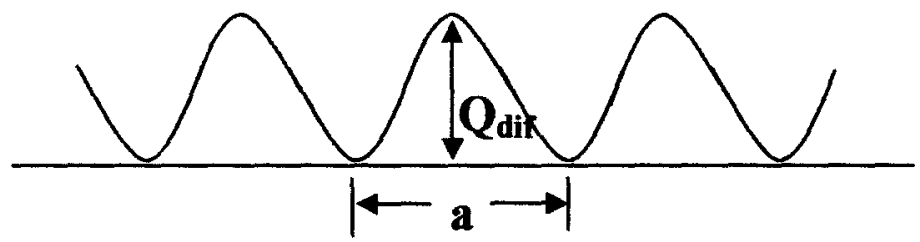

Figura 28 - Relevo do potencial sobre a superficie de um sólido [108].

Desse modo as partículas irão sempre se localizar em "vales" de potencial, e para que estas passem para uma posição adjacente é necessário vencer uma barreira de potencial, com energia de ativação $Q_{\text {dif }}$ [108]. Desta forma o coeficiente de difusão superficial, $D_{d i f}$, está relacionado com a energia de ativação $Q_{d i f}$, por:

$$
D_{d i f}=a^{2} v \exp \left(-\frac{Q_{d i f}}{k T_{f s}}\right)
$$

onde $\underline{a}$ e $Q_{\text {dif }}$ são representados na Figura 28. Se dois núcleos estão próximos um do outro, estes se juntam pelo processo denominado coalescência, como ilustra a Figura 29.

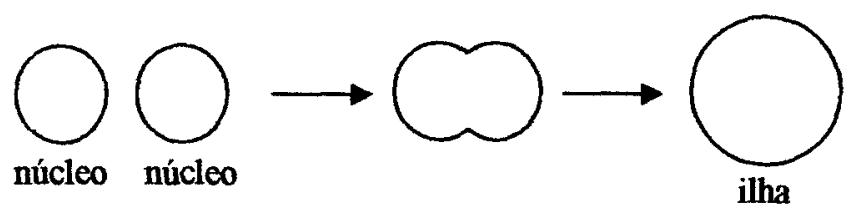

Figura 29 - Processo da coalescência de dois núcleos, formando uma ilha.

Neste processo a energia do sistema é diminuída, as grandes ilhas crescem mais rápido e as pequenas desaparecem, devido a coalescência com as maiores, e a cada instante existe uma redistribuição de ilhas. No caso de evaporação de vidros, como $T_{f s}$ é relativamente baixa $\left(\approx 200^{\circ} \mathrm{C}\right)$ o coeficiente de difusão superficial, $D_{d i f}$, também é baixo, o que leva a situação de menor efeito de coalescência e distribuição homogênea de grãos muito pequenos (10-50 nm). Dessa forma os filmes apresentam maior porcentagem de vazios estruturais e estrutura colunar, quando comparado com materiais cristalinos de alto ponto de fusão. 


\subsubsection{O Sistema de Evaporação por Canhão de Elétrons}

O sistema montado pode ser dividido em duas partes principais: (I) câmara de evaporação; e (II) sistema de vácuo. Ainda que os dispositivos principais do sistema sejam importados (canhão de elétrons, medidor de espessura, e bombas difusora e mecânica), toda a estrutura que suporta esses equipamentos e sua adaptação ao sistema da evaporadora foi desenvolvida em nossos laboratórios. A Figura 30 mostra um esquema geral do sistema montado.

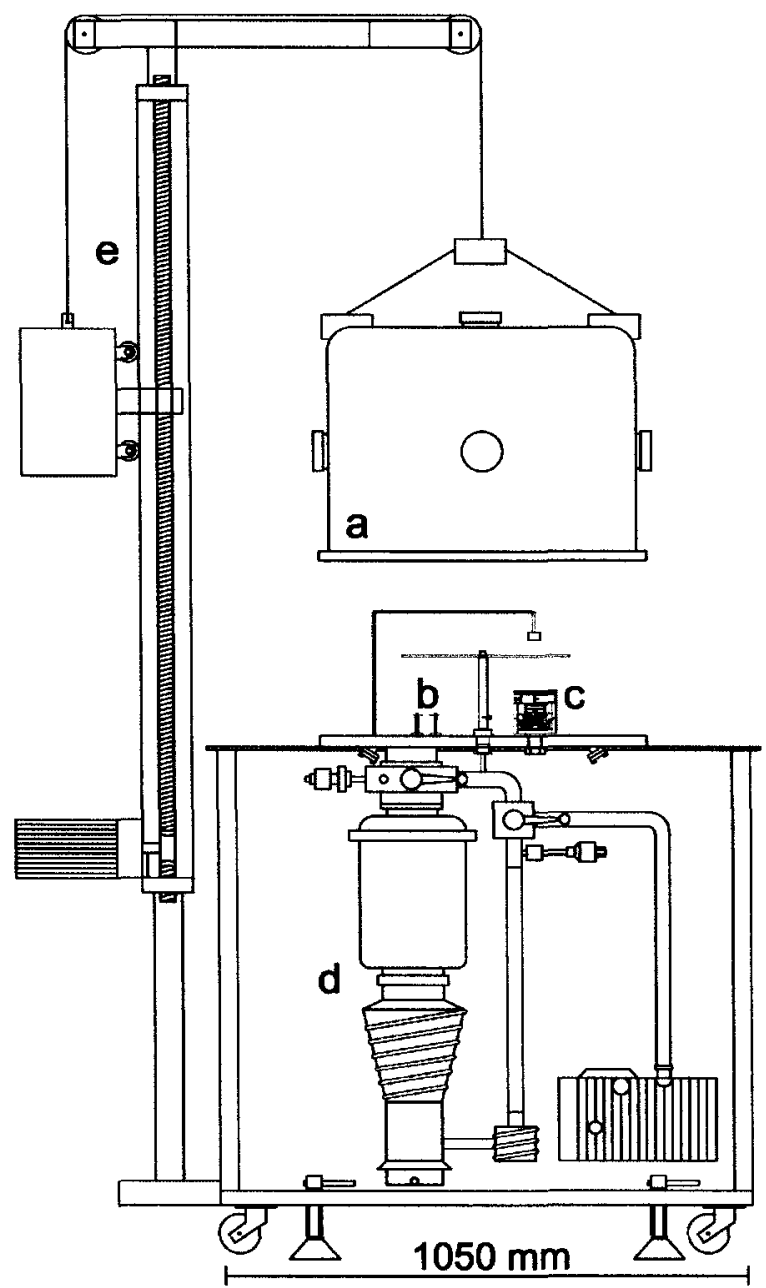

Figura 30 - Visão geral do sistema de evaporação.a) Câmara de evaporação, b)Eletrodos para evaporação resistiva, c) Canhão de elétrons, d) Sistema de vácuo, e) Sistema para elevação da câmara.

Uma estrutura de ferro com tampo de alumínio suporta todo o do sistema de evaporação e de vácuo. A estrutura possui quatro pés fixáveis, e pode ser movimentado 
através de um conjunto de rodas. Para erguer ou descer a campânula, foi adaptado um sistema de controle automático, acionado por controle remoto.

A Câmara de Evaporação possui volume interno de 130 litros, sendo que a campânula foi construída utilizando-se chapa de aço inox, com reforços para suportar a pressão atmosférica; possui cinco janelas de vidro que permitem o monitoramento do processo de evaporação. O canhão de elétrons é da Telemark (modelo 231), refrigerado a água (8 litros/min.), e trabalha com filamento de tungstênio para a emissão de elétrons. A corrente máxima de alimentação do filamento é de $50 \mathrm{~A}$ com $12 \mathrm{~V}$ e o feixe de elétrons emitido é acelerado na faixa de voltagem de 4 a $10 \mathrm{KV}$, com corrente máxima do feixe de $500 \mathrm{~mA}$, em pressão de $10^{-6}$ Torr [109].

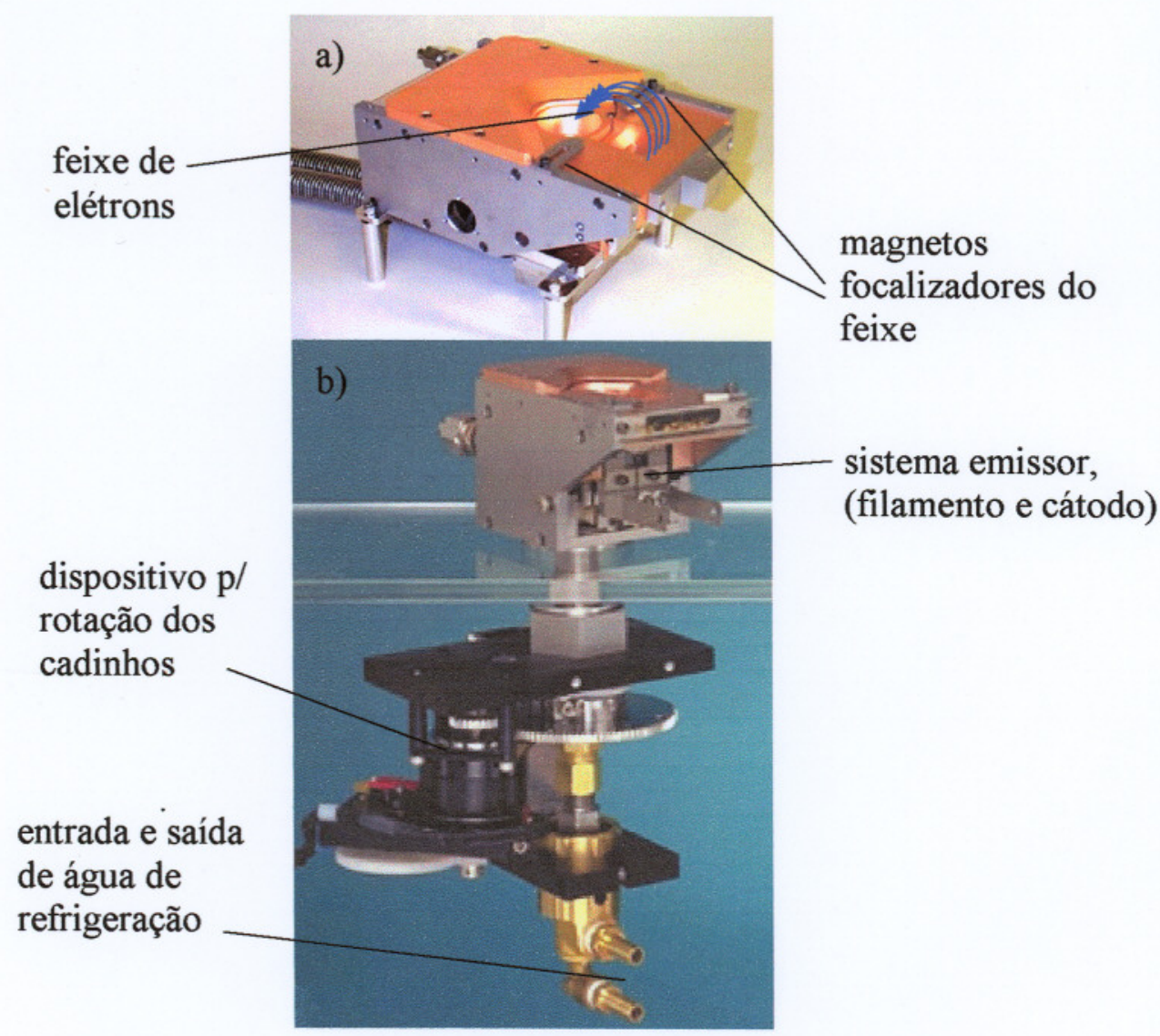

Figura 31-Canhão de Elétrons: a) Vista superior; b) vista lateral

O canhão de elétrons é acionado através de um módulo de controle, onde se ajusta a tensão e a corrente do feixe. A posição, amplitude, e freqüência de varredura do feixe são controladas em um módulo de varredura. $\mathrm{O}$ feixe emitido é direcionado para $\mathrm{o}$ cadinho realizando um giro de $270^{\circ}$, através da ação de um magneto e de guias laterais. 
A focalização do feixe sobre o cadinho é fortemente dependente do alinhamento do sistema emissor que compreende o filamento e o cátodo. $O$ canhão possui um suporte rotativo para quatro cadinhos, permitindo a evaporação de multicamadas sem quebra de vácuo. O canhão de elétrons é ilustrado na Figura 31.

Problemas de faiscamento no interior da campânula podem ser evitados observando-se os seguintes itens: (a) rigorosa limpeza dos elementos do interior da campânula; (b) perfeito alinhamento e calibração nas distâncias milimétricas na montagem do sistema emissor (filamento e cátodo); (c) a focalização do feixe sobre a amostra a ser evaporada; $\mathrm{e}(\mathrm{d})$ as condições de operação do canhão em relação à pressão no interior da câmara e a corrente do feixe de elétrons. A instrumentação eletrônica para acompanhar o processo de evaporação no canhão compreende: (a) módulo de controle de tensão e corrente no filamento; (b) módulo de varredura xy do feixe de elétrons; (c) transformador de corrente; e (d) controle posicionador dos cadinhos. Com a finalidade de se monitorar a taxa de deposição e a espessura do filme foi instalado um medidor de espessura da Sycon Instruments (STM - 100 / MF) que utiliza como sensor um cristal de quartzo [110]. $O$ cristal é embutido em um poste de aço inox, refrigerado a água, e situado próximo ao substrato. $\mathrm{O}$ bom funcionamento do medidor de espessura depende do conhecimento prévio de alguns parâmetros referentes ao material a ser evaporado (ex. densidade).

O Sistema de Vácuo permite trabalhar com pressões de aproximadamente $10^{-6}$ torr na câmara de evaporação, pois o sistema possui uma bomba mecânica (DUO 008B da Balzers - Pfeiffer) com capacidade de 2,2 1/s e uma bomba difusora (DIF 160I da Balzers) com capacidade de 2,6 1/s. O sistema de vácuo é conectado à base da evaporadora através de uma válvula tipo borboleta (BVB 100H/HX da Balzers). A bomba difusora está conectada a um reservatório de $\mathrm{N}_{2}$ líquido com 2 litros de capacidade.

\subsubsection{A deposição dos filmes a partir de vidros $\left[\mathrm{Sb}\left(\mathrm{PO}_{3}\right)_{3}\right]_{n}-\mathrm{Sb}_{2} \mathrm{O}_{3}$}

Antes do início da evaporação dos vidros para a deposição dos filmes é necessário que o sistema de vácuo esteja completamente limpa, livre de resíduos de evaporações anteriores. Utilizamos substratos lapidados de quartzo amorfo com $1 \times 1$ $\mathrm{cm}^{2}$ e $1 \mathrm{~mm}$ de espessura para deposição dos filmes. Para experimentos que exigiam 
filmes com maior área, utilizamos lâminas de microscópio de $2,5 \times 6,0 \mathrm{~cm}^{2} \mathrm{e} 1 \mathrm{~mm}$ de espessura como substratos. Os substratos utilizados exigem rigorosa limpeza que foi realizada em banho de solução sulfocrômica no ultra-som e posteriormente em banho com água deionizada e finalmente a secagem era feita com jato de nitrogênio seco antes de serem colocados no vácuo.

Terminado os procedimentos de limpeza da evaporadora e dos materiais utilizados o vidro precursor era colocado em um cadinho e colocado no canhão de elétrons e os substratos colocados no suporte situado $15 \mathrm{~cm}$ acima do cadinho.

$\mathrm{Na}$ seqüência a campânula é fechada para o início do processo de vácuo. Um vácuo primário é feito com a bomba mecânica ( 100mTorr), a partir daí a bomba difusora é acionada chegando a um vácuo de $3 \times 10^{-6}$ Torr.

A temperatura de fusão dos vidros é relativamente alta $\left(\approx 900{ }^{\circ} \mathrm{C}\right)$, e para isto utilizou-se cadinhos de Tântalo que tem ponto de fusão em torno de $2996{ }^{\circ} \mathrm{C}$ a $1 \mathrm{~atm}$. Feito o vácuo e ligado o sistema de refrigeração do sistema, o canhão de elétrons é acionado com tensão de 6-8 KV para aceleração do feixe sobre o vidro precursor e a corrente do feixe aumentada gradativamente observando-se o início da evaporação pelo medidor de espessura. A taxa de evaporação obtida com o canhão de elétrons para este material foi de 10 a $100 \AA / \mathrm{seg}$ com corrente do feixe de $30-40 \mathrm{~mA}$, de maneira que conseguimos produzir filmes com até de $10 \mu \mathrm{m}$ de espessura em aproximadamente 1 hora de deposição.

\subsection{Caracterização das Amostras}

\subsubsection{Técnicas de Análise Térmica}

\subsubsection{Calorimetria exploratória diferencial (DSC)}

A calorimetria exploratória diferencial é uma das técnicas de análise térmica que tem sido usada por mais de duas décadas para medir temperaturas e fluxo de calor associado com transições em materiais em função do tempo. Tais medidas fornecem informações quantitativas e qualitativas sobre variações químicas e fisicas envolvendo processos endotérmicos ou exotérmicos. O DSC é a técnica de análise térmica mais 
empregada com aplicabilidade em polímeros e materiais inorgânicos. A amostra (acondicionada em um pequeno cadinho de metal) e referência (uma cadinho vazio) situam-se em uma plataforma formada por um disco termoelétrico (constantan) que atua como uma fonte de transferência de calor primária de um forno com temperatura programada para a amostra e a referência. Tradicionalmente, a temperatura do forno é aumentada ou diminuída de maneira linear, enquanto que a diferença resultante do fluxo de calor da amostra e da referência é monitorada por um termopar fixo abaixo da plataforma.

A temperatura da célula da amostra (S) é mantida sempre igual à da célula de referência (R), por ajuste contínuo e automático. É feito o registro de um sinal proporcional à diferença entre o calor fornecido à amostra e à referência, $\mathrm{dH} / \mathrm{dT}$, e é registrada a temperatura média entre a amostra e a referência (R). Com a obtenção das curvas de DSC as medidas das temperaturas críticas denominadas: temperatura de transição vitrea $\left(T_{g}\right)$, temperatura de cristalização $\left(T_{x}\right)$ e temperatura de fusão $\left(T_{f}\right)$ são obtidas pelo método das tangentes como mostra a Figura 32.

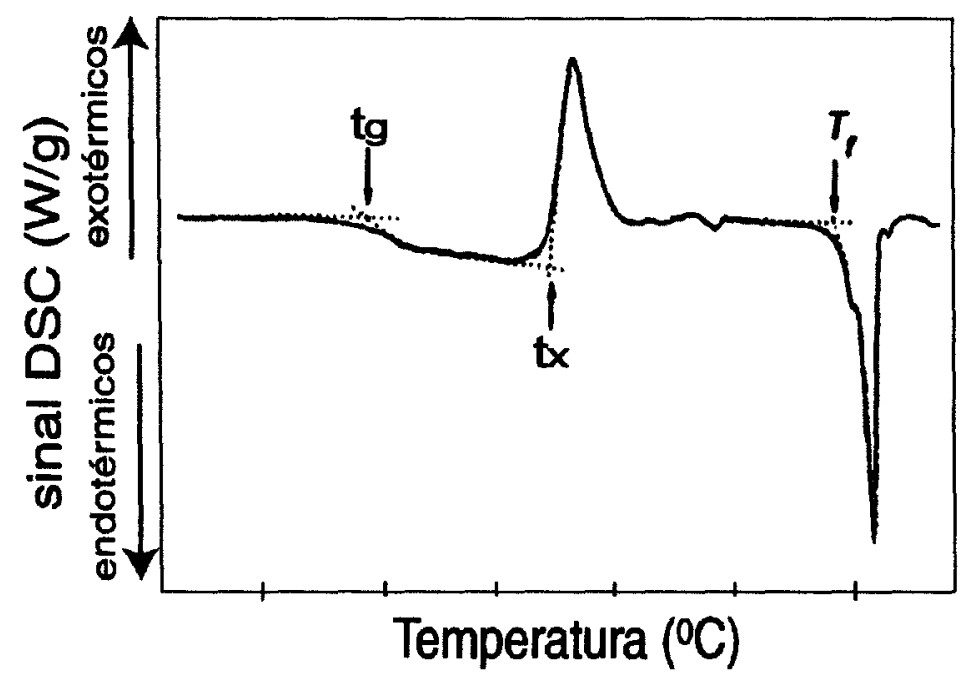

Figura 32 - Curvas de Calorimetria Exploratória Diferencial (DSC) mostrando as temperaturas características $\left(T_{\mathfrak{g}}, T_{x}, T_{f}\right)$ do sistema obtidas pelo método de intersecção de tangentes.

As medidas de Calorimetria Exploratória Diferencial (DSC) foram realizadas utilizando um aparelho de análise térmica NETZSCH DSC-404, o qual permitiu as 
medidas das temperaturas críticas: temperatura de transição vítrea $\left(T_{\mathrm{g}}\right)$, temperatura de cristalização $\left(T_{x}\right)$ e temperatura de fusão $\left(T_{f}\right)$.

\subsubsection{Técnicas de Análise de Superficie}

\subsubsection{Perfilometria}

O perfilômetro mede a variação de relevo linear (ou espessura) de uma amostra através do movimento mecânico de uma ponta de diamante. Para o registro do perfil do relevo em análise, a amostra é deslocada sob a ponta diamantada por uma base controlada por mecânica de precisão, onde é possível controlar o nivelamento e a velocidade de deslocamento da amostra durante a medida. Nenhuma preparação prévia da amostra é requerida, e amostras de vidro não são deformadas pela ponta diamantada, como ocorre no caso de materiais muito moles (e.g. polímeros). As medidas são registradas por este equipamento na forma gráfica. As medidas de espessura de filmes e as variações de relevo das regiões irradiadas que sofreram fotocontração foram realizadas utilizando um perfilômetro Talystep Rank Taylor Hobson.

\subsubsection{Microscopia de força atômica (AFM)}

A microscopia por força atômica ("atomic force microscopy", AFM) é uma importante ferramenta no estudo de filmes para obtenção de imagens tridimensionais e estudo de rugosidade, estrutura, etc. Com esta técnica pode-se obter imagens com resolução na escala atômica.

Com a técnica microscopia por força atômica, as imagens são geradas através da medida das forças newtonianas de atração e repulsão entre a superficie da amostra e uma agulha extremamente fina que varre a amostra. A agulha é situada na ponta de um braço denominado "cantilever". O cantilever tem de 100 a $500 \mu \mathrm{m}$ de comprimento e 0,5 a $5 \mu \mathrm{m}$ de espessura, e a agulha possui alguns micrômetros de comprimento e diâmetro menor que $400 \AA$. O sistema (cantilever e agulha) funciona em conjunto com um sistema de varredura piezoelétrico que faz a movimentação da amostra nas direções $\mathrm{x}, \mathrm{y}$ e $\mathrm{z}$ em escala nanométrica para a varredura e obtenção das imagens por medidas de 
força. $\mathrm{O}$ sistema piezoelétrico movimenta a amostra com deslocamento nas direções $\mathrm{x}, \mathrm{y}$ e $z$, através da variação da voltagem nele aplicada e o deslocamento é controlado por um circuito de realimentação que tem como função manter a força e/ou distancia da agulha a amostra constante.

As forças envolvidas são da ordem de $10^{-12} \mathrm{~N}$ e o sistema de detecção é bastante sensível. Um sistema ótico composto por Laser e detector é responsável pela detecção da sensível deflexão do cantilever devido à topografia da amostra. Com a captação do movimento do cantilever nas direções $\mathrm{x}$, y e $\mathrm{z}$ é construída a imagem da superfície da amostra [111]. A resolução espacial é de poucos nanômetros para varreduras acima de $200 \mu \mathrm{m}$, mas pode situar-se em escala atômica, para varreduras pequenas. As medidas de AFM em filmes foram realizadas através de um microscópio Nanoscope III-a operando em modo de contato.

\subsubsection{Microscopia eletrônica de varredura (MEV)}

A microscopia eletrônica de varredura MEV ou SEM (Scanning Electron Microscopy) permite caracterizar a superficie dos materiais, sua topografia, dimensões dos grãos, homogeneidade e dispersão das partículas. O microscópio eletrônico opera pelo princípio de incidência de um estreito feixe de elétrons acelerados sobre o material a ser analisado e captação de elétrons espalhados pela amostra para a formação das imagens. $O$ feixe de elétrons é emitido por um filamento e acelerado por uma diferença de potencial de até $20 \mathrm{KV}$, e a corrente do feixe que incide na amostra é da ordem de $10^{-}$ ${ }^{9}$ a $10^{-12}$ A. O feixe varre uma área da amostra com uma freqüência determinada por um sistema de lentes magnéticas e bobinas defletoras que controlam também o diâmetro e focalização do feixe sobre a amostra. Parte dos elétrons que incidem na amostra é espalhada por choques elásticos ou inelásticos, e estes elétrons espalhados são captados por um detector, que associa a energia do elétron espalhado com o relevo da amostra. A resposta do detector de elétrons espalhados pelo material modula o brilho e contraste de um tubo de raios catódicos de um sistema de vídeo para a formação das imagens [112].

Os contrastes topográficos observados nas cores preto e branco das imagens surgem devido à dependência do ângulo de incidência entre o feixe e a superficie do material e também da posição do detector. Dependendo desse ângulo, do número e da trajetória dos elétrons retroespalhados e secundários emitidos pela superficie, mais 
brilhante será a imagem obtida. Isto ocorre em regiões dos contornos de grãos e elevações da superficie. As medidas de MEV foram realizadas através de um microscópio Zeiss DSM-960.

\subsubsection{Espectroscopia de dispersão de Raios-X (EDX/WDX)}

Quando os átomos de um material são ionizados por uma radiação de alta energia, eles emitem Raios-X característicos. A técnica de EDX (Energy Dispersive of $\mathrm{X}$-ray), está baseada na coleta e dispersão de energia de Raios-X característicos emitidos por uma amostra quando bombardeada pelo um feixe eletrônico de alta energia $(\sim 20 \mathrm{KeV})$. Um aparelho de EDX consiste de uma fonte de radiação de alta energia, usualmente elétrons; detector, $\mathrm{Si}(\mathrm{Li})$; e um processador de sinal. $\mathrm{O}$ espectrômetro de EDX geralmente é acoplado abaixo do canhão de elétrons do MEV. Os Raios-X que entram no detector de $\mathrm{Si}(\mathrm{Li})$ são convertidos em sinais que podem ser processados como um histograma de energia de Raios- $X$. $O$ espectro de Raios-X consiste de uma série de picos representativos do tipo e da quantidade relativa de cada elemento na amostra. As emissões de raios- $X$ mais intensas e utilizadas para este tipo de medida são as linhas $K_{\alpha}, K_{\beta}, L_{\alpha}, L_{\beta}$, emitida pelos elementos devido a transições eletrônicas nas camadas $\mathrm{K}$ e L. Um mapeamento da distribuição dos constituintes dos elementos pertencentes à amostra pode ser visualizado qualitativamente por varredura de áreas via Raios-X (mapeamento por pontos).

Para as medidas de Microscopia eletrônica de varredura (MEV) utilizou-se um microscópio Zeiss DSM-960, acoplado a um analisador EDX QX2000. Neste microscópio, em particular, é possível detectar elementos com peso atômico acima do sódio (Na). A técnica de WDX é semelhante à técnica de EDX, com a diferença que a varredura não é feita em dispersão de energia, mas sim em dispersão de comprimentos de onda dos fótons de Raios- $X$ emitidos pelo material através de um monocromador acoplado ao sistema. Para as análises de WDX utilizamos um microanalisador Microspec WDX-3PC acoplado em um microscópio Leica Stereoscan 440, com opção de detecção de elementos leves com massa atômica a partir do Boro (massa atômica:10). 


\subsubsection{Análise de Materiais por Feixe Iônico (RBS)}

O método de análise RBS (Rutherford Backscattering Spectrometry) faz parte de um conjunto de métodos nuclear-espectroscópico mais amplo denominado genericamente de métodos de análise de materiais por feixe iônico (IBA- Ion Beam Analysis). Esses métodos têm em comum a utilização de feixes de íns $\left(\mathrm{H}^{+}, \mathrm{He}^{+}, \mathrm{He}^{++}\right)$ monoenergéticos com energia da ordem de alguns $\mathrm{MeV}$ e dezenas de $\mathrm{nA}$ de corrente, sendo usados para a determinação de composição elementar e perfil elementar em profundidade de filmes e materiais em geral através de bombardeamento e detecção de íns. A energia dos íons de alguns $\mathrm{MeV/u.m.a.} \mathrm{limita} \mathrm{a} \mathrm{profundidade} \mathrm{analisada} \mathrm{a} \mathrm{alguns}$ $\mu \mathrm{m}$, por isto esta técnica é também conhecida como caracterização de filmes. O RBS permite identificar e quantificar todos os elementos da tabela periódica, exceto $\mathrm{H} \mathrm{e} \mathrm{He}$, com limites de deteç̧ão variando de frações de por cento até ppm em amostras espessas e fração de monocamada em filmes finos.

No retroespalhamento Rutherford (RBS), partículas monoenergéticas de um feixe de íons são aceleradas em torno de 1,0 a 4,0 MeV por um acelerador linear e colidem com átomos de uma amostra em análise, sendo retroespalhadas pelas nuvens eletrônicas (colisão elástica) e detectadas por um detector que obtém a energia. $O$ feixe de partículas retroespalhado sai da amostra possuindo uma distribuição de energia que depende da profundidade de penetração do feixe, da concentração dos elementos na amostra e da seção de choque de cada átomo constituinte do material.

$\mathrm{Na}$ colisão, a energia é transferida da partícula incidente para o átomo estacionário. A taxa de redução da energia da partícula espalhada depende da razão das massas da partícula incidente e do átomo alvo e permite determinar a identidade do átomo alvo. Identificado o átomo alvo, sua densidade em átomos $/ \mathrm{cm}^{2}$ pode ser determinada a partir da probabilidade de colisão entre as partículas incidentes e os átomos do alvo, medindo-se o número total de partículas detectadas, A, para um certo número $Q$, de partículas incidentes. A conexão entre $A$ e $Q$ é dada pela seç̧ão de choque de espalhamento.

Finalmente, a distância à superficie do local onde ocorreu a colisão pode ser inferida a partir da perda de energia da partícula em seu percurso no interior da amostra. Sendo a perda de energia diretamente proporcional ao comprimento da trajetória percorrida pela partícula no interior da amostra, é possível estabelecer uma escala de profundidade e associar a energia da partícula detectada ao local em que ocorreu a 
colisão. $\mathrm{O}$ grande sucesso das análises RBS com feixes $\mathrm{H}^{+}$e $\mathrm{He}^{+}$com energia da ordem de $\mathrm{MeV}$, deve-se, entre outros, à possibilidade de modelar teoricamente os espectros experimentais com excelente precisão a partir de primeiros princípios apenas supondo um espalhamento clássico em campo de força central.

Um espectro RBS é um gráfico da intensidade (taxa de contagens) em função da energia das partículas detectada. Em outras palavras o espectro de RBS é um histograma onde o eixo das energias (abscissa) é dividido em 512 ou 1024 canais. Cada canal corresponde a um pequeno intervalo de energia, da ordem de $5,0 \mathrm{KeV} / \mathrm{canal}$. Um espectro típico de uma análise RBS de um filme fino de $\mathrm{SiO}_{2}$ com espessura $\mathrm{t}=300 \mathrm{~nm}$ depositado sobre carbono está representado na Figura 33 [113].

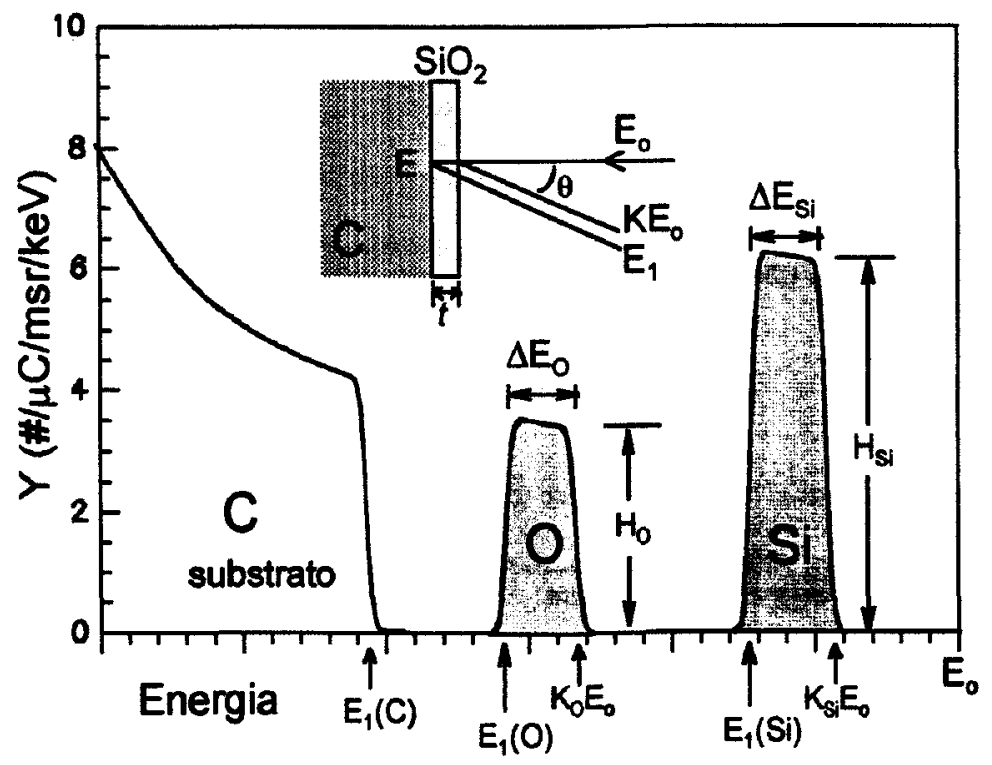

Figura 33 - Espectro RBS de um filme fino de $\mathrm{SiO}_{2} \mathrm{com} 300 \mathrm{~nm}$ de espessura sobre substrato de carbono.

Conforme o diagrama acima, o feixe de íons que incide na amostra com energia $E_{0}$ é retroespalhado logo na superficie, retornando com distribuição de energias $\mathrm{K}_{\mathrm{O}} \mathrm{E}_{0}$ ou $\mathrm{K}_{\mathrm{Si}} \mathrm{E}_{0}$, para o caso colisão com oxigênio ou silício respectivamente. $\mathrm{A}$ largura dos picos no espectro RBS é devida ao retroespalhamento de íons que atingem diferentes profundidades no material $e$, portanto geram um feixe retroespalhado com certa distribuição de energia. 
Num exemplo como o da Figura 33, a largura dos picos elementares no espectro RBS é dada por: $\Delta \mathrm{E}_{\mathrm{O}}=[\mathrm{S}]_{\mathrm{o}}{ }^{\text {meio }}$.t e $\Delta \mathrm{E}_{\mathrm{Si}}=[\mathrm{S}]_{\mathrm{si}}{ }^{\text {meio }}$.t, onde $[\mathrm{S}]_{\mathrm{y}}{ }^{\text {filme }}$ indica que no cálculo de [S] usa-se o fator cinemático $\mathrm{K}_{\mathrm{y}}$ e o poder de frenagem do meio $\left(\mathrm{SiO}_{2}\right)$, sendo $\mathrm{S}$ o fator de perda de energia expressa em unidades de eV/A.

Ao atingir a interface com o substrato, a energia do feixe é $E=E_{0}-\Delta E$. Para determinar $\Delta \mathrm{E}$ do filme é necessário saber sua estequiometria a qual em geral, é a incógnita do problema. No caso usam-se métodos iterativos e programas de computador que permitem simular espectros RBS para uma dada composição/estrutura da amostra (programa RUMP-RBS Data Analisys, Simulation and Plotting; http://www.genplot.com).

Através do programa RUMP é possível obter simulações dos espectros extraindo parâmetros como concentração e espessura de camadas para cada elemento constituinte da amostra. Depois de obtido um espectro de simulação que se ajuste bem com o espectro experimental o programa fornece os valores relativos da concentração de cada elemento na amostra e a espessura da camada de material. Há simulações onde é necessário adicionar ao programa dados de várias camadas com diferentes espessuras e concentrações para obter um espectro que se ajuste bem com o experimental. Nem sempre é possível ajustar perfeitamente um espectro experimental, principalmente para amostras mais espessas, onde os espectros podem se tornar alargados e ruidosos.

Os experimentos de RBS, utilizado para determinar a composição das áreas irradiadas e não irradiadas com laser UV, foram realizados no LAMFI-USP-São Paulo, usando um feixe de $\mathrm{He}^{+}$com energia de $2,9 \mathrm{MeV}$, e um ângulo de deteç̧ão de $\theta=170^{\circ}$. A partir dos dados de RBS as quantidades de $\mathrm{Sb}, \mathrm{P}, \mathrm{e} O$ foram determinadas em função da profundidade de penetração do feixe de íons.

\subsubsection{Espectroscopia de Fotoelétrons excitados por Raios-X (XPS)}

Uma das técnicas usadas para estudar e medir a composição química da estrutura das camadas superficiais é o ESCA (Electron Spectroscopy for Chemical Analysis), também chamado de XPS (X-ray Photoelectron Spectroscopy).

A técnica de XPS é usada principalmente nos seguintes campos de aplicação: corrosão, catálise, materiais, semicondutores, polimeros e fundamentalmente 
investigação. $\mathrm{O}$ efeito fotoelétrico é um processo de interação direta de fótons com o átomo, gerando a emissão de fotoelétrons (neste caso por excitação de raios-X), e este efeito é o principio básico da técnica de XPS. Esta técnica só passou a ser utilizada com o aperfeiçoamento dos sistemas de bombeamento de UHV (ultra-alto vácuo), sendo que nos anos 50 pesquisadores dirigidos por Siegbahn, fizeram as primeiras medidas de energia de elétrons liberados por irradiação com raios-X. Mais tarde, foi descoberto que os fotoelétrons de energia mais baixa emergiam das camadas mais superficiais dos materiais sólidos. Com essas descobertas, começaram a aparecer os sistemas comerciais de XPS no final dos anos 60 e início dos anos 70, com a função de medir as propriedades dos sólidos.

A analise de superficie de um material é realizada pelo XPS através da medida da energia de elétrons emitidos de uma amostra atingida por raios- $\mathrm{x}$ monoenergéticos. Raios-x Mg K $\mathrm{K}_{\alpha}\left(1253,6 \mathrm{eV}\right.$ ) ou Al K $\mathrm{K}_{\alpha}(1486,6 \mathrm{eV})$ são os comumente utilizados para excitação. Estes fótons têm uma força de penetração no sólido, limitada na ordem de 1 a 10 micrômetros. Exemplos de medidas precisas de picos de fotoelétrons demonstraram a capacidade da técnica para caracterizar filmes.

A energia de ligação do elétron com o átomo pode ser considerada como a energia de ionização do átomo. Dessa forma o XPS reproduz diretamente a estrutura a nível eletrônico, desde as camadas mais internas até a superficie atômica. Todos os elementos químicos, com exceção de $\mathrm{H}$ e He, podem ser analisados, mesmo que os elementos sejam só uma parte de um composto químico. As energias cinéticas de fotoelétrons e elétrons Auger são características de cada elemento, assim a distribuição de energia dos elétrons emitidos pela amostra revela todos elementos da superfície. $\mathrm{Na}$ Figura 34 pode se observar um espectro de XPS plotado na forma de intensidade em função da energia de ligação dos elétrons, obtido para uma mostra metálica contendo $\mathrm{Fe}, \mathrm{Ni}, \mathrm{Cr}$ e $\mathrm{O}$.

Como os termos referentes à função trabalho podem ser compensados eletronicamente, a energia cinética dos fotoelétrons emitidos pela amostra é dada pela fórmula $E_{\text {cinética }}=h \nu-E_{B}$, onde $h v$ é a energia dos fótons de raios-X, $\mathrm{E}_{\mathrm{B}}$ a energia de ligação do elétron em relação ao nível de vácuo. Os elétrons com energia cinética entre 10 e $1500 \mathrm{eV}$ são ideais para o estudo de superficies, pois seus caminhos livres médios nos sólidos são de algumas camadas atômicas (0,5 a 3,0 nm) [114]. 


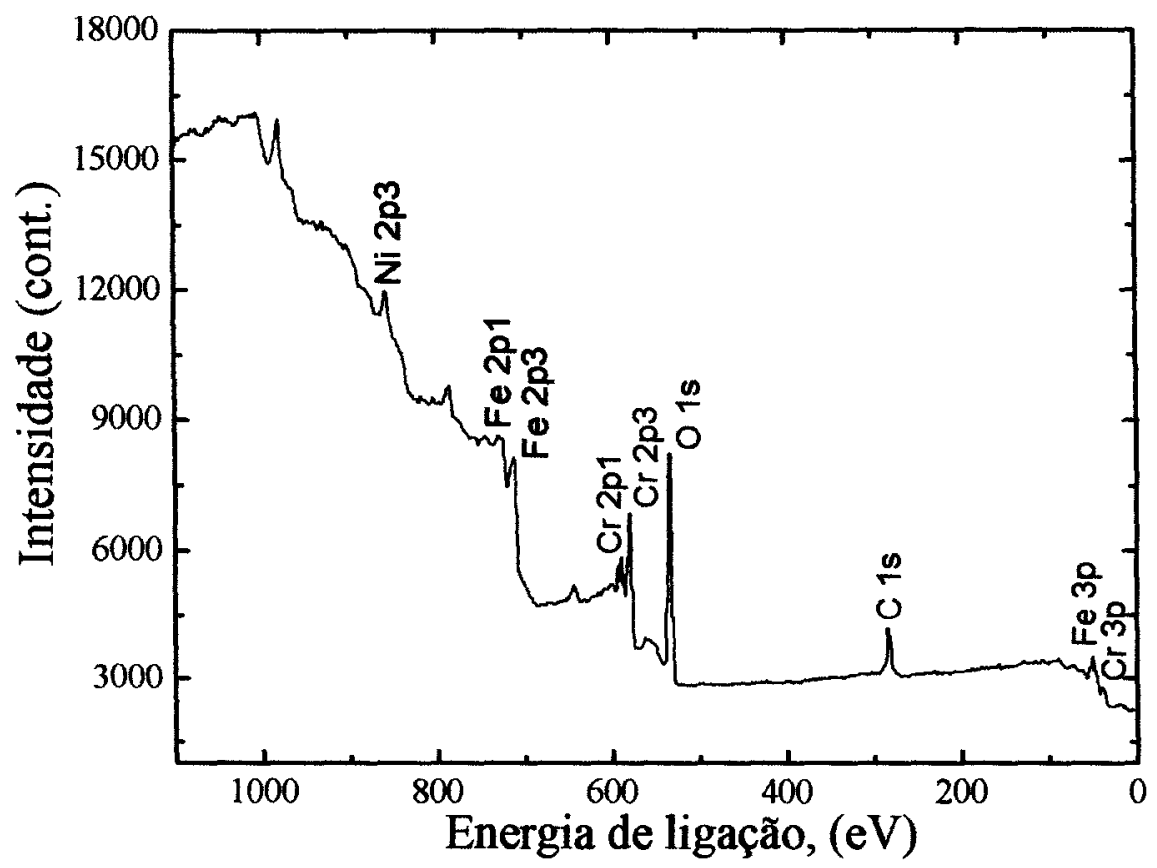

Figura 34 - Espectro de XPS na forma de intensidade em função da energia dos elétrons, obtido para uma mostra metálica [115].

A identificação dos elementos presentes na superficie é feita diretamente pela determinação das energias de ligação dos picos de fotoelétron das camadas mais internas do átomo ( $\mathrm{K}$ e L). A intensidade (área integrada do pico) é proporcional ao número de átomos no volume detectado, permitindo obter-se informações sobre a composição da superficie [116]. Para uma análise precisa de elementos e concentrações numa amostra varreduras são feitas sistematicamente na posição do pico fotoelétrico correspondente para determinado elemento, para se minimizar a relação sinal ruído e obter uma curva que possa ser deconvoluída por funções gaussianas e/ou lorentzianas e devidamente analisada.

Um equipamento para análise de superfícies é composto por uma câmara de UHV, uma fonte de raios-X, um canhão de elétrons, um canhão de íons, um manipulador de amostra, um espectrômetro, um detector de elétrons e computador para controle e aquisição de dados. $O$ canhão de íons é utilizado para limpeza da amostra in situ e também para medidas em várias profundidades através da erosão controlada da amostra. Os analisadores de elétrons são peça fundamental do equipamento de XPS, e os mais usados são o de espelho cilindrico (CMA) e o hemisférico concêntrico (CHA), apresentando detecção com resolução em energias dos elétrons menor que $0,1 \mathrm{eV}$. 
Os experimentos de XPS, utilizado para determinar a composição das áreas irradiadas e não irradiadas com laser UV, foram realizados no CCDM-DEMaUFSCAR, usando um espectromicroscópio de superfícies (Kratos-XSAM HS). A partir dos dados de XPS as quantidades e estados de oxidação de $\mathrm{Sb}, \mathrm{P}$, e $\mathrm{O}$ foram determinadas.

\subsubsection{Espectroscopia Óptica e Vibracional}

\subsubsection{Espectroscopia de Absorção Óptica no UV-VIS}

A absorção óptica é o fenômeno que ocorre quando um feixe de luz atravessa um material de determinada espessura e parte da luz é absorvida sendo que a intensidade do feixe que passa pelo material é diminuída por um fator que pode ser medido. $O$ fenômeno de absorção está relacionado diretamente com efeitos de transição eletrônica e vibração dos átomos que compõem o material. Quando um feixe de luz passa por um material os átomos absorvem parte dessa luz ficando excitados, ou seja, os elétrons passam para níveis de maior energia e decaem posteriormente emitindo radiação com energia menor do que a radiação incidente ou gerando vibrações na estrutura do material (fônons). A absorção é descrita pela lei de Lambert, $I=I_{0} e^{-\alpha x}$, onde $I_{0}$ é a intensidade da luz inicial incidente sobre a mostra, $I$ é a intensidade transmitida e $x$ é a espessura da amostra. A absorção óptica ou absorbância é definida como $\log (I / I)$, sendo $\alpha=[\log (\operatorname{lo} / I) / 0,43 . x]$ o coeficiente de absorção óptica. Os resultados fornecidos por esta técnica podem ser apresentados na forma gráfica de absorção $\left(\log \left(I_{\delta} I\right)\right)$ ou transmitância $\left(I / I_{0}\right)$ em função do comprimento de onda.

As medidas foram realizadas no espectrofotômetro Cary 17 da Varian que opera na faixa de 185 a $2500 \mathrm{~nm}$. Este equipamento possui duas fontes de luz e dois tipos de detector para cobrir toda região de 185 a $2500 \mathrm{~nm}$. Uma lâmpada de tungstênio é utilizada para a região do visível e infravermelho (VIS-IR) e uma lâmpada de Deutério para a região do ultravioleta (UV). Os detectores são uma fotomultiplicadora com resposta na faixa do UV-VIS e um detector de PbS com resposta na região do IR.

$\mathrm{O}$ equipamento Cary-17 possui um monocromador sofisticado para selecionar o comprimento de onda da fonte de luz utilizada. Outra parte importante do equipamento 
é o sistema divisor de feixe, o qual divide o feixe de luz selecionado pelo monocromador em dois, sendo que um passa pela amostra e o outro que serve como referência.

\subsubsection{Espectroscopia de Absorção no infravermelho (FTIR)}

Esta técnica envolve os mesmos princípios da absorção óptica no visível, com a diferença que as transições envolvidas não são mais eletrônicas e sim dos movimentos vibracionais moleculares da matéria que possuem freqüências na região do infravermelho. As oscilações induzidas por certos modos vibracionais da matéria fornecem um significado para a questão da absorção da radiação infravermelha quando as freqüências estão em ressonância. Nos experimentos de absorção no infravermelho, a intensidade do feixe da radiação infravermelha é medida antes $\left(I_{o}\right)$ e depois $(I)$ de sua interação com a amostra em função da frequêencia da luz. $O$ objetivo do experimento de infravermelho é determinar a razão da intensidade $I / I_{o}$ como função da frequêencia da luz. O gráfico dessa razão em função da freqüência é o espectro no infravermelho, que é usualmente apresentado em três formas: transmitância, refletância ou absorbância.

As medidas de Espectroscopia no infravermelho (FTIR) foram realizadas utilizando-se um espectrofotômetro de FTIR marca Nicolet Magna 850 a fim de determinar os tipos ligações químicas presentes nos vidros no intervalo de 4000 a 400 $\mathrm{cm}^{-1}$.

\subsubsection{Espectroscopia de Emissão Óptica no UV-VIS}

Emissão óptica ou Luminescência é o fenômeno no qual um átomo emite luz quando seus elétrons são excitados de um nível de mais baixa energia para um nível de mais alta energia e após o decaimento desses elétrons para o nivel inicial ocorre a emissão de fótons. Para que os elétrons sejam excitados de um nível para outro é necessário uma fonte de excitação externa, como por exemplo, uma descarga elétrica ou mesmo calor, aplicado a um material, fazendo com que este emita luz [117]. Existem vários tipos de processos onde ocorre luminescência gerada por diferentes fontes de excitação, dentre estes podemos citar a termoluminescência, eletroluminescência, 
sonoluminescência, triboluminescência e fotoluminescência. Em nosso caso trabalhamos com o efeito de fotoluminescência que consiste em emissão de luz pela amostra devido à excitação gerada por laser.

$O$ espectro de luminescência dos filmes foi obtido através de excitação com Laser de $\mathrm{Kr}^{+}$, e os dados coletados por uma montagem que consiste de um monocromador, uma fotomultiplicadora Hamamatsu R446, um lock-in modelo 124A da Princeton Applied Research e um modulador eletro-mecânico New Focus 3501, conectados a um microcomputador através de interface serial operando com um programa de aquisição de dados que controla o monocromador e o lock-in. $\mathrm{O}$ sinal de luminescência de filmes quando excitados por Laser é bastante fraco devido possuírem um volume de material excitado muito pequeno. Para minimizar as perdas de luz e melhorar a captação de sinal de luminescência dos filmes utilizamos um monocromador Thermal Jarrel-Ash Monospec 27 de 0,27 m de foco para a montagem do sistema. A excitação é feita pelo feixe Laser que incide de forma rasante à superfície do filme produzindo um risco de luminescência que é captada por uma lente e focalizada sobre a fenda de entrada do monocromador (Figura 35).

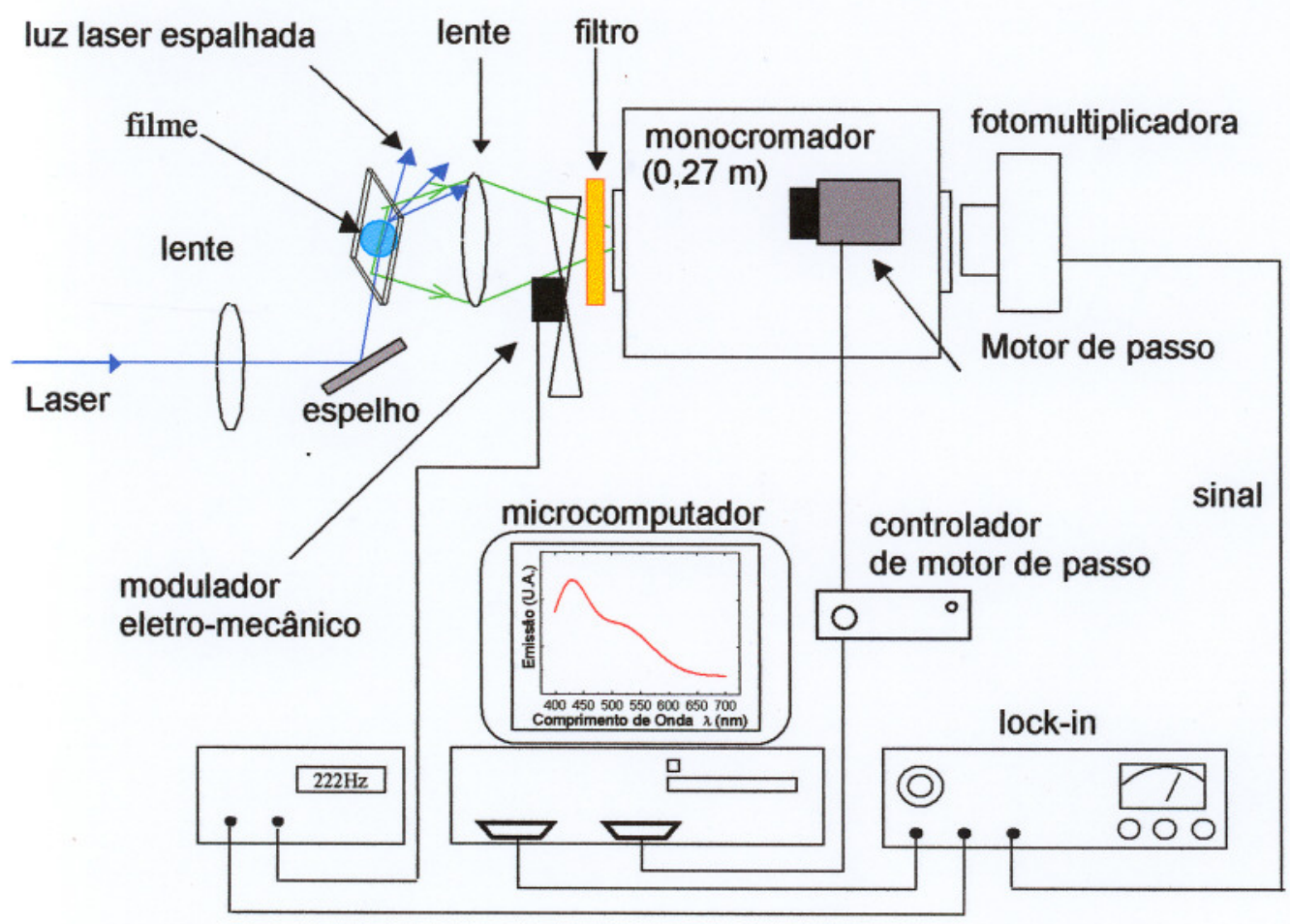

Figura 35 - Diagrama esquemático do arranjo experimental utilizado para colher os espectros de luminescência dos filmes. 


\subsubsection{Técnicas para determinação Estrutural}

\subsubsection{Difração de Raios-X (XRD)}

A difração de Raios- $X$ consiste em incidir um feixe de raios- $X$ monocromático sobre uma amostra e verificar o padrão de difração gerado pelos planos ou "arranjos" atômicos da amostra durante a passagem de radiação para diferentes ângulos de incidência. Esta técnica para a caracterização de vidros é geralmente utilizada para identificar a formação ou não de fases cristalinas. Em difratogramas padrões de materiais vítreos é observada a presença de um "halo" difuso de difração, pois a ausência de periodicidade na rede vítrea não permite a existência de máximos definidos de difração. Este "halo" pode ser atribuído à ordem de curto alcance (10-15 $\AA$ ) existente nos vidros.

A técnica de difração de raios-X também é muito utilizada para identificar diferentes fases durante processos de cristalização em vidros como seqüência de cristalização de fases. A partir dai é possível interpretar os mecanismos de formação e cristalização, além de propiciar conclusões quanto à estrutura inicial do vidro [118]. Para caracterização dos vidros utilizou-se um difratômetro de Raios-X da Rigaku Rotaflex, que opera com radiação da linha $\mathrm{K}_{\alpha}$ de emissão do $\mathrm{Cu}$ e comprimento de onda de $1,5406 \AA$. Os espectros foram obtidos num intervalo angular com $2 \theta$ variando de 5 a 100 graus com resolução de 0,02 graus e tempo de varredura de 2 graus por minuto.

\subsubsection{Espectroscopia de Absorção de Raios-X (XAS)}

Desde o desenvolvimento de aceleradores síncrotron ${ }^{\mathrm{iii}}$ nos anos 70 e a crescente pesquisa em espectroscopia utilizando radiação síncrotron, grandes avanços foram realizados para uso de tal técnica como uma ferramenta para o estudo de propriedades de materiais amorfos $[119,120]$. Devido às importantes características da radiação síncrotron gerada por tais aceleradores como grande faixa espectral (desde radiação

\footnotetext{
iii Acelerador Sincrotron é definido como equipamento onde elétrons são acelerados através de campos eletromagnéticos em um caminho circular fixo ou "anel" e são mantidos acelerados nesta trajetória circular. Radiaçäo Sincrotron é a luz emitida por elétrons com altas energias quando acelerados a velocidades relativísticas por um campo magnético.
} 
visível até raios- $X$ ), alta intensidade, coerência e polarização espectral muito definidas, hoje é possivel realizar experimentos que envolvem técnicas como a Espectroscopia de Absorção de Raios-X (XAS) para o estudo estrutural de materiais amorfos, com métodos de análise bastante aprofundados como Estrutura Fina da Absorção de Raios-X (XAFS) e Estrutura Próxima a Borda de Absorção de Raios-X (XANES).

$O$ desenvolvimento de facilidades da luz síncrotron como o do Laboratório Nacional de Luz Síncrotron (LNLS)-Campinas - SP, gerou um aumento na pesquisa em muitas áreas da radiação síncrotron no país, tais como fisica e química do estado sólido, estudos de catalisadores e de suas variações estruturais, eletroquímicas de superficie e materiais magnéticos e dicroísmo circular magnético de raios- $\mathrm{X}$. Tais pesquisas estão fornecendo novas informações relevantes para entender as propriedades fisicas de materiais amorfos.

\subsection{As técnicas de XANES e XAFS}

Radiação com energia na faixa de raios-X $(\sim 0.5$ a $500 \mathrm{KeV})$ é absorvida por toda matéria através do efeito fotoelétrico. Neste processo, um fóton de raio-X é absorvido por um elétron das camadas mais internas de um átomo, como elétrons dos niveis 1s ou 2p. Para ocorrer absorção de um fóton por um nível eletrônico das camadas mais internas do átomo, a energia desse nível deve ser menor que a energia do raio- $\mathrm{X}$ incidente. A energia extra neste processo de absorção gera um fotoelétron que é ejetado do átomo absorvedor para o contínuo, podendo este percorrer diferentes caminhos entre os átomos vizinhos e afetando diretamente a absorção de raios- $\mathrm{X}$ no material. As implicações deste processo de espalhamento de elétrons no material em função da energia do raio-X de excitação, dão origem ao espectros de XAFS e XANES os quais são discutidos a seguir.

Durante a absorção, um átomo é dito no estado excitado quando um dos níveis eletrônicos de camadas mais internas (K ou L) possui buraco eletrônico devido à ejeção de um elétron para o contínuo. Este estado excitado irá decair tipicamente em poucos femto segundos $\left(10^{-12} \mathrm{seg}\right.$.) após o evento de absorção. 


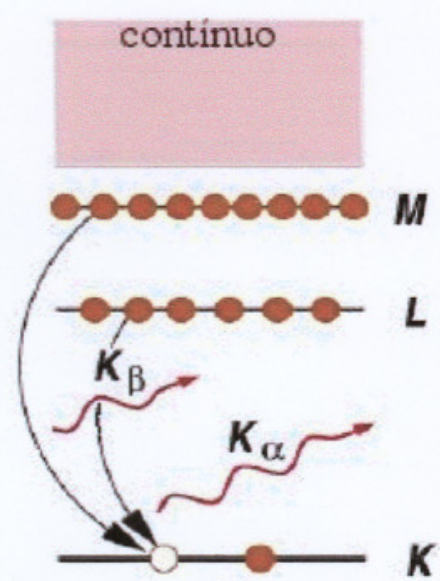

(a)

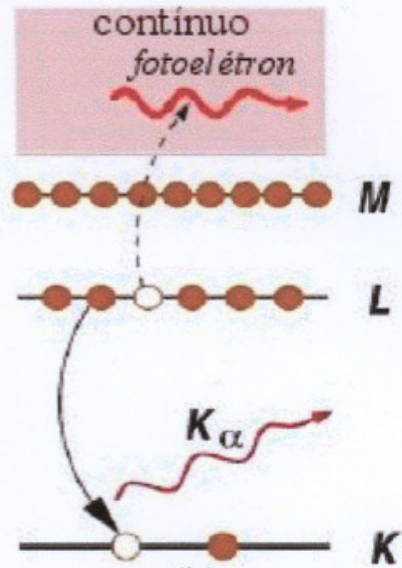

(b)

Figura 36 - Diagrama esquemático do decaimento do estado excitado após o efeito de absorção de raios-X. a) Fluorescência de raios-X; b) Efeito de emissão de elétron Auger e fluorescência.

Há dois mecanismos principais para o decaimento do estado excitado atômico apos o evento de absorção do raio-X. No primeiro mecanismo ocorre a fluorescência de raios- $\mathrm{X}$, onde por exemplo um elétron da camada $\mathrm{L}$ ou $\mathrm{M}$ decai e preenche um buraco eletrônico da camada $\mathrm{K}$, emitindo um fóton de raio-X com energia bem definida (emissão de linhas de raios-X: $K_{\alpha}, K_{\beta}$ ) como ilustra a Figura 36-a. A fluorescência emitida por esse mecanismo é característica do átomo, e pode ser usada para identificar os átomos de um sistema e para quantificar suas concentrações. No segundo processo ocorre o efeito Auger, na qual um elétron decai de um nível superior preenchendo um buraco eletrônico da camada $\mathrm{K}$ emitindo um fóton $\mathrm{K}_{\alpha}$, e parte dessa energia faz com que um segundo elétron de uma camada superior (L por exemplo) seja ejetado para o contínuo gerando o chamado fotoelétron ou elétron Auger (Figura 36-b). Na faixa de energias $>2 \mathrm{keV}$ a fluorescência de Raios-X é muito mais provável do que emissão de elétrons Auger, mas para energias menores o processo Auger é dominante.

Ambos processos são usados para medir o coeficiente de absorção de raios-X $(\mu)$ de uma amostra e extrair o sinal de XAFS. O sinal de XAFS pode ser medido ou em geometria de transmissão ou fluorescência (a geometria para medida Auger é tipicamente a mesma usada para fluorescência). A absorção é descrita pela lei de Lambert, $I=I_{0} e^{-\mu t}$, onde $I_{0}$ é a intensidade de raios-X inicial incidente sobre a mostra, $I$ é a intensidade transmitida e $t$ é a espessura da amostra como mostra a Figura 37. A absorbância é definida como $\log \left(I_{0} I\right)$, sendo $\mu(E)=\log \left(I_{0} I\right) / t$ o coeficiente de absorção 
linear que é uma função da energia de fóton. O coeficiente de absorção como função da energia $(E)$ depende também da densidade da amostra $(\rho)$, do número atômico $(Z)$, da massa atômica $(A)$ e pode ser expresso como $\mu \approx \rho Z^{4} / A E^{3}$. A dependência do coeficiente de absorção de uma amostra em geometria de transmissão é dada por $\mu(E) \approx \log \left(I_{0} I\right)$ e para fluorescência (ou emissão Auger) como $\mu(E) \approx I_{f} / I_{0}$ onde $I_{f}$ é a intensidade da fluorescência.

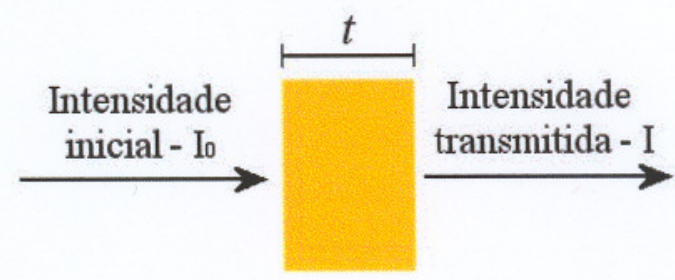

Figura 37 - Esquema ilustrativo sobre a definição de absorção de um feixe de luz que atravessa uma amostra de espessura $t$, onde absorbância é definido como $\log \left(I_{\delta} I\right)$.

A Espectroscopia de Absorção de Raios-X (XAS) é uma ferramenta estrutural vastamente utilizada para a investigação da ordem local na matéria condensada $[121,122]$. A analise de espectros de absorção de raios- $\mathrm{X}$ de um material, bem como a posição da borda de absorção raios-X e as oscilações na estrutura fina apresentada acima da borda, é possível determinar parâmetros estruturais que descrevem a ordem local ao redor desses átomos. Um espectro de absorção de raios-X é tipicamente dividido em dois regimes dos quais pode-se extrair diferentes informações a respeito do material analisado:

1) Estrutura Próxima a Borda de Absorção de Raios-X (X-ray Absorption Near Edge Structure -XANES), localizada a partir da borda até $30 \mathrm{eV}$ acima dela.

2) Estrutura Fina da Absorção de Raios-X Estendida (Extended X-Ray Absorption Fine Structure - EXAFS) região de $30 \mathrm{eV}$ acima da borda até $\sim 1000 \mathrm{eV}$.

A Figura 38 mostra um espectro típico de XAFS da borda $\mathrm{K}$ para o átomo de ferro, na forma de coeficiente de absorção $\mu(E)$ vs. Energia, onde as regiões de XANES e EXAFS estão indicadas.

Apesar das duas regiões do espectro refletir a mesma origem física, esta distinção é conveniente para motivos de interpretação de resultados. XANES é fortemente sensível ao estado de oxidação formal e tipo de coordenação do átomo absorvedor, enquanto EXAFS é mais sensível a variações nas distâncias, número de coordenação e espécies vizinhas do átomo absorvedor. 


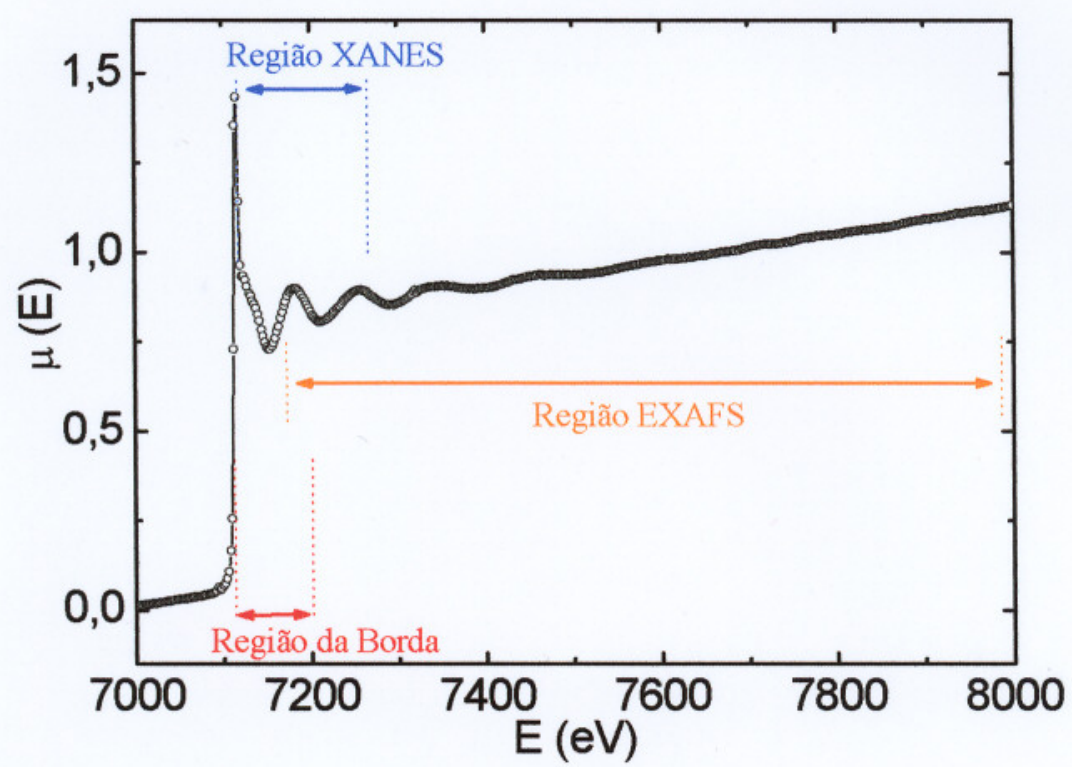

Figura 38 - Espectro típico de XAFS da borda K para o átomo de ferro, na forma de coeficiente de absorção $\mu(E)$ vs. Energia, onde as regiões de XANES e EXAFS estão indicadas.

Uma forma simplificada de entender o princípio físico envolvido na formação do espectro é considerar a região da borda de absorção baseada na hipótese de que o único mecanismo de interação é a ejeção de um elétron $\mathrm{K}$ para o contínuo. A posição da borda corresponde à energia de ligação do elétron ejetado. Por outro lado, os fotoelétrons podem ser analisados como ondas esféricas emitidas e retroespalhadas entre os átomos vizinhos do material, interferindo entre si. Este fenômeno de interferência entre ondas emitidas e retroespalhadas gera as oscilações da absorção acima da borda, ou seja, a estrutura fina da absorção de raios-X. Neste processo de interferência o padrão formado varia entre interferência construtiva total (duas ondas totalmente em fase) ou destrutiva total (duas ondas fora de fase). Uma vez que o caminho percorrido por duas ondas define sua fase final, através da técnica de EXAFS pode ser obtida a distância entre os átomos vizinhos que está diretamente relacionada com o padrão de interferência entre estas ondas.

Sobre a técnica de XANES, este efeito apresenta um sinal de absorção muito maior do que o observado para EXAFS, e dessa forma pode ser realizado em concentrações muito baixas e em condições de imperfeição de amostra. A interpretação 
dos espectros de XANES é mais complicada pelo fato de não haver uma descrição simplesmente analítica para esta região do espectro. Porém muita informação química e estrutural pode ser extraída da região XANES, tais como a valência formal de elementos (muito difícil de se obter por meios não destrutivos) e ambiente de coordenação. A Figura 39 mostra espectros XANES para vários compostos de ferro. Claramente, a posição e forma da borda de absorção são sensíveis ao estado de valência formal, tipo de ligante, e ambiente de coordenação. XANES também pode ser utilizada como ferramenta para identificar diferentes fases partindo-se de padrões conhecidos.

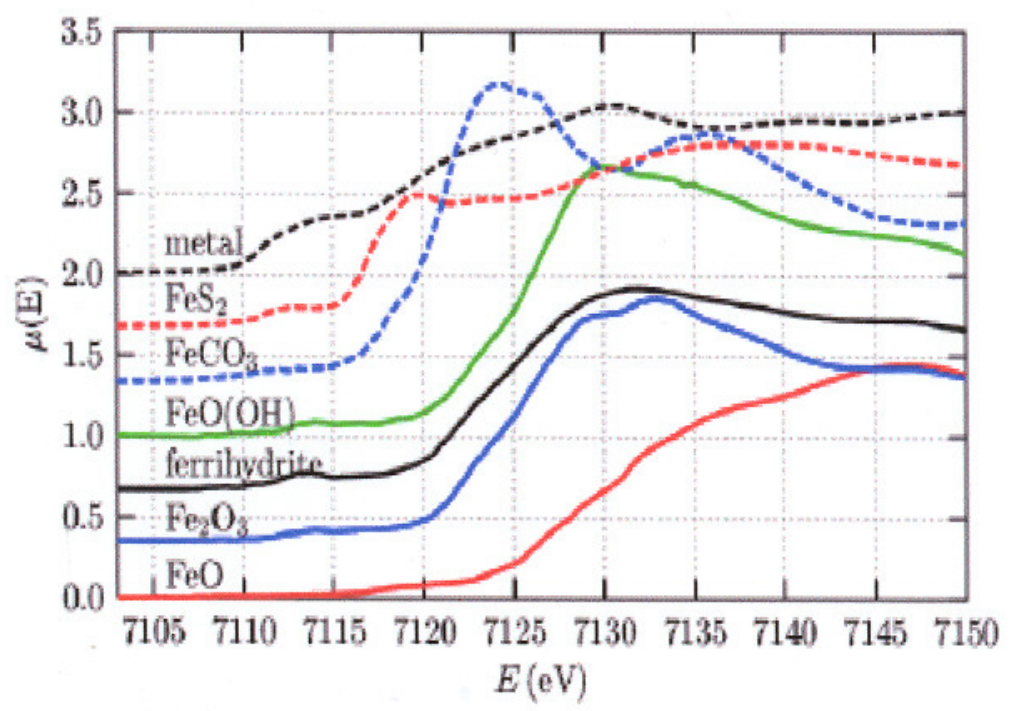

Figura 39 - Espectro de XANES da borda K do ferro, para vários compostos [123].

Para muitos sistemas, as análises de XANES baseado em combinações lineares de espectros conhecidos de compostos padrões são suficientes para prover razões entre valências e fases diferentes. A Figura 40 mostra um exemplo de aplicação da técnica de XANES para obtenção de dados sobre coordenação química em compostos de fósforo. As posições das ressonâncias A, B e C indicam diferenças nas distâncias internucleares entre diferentes grupos fosfatos. Informações iniciais para interpretação dos espectros podem ser obtidas através da utilização do fosfato de cálcio cristalino para obtenção de um espectro padrão. 


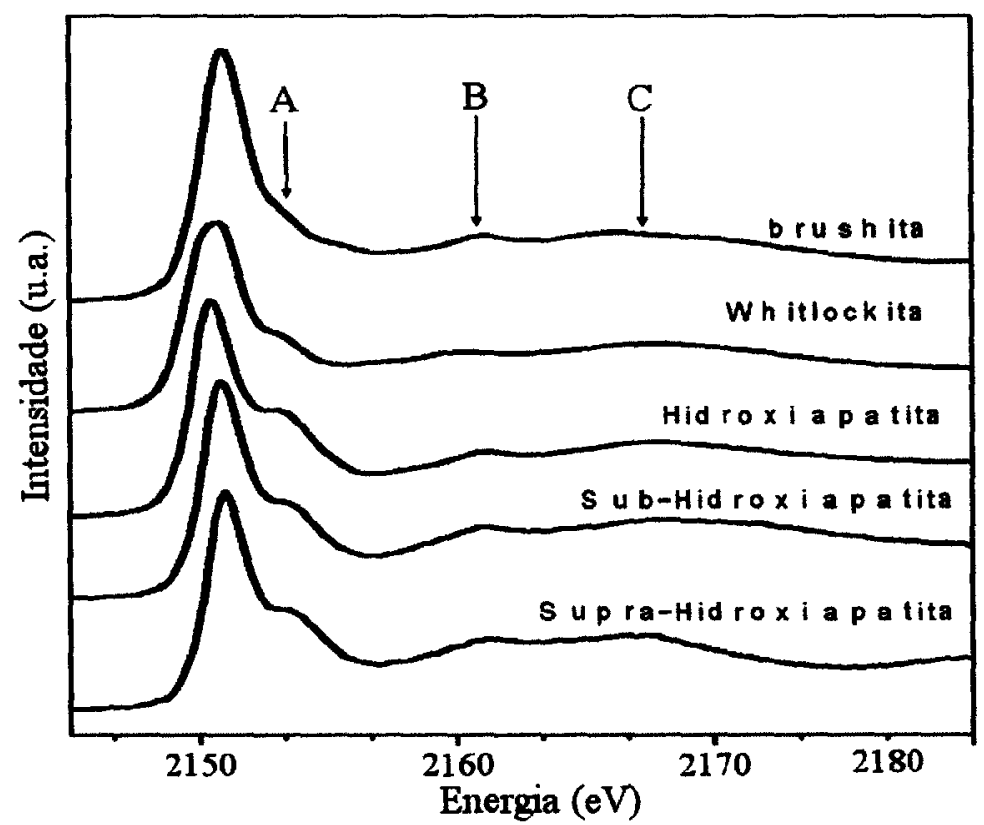

Figura 40 - Exemplo de análise para determinação da estrutura local dos átomos de fósforo em amostras de fosfatos de cálcio através de XANES na borda $\mathrm{K}$ do fósforo $(2149 \mathrm{eV})$. As posições das ressonâncias A, B e C indicam diferenças nas distâncias internucleares. Os compostos brushita, whitlockita, sub e supra-hidroxiapatita, são relativas a fases hidroxiapatita com diferentes concentrações de fósforo.

Apesar da falta de expressões analíticas que facilitem a interpretação dos espectros de XANES, tal técnica pode ser descrita qualitativamente (ou às vezes quantitativamente) em termos de: Química de Coordenação (regular, octaédrica distorcida, tetraédrica, etc); Orbitais moleculares (hibridização p-d, etc); Estrutura de bandas (densidade de estados eletrônicos); Espalhamentos múltiplos (múltiplos espalhamentos do fotoelétron).

\subsubsection{Ressonância Magnética Nuclear (NMR)}

A Ressonância Magnética Nuclear consiste na absorção seletiva de ondas de radio (na faixa de $\mathrm{MHz}$ ) por certos núcleos atômicos submetidos a um forte campo magnético estacionário. Este fenômeno foi observado em 1946 nos EUA pelos físicos Felix Bloch e Edward M. Purcell independentemente, onde verificaram tal efeito em todos os núcleos estáveis com momento magnético diferente de zero. 
Um átomo com spin nuclear apresenta um momento magnético alinhado ao longo do eixo do spin e uma importante aplicação do magnetismo nuclear é a ressonância magnética. Nesta técnica o material é colocado em um forte campo que tende a orientar seus spins, que alinhados irão precessionar ao redor do eixo na direção do campo, gerando uma magnetização do material nesta direção (Figura 41-a).

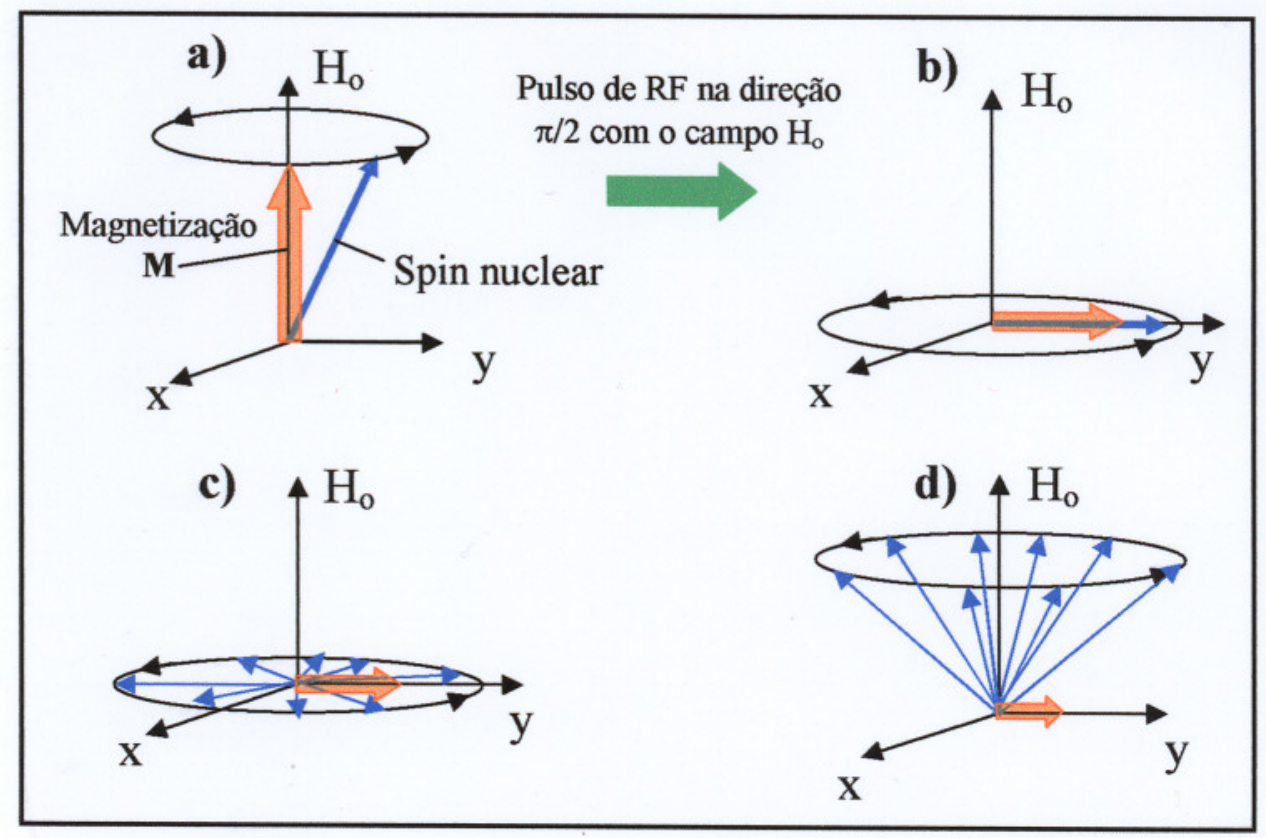

Figura 41 - a) Os spins nucleares se orientam e precessionam na direção do campo magnético externo Ho. b) Com um pulso de RF perpendicular a Ho e na frequeência de ressonância dos núcleos os spins orientam-se e giram no plano xy. c) diminuição da magnetização no plano xy. d) retorno dos spins à posição original após o pulso de RF (tempo de relaxação).

Quando o material sob o forte campo magnético é irradiado com pulsos de ondas de rádio externas com a mesma freqüência de precessão dos spins, a energia das ondas de rádio será absorvida, fazendo com que os spins entrem em ressonância, e a magnetização total do material mudará para a direção na qual foi aplicada a rádio freqüência (Figura 41-b). Após o pulso de radio freqüência, como cada núcleo da amostra "sente" um campo ligeiramente diferente e os spins giram um pouco fora de fase e a magnetização no plano xy começa a diminuir (Figura 41-c). Por último os spins começam a retornar à sua posição original um tempo após o pulso de RF (tempo de relaxação) (Figura 41-d).

Essa absorção seletiva, chamada ressonância, é produzida sintonizando-se a radio freqüência com a freqüência de precessão dos spins nucleares. Medindo-se a variação da magnetização do material no tempo (Figura 42-a), após a aplicação de um 
curto pulso de rádio frequeência, é possível obter várias informações sobre a amostra analisada [124].
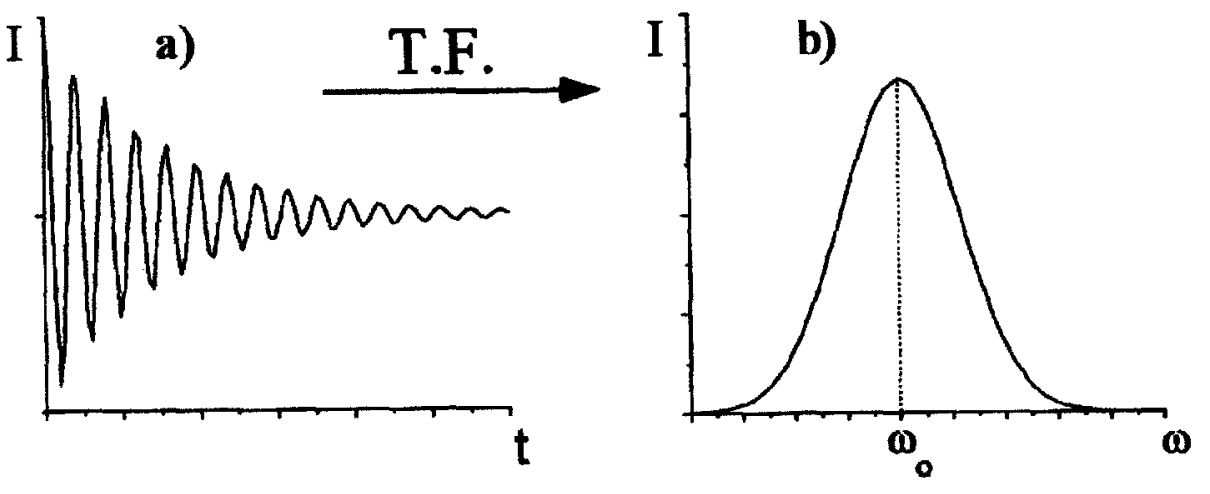

Figura 42 - a) Sinal captado pela bobina que envolve a amostra, mostrando a variação da magnetização dos spins em função do tempo. b) Transformada de Fourier da variação da magnetização fornecendo o gráfico de Intensidade vs. Freqüência de Ressonância.

Nos experimentos de RMN, o espectrômetro é composto basicamente de um potente imã que gera o campo magnético estático, e de bobinas que são utilizadas para a incidência de radio frequêencia sobre a amostra e também para captar o sinal emitido pela amostra.

O espectro captado pelo equipamento após alguns tratamentos matemáticos, apresenta picos que podem ser bastante estreitos apresentados na forma gráfica de intensidade em função da frequeência de ressonância em MHz (Figura 42-b). Através destes resultados pode-se extrair informações como: tipos de ligações químicas, composição local, ângulo de ligações químicas, coordenação atômica ao redor de um núcleo, etc.

\subsection{A técnica de MAS-NMR}

A mais importante conseqüência da seletividade da Ressonância Magnética é a possibilidade de se medir deslocamentos químicos, ou seja, pequenos deslocamentos nas linhas de ressonância de spins nucleares de mesmas espécies contidas em diferentes ambientes moleculares. A origem fisica dessa técnica é relacionada com o pequeno deslocamento das freqüências de ressonância para maiores ou menores valores, devido a influencia das nuvens eletrônicas ao redor das moléculas observadas, causando uma 
blindagem que faz com que tais moléculas "sintam" campos magnéticos ligeiramente diferentes uma das outras dependendo do ambiente químico no qual se localizem. Como estes deslocamentos nas freqüências são pequenos quando comparados com valores da ordem de $\mathrm{MHz}$, as unidades de medidas de deslocamentos químicos são apresentados na escala de partes por milhão (ppm), ou seja, são deslocamentos em freqüência da ordem de KHz.

Através da técnica de RMN com Rotação em Ângulo Mágico (Magic Angle Spinning Nuclear Magnetic Ressonance; MAS-NMR) na freqüência do fósforo é possível se obter informações a respeito do ambiente químico em torno desse elemento na matriz vítrea. No sistema estudado o fósforo se apresenta ligado a oxigênios formando grupos $\left(\mathrm{PO}_{4}\right)^{3-}$ que podem se ligar entre si formando longas cadeias poliméricas no vidro.

As medidas foram realizadas num espectrômetro VARIAN Unity INOVA operando a $400 \mathrm{MHz}$ e campo magnético de $9,4 \mathrm{~T}$, com a amostra em rotação de $6,5 \mathrm{kHz}$ em ângulo mágico. A função da rotação da amostra em ângulo mágico é aumentar a separação das linhas espectrais obtidas, devido à diminuição dos efeitos de orientação dos núcleos de ${ }^{31} \mathbf{P}$ com o campo magnético. Com a rotação a parte angular da interação de deslocamento químico, que define a freqüência de RMN, é promediada a zero e é possivel ver somente a parte da interação que não depende da orientação e sim da vizinhança eletrônica do núcleo. $O$ resultado é um estreitamento grande da linha que permite que núcleos com diferentes disposições de nuvens eletrônicas, ou seja, diferentes configurações de grupos fosfatos possam ser distinguidas.

As medidas de Ressonância Magnética Nuclear (RMN) foram realizadas em cooperação com o Professor Tito José Bonaganba do IFSC-USP. Através dos espectros de MAS-RMN é possível obter informações importantes sobre a formação vítrea como formação de fase microcristalina para determinadas composições do sistema vítreo $\left.x\left[\mathrm{SbPO}_{3}\right)_{3}\right]_{n}-(100-x) \mathrm{Sb}_{2} \mathrm{O}_{3}$. 


\subsubsection{Ressonância Paramagnética Eletrônica (RPE)}

A Ressonância Paramagnética Eletrônica (Electron Paramagnetic ResonanceEPR), é um ramo da espectroscopia onde radiação eletromagnética (usualmente microondas) é absorvida por moléculas, ions, ou átomos que possuam elétrons com spins desemparelhados, isto é, spin eletrônico $S>0$. Um grande número de materiais contém elementos paramagnéticos, que podem ser desde íons de metais de transição, impurezas em semicondutores, ou até elétrons aprisionados em defeitos estruturais gerados por radiação [125].

Um dos fundamentos da técnica de RPE é a identificação das espécies químicas estudadas. Em casos onde duas ou mais espécies paramagnéticas coexistem, as linhas espectrais de cada espécie pode ser simultaneamente observada. Esta capacidade da técnica de RPE é resultado da grande sensibilidade do momento magnético de spins eletrônicos a campos magnéticos locais na amostra. Estes campos geralmente surgem de momentos magnéticos nucleares dos vários núcleos atômicos presente no meio. Como exemplo podemos citar átomos intersticiais (ou íons) dentro de um cristal ou matriz vitrea, ou núcleos (como nitrogênio) dentro de uma estrutura molecular que também contém elétrons desemparelhados. A técnica de RPE é muito sensível à natureza química (i.e. eletrônica) da matéria, com capacidade de detectar concentrações de spins de ppb (partes por bilhão). Na pratica este limite de detecção é um pouco afetado pelos efeitos de largura de linhas espectrais. Dessa forma a técnica de RPE permite o estudo de estruturas internas com grandes detalhes.

No RPE a amostra é imersa em um campo magnético que pode ser variado até $10^{4}$ Gauss ( 1 Tesla $=10^{4}$ Gauss) e exposta à radiação de microondas $(\mathrm{GHz})$, onde se mede a absorção de microondas pelos elétrons da amostra. Pela aplicação do campo magnético B sobre um material contendo espécies paramagnéticas, o momento magnético individual que surge via spin eletrônico de elétrons desemparelhados pode ser orientado paralelo ou antiparalelo ao campo aplicado. Isto cria níveis distintos de energia para elétrons desemparelhados, gerando absorção de microondas. A condição de ressonância ocorre quando o campo magnético e a freqüência de microondas coincidem, isto é, quando a energia de microondas corresponde a diferença de energia $\Delta \mathrm{E}$ entre dois estados de spin eletrônicos como mostra a Figura 43. A equação que descreve a absorção de microondas entre dois estados de spin eletrônicos é dada por 
$\Delta \mathrm{E}=h v=\mathrm{g}_{\mathrm{e}} \mu_{\mathrm{B}} \mathrm{B}_{0}$, onde $h$ é a constante de Planck, $v$ é a freqüência de microondas, $\mathrm{g}_{\mathrm{e}}$ é o fator Zeeman, $\mu_{\mathrm{B}}$ o magnéton de Bohr e B é o campo magnético aplicado.

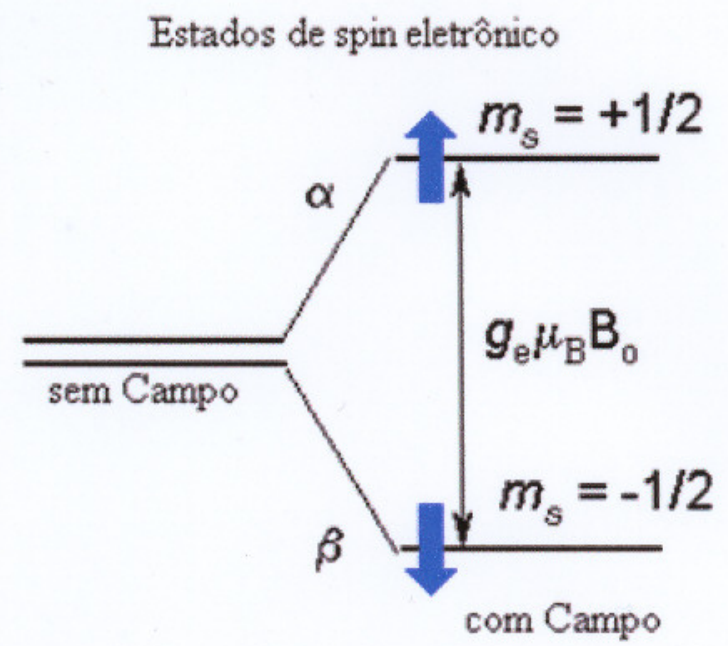

Figura 43 - Representação da diferença de energia $\Delta \mathrm{E}=h \mathrm{v}=\mathrm{g}_{\mathrm{e}} \mu_{\mathrm{B}} \mathrm{B}_{0}$ entre dois estados de spin eletrônicos gerados por aplicação de campo magnético $\mathrm{B}_{0}$.

Os espectrômetros consistem de um eletroímã com fontes de alimentação para gerar e modular um campo magnético uniforme, e também componentes que geram e detectam a radiação de microondas. Os espectros de RPE são geralmente apresentados na forma da primeira derivada do sinal de absorção de microondas em função do campo magnético aplicado, e pela interpretação dos espectros é possível extrair informações estruturais da amostra analisada.

As medidas de RPE foram realizadas em colaboração com o Prof. Claudio Magon do Grupo de Ressonância Magnética. Os espectros de RPE de onda contínua (CW) e pulsado (ESEEM) foram obtidos em um espectrômetro Bruker Elexsys E-580 FT/CW X-band equipado com controlador de temperatura Oxford para a faixa de temperatura de 4-300K. Vidros dopados com $\mathrm{Cu}^{2+}$ na forma de pó e filmes na forma de pó do mesmo sistema irradiado e não irradiado com UV foram medidos. $\mathrm{O}$ íon $\mathrm{Cu}^{2+}$ foi utilizado como sonda estrutural nos vidros e filmes por ser um íon paramagnético que apresenta intenso sinal de RPE quando comparado com vidros dopados com $\mathrm{Mn}^{2+} \mathrm{e}$ $\mathrm{Cr}^{3+}$. A concentração ótima de $\mathrm{Cu}^{2+}$ incorporada no sistema vítreo foi de 2 moles \%, para garantir filmes com concentração de cobre razoável após as perdas inerentes do processo de deposição de filmes por canhão de elétrons. 


\subsubsection{Técnicas de Gravação Holográfica}

A técnica de gravação holográfica permite a produção de estruturas com dimensões próximas ao comprimento de onda da luz, tal como redes holográficas de relevo gravadas em um material através de um padrão de interferência criado com luz laser $[126,127]$. A Holografia é geralmente relacionada com desenvolvimento de meios para armazenamento óptico, mas é usada também como ferramenta para o estudo das mudanças ópticas induzidas por luz em materiais fotossensiveis.

Em vidros e filmes existem diferentes métodos para a produção de redes de difração, por exemplo, técnica de troca iônica [128], deposição através de vapor químico (como PECVD [129], FHD [130]) seguido por ataque químico, gravação por incidência de luz através de uma máscara fotolitográfica [131], ou através da gravação direta de padrão de interferência com radiação UV [132]. A vantagem da gravação direta com radiação UV é que não há necessidade de usar a fotolitografia, que envolve um processo de fabricação de mascaras com alto custo. Para gravação de redes holográficas através de irradiação com UV foram utilizados filmes de vidros a base de polifosfato de antimônio. A vantagem do uso de filmes e vidros como material para o registro de redes de difração são: procedimento de preparação relativamente fácil $\mathrm{e}$ baixo custo, vasta gama de composições e a possibilidade da introdução de um grande número de componentes e íons ativos. Devemos frisar que seria interessante a produção de filmes por evaporação dos elementos precursores sem a necessidade da etapa de fusão e preparação dos vidros, porém alguns testes mostraram que a evaporação dos pós precursores prensados na forma de pastilhas gera o efeito de evaporação incongruente dos materiais, causando perda de estequiometria e filmes inomogêneos [133].

\subsubsection{Gravação de Redes e Medidas de Eficiência}

Quando dois conjuntos de ondas planas monocromáticas igualmente polarizadas de igual intensidade interceptam-se, um padrão de interferência será formado na região de intersecção se ambos conjuntos de ondas possuem o mesmo comprimento de onda e coerência. A distribuição de intensidades no padrão de interferência formado será um conjunto de franjas igualmente espaçadas (linhas claras e escuras), onde as intensidades 
combinadas variam na forma senoidal se varremos o padrão ao longo de uma linha. Os centros das franjas adjacentes, isto é, as linhas de máxima intensidade, são separadas pela distância $\Lambda=\lambda(2 \operatorname{sen} \theta)$, onde $\theta$ é metade do ângulo entre os feixes que se interceptam e $\lambda$ o comprimento de onda dos mesmos. Dessa forma um material fotossensível exposto a este perfil de interferência gravará o padrão de franjas, uma vez que as regiões de intensidade zero deixarão o material sem exposição enquanto que as regiões de máxima intensidade deixarão o material exposto à luz.

Em nosso caso o padrão de interferência ou "holograma" foi produzido utilizando uma montagem tipo espelho de Lloyd como ilustrado na Figura 44. Nesta montagem o holograma é formado pela separação de um feixe laser em dois feixes equivalentes usando um espelho plano. $O$ mesmo espelho divide o feixe laser de gravação em dois feixes iguais e os reflete superpostos sobre a superficie da amostra, a qual é fixada na região de interferência, formando $90^{\circ}$ com a extremidade do espelho (Figura 44).

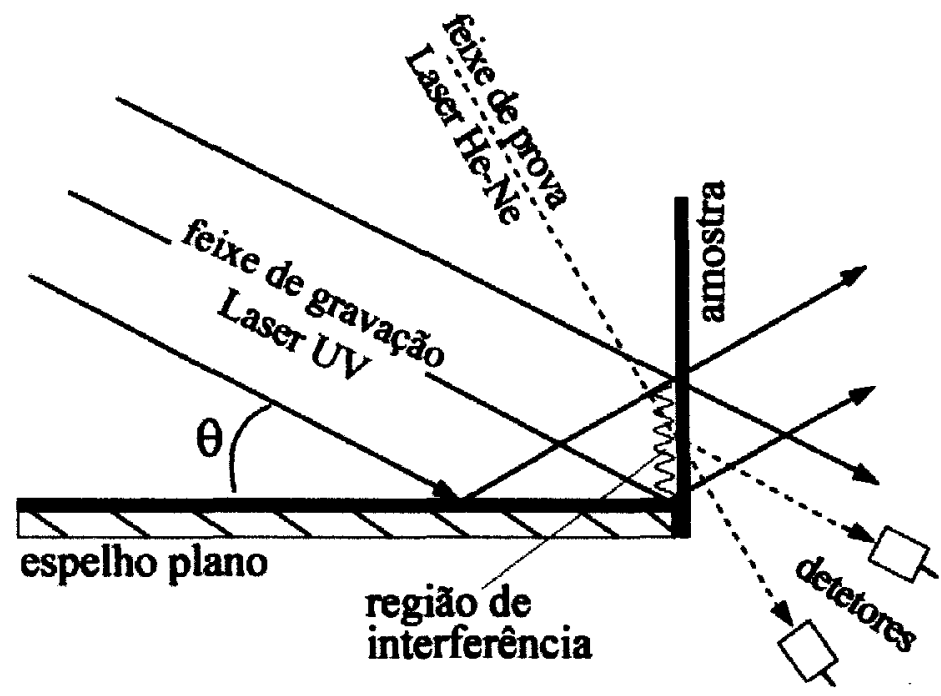

Figura 44 - Montagem do espelho de Lloyd para gravação de redes holográficas e medidas de eficiência de difração em tempo real em filmes.

Neste caso o período da rede gravada pelo padrão de interferência será definido pelo espaçamento de franjas $\Lambda=\lambda /(2 \operatorname{sen} \theta)$, onde $\theta$ é o angulo formado entre o eixo de propagação do feixe de gravação e o plano do espelho. Com esta montagem é possível medir a eficiência de difração da rede que está sendo gravada sobre o material, pelo monitoramento da intensidade de difração de primeira ordem de um feixe de prova de He-Ne transmitido através do filme durante a gravação. Usando um sistema de 
aquisição de dados composto por 2 amplificadores lock-in (SR-530), dois detectores de silício, e um microcomputador de controle a eficiência de difração das redes gravadas foi medida em função do tempo. Para a gravação das redes utilizamos um laser de $\mathrm{Kr}^{+}$ (Coherent, modelo Innova) com comprimento de onda em 350,7 nm. O feixe do laser de $\mathrm{Kr}^{+}$apresenta perfil de intensidade gaussiano e diâmetro de aproximadamente $1,6 \mathrm{~mm}$ $\left(1 / \mathrm{e}^{2}=1,6 \mathrm{~mm}\right)$ e potência nominal máxima de saida de 2,0 Watts. Utilizamos em nossos experimentos potência nominal variando de 50 a $600 \mathrm{~mW}$ que corresponde a densidade de potência de 2,5 a $30 \mathrm{~W} / \mathrm{cm}^{2}$, respectivamente, calculando-se a área do feixe considerando o diâmetro efetivo de $1,6 \mathrm{~mm}$.

A eficiência de difração $(\eta)$ de redes holográficas é definida como $\eta=I_{d} I_{t}$, onde $I_{d}$ é a intensidade do feixe de primeira ordem de difração do laser de prova e $I_{t}$ é a intensidade do feixe de prova transmitido através da amostra [134]. 


\section{RESULTADOS EXPERIMENTAIS E ANALISE}




\subsection{Estudo do Sistema Vitreo $x\left[\mathrm{Sb}\left(\mathrm{PO}_{3}\right)_{3}\right]_{n}-(100-x) \mathrm{Sb}_{2} \mathrm{O}_{3}$}

Nesta seção estudamos detalhadamente o sistema vítreo $x\left[\mathrm{Sb}\left(\mathrm{PO}_{3}\right)_{3}\right]_{n}-(100-$ x) $\mathrm{Sb}_{2} \mathrm{O}_{3}$, variando a concentração, $x$, de 5 a 40 moles $\%$ em passos de $5 \%$. Dessa forma determinamos a região de formação vítrea, complementando com medidas de Calorimetria Exploratória Diferencial (DSC), Absorção óptica no Infravermelho (FTIR), Difração de Raios-X (XRD), Ressonância Magnética Nuclear do ${ }^{31} \mathrm{P}$ (MASRMN) e Absorção de Raios-X próximo da Borda de Absorção (XANES). Apresentamos também resultados de transmitância óptica, durabilidade química, densidade e índice de refração.

\subsubsection{Difração de Raios-X (XRD)}

A Figura 45 mostra o espectro de raios- $\mathrm{X}$ obtido para diferentes concentrações de polifosfato de antimônio no sistema $\left[\mathrm{Sb}\left(\mathrm{PO}_{3}\right)_{3}\right]_{n}-\mathrm{Sb}_{2} \mathrm{O}_{3}$. No caso do sistema vítreo duas bandas são observadas, uma em torno de $\mathbf{3 0}$ graus e outra em torno de $\mathbf{5 5}$ graus. Fora da região de formação vítrea observam-se picos estreitos relativos à formação de fase cristalina somada a fase vítrea, para composições $\operatorname{com} x=5, x=35$ e $x=40$.

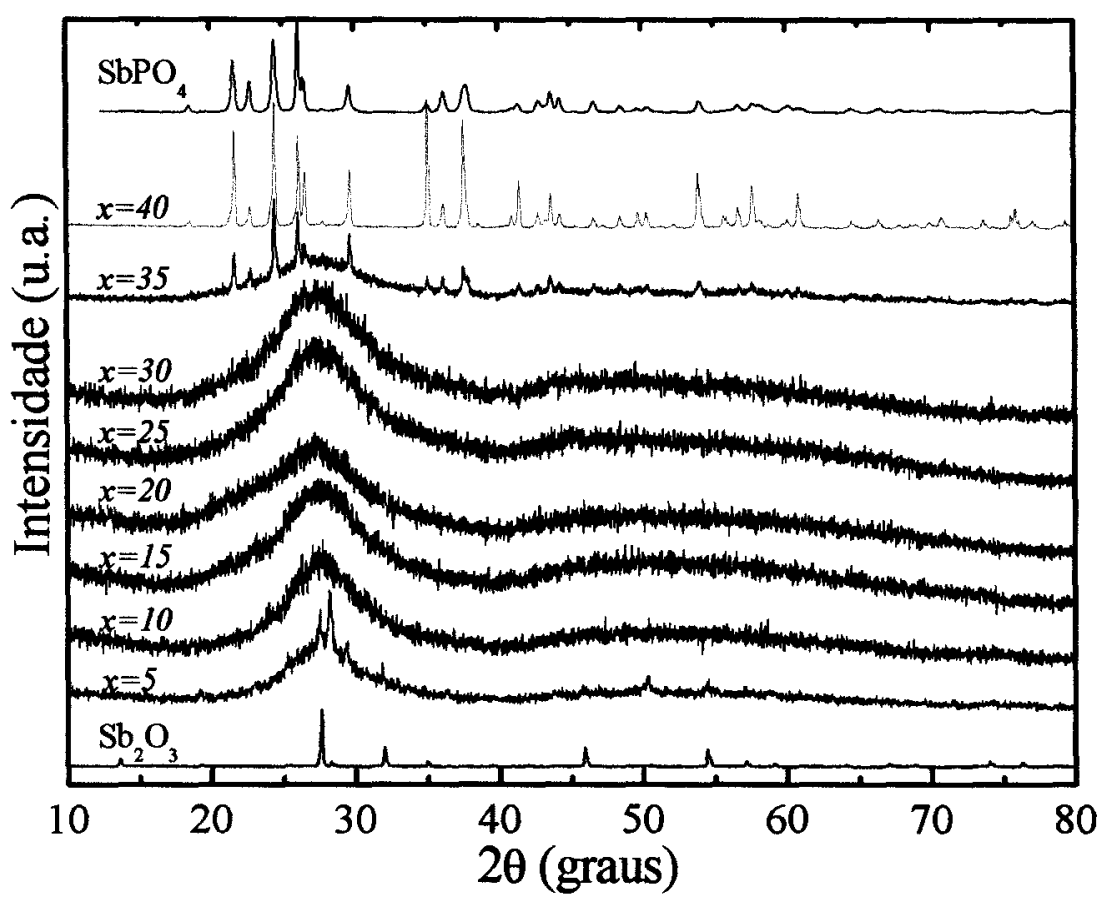

Figura 45 - Difratograma de Raios-X mostrando a evolução na estrutura do vidro em função da composição ( $x$, em moles \%) para o sistema $x\left[\mathrm{Sb}\left(\mathrm{PO}_{3}\right)_{3}\right]_{n}-(100-x) \mathrm{Sb}_{2} \mathrm{O}_{3},(5 \leq x \leq 40)$. 
Para altas concentrações de polifosfato $(x \geq 35)$ observa-se pelo espectro a formação de uma fase única cristalina de $\mathrm{SbPO}_{4}$, isto ocorre devido a introdução de grande quantidade de $\left(\mathrm{PO}_{4}\right)^{-3}$ na matriz. Para baixas concentrações de polifosfato $(x=5)$ observa-se a formação da fase cristalina $\mathrm{Sb}_{2} \mathrm{O}_{3}$ devido a pouca quantidade de formador vítreo $\left(\left[\mathrm{Sb}\left(\mathrm{PO}_{3}\right)_{3}\right]_{n}\right)$.

\subsubsection{Absorção Óptica no Infravermelho (FTIR)}

As medidas de Absorção Óptica no Infravermelho foram realizadas no IQUNESP, em colaboração com o Prof. Younés Messaddeq. Através dos espectros de Absorção Óptica no Infravermelho dos vidros diluídos em $\mathrm{KBr}$ (Figura 46) podemos observar regiões de cristalização onde aparecem picos estreitos sobre o espectro de banda larga típico dos vidros, nas regiões em torno de $500-600 \mathrm{e} 1000-1700 \mathrm{~cm}^{-1}$.

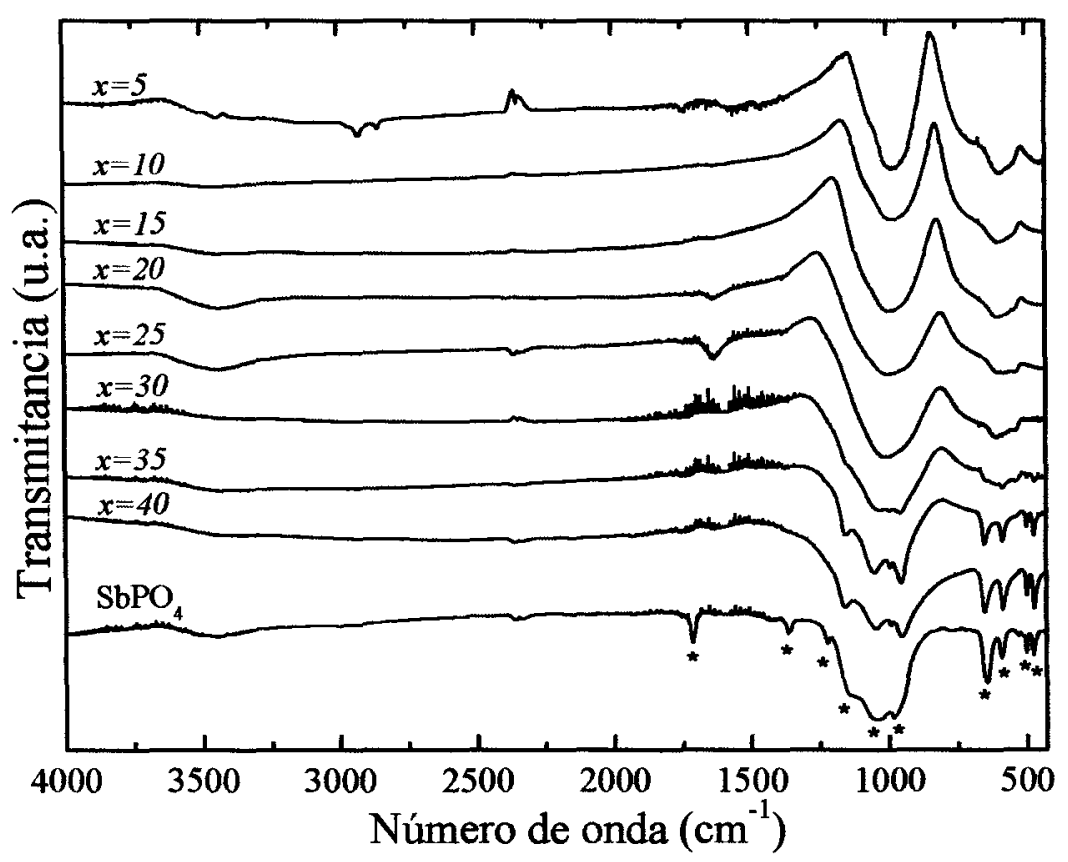

Figura 46 - Espectro de IR do vidro em função da composição ( $x$, em moles \%) para o sistema $x\left[\mathrm{Sb}\left(\mathrm{PO}_{3}\right)_{3}\right]_{n}-(100-x) \mathrm{Sb}_{2} \mathrm{O}_{3},(5 \leq x \leq 40)$. Os picos marcados por asterisco são relativos à formação de fase cristalina.

Diferentemente ao espectro de Raios- $\mathrm{X}$ as composições vítreas que apresentam grandes variações no espectro de IR (aparecimento dos picos estreitos marcados por asteriscos) são as composições que possuem concentrações $x \geq 30$ de polifosfato. No 
caso de $x=30$ há um surgimento de picos sobre a banda em $1000 \mathrm{~cm}^{-1}$ indicando a formação de microcristalinidade, porém o aparecimento destes picos indicando início de formação de microcristalinidade é muito pouco acentuado e não se observa no espectro de raios- $\mathrm{X}$. As bandas abaixo de $700 \mathrm{~cm}^{-1}$ são atribuídas ao estiramento $\mathrm{Sb}-\mathrm{O}$, enquanto que as bandas de 750 a $1300 \mathrm{~cm}^{-1}$ são devidas às ligações $\mathrm{P}=\mathrm{O}, \mathrm{P}-\mathrm{O}-\mathrm{P}$, ou $\mathrm{P}-\mathrm{O}$. Os picos acima de $1300 \mathrm{~cm}^{-1}$ são relativos a vapor de água ou $\mathrm{CO}_{2}$ atmosférico.

\subsubsection{Calorimetria Exploratória Diferencial (DSC)}

A Figura 47 mostra as curvas de Calorimetria Exploratória Diferencial para o sistema vítreo $x\left[\mathrm{Sb}\left(\mathrm{PO}_{3}\right)_{3}\right]_{n}-(100-x) \mathrm{Sb}_{2} \mathrm{O}_{3}(5 \leq x \leq 40)$. A partir destas curvas é possível se obter as temperaturas características dos vidros $\left(T_{g}\right.$, temp. de transição vítrea; $T_{x}$, temperatura de cristalização; $T_{f}$, temp. de fusão), pelo método de intersecção de tangentes como exemplificado anteriormente (Figura 32).

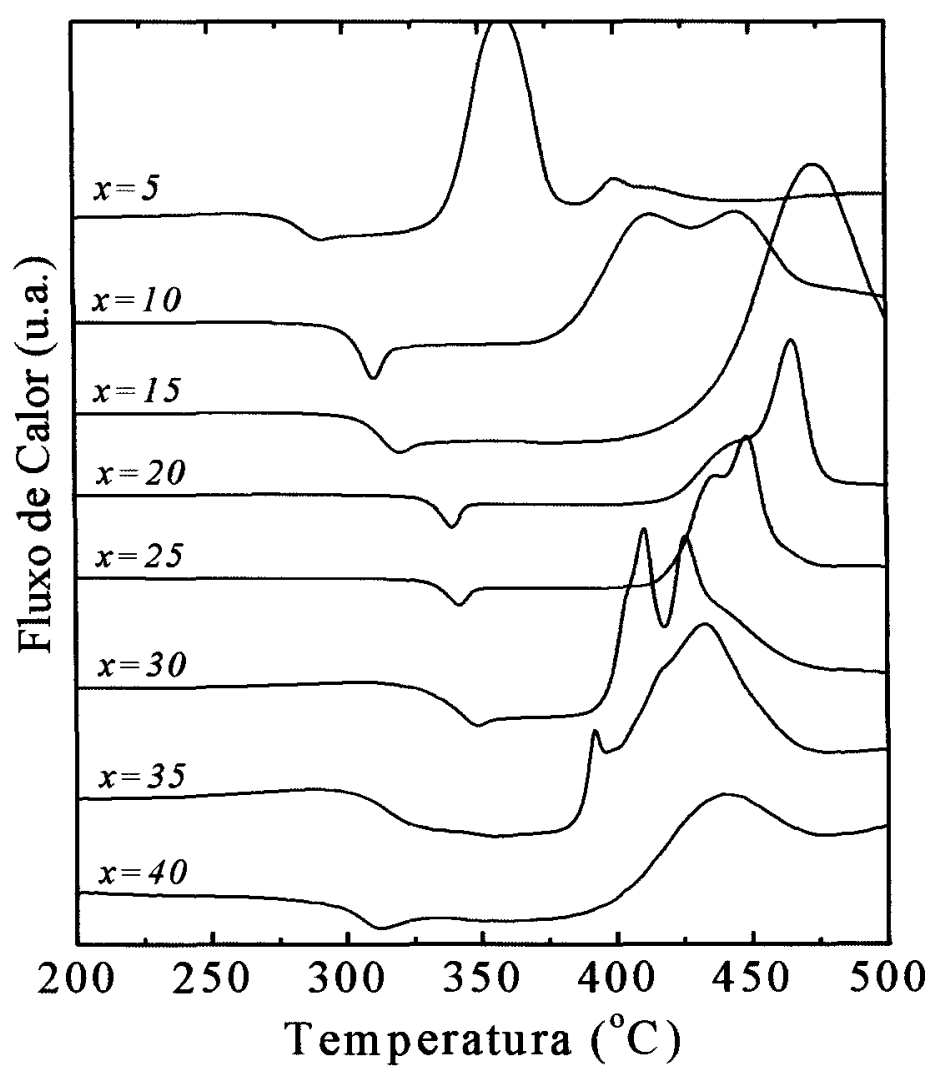

Figura 47 - Curvas de Calorimetria Exploratória Diferencial em função da composição $(x$, em moles \%) para o sistema vítreo $x\left[\mathrm{Sb}\left(\mathrm{PO}_{3}\right)_{3}\right]_{n}-(100-x) \mathrm{Sb}_{2} \mathrm{O}_{3},(5 \leq x \leq 40)$. 
A Tabela 3 apresenta as temperaturas características obtidas a partir dos resultados de Calorimetria Exploratória Diferencial, para o sistema vítreo em questão. Os valores considerados para as composições dos vidros são nominais, visto que a perda de material durante a fusão está em torno de $1 \%$.

Tabela 3 - Composições e temperaturas características do sistema $x\left[\mathrm{Sb}\left(\mathrm{PO}_{3}\right)_{3}\right]_{n}-(100-x) \mathrm{Sb}_{2} \mathrm{O}_{3}$.

\begin{tabular}{cccccc}
\hline \multicolumn{2}{c}{ Composição Química $(\mathrm{mol} \%)$} & \multicolumn{3}{c}{ Temperaturas Características $\left({ }^{\circ} \mathrm{C}\right)$} \\
\hline$x$ & {$\left[\mathrm{Sb}\left(\mathrm{PO}_{3}\right)_{3}\right]_{n}$} & $\mathrm{Sb}_{2} \mathrm{O}_{3}$ & $\mathrm{~T}_{\mathbf{g}}$ & $\mathrm{T}_{\mathbf{x}}$ & $\mathrm{T}_{\mathbf{x}}-\mathrm{T}_{\mathbf{g}}$ \\
\hline 5 & 5 & 95 & 275,6 & 338 & 62,4 \\
10 & 10 & 90 & 300 & 382 & 82 \\
15 & 15 & 85 & 304,0 & 434 & 130 \\
20 & 20 & 80 & 330,5 & 420,5 & 90 \\
25 & 25 & 75 & 331,0 & 420,0 & 89 \\
30 & 30 & 70 & 327,0 & 396,1 & 69,1 \\
35 & 35 & 65 & 300,0 & 386,4 & 86,4 \\
40 & 40 & 60 & 295,0 & 395 & 100
\end{tabular}

* $\mathrm{T}_{\mathrm{g}}$ - Temperatura de Transição Vítrea, $\mathrm{T}_{\mathrm{x}}-$ Temperatura de inicio de cristalização, $\mathrm{T}_{\mathrm{x}}-\mathrm{T}_{\mathrm{g}}-$ Parâmetro de estabilidade do vidro (quanto maior este parâmetro, maior a estabilidade térmica do vidro).

A Figura 48 sintetiza o comportamento térmico do sistema vítreo em função do aumento da concentração de formador vítreo, $\left[\mathrm{Sb}\left(\mathrm{PO}_{3}\right)_{3}\right]_{n}$. O parâmetro $\mathrm{T}_{\mathrm{x}}-\mathrm{T}_{\mathrm{g}}$ mostra a estabilidade do vidro frente à devitrificação, quanto maior a distancia entre a temperatura de cristalização e a temp. de transição vítrea, maior a estabilidade do vidro.

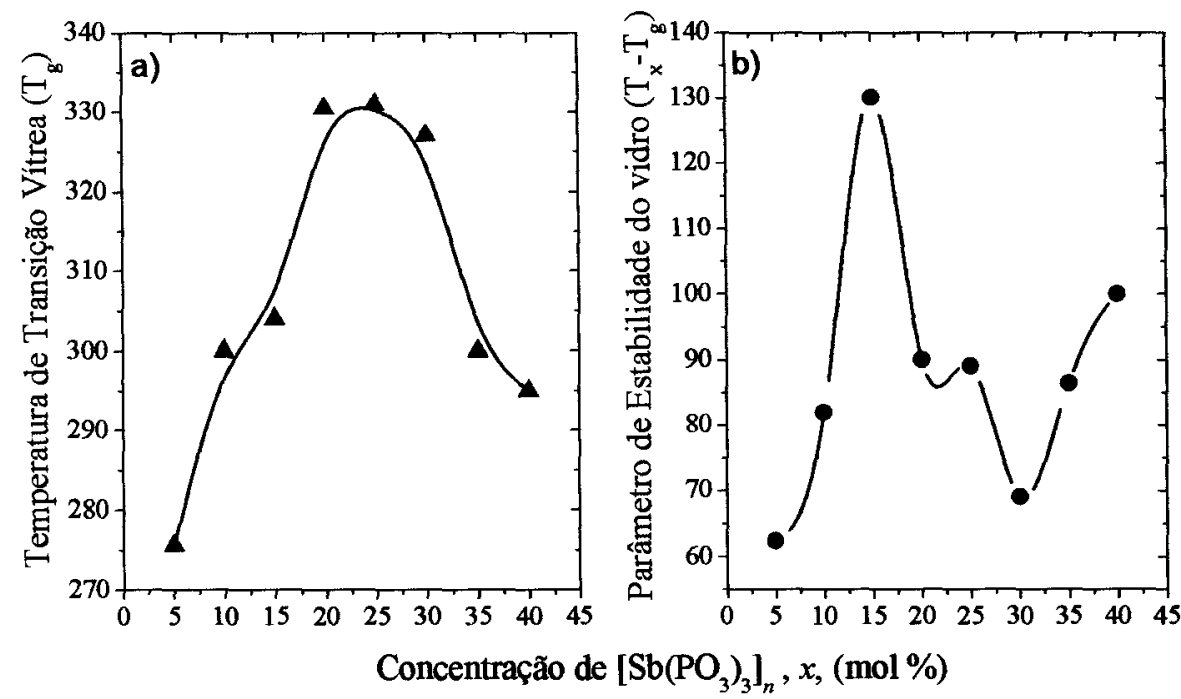

Figura 48 - Evolução da temperatura de transição vítrea $\left(\mathrm{T}_{\mathrm{g}}\right)$ e do parâmetro de estabilidade térmica $\left(\mathrm{T}_{\mathrm{x}}-\mathrm{T}_{\mathrm{g}}\right)$ para o sistema $x\left[\mathrm{Sb}\left(\mathrm{PO}_{3}\right)_{3}\right]_{n}-(100-x) \mathrm{Sb}_{2} \mathrm{O}_{3}$ em função da composição $(x$, em moles \%). 
Neste caso verificamos que a maior $\mathrm{T}_{\mathrm{g}}\left(331{ }^{\circ} \mathrm{C}\right)$ ocorre para composição $x=25$ enquanto que a composição mais estável ocorre para $x=15 \operatorname{com~} \mathrm{T}_{\mathrm{X}}-\mathrm{T}_{\mathrm{g}}$ em $130^{\circ} \mathrm{C}$.

\subsubsection{Ressonância Magnética Nuclear (MAS - NMR)}

As medidas de Ressonância Magnética Nuclear (RMN) foram realizadas em cooperação com o Professor Tito José Bonaganba do IFSC-USP. Através da técnica de RMN com Rotação em Ângulo Mágico na frequeência do fósforo é possível obter informações a respeito do ambiente químico em torno desse elemento na matriz vítrea. No sistema estudado o fósforo se apresenta ligado a oxigênios formando grupos $\left(\mathrm{PO}_{4}\right)^{3-}$ que podem se ligar entre si formando longas cadeias poliméricas no vidro.

Para o estudo da configuração de grupos $\mathrm{PO}_{4} \mathrm{em}$ vidros fosfato pela técnica de $R M N$ utiliza-se a terminologia $Q^{n}$ para definir o tipo de sítio ocupado pelo fósforo, onde $\mathrm{Q}^{3}$ seria o grupo fosfato que possui 3 Oxigênios Ligantes e $\mathrm{Q}^{0}$ o grupo fosfato isolado que não possui nenhum Oxigênio Ligante. As configurações $\mathrm{Q}^{\mathrm{n}}$ para grupos $\mathrm{PO}_{4}$ podem ser melhor relembrada como descrito na seção 1.2.4.2 (A Despolimerização estrutural e a nomenclatura $Q^{i}$ em fosfatos) através da Figura 12, onde as ligações em azul representam os Oxigênios Ligantes de cada grupo.

Dessa forma, através da técnica de RMN do fósforo pode-se identificar quais tipos de sítios $\mathrm{Q}^{\mathrm{n}}$ a amostra possui (posição da linha) e qual a proporção de cada sítio na amostra (intensidade da linha), pois cada sítio $Q^{n}$ possui diferente freqüência de ressonância com base numa amostra padrão.

Neste caso foi utilizado como padrão uma solução de $85 \%$ de $\mathrm{H}_{3} \mathrm{PO}_{4}$ para determinar a posição de frequêencia zero do espectro, pois esta solução apresenta $100 \%$ de sítios $\mathbf{Q}^{0}$ para o fósforo. Os resultados são apresentados na forma de intensidade do sinal de RMN em função do deslocamento em frequeência da resposta dos diferentes sítios $\mathbf{Q}^{\mathbf{n}}$. As medidas foram realizadas num espectrômetro VARIAN Unity INOVA operando a $400 \mathrm{MHz}$ e campo magnético de 9,4T, com a amostra em rotação de $6,5 \mathrm{kHz}$ em ângulo mágico. A função da rotação da amostra em ângulo mágico é aumentar a separação das linhas espectrais obtidas, devido à diminuição dos efeitos de orientação dos núcleos de ${ }^{31} \mathrm{P}$ com o campo magnético. Com a rotação a parte angular da interação de deslocamento químico, que define a frequêencia de RMN, é promediada a zero e é possivel ver somente a parte da interação que não depende da orientação e sim da 
vizinhança eletrônica do núcleo. 0 resultado é um estreitamento grande da linha que permite que núcleos com diferentes nuvens eletrônicas, ou seja, diferentes Q's, possam ser distinguidos.

A Figura 49 mostra os primeiros resultados de RMN obtidos para o sistema vítreo $\left[\mathrm{Sb}\left(\mathrm{PO}_{3}\right)_{3}\right]_{n}-\mathrm{Sb}_{2} \mathrm{O}_{3}$, onde foi observado a predominância de dois sítios $\mathrm{Q}^{0}$ para $\mathrm{o}$ fósforo nos vidros, em comparação com o espectro conhecido do $\mathrm{SbPO}_{4}$ cristalino e do precursor $\left[\mathrm{Sb}\left(\mathrm{PO}_{3}\right)_{3}\right]_{\mathrm{n}}$ amorfo.

O $\mathrm{SbPO}_{4}$ cristalino possuí apenas sítios $\mathrm{Q}^{0}$ para o fósforo em sua estrutura tridimensional e o $\left[\mathrm{Sb}\left(\mathrm{PO}_{3}\right)_{3}\right]_{n}$ apenas $\mathrm{Q}^{2}$ por ser um formador vítreo com estrutura polimérica. A presença de cátions pesados $\mathrm{Sb}^{3+}$ na estrutura do vidro desloca as posições dos picos $\mathrm{Q}^{0}$ de -11 para -18 ppm e desloca as posições dos picos de $\mathrm{Q}^{2}$ para posição em torno de $-36 \mathrm{ppm}$, respectivamente.

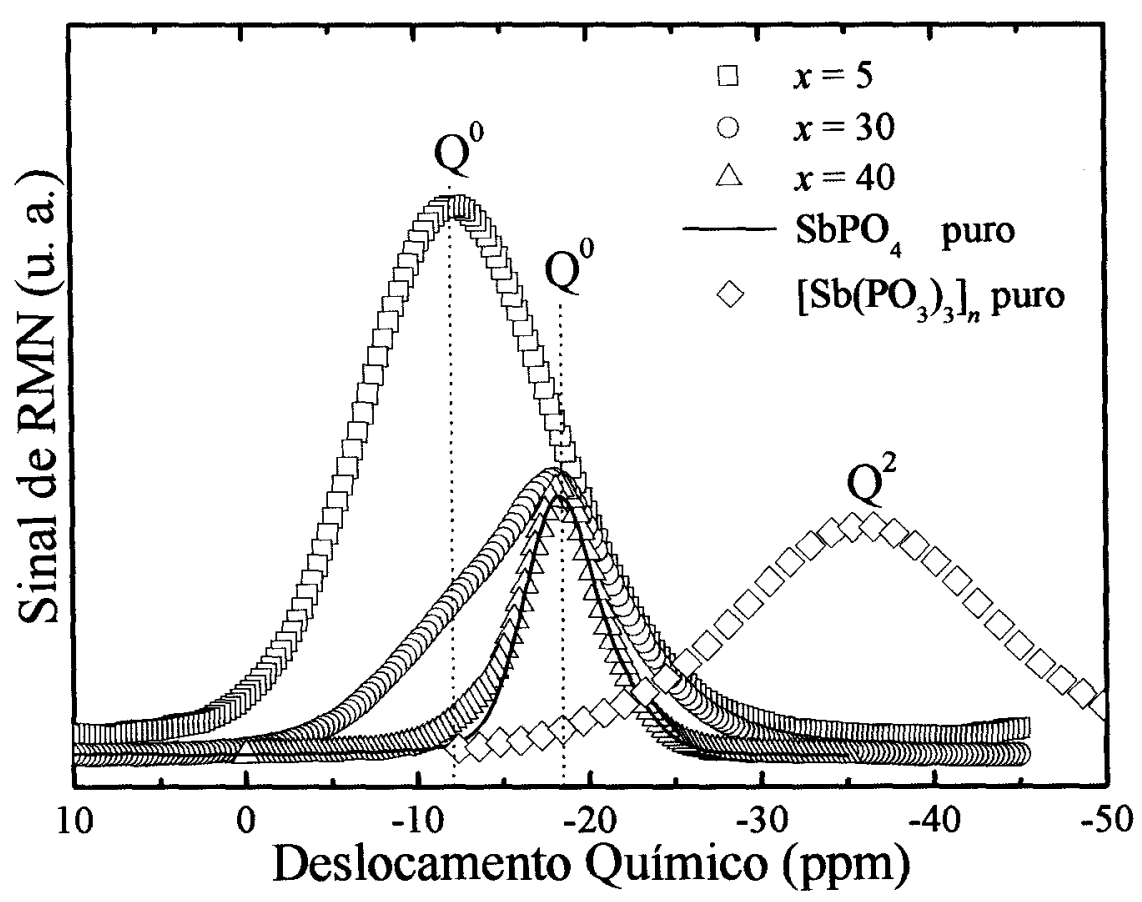

Figura 49 - Espectros de $\mathrm{RMN}$ para o sistema vítreo $x\left[\mathrm{Sb}\left(\mathrm{PO}_{3}\right)_{3}\right]_{n}-(100-x) \mathrm{Sb}_{2} \mathrm{O}_{3}$ em comparação com $\mathrm{SbPO}_{4}$ e $\left[\mathrm{Sb}\left(\mathrm{PO}_{3}\right)_{3}\right]_{n}$.

No caso dos vidros $x\left[\mathrm{Sb}\left(\mathrm{PO}_{3}\right)_{3}\right]_{n}-(100-x) \mathrm{Sb}_{2} \mathrm{O}_{3}$ observa-se pelas medidas de MAS-NMR que os sítios $Q^{0}$ estão localizados em uma banda larga em $-11,0$ e se desloca para $-18,0$ ppm com o aumento de $\left[\mathrm{Sb}\left(\mathrm{PO}_{3}\right)_{3}\right]_{n}$. Com o aumento da concentração de formador $\left(\left[\mathrm{Sb}\left(\mathrm{PO}_{3}\right)_{3}\right]_{n}\right)$, grande quantidade de grupos fosfatos são 
adicionados a estrutura, ou seja, gerando maior deslocamento químico negativo da banda relativa ao sítio $\mathrm{Q}^{0}$ do fósforo. Para altas concentrações de $\left[\mathrm{Sb}\left(\mathrm{PO}_{3}\right)_{3}\right]_{n}(x=30)$ verifica-se que o espectro apresenta sobreposição de duas bandas relativas ao sítio $\mathrm{Q}^{0}, \mathrm{e}$ para $x=40 \mathrm{o}$ espectro fica muito próximo do espectro do $\mathrm{SbPO}_{4}$ cristalino.

Esse resultado mostra com detalhes a transição da estrutura de fase amorfa para fase cristalina e pode ser utilizado para determinar precisamente quantidades de fase cristalina no material, bem como o início da formação de microcristalinidade que não pôde ser detectada por difração de raios-X (Figura 45). Este resultado também está de acordo com a cristalização do vidro observada pelas medidas de FTIR, onde para concentrações de polifosfato $x \geq 30$ ocorre formação de microcristalinidade.

A Figura 50 mostra a evolução dos espectros de RMN para o sistema vítreo $x\left[\mathrm{Sb}\left(\mathrm{PO}_{3}\right)_{3}\right]_{n}-(100-x) \mathrm{Sb}_{2} \mathrm{O}_{3}$, variando-se a concentração de polifosfato de 5 a 40 moles $\%$. O menor deslocamento químico negativo observado para $x=5(-11 \mathrm{ppm})$ comparado com concentrações mais altas de polifosfato $(x \geq 30)$ e com o espectro do $\mathrm{SbPO}_{4}(-18$ ppm) indica menor efeito dos cátions $\mathrm{Sb}^{3+}$ sobre os átomos de fósforo, neste caso devido a presença de uma fase vítrea mais dispersa (grupos fosfatos mais distantes um dos outros) como conseqüência da menor concentração de fósforo no vidro. Nos espectros de MAS-NMR quanto menos dispersa for a fase, maior será a interação entre os núcleos vizinhos e maior será o deslocamento químico negativo nos espectros.

Dessa forma podemos acompanhar a evolução das quantidades de sítios para fósforos em fase mais dispersa $Q^{0}{ }_{-11 p p m} e$ fósforos em fase menos dispersa $Q^{0}{ }_{-18 p p m}$ na estrutura dos vidros pela deconvolução dos espectros com duas gaussianas nas posições -11 e -18 ppm e também a observar com precisão o início da formação de microcristalinidade nos vidros. Para as composições $x=30, x=35$ e $x=40$ foi utilizada uma terceira gaussiana que representa a formação de grupos $\mathrm{Q}^{0}$ em fase cristalina $\left(Q^{0}{ }_{\text {cristalino }}\right)$ no vidro. 


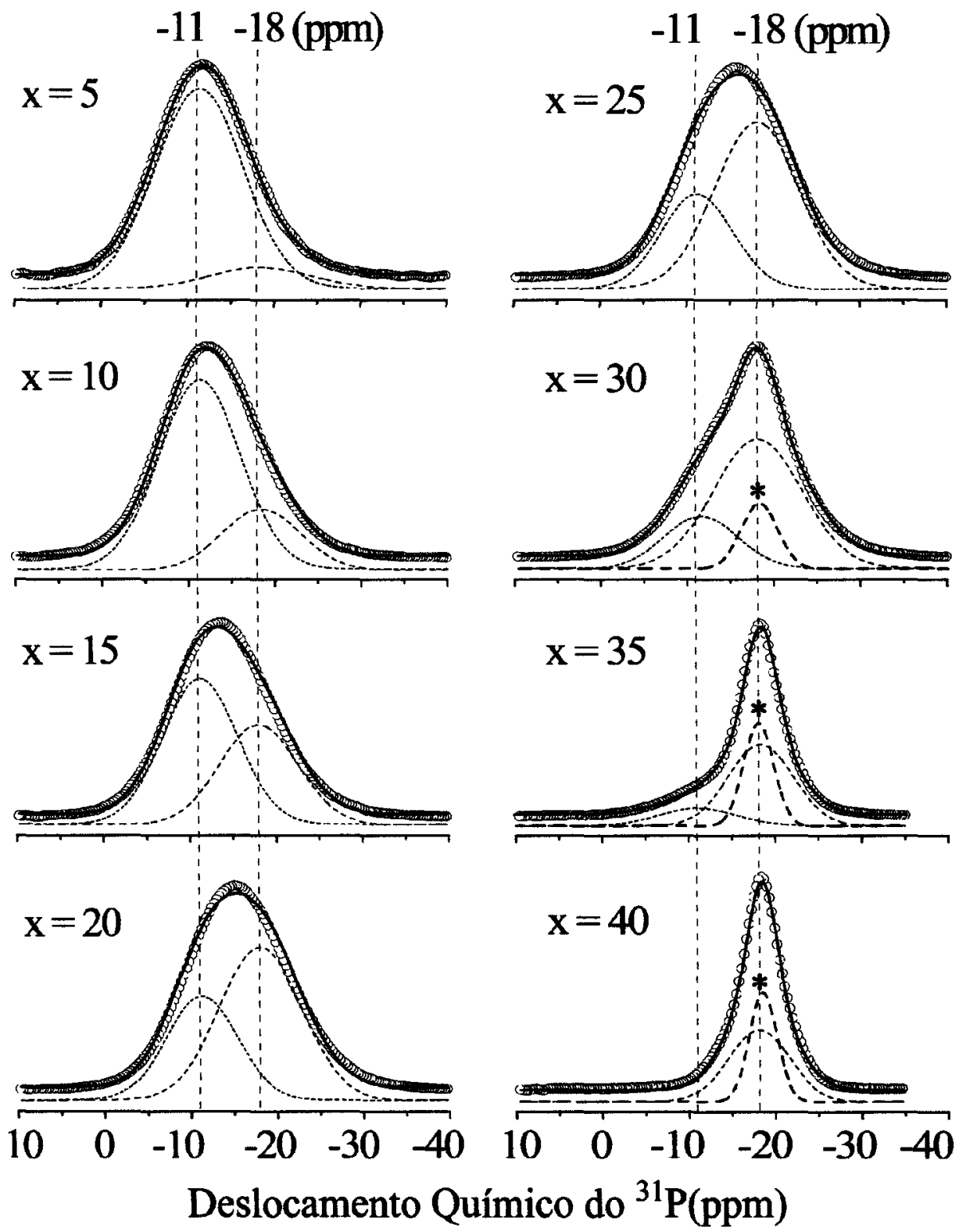

Figura 50 - Espectro de $\mathrm{RMN}$ para o sistema vítreo $x\left[\mathrm{Sb}\left(\mathrm{PO}_{3}\right)_{3}\right]_{n}-(100-x) \mathrm{Sb}_{2} \mathrm{O}_{3}(5 \leq x \leq 40)$. Os picos marcados com asterisco representam o crescimento da fase microcristalina no vidro.

A Figura 51 mostra o comportamento estrutural do vidro em função da evolução de sítios $Q^{0}{ }_{-11 \text { ppm }}$ e $Q^{0}{ }_{-18 p m}$ do fósforo para vidros $x\left[\mathrm{Sb}\left(\mathrm{PO}_{3}\right)_{3}\right]_{n}-(100-x) \mathrm{Sb}_{2} \mathrm{O}_{3}$ com variação de polifosfato de 5 a 40 moles $\%$. A quantidade de $Q^{0}{ }_{-11 p p m}$ diminui com a adição de polifosfato e a quantidade de $\mathrm{Q}^{0}{ }_{-18 p p m}$ atinge seu máximo para a composição $x=25$, que é a composição que possui a maior $\mathrm{T}_{\mathrm{g}}$ (vide Tabela 3 ). A composição vítrea $x=15$ que apresenta quantidades próximas de $Q^{0}{ }_{-11}$ ppm e $Q^{0}{ }_{-18 p p m}$ é a que possui maior estabilidade térmica $\left(\mathrm{T}_{\mathrm{x}}-\mathrm{T}_{\mathrm{g}}=130^{\circ} \mathrm{C}\right)$, e isto pode representar maior conectividade entre 
as cadeias de polifosfato, pois quanto maior o número de espécies diferentes $\mathrm{Q}^{\mathrm{n}}$ maior o entrelaçamento das cadeias poliméricas aumentando a estabilidade térmica frente a devitrificação.

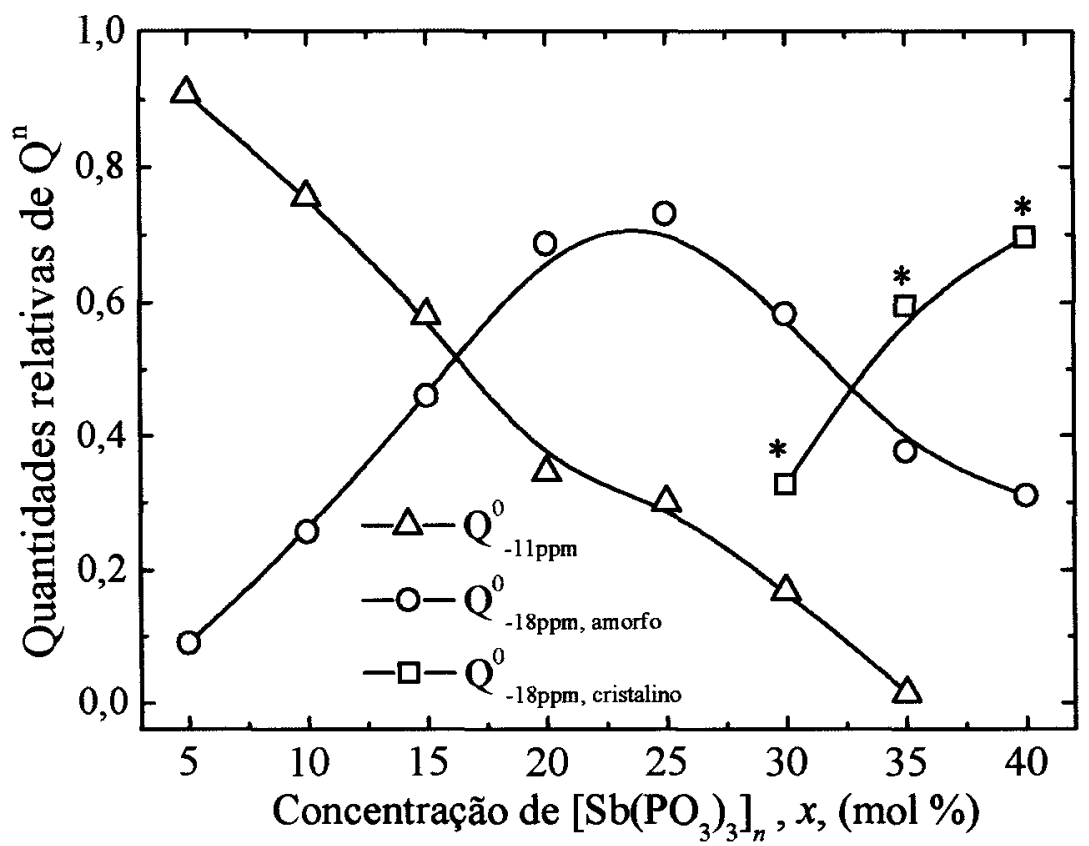

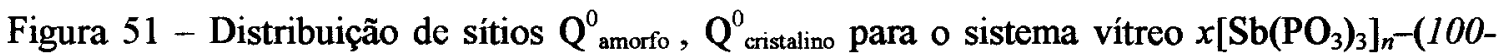
$x) \mathrm{Sb}_{2} \mathrm{O}_{3}$ em função da composição ( $x$, em moles \%), determinados a partir dos espectros de deslocamento químico do ${ }^{31} \mathrm{P}$. Os dados marcados com asterisco representam o crescimento da fase microcristalina no vidro como observado na Figura 50.

Para os vidros com composições de $x=30, x=35$ e $x=40 \mathrm{~mol} \%$ de polifosfato

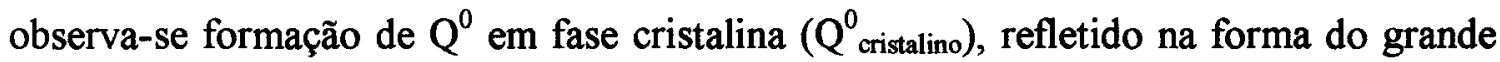
estreitamento observado nos espectros de RMN, como foi observado também por Raios-X e IR dos vidros de mesma composição. É interessante comparar as curvas relativas ao $Q^{0}{ }^{1}{ }_{18 p p m}$ (fase amorfa) com as curvas de $T_{g}$ do vidro (Figura 48-a), pois ambas apresentam o mesmo comportamento em função da concentração de $\left[\mathrm{Sb}\left(\mathrm{PO}_{3}\right)_{3}\right]_{\text {n }}$. Já a curva de $T_{x}-T_{g}$ dos vidros (Figura 48-b) tem um comportamento ascendente para $x$ $\geq 30$, como também a curva de $Q^{0}{ }_{-18 p p m}$, (fase cristalina) que indica formação de nova fase microcristalina no vidro, alterando a estabilidade térmica. 


\subsubsection{Formação vitrea no sistema $x\left[\mathrm{Sb}\left(\mathrm{PO}_{3}\right)_{3}\right]_{n}-(100-x) \mathrm{Sb}_{2} \mathrm{O}_{3}$}

Este diagrama de formação vítrea é baseado nos resultados de Difração de Raios-X, Absorção Óptica no Infravermelho, e MAS-NMR apresentados anteriormente. Com estes resultados podemos fazer precisamente uma distinção entre fase cristalina, fase vítrea ou fase vítrea com microcristalinidade em função da concentração de $\left[\mathrm{Sb}\left(\mathrm{PO}_{3}\right)_{3}\right]_{n}$ no vidro. A Figura 52 mostra o diagrama de formação vítrea para este sistema para concentrações de $\left[\mathrm{Sb}\left(\mathrm{PO}_{3}\right)_{3}\right]_{n}$ de 5 a 40 moles \%.

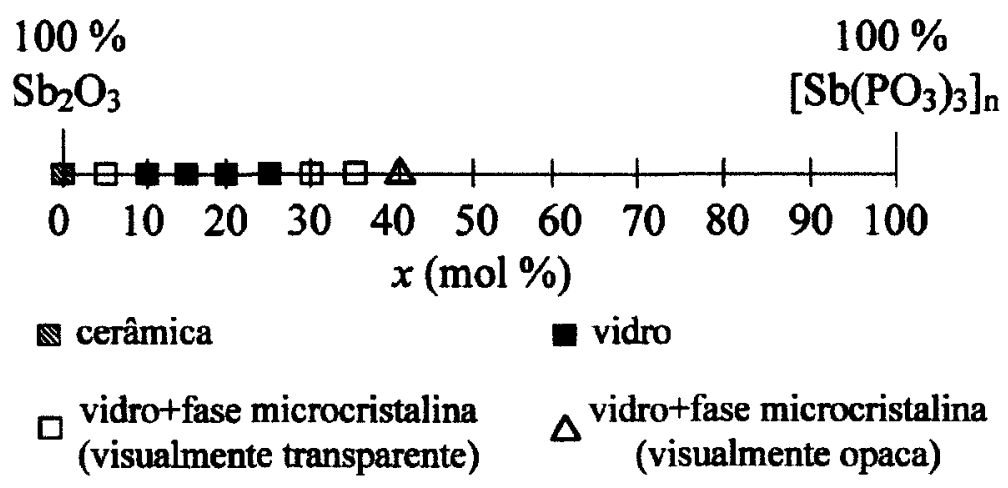

Figura 52 - Região de Formação Vítrea no sistema binário $x\left[\mathrm{Sb}\left(\mathrm{PO}_{3}\right)_{3}\right]_{n}-(100-x) \mathrm{Sb}_{2} \mathrm{O}_{3}$.

Este sistema vítreo apresenta uma faixa menos extensa de formação em comparação com os vidros a base de ortofosfato $\left(\mathrm{SbPO}_{4}\right)$, devido a grande quantidade de grupos $\mathrm{PO}_{3}$ que é adicionada com o aumento da concentração do formador $\left[\mathrm{Sb}\left(\mathrm{PO}_{3}\right)_{3}\right]_{n}$. Para cada mol de polifosfato de antimônio adicionado, 3 moles de grupos $\mathrm{PO}_{3}$ são introduzidos na matriz vítrea.

\subsubsection{Janela de Transmitância e Durabilidade Química}

A Figura 53 apresenta a janela de transmitância óptica na região do VIS-IR, para vidros com composição $20 \%\left[\mathrm{Sb}\left(\mathrm{PO}_{3}\right)_{3}\right]_{n}-80 \% \mathrm{Sb}_{2} \mathrm{O}_{3}$. Estes vidros têm transmitância em torno de $80 \%$ na faixa de 0,35 a $8 \mu \mathrm{m}$. Este resultado não apresenta alterações significativas para diferentes composições dos vidros. 


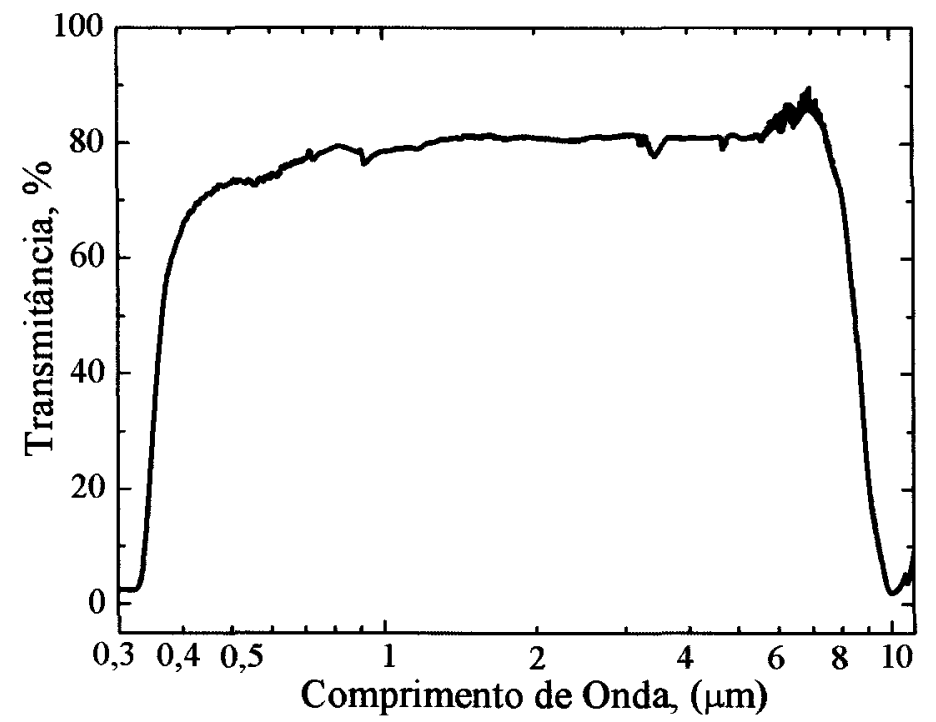

Figura 53 - Janela de transmitância para vidros com composição $20 \%\left[\mathrm{Sb}\left(\mathrm{PO}_{3}\right)_{3}\right]_{n}-80 \% \mathrm{Sb}_{2} \mathrm{O}_{3}$.

A durabilidade química dos vidros foi medida como a taxa de dissolução em função da área da amostra e do tempo de imersão em água deionizada a temperatura ambiente como mostra a Figura 54. As amostras ficaram imersas por seis meses, e a perda de massa foi medida a cada mês, com a lavagem das amostras em ultra-som e secagem em jato de nitrogênio seco.

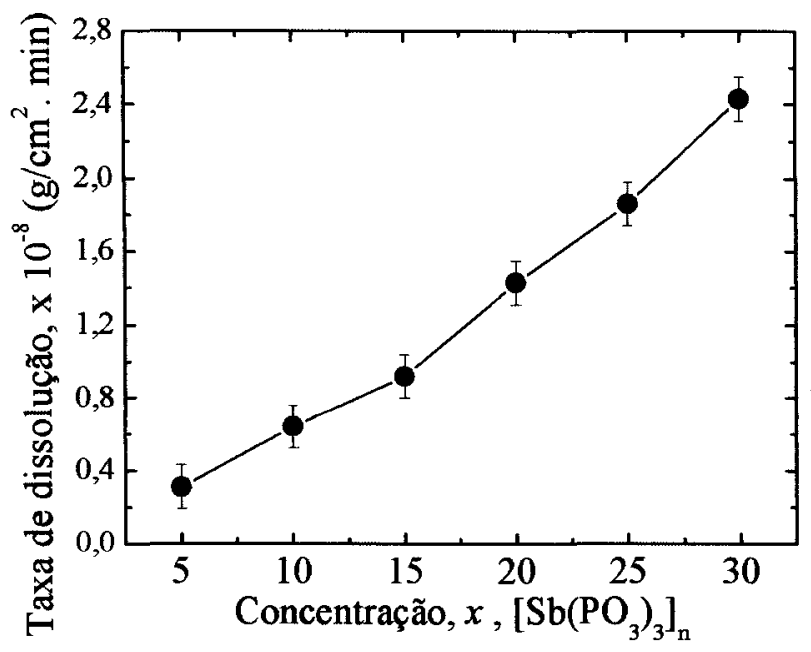

Figura 54 - Taxa de dissolução (durabilidade química) dos vidros $x\left[\mathrm{Sb}\left(\mathrm{PO}_{3}\right)_{3}\right]_{n}-(100-x) \mathrm{Sb}_{2} \mathrm{O}_{3}$.

A taxa de dissolução aumenta para vidros com maiores concentrações de polifosfato de antimônio, pois terminações P-O em cadeias de fosfatos são altamente higroscópicas. Para comparação temos a taxa de dissolução do vidro Soda-Lime-Silica (muito utilizado comercialmente) igual a $10^{-8} \mathrm{~g} / \mathrm{cm}^{2}$ min a $70^{\circ} \mathrm{C}$. 


\subsection{7 Índice de Refração e Densidade dos vidros $x\left[\mathrm{Sb}\left(\mathrm{PO}_{3}\right)_{3}\right]_{n}-(100-x) \mathrm{Sb}_{2} \mathrm{O}_{3}$}

Nesta seção apresentamos resultados de índice de refração e densidade para algumas composições do sistema vítreo $x\left[\mathrm{Sb}\left(\mathrm{PO}_{3}\right)_{3}\right]_{n}-(100-x) \mathrm{Sb}_{2} \mathrm{O}_{3}$, como mostra a Figura 55. Comparamos o comportamento dessas grandezas com a massa molar normalizada de cada composição levando em conta a quantidade nominal de átomos \% e seus respectivos pesos atômicos para cada composição vítrea. Os dados marcados por asteriscos são provenientes da referência 135 .

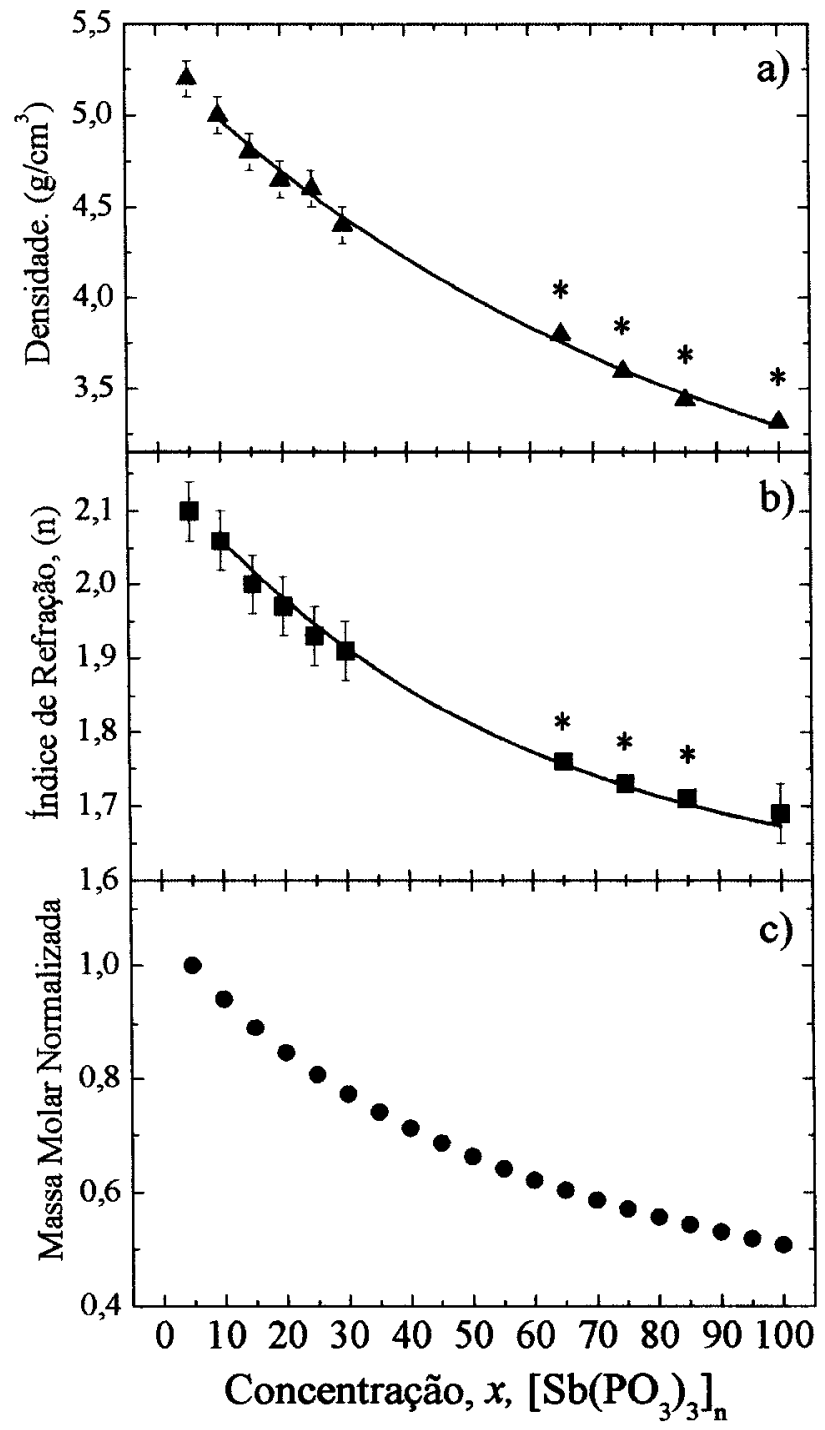

Figura 55 - Comportamento de parâmetros como: a) Densidade; b)Índice de refração; c) Massa molar normalizada da composição, para vidros $x\left[\mathrm{Sb}_{(}\left(\mathrm{PO}_{3}\right)_{3}\right]_{n}-(100-x) \mathrm{Sb}_{2} \mathrm{O}_{3} \mathrm{em}$ função da concentração nominal de formador vítreo, $x$. 
Podemos verificar que tanto a densidade como o índice de refração diminuem com o aumento da concentração de formador, $x$, no vidro. Isto ocorre, pois o aumento de polifosfato causa uma diminuição na massa molar normalizada da composição devido à introdução de grande quantidade de oxigênio e fósforo (que são elementos leves) em comparação com a introdução de antimônio na mistura. Além disso, fatores estruturais e atômicos como conectividade entre grupos fosfatos, comprimento de ligações químicas e seção de choque estão envolvidos no comportamento desses parâmetros.

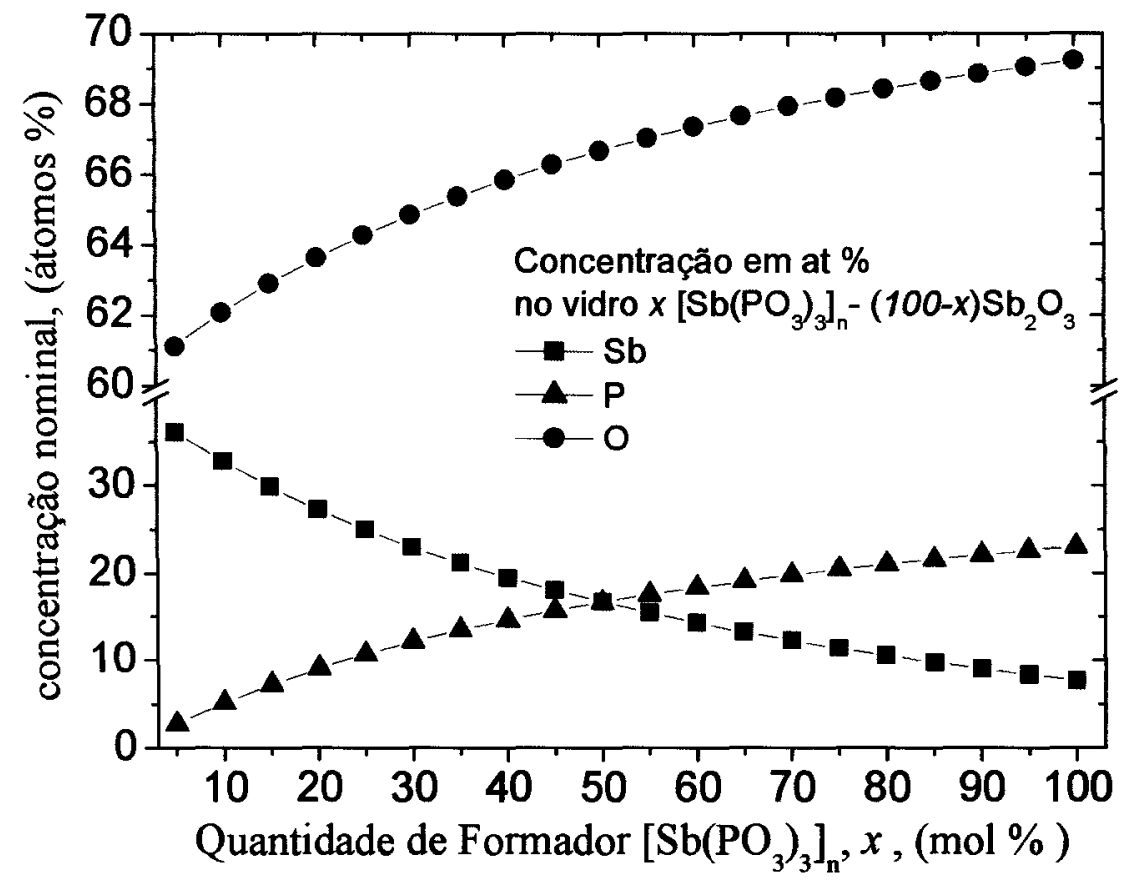

Figura 56 - Concentração nominal de $\mathrm{Sb}, \mathrm{P}$ e $\mathrm{O}$ nos vidros de $x\left[\mathrm{Sb}\left(\mathrm{PO}_{3}\right)_{3}\right]_{n}-(100-x) \mathrm{Sb}_{2} \mathrm{O}_{3}$.

A evolução das quantidades em átomos \% de antimônio ( $\mathrm{Sb}$ ), fósforo $(\mathrm{P})$, e oxigênio $(\mathrm{O})$ na composição nominal dos vidros em função da concentração de polifosfato pode ser acompanhada na Figura 56. 


\subsubsection{Absorção de Raios-X próximo da Borda de Absorção (XANES)}

Pela técnica de XANES acompanhamos a evolução da estrutura dos vidros em função da concentração de polifosfato, como também a formação de fase cristalina, como observado nos resultados anteriores. As medidas nas bordas $\mathrm{K}$ do fósforo foram realizadas no LNLS-Campinas. Para a borda K do fósforo foi utilizada a linha SXS (Soft X-Ray Spectroscopy) que opera com energia de 790 a $4000 \mathrm{eV}$, sendo que a energia da borda $\mathrm{K}$ de absorção do $\mathrm{P}$ está em torno de $2145 \mathrm{eV}$, e foi medida na configuração TEY (Total Electron Yeild). Os espectros foram tratados utilizando o programa GALAAD [136], e a normalização dos espectros foi feita para borda $\mathrm{K}$ do $\mathrm{P}$ em $2152 \mathrm{eV}$.

\subsubsection{XANES da borda $\mathrm{K}$ do fósforo de vidros $x\left[\mathrm{Sb}\left(\mathrm{PO}_{3}\right)_{3}\right]_{n}-(100-x) \mathrm{Sb}_{2} \mathrm{O}_{3}$}

A Figura 57 apresenta os espectros de XANES para os vidros de $x\left[\mathrm{Sb}\left(\mathrm{PO}_{3}\right)_{3}\right]_{n}-$ (100-x) $\mathrm{Sb}_{2} \mathrm{O}_{3}$ com composição de polifosfato de 5 a 20 moles \%. Com o aumento de polifosfato nos vidros os espectros apresentam maior intensidade da linha branca (pico em $2148 \mathrm{eV}$ ) e este aumento é relacionados com aumento no comprimento das cadeias de fosfatos (polimerização) e quebra de simetria entre grupos tetraédricos $\mathrm{PO}_{4}$ [137].

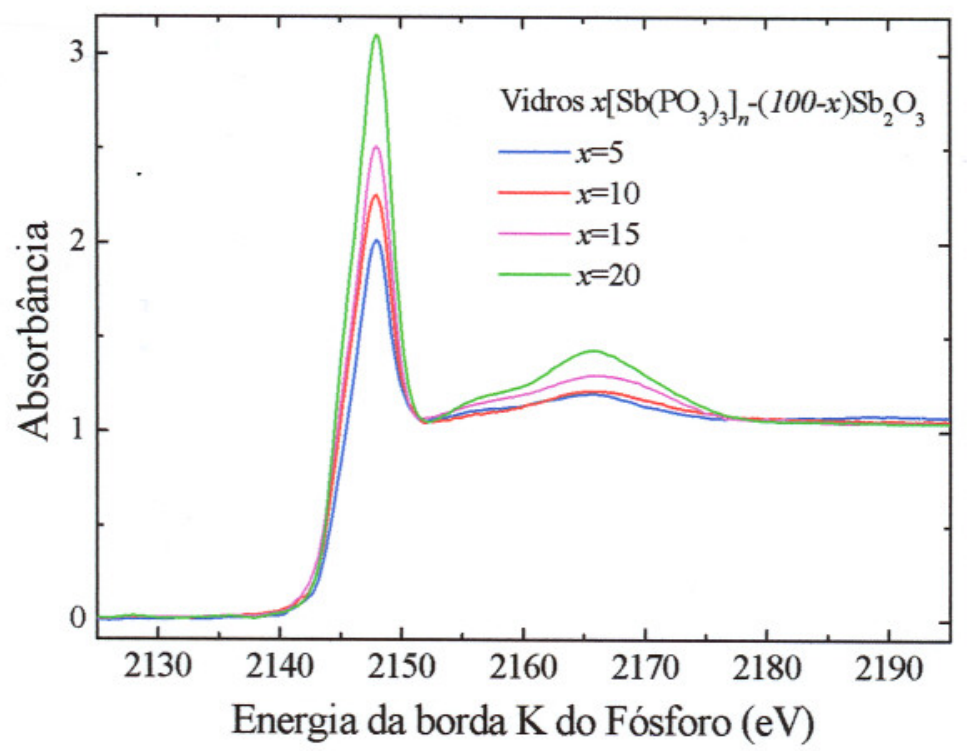

Figura 57 - Espectro de XANES da borda K do fósforo para o sistema vítreo $x\left[\mathrm{Sb}\left(\mathrm{PO}_{3}\right)_{3}\right]_{n}-$ $(100-x) \mathrm{Sb}_{2} \mathrm{O}_{3}(5 \leq x \leq 20)$. 
A Figura 58 apresenta os espectros de XANES para os vidros de $x\left[\mathrm{Sb}\left(\mathrm{PO}_{3}\right)_{3}\right]_{n}{ }^{-}$ (100-x) $\mathrm{Sb}_{2} \mathrm{O}_{3}$ com composição de polifosfato de 20 a 40 moles $\%$. O desdobramento do pico mais intenso do espectro (linha branca) para concentrações de polifosfato acima de $30 \%$ indica formação de tetraedros de fosfatos isolados em fase cristalina, ou seja, com o aumento da concentração de polifosfato ocorre formação de microcristalinidade no vidro para $x \geq 30$, como observado anteriormente nos resultados de Raios-X, IR e MASNMR. Além do desdobramento da linha branca observa-se o estreitamento das bandas em 2155 e $2166 \mathrm{eV}$, indicando maior organização estrutural.

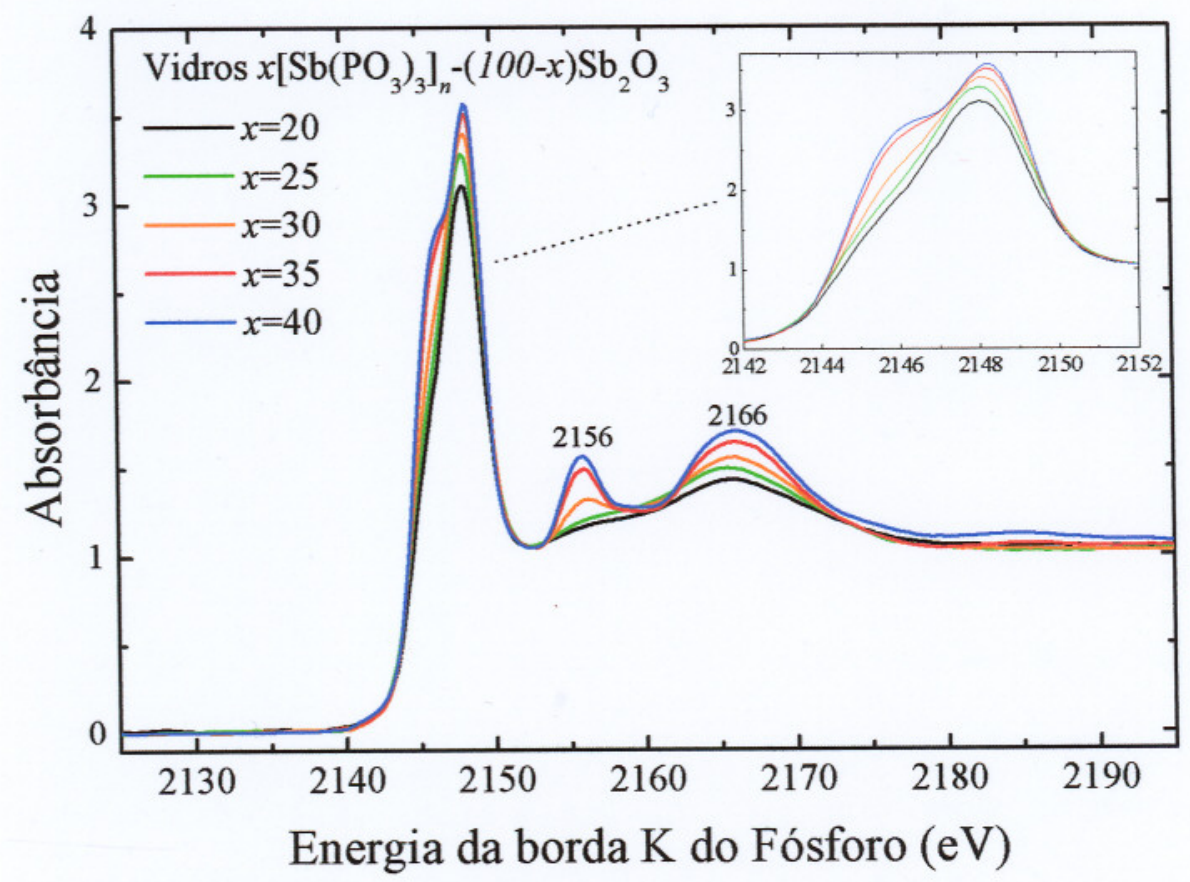

Figura 58 - Espectro de XANES da borda $\mathrm{K}$ do fósforo para o sistema vítreo $x\left[\mathrm{Sb}\left(\mathrm{PO}_{3}\right)_{3}\right]_{n}-$ $(100-x) \mathrm{Sb}_{2} \mathrm{O}_{3}(20 \leq x \leq 40)$.

A diferença em energia entre as posições de ressonância (bandas em 2156 e $2166 \mathrm{eV}$ ) indica o efeito de átomos que estão fora da primeira esfera de coordenação em torno do átomo absorvedor [138]. 
Na Figura 59 são apresentados espectros de referência que mostram as diferenças entre os espectros de XANES para amostras cristalinas $\left(\mathrm{SbPO}_{4} \mathrm{e} \mathrm{NH}_{4} \mathrm{H}_{2} \mathrm{PO}_{4}\right)$ e para amostras amorfas (polifosfato).

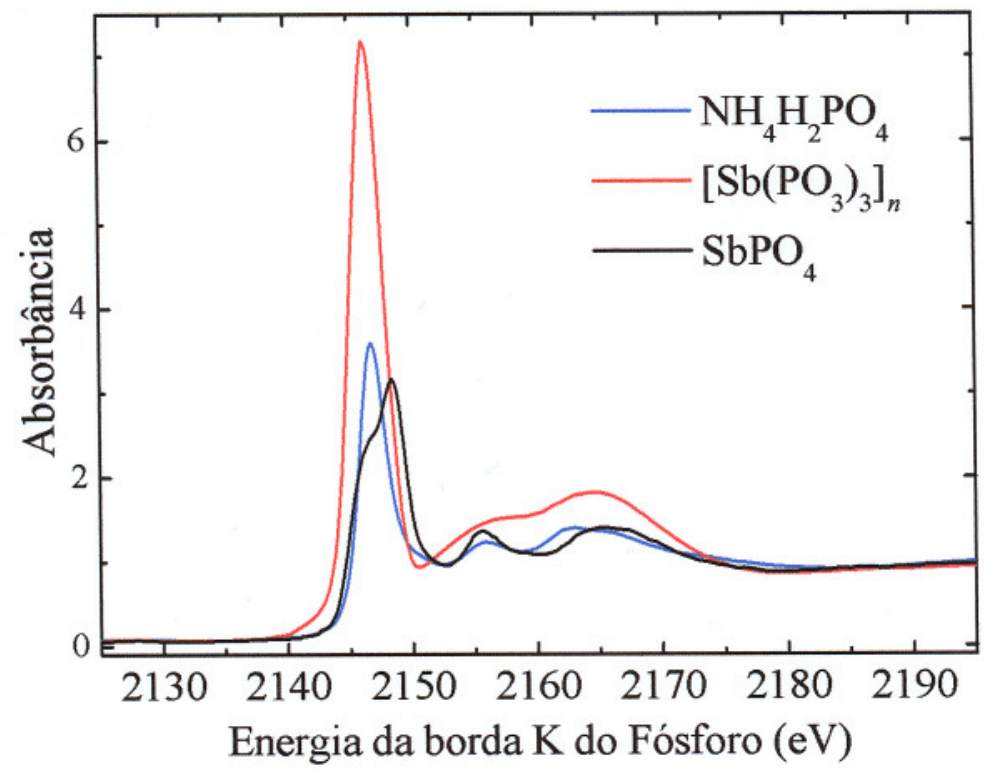

Figura 59 - Espectros de Referência de XANES da borda K do fósforo para diferentes matrizes.

Através destes espectros pode-se verificar o desdobramento da linha branca no caso do $\mathrm{SbPO}_{4}$ cristalino devido a grande quantidade de $\mathrm{PO}_{4}$ em fase cristalina, e o estreitamento das posições de ressonância. $\mathrm{O}$ espectro do difosfato de amônia também apresenta bandas mais estreitas devido a sua cristalinidade, porém a linha branca não apresenta desdobramento. Já o polifosfato apresenta intensidade da linha branca muito maior devido a maior polimerização das cadeias de fosfato e menor simetria entre grupos tetraédricos $\mathrm{PO}_{4}$ [137]. O espectro nas posições de ressonância (em 2156 e 2166 eV) é alargado típico de um material amorfo. 


\subsubsection{Efeito de escurecimento em vidros de $x\left[\mathrm{Sb}\left(\mathrm{PO}_{3}\right)_{3}\right]_{n}-(100-x) \mathrm{Sb}_{2} \mathrm{O}_{3}$}

Durante a preparação dos vidros de $x\left[\mathrm{Sb}\left(\mathrm{PO}_{3}\right)_{3}\right]_{n}-(100-x) \mathrm{Sb}_{2} \mathrm{O}_{3}$ verificamos que algumas amostras após vertidas apresentaram um efeito de escurecimento quando fundidos em temperatura ligeiramente acima de $900{ }^{\circ} \mathrm{C}$. A Figura 60 apresenta algumas fotos dos vidros produzidos em nosso laboratório mostrando o efeito de escurecimento obtido com o aumento da temperatura de fusão. São mostradas também algumas imagens dos vidros sem o efeito de escurecimento produzidos no laboratório.

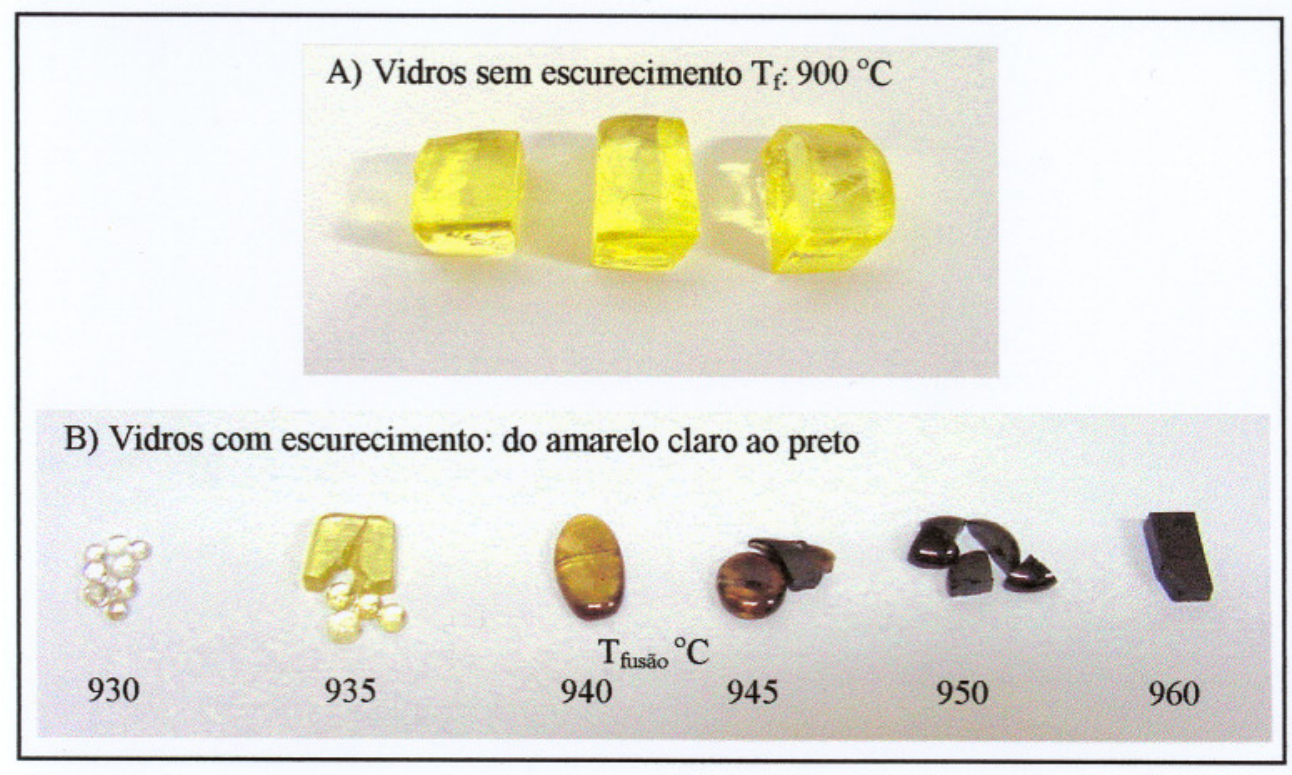

Figura 60 - Imagens de vidros produzidos: A) vidros fundidos a temperatura normal, B) vidros do amarelo claro ao preto com diferentes intensidades de escurecimento controlado pela temperatura de fusão $\left(20 \%\left[\mathrm{Sb}\left(\mathrm{PO}_{3}\right)_{3}\right]_{n}-80 \% \mathrm{Sb}_{2} \mathrm{O}_{3}\right)$.

Verificou-se que com um controle da temperatura é possível variar a intensidade do escurecimento nos vidros. A Figura 61 apresenta o espectro de absorção óptica na região do UV-VIS para os vidros com efeito de escurecimento. $\mathrm{O}$ deslocamento na borda de absorção para maiores comprimentos de onda indica o escurecimento dos vidros. 


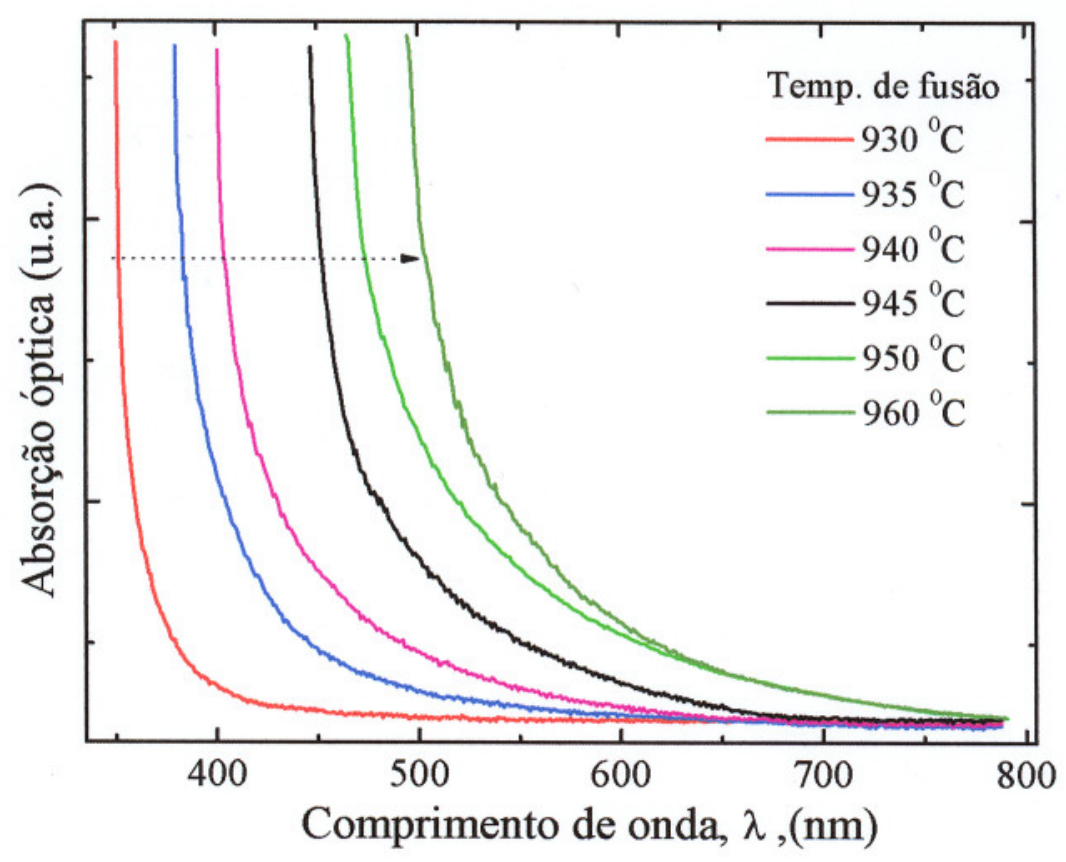

Figura 61 - Deslocamento da borda de absorção óptica para vidros $20 \%\left[\mathrm{Sb}\left(\mathrm{PO}_{3}\right)_{3}\right]_{n}-$ $80 \% \mathrm{Sb}_{2} \mathrm{O}_{3}$ com efeito de escurecimento. A seta indica o sentido de aumento da temperatura de fusão.

Com o intuito de se obter informações sobre este efeito de escurecimento nos vidros, causado pelo aumento da temperatura de fusão, realizamos medidas de XANES da borda $\mathrm{K}$ do fósforo para estas amostras. Com estes dados podemos verificar se ocorrem mudanças tanto no estado de oxidação do fósforo como na estrutura ao redor do fósforo. Apresentamos também na seqüência medidas de microscopia eletrônica de varredura dos vidros com efeito de escurecimento. 


\subsubsection{XANES da borda $\mathrm{K}$ do fósforo para vidros com escurecimento}

A Figura 62 mostra os espectros de XANES da borda $\mathrm{K}$ do fósforo para os vidros com efeito de escurecimento. Segundo estes resultados podemos concluir que esteja ocorrendo uma diminuição na conectividade entre os grupos fosfatos quanto mais escuro o vidro, observando a queda na intensidade da linha branca (pico em $2148 \mathrm{eV}$ ), pois como já mencionamos na seção 3.1.8.1, o aumento na intensidade da linha branca é relacionado com aumento no comprimento das cadeias de fosfatos e quebra de simetria entre grupos tetraédricos $\mathrm{PO}_{4}$. Nenhuma alteração no estado de oxidação do fósforo pode ser notada, pois não há deslocamento em energia da linha branca.

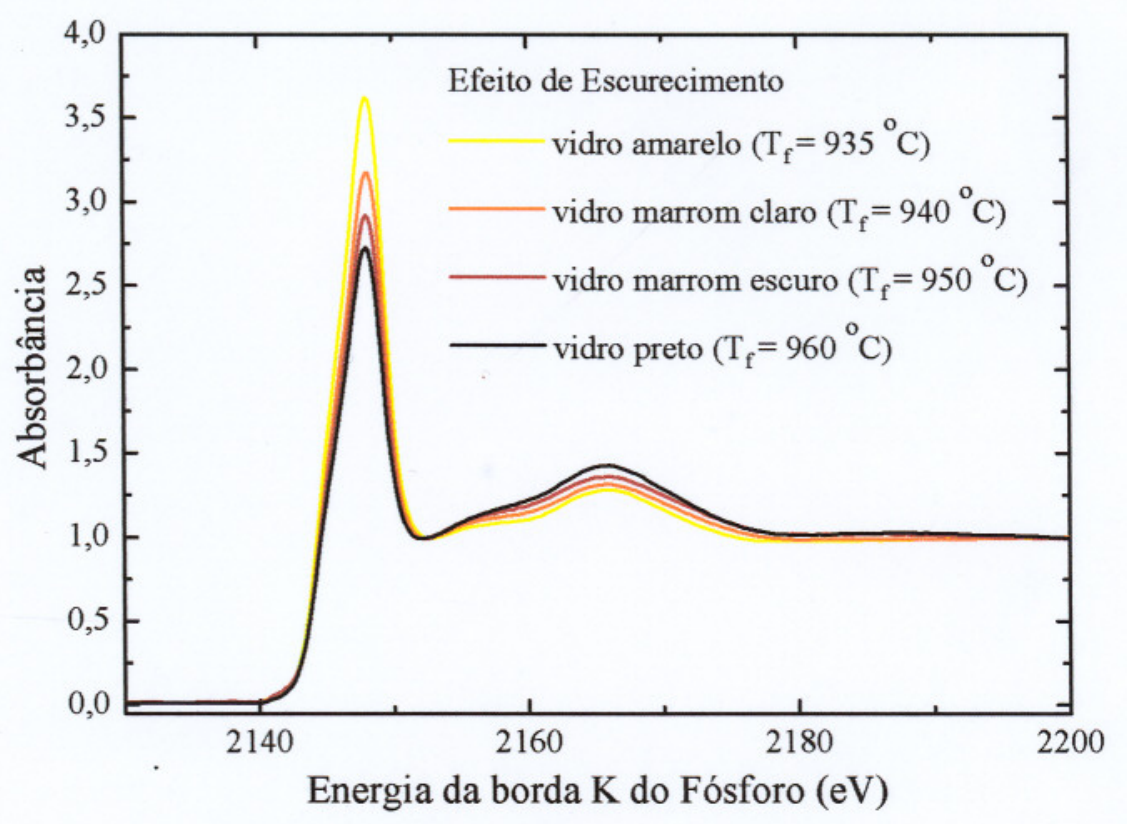

Figura 62 - Espectro de XANES da borda $\mathrm{K}$ do fósforo para vidros $20 \%\left[\mathrm{Sb}\left(\mathrm{PO}_{3}\right)_{3}\right]_{n}-80 \%$ $\mathrm{Sb}_{2} \mathrm{O}_{3}$ preparados a diferentes temperaturas de fusão.

Provavelmente as amostras estejam perdendo elementos mais leves como o oxigênio e fósforo com o aumento da temperatura de fusão, alterando a estrutura formada pelas cadeias de fosfatos no vidro. Esta suposição é bastante coerente pois observamos também a formação de partículas de antimônio metálico dissolvido no vidro, por resultados de MEV apresentados a seguir 
3.1.9.2 Microscopia Eletrônica de Varredura para vidros com escurecimento

A Figura 63 mostra imagens de microscopia eletrônica de varredura, onde são observadas pequenas partículas de antimônio metálico dissolvidas nos vidros com efeito de escurecimento.
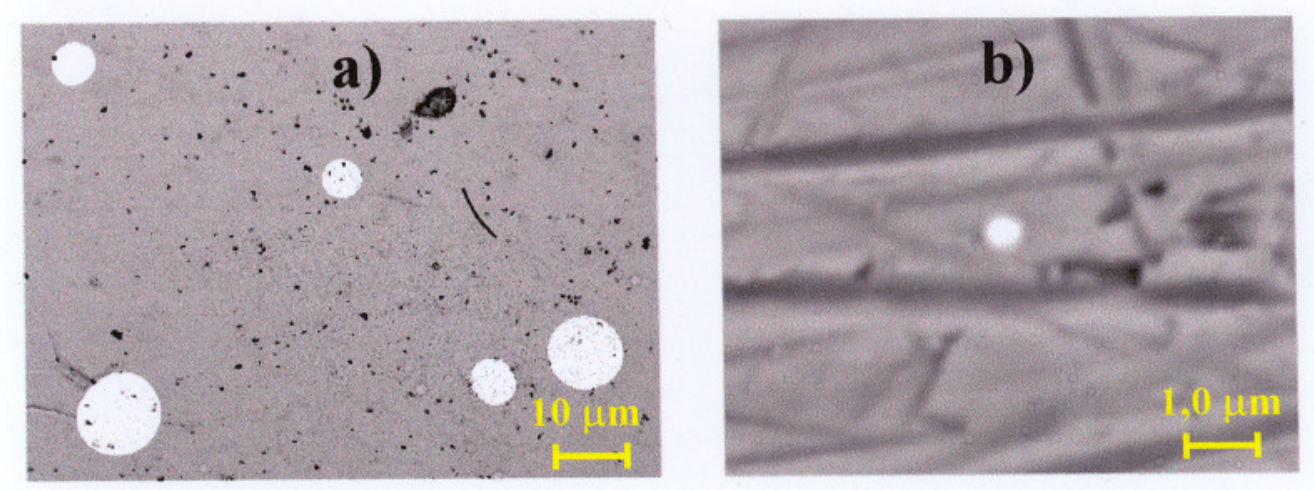

Figura 63 - Microscopia Eletrônica de Varredura de vidros $20 \%\left[\mathrm{Sb}\left(\mathrm{PO}_{3}\right)_{3}\right]_{n}-80 \% \mathrm{Sb}_{2} \mathrm{O}_{3}$ com escurecimento $\left(\mathrm{T}_{\mathrm{f}}=940^{\circ} \mathrm{C}\right)$. A região escura representa a matriz vitrea e as regiões claras são partículas com $100 \%$ de antimônio metálico. a) magnificação de $100 \mathrm{X}$; b) magnificação de $1000 \mathrm{X}$.

Este efeito de formação de partículas metálicas é típico para amostras com composições deficientes em oxigênio. Este fenômeno pode ser explicado pela formação de uma atmosfera altamente redutora pela degradação do cadinho de carbono vítreo. Com a temperatura o Carbono liberado pelo cadinho passa de $\mathrm{C}^{\circ}$ para $\mathrm{C}^{2+} \mathrm{e} \mathrm{C}^{4+}$ formando $\mathrm{CO}$ e $\mathrm{CO}_{2}$. Dessa forma o Carbono perde elétrons reduzindo os átomos de $\mathrm{Sb}^{3+}$ do líquido fundido para $\mathrm{Sb}^{0}$. Este efeito foi também observado em vidros a base de Arsênio, produzidos em cadinhos de carbono vítreo e foi reportado por R. Balda et al.[139].

Outro fato interessante ocorre quando um vidro escuro é refundido mantendo-se a temperatura mais baixa, havendo recuperação da característica original do vidro como transparência visual e coloração amarela. Isto indica que os átomos de antimônio voltam a reagir com o oxigênio da atmosfera formando $\mathrm{Sb}^{3+}$ na forma de $\mathrm{Sb}_{2} \mathrm{O}_{3}$ na estrutura. Já o recozimento dos vidros escurecidos em atmosfera de $\mathrm{O}_{2}$ com temperatura próxima da $\mathrm{T}_{\mathrm{g}}$ não promove a recuperação da cor natural dos vidros. 


\subsection{Estudo dos Fenômenos Fotoinduzidos em Filmes de $\left[\mathrm{Sb}\left(\mathrm{PO}_{3}\right)_{3}\right]_{n}-$ $\mathrm{Sb}_{2} \mathrm{O}_{3}$}

Nesta seção apresentamos resultados de fotocontração em filmes, em função de diferentes parâmetros como: tempo de irradiação, potência de irradiação, composição química e atmosfera ao redor do filme. As medidas de fotocontração foram obtidas com um perfilômetro Talystep Taylor-Hobson. Realizamos também medidas de AFM e microscopia óptica.

Na seqüência apresentamos resultados de análises químicas por RBS, WDX e XPS de filmes irradiados e não irradiados com laser UV. Na parte de caracterização estrutural apresentamos resultados de XANES, Difração de raios-X, FTIR, Luminescência, e RPE dos filmes. Por último, mostramos a aplicabilidade do material para gravação óptica e holografia através de resultados de redes holográficas e medidas de eficiência de difração em tempo real. 


\section{EVOLUCÃO DO EFEITO DE FOTOCONTRACÃO}

\subsubsection{Fotocontração VS. Tempo e Potência de exposição ao laser}

O efeito de fotocontração nos filmes foi notado primeiro devido ao fotoclareamento observado visualmente após a exposição ao UV e foi confirmado por medidas de perfilometria da região irradiada com UV. O efeito de fotoclareamento ocorre gerando deslocamento de $\sim 30 \mathrm{~nm}$ do bandgap $(3,58 \mathrm{eV}, 347 \mathrm{~nm})$ para maiores energias $(4,01 \mathrm{eV}, 310 \mathrm{~nm})$ como apresentado na Figura 64. Os valores do bandgap foram obtidos plotando-se $(\alpha h v)^{1 / 2}$ vs. hu segundo o formalismo de Urbach para materiais amorfos $[70,92]$.

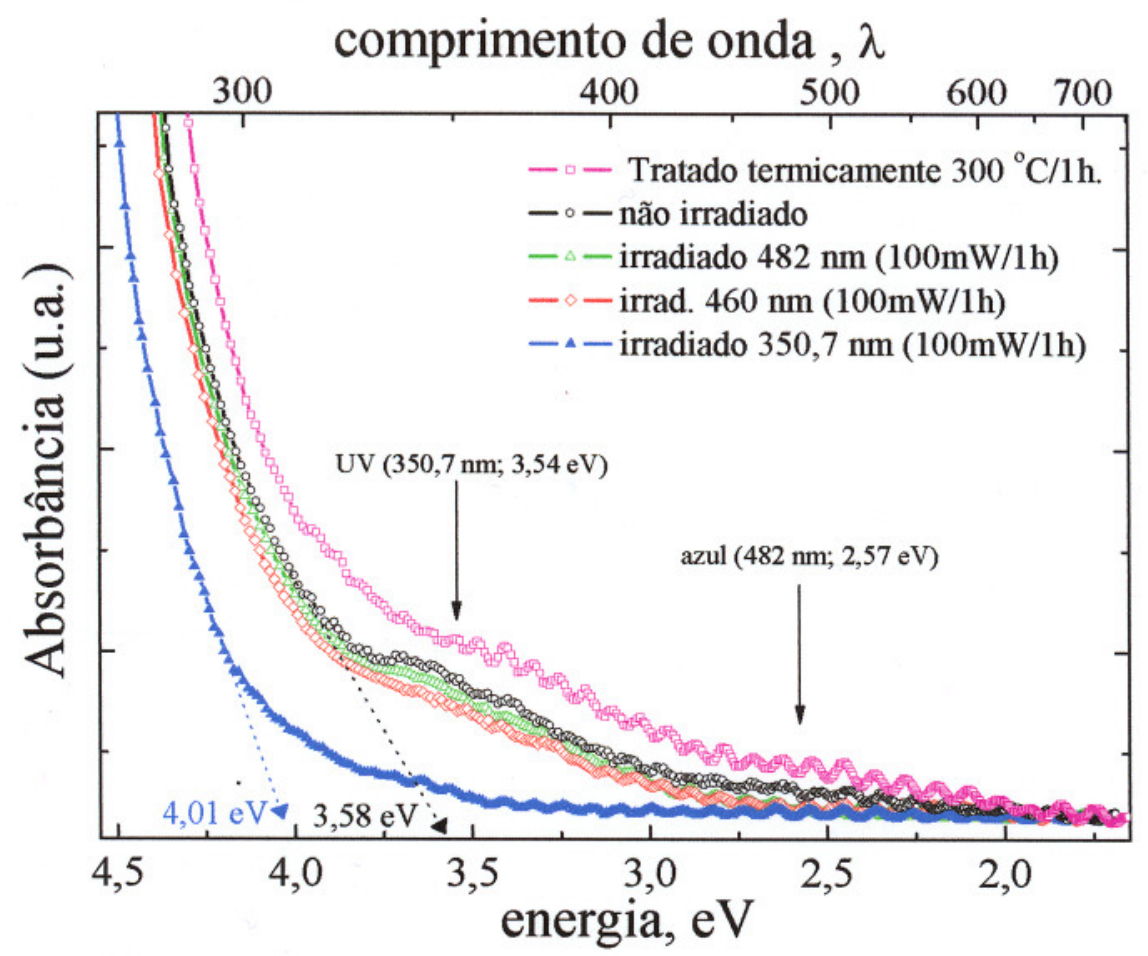

Figura 64 - Deslocamento da borda de absorção óptica em filmes $20 \%\left[\mathrm{Sb}\left(\mathrm{PO}_{3}\right)_{3}\right]_{n}-80 \% \mathrm{Sb}_{2} \mathrm{O}_{3}$ irradiados com $100 \mathrm{~mW}$ em diferentes comprimentos de onda (fotoclareamento) e filme tratado termicamente (fotoescurecimento).

Também observamos um pequeno deslocamento do bandgap para irradiações com $\lambda=482$ e $460 \mathrm{~nm}$. No caso de um filme tratado termicamente verificamos um efeito contrário (fotoescurecimento), com deslocamento do bandgap para menores energias (Figura 64). Nesses últimos casos não foi observado efeito de fotocontração nos filmes. 
A Figura 65-a) mostra o resultado de fotocontração obtido em filme de 3,5 $\mu \mathrm{m}$ de espessura irradiado com laser UV sem a utilização de mascara entre amostra e feixe laser. Nota-se neste caso que a forma da fotocontração apresenta o mesmo perfil de intensidade do feixe de laser e aproximadamente o mesmo diâmetro $\left(1 / \mathrm{e}^{2}=1,6 \mathrm{~mm}\right)$ do feixe do laser de $\mathrm{Kr}^{+}$utilizado.
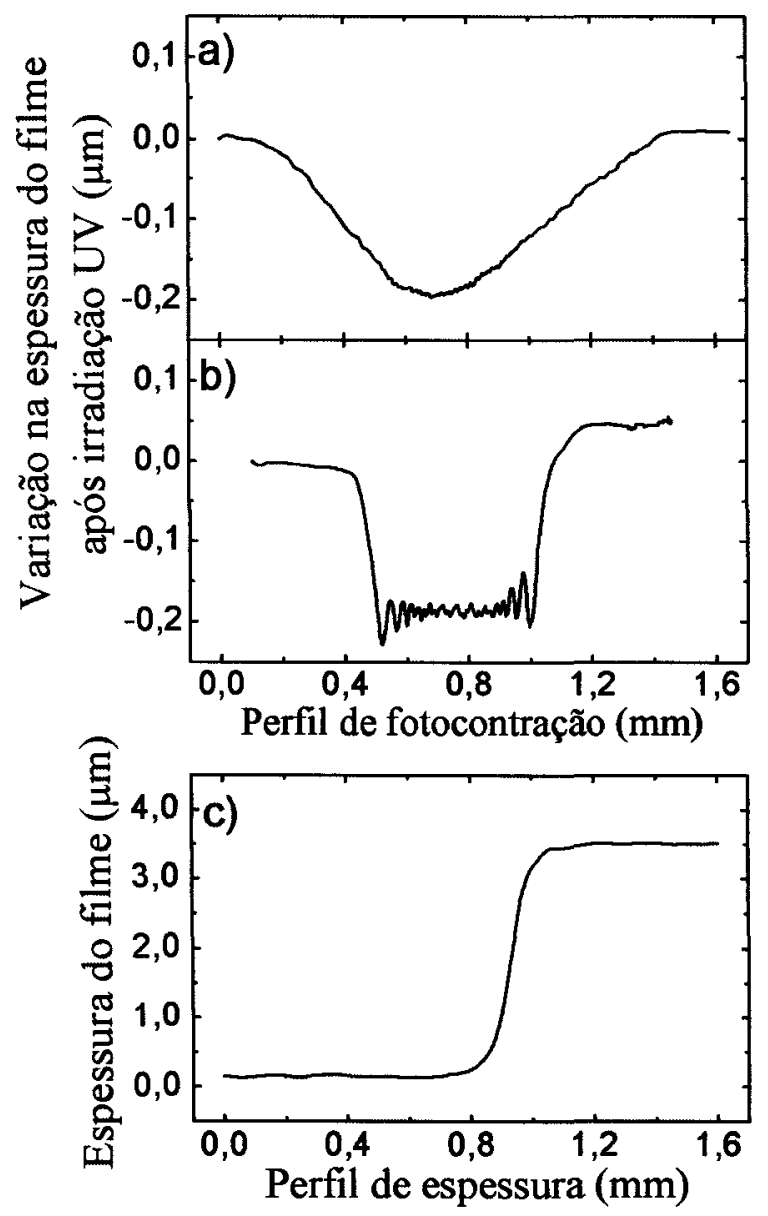

Figura 65 - a) Fotocontração em filme de 3,5 $\mu \mathrm{m}$ irradiado com feixe de laser UV sem a utilização de máscara, b) Fotocontração no filme irradiado com a utilização de máscara retangular $(0,5 \times 2,0 \mathrm{~mm})$ na superficie da amostra c) Perfil da espessura do filme medida por perfilometria. (filme de $20 \%\left[\mathrm{Sb}\left(\mathrm{PO}_{3}\right)_{3}\right]_{n}-80 \% \mathrm{Sb}_{2} \mathrm{O}_{3}$; irradiação: $5 \mathrm{~W} / \mathrm{cm}^{2}, 1$ hora) 
A partir daí notamos que o material apresentava boa resposta de fotocontração em relação à forma do feixe e intensidade da radiação. A Figura 65-b) mostra o perfil de fotocontração do filme irradiado utilizando-se uma máscara retangular colocada na superfície do filme. Além do perfil da fotocontração acompanhar a forma imposta pela mascara ao feixe do laser, pode-se observar inclusive a gravação de um padrão de interferência dentro do buraco criado pela fotocontração. Este padrão de interferência é relacionado com as difrações de borda causadas no feixe de laser pela mascar utilizada. A partir destes resultados realizamos vários experimentos a fim de determinar o comportamento de fotocontração em função de diferentes parâmetros como tempo e potência do laser de irradiação.

A Figura 66 apresenta o perfil da fotocontração medido por perfilometria em um filme após irradiação com laser UV utilizando-se máscaras com furos circulares de aproximadamente $0,8 \mathrm{~mm}$ de diâmetro (Figura 67). A partir deste tipo de medida foram obtidos os valores de fotocontração para amostras irradiadas em função de parâmetros como tempo de exposição, potência do laser, tipo de atmosfera, etc. A distância definida por "Média" da fotocontração para um perfil é a média aritmética do valor da fotocontração das duas bordas do perfil, sem considerar as variações devido às difrações de borda como mostra a Figura 66.

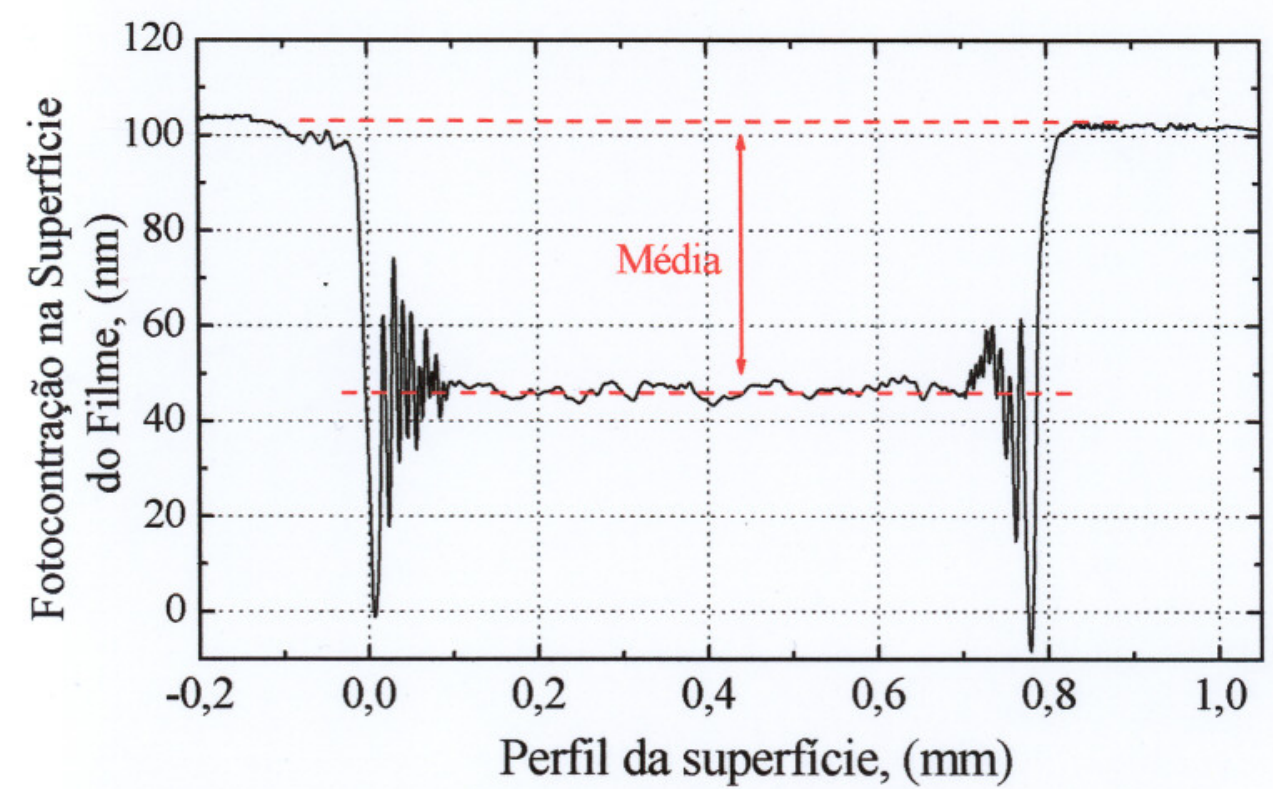

Figura 66 - Perfil da fotocontração provocada por laser na superficie de um filme de $20 \%$ $\left[\mathrm{Sb}\left(\mathrm{PO}_{3}\right)_{3}\right]_{n}-80 \% \mathrm{Sb}_{2} \mathrm{O}_{3}$, (espessura: $\left.1,0 \mu \mathrm{m}\right)$ exposto a $100 \mathrm{~mW}$ de $\mathrm{UV}\left(5 \mathrm{~W} / \mathrm{cm}^{2}\right)$ por 4 horas. 


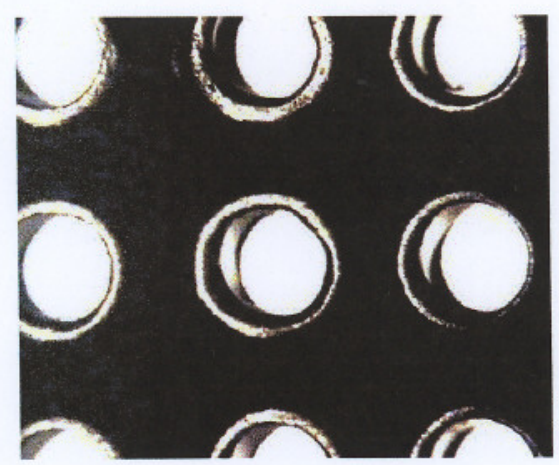

Figura 67 - Máscaras com furos circulares de aproximadamente $0,8 \mathrm{~mm}$ de diâmetro em lâmina de metal utilizadas no processo de irradiação de filmes com laser UV.

A Figura 68 apresenta um panorama de imagens de fotocontração na superfície de filmes, obtidos por microscopia óptica, microscopia de força atômica, e perfilometria.

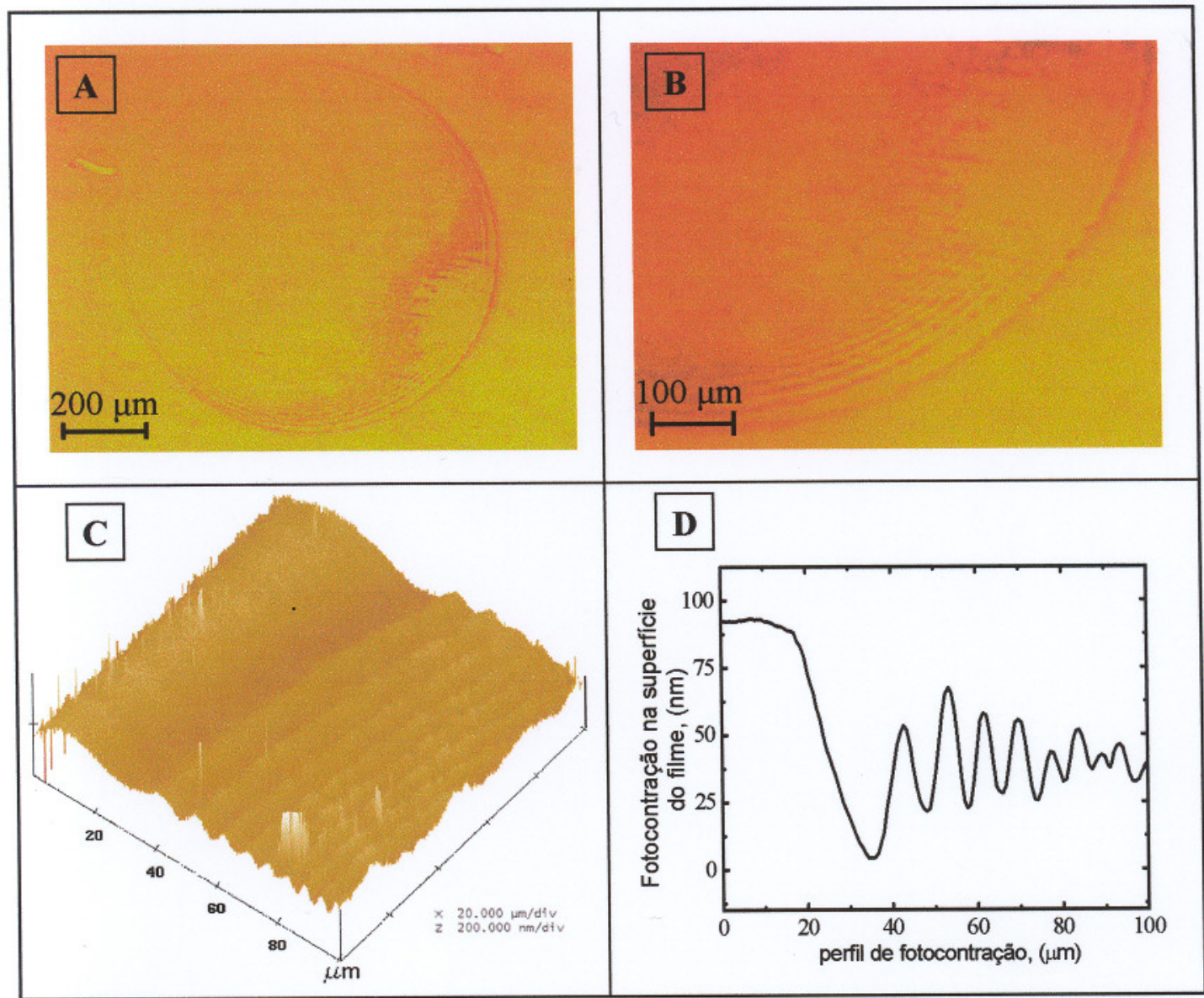

Figura 68 - Imagens de fotocontração na superficie de filmes de $20 \%\left[\mathrm{Sb}\left(\mathrm{PO}_{3}\right)_{3}\right]_{n}-80 \% \mathrm{Sb}_{2} \mathrm{O}_{3}$ (espessura: $1,0 \mu \mathrm{m})$ expostos a $100 \mathrm{~mW}$ de UV $\left(5 \mathrm{~W} / \mathrm{cm}^{2}\right)$ por 4 horas. A) e B) microscopia óptica; C) microscopia de força atômica; D) Perfilometria por talystep. 
A partir destes resultados de fotocontração, obtivemos uma seqüência de medidas de perfilometria para amostras irradiadas em função de parâmetros como tempo e potência de exposição ao laser. Dessa forma traçamos gráficos que mostram o comportamento da fotocontração, apresentados a seguir.

A Figura 69 mostra a evolução da fotocontração obtida para um filme de $0,8 \mu \mathrm{m}$ de espessura irradiado com $100 \mathrm{~mW}$ de potência $\left(5,0 \mathrm{~W} / \mathrm{cm}^{2}\right)$ de laser UV $(350,7 \mathrm{~nm})$, para até 10 horas de exposição ao laser. A fotocontração aumenta abruptamente para tempos de exposição até 2 horas e após 4 horas de exposição ao laser o efeito tende à saturação.

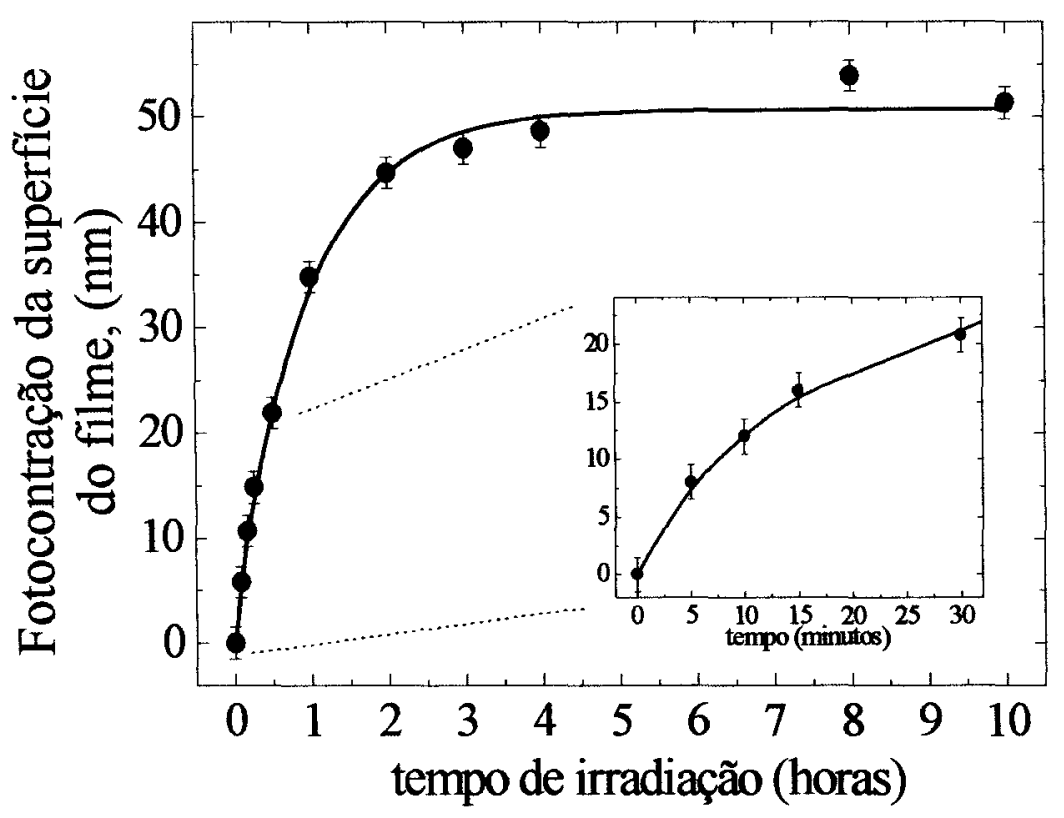

Figura 69 - Fotocontração em função do tempo de irradiação em filmes de $20 \%\left[\mathrm{Sb}\left(\mathrm{PO}_{3}\right)_{3}\right]_{n}-80$ $\% \mathrm{Sb}_{2} \mathrm{O}_{3}$ (espessura:0,8 $\mu \mathrm{m}$ ) expostos a $5 \mathrm{~W} / \mathrm{cm}^{2}$ de UV $(100 \mathrm{~mW}$ ). As linhas sólidas foram incluídas como referência visual.

Como detalhado na ampliação da região de 0 a 30 minutos de exposição o material mostra uma resposta bastante sensível em relação à evolução da fotocontração com variações de aproximadamente $1,0 \mathrm{~nm}$ para cada minuto de irradiação. Deve-se lembrar que a resolução do Perfilômetro utilizado é de $0,5 \mathrm{~nm}(5 \AA)$ na escala mais sensivel do equipamento.

A Figura 70 apresenta a evolução da fotocontração em função do tempo de exposição de até 2 horas para diferentes potências (Figura 70-a) e fotocontração em 
função da potências de irradiação (Figura 70-b) de 50 a $300 \mathrm{~mW}\left(2,5-15,0 \mathrm{w} / \mathrm{cm}^{2}\right)$. As curvas de ajuste são para melhor visualização da evolução da fotocontração.

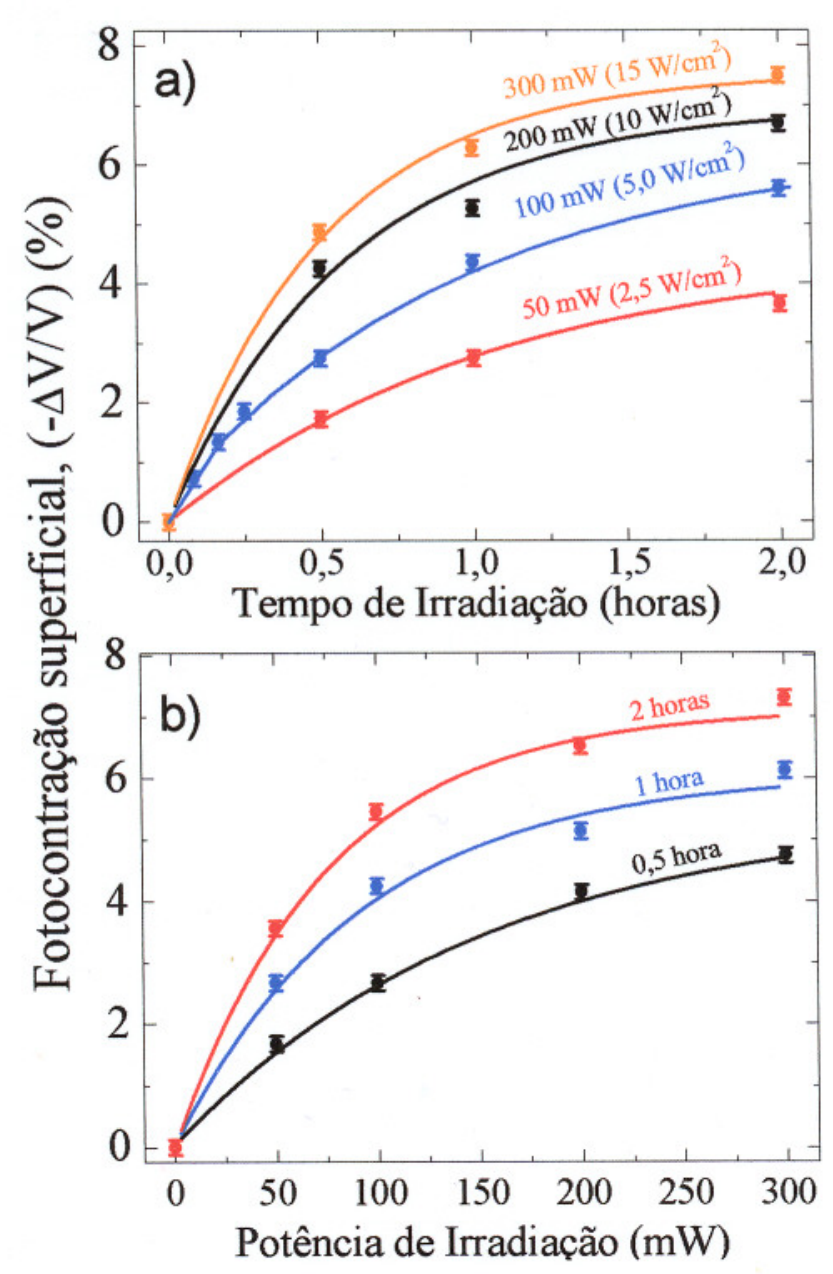

Figura 70 - Fotocontração em um filme de $20 \%\left[\mathrm{Sb}\left(\mathrm{PO}_{3}\right)_{3}\right]_{n}-80 \% \mathrm{Sb}_{2} \mathrm{O}_{3}$ (espessura:0,8 $\mu \mathrm{m}$ ), a) em função do tempo de exposição, b) em função da potência de irradiação UV. As linhas sólidas foram incluídas como referência visual.

Pode-se observar que o efeito de fotocontração apresenta forte dependência com a potência utilizada durante a irradiação. Acreditamos que para potências acima de 300 $\mathrm{mW}$ no feixe ocorra saturação do efeito de fotocontração, pois as curvas relativas a 200 e $300 \mathrm{~mW}$ de potência estão mais próximas em comparação com as curvas para potências menores $(50 \mathrm{e} 100 \mathrm{~mW})$. A fotocontração evolui não linearmente com a potência de exposição ao laser, mesmo para diferentes tempos e potências de exposição. 


\subsubsection{Fotocontração em função da concentração de $\left[\mathrm{Sb}\left(\mathrm{PO}_{3}\right)_{3}\right]_{n}$}

A Figura 71 mostra a evolução da fotocontração em função da concentração de polifosfato de antimônio para filmes de $1,0 \mu \mathrm{m}$ de espessura irradiados com $100 \mathrm{~mW}$ $\left(5,0 \mathrm{~W} / \mathrm{cm}^{2}\right)$ por 4 horas. Para concentrações em torno de 10 moles $\%$ de $\left[\mathrm{Sb}\left(\mathrm{PO}_{3}\right)_{3}\right]_{n}$ a contração é menor que $2,0 \%$, atingindo máximo de $\sim 8,0 \%$ de fotocontração para $25 \%$ de polifosfato. Acima desse valor o efeito é diminuído drasticamente, provavelmente devido aos efeitos de cristalização das amostras como mostrado em resultados anteriores.

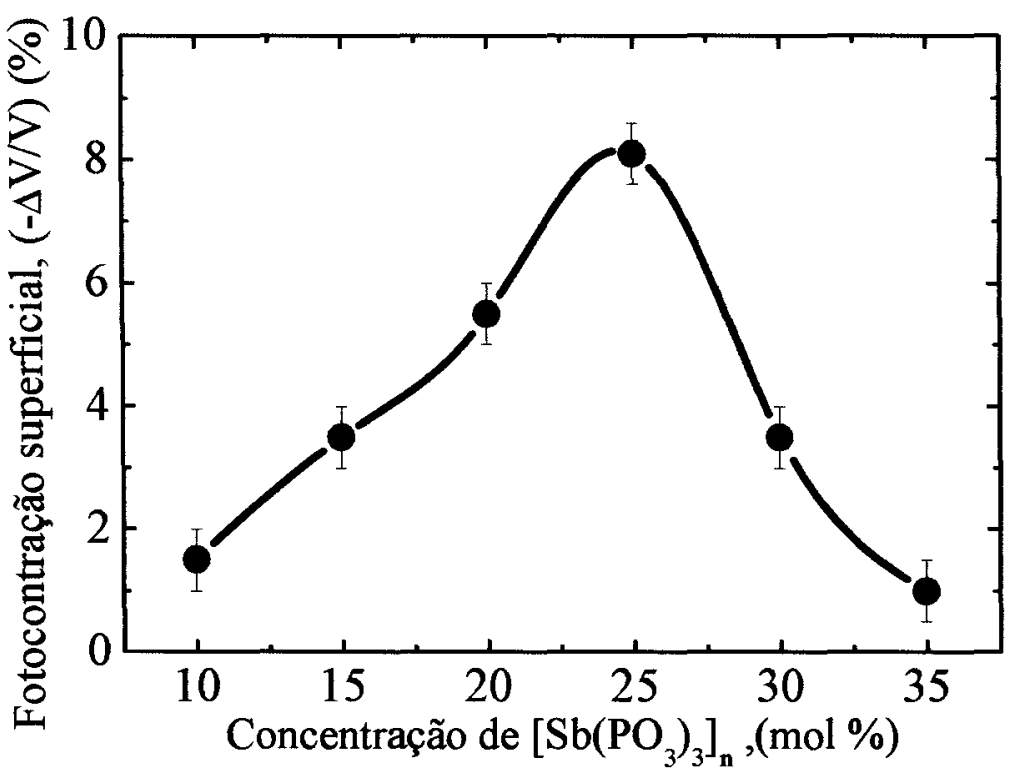

Figura 71 - Fotocontração em filmes de $x\left[\mathrm{Sb}\left(\mathrm{PO}_{3}\right)_{3}\right]_{n}-(100-x) \mathrm{Sb}_{2} \mathrm{O}_{3}$ (espessura:1,0 $\mu \mathrm{m}$ ) irradiado por 4 horas com $100 \mathrm{~mW}\left(5,0 \mathrm{~W} / \mathrm{cm}^{2}\right)$, em função da concentração de formador vítreo $\left[\mathrm{Sb}\left(\mathrm{PO}_{3}\right)_{3}\right]_{n}$. A linha sólida foi incluída como referência visual.

Como verificamos anteriormente as mudanças na estrutura dos vidros devido à concentração de $\left[\mathrm{Sb}\left(\mathrm{PO}_{3}\right)_{3}\right]_{n}$ consistem em alterações na conectividade entre grupos fosfatos que podem, nesse caso, ser do tipo $Q^{0}$ para os vidros e $Q^{2}$ para o formador polifosfato. Como os grupos fosfatos $\left(\mathrm{PO}_{4}\right)^{3-}$ são os principais responsáveis não só pela formação da estrutura vitrea como também pelas propriedades de polimerização da estrutura, acreditamos que o efeito de fotocontração nos filmes esteja ligado diretamente com a disposição das cadeias de fosfato na estrutura dos filmes.Além disso este resultado mostra que o efeito de fotocontração nos filmes depende principalmente da concentração de grupos $\mathrm{PO}_{4}$ nas amostras e da fase (amorfa ou cristalina) dos mesmos. 


\subsubsection{Fotocontração em diferentes atmosferas e no vácuo}

Após vários estudos em efeitos fotoinduzidos, uma atenção maior tem sido dada ao problema do fenômeno fotoinduzido assistido por oxigênio em vidros e filmes. $\mathbf{O}$ ponto inicial para estes estudos foi à observação de Tanaka et al. [140] que após iluminar filmes de $\mathrm{Ge}_{35} \mathrm{~S}_{65}$ com luz próxima ao bandgap, verificou um deslocamento na borda de absorção óptica para a região do azul dependente da pressão do ar. Resultados similares, isto é, a dependência do deslocamento no bandgap em função da pressão do ar e o aparecimento de uma banda de absorção na região entre $800-870 \mathrm{~cm}^{-1}$ (indicando a oxidação do $\mathrm{Ge}$ ) também foram observados em vidros ricos em enxofre [141].

Neste caso, os autores concluíram que o clareamento (bleaching) fotoinduzido em ar é provavelmente associado com o aparecimento da ligação Ge-O-Ge (as ligações Ge-Ge são substituídas por ligações Ge-O mais fortes e, então, a densidade de estados localizados diminui, enquanto que o clareamento induzido termicamente é um fenômeno intrínseco, mais provavelmente refletindo um aumento da ordem na rede). Similarmente estudos em vidros GaGeS produzidos em vácuo mostraram que a irradiação dos vidros com laser UV em atmosfera rica em $\mathrm{O}_{2}$ promove a formação de ligações $\mathrm{Ge}-\mathrm{O}$ por adsorção de oxigênio, favorecendo os efeitos fotoinduzidos (fotoexpansão e fotoclareamento) no material [142].

No entanto, Kawaguchi et al. [143] mostraram por ressonância spin-eletron (ESR) e analise química por espectroscopia de elétron (ESCA) que o clareamento induzido através da iluminação em filmes Ge-S resulta da fotopolimerização, e que a foto-oxidação ocorre principalmente na superficie do filme. Esta hipótese foi ilustrada estudando a cinética do fotoclareamento e medindo o perfil do oxigênio através de ESCA. Sendo assim, parece que (i) a foto-oxidação acentua o deslocamento para o azul do bandgap, mas não é a única origem do clareamento, e (ii) uma camada fina do filme (acima de $200 \AA$ ) é oxidada através de uma iluminação prolongada.

As mudanças fotoinduzidas no bandgap assistidas por oxigênio também foram observadas em filmes depositados obliquamente. Harshavardhan e Hedge [144] observaram mudanças irreversíveis em filmes de germânio depositados a $80^{\circ} \mathrm{e}$ atribuíram a origens extrínsecas. Os principais argumentos para esta conclusão estão baseados em medidas de espectroscopia de fotoelétron (XPS) e medidas de 
espectroscopia de massa. Estas indicam uma perda de material da superfície do filme devido à vaporização de uma parte de óxido.

Deste modo, foi interessante verificar no presente trabalho o papel de oxigênio e outros gases no efeito de fotocontração dos filmes antes e após a irradiação com UV. A Figura 72 apresenta os resultados de fotocontração em filmes de $20 \%\left[\mathrm{Sb}\left(\mathrm{PO}_{3}\right)_{3}\right]_{n}-80$ $\% \mathrm{Sb}_{2} \mathrm{O}_{3}$ com $1,0 \mu \mathrm{m}$ de espessura irradiados por 4 horas com $100 \mathrm{~mW}$ e $300 \mathrm{~mW}$ de potência em diferentes atmosferas $\left(\mathrm{O}_{2}, \mathrm{Ar}, \mathrm{He}, \mathrm{N}_{2}\right.$ e vácuo $)$.

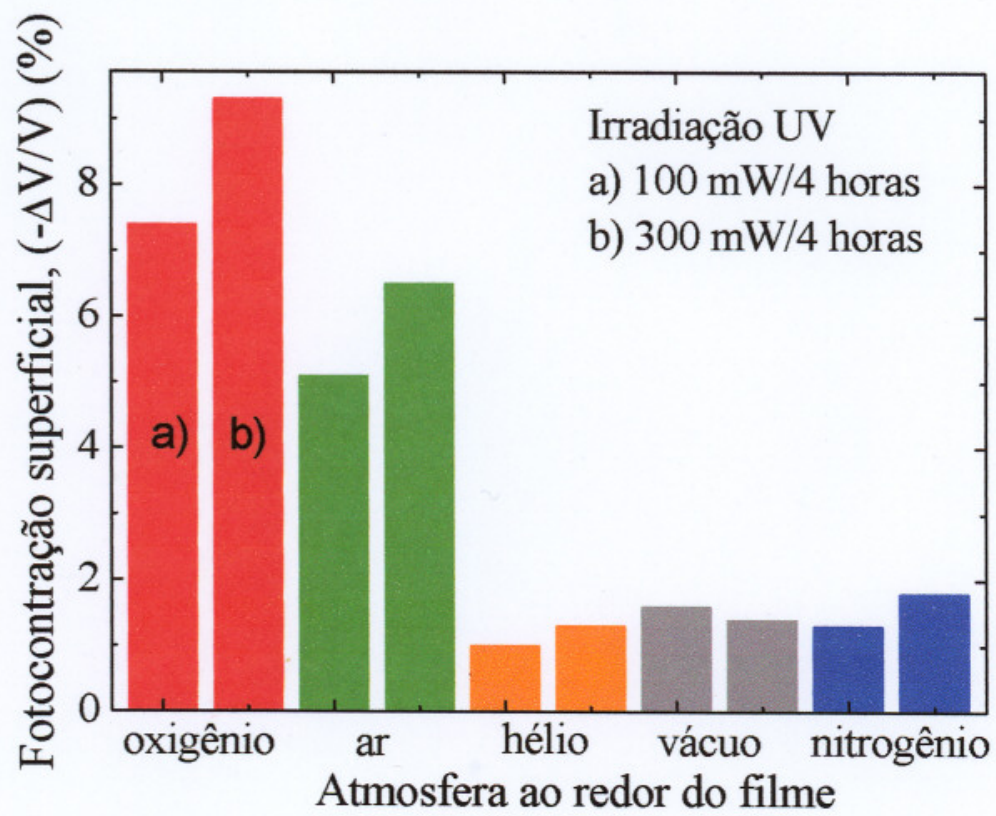

Figura 72 - Variação da fotocontração em função da atmosfera em filmes de $20 \%\left[\mathrm{Sb}\left(\mathrm{PO}_{3}\right)_{3}\right]_{n}$ $80 \% \mathrm{Sb}_{2} \mathrm{O}_{3}$ (espessura: $1,0 \mu \mathrm{m}$ ) irradiados com laser $\mathrm{UV}$ por 4 horas. a) com $100 \mathrm{~mW}(5,0$ $\left.\mathrm{W} / \mathrm{cm}^{2}\right)$, b) com $300 \mathrm{~mW}\left(15 \mathrm{~W} / \mathrm{cm}^{2}\right)$. (desvio médio: $0,5 \%$ )

Observamos que o efeito de fotocontração é muito mais acentuado $(\sim 50 \%$ maior) em atmosfera rica em $\mathrm{O}_{2}$, do que no filme irradiado em atmosfera ambiente. $\mathrm{O}$ - filme irradiado em atmosferas de $\mathrm{He}, \mathrm{N}_{2}$ e no vácuo apresentou efeito de fotocontração muito pequeno (menor que $2 \%$ ).

Como citado antes, sabe-se que a atmosfera apresenta forte influencia nos efeitos fotoinduzidos em materiais, agindo como catalisador na formação de novas ligações químicas, alterando a estrutura do material irradiado de forma mais intensa durante a irradiação com luz [140-144]. Dessa forma acreditamos que atmosferas ricas principalmente em $\mathrm{O}_{2}$ venham a favorecer o efeito de fotocontração nos filmes não só pela possível adsorção na estrutura do material como em efeitos de foto-oxidação de 
partículas metálicas de antimônio que estejam em dissolvidas na estrutura do filme, como já mostrado na seção 3.1.9.2.

\subsubsection{Fotocontração em função da espessura do filme}

A Figura 73 apresenta o comportamento da fotocontração observado em filmes com espessura variando de $0,5 \mu \mathrm{m}$ a $9,7 \mu \mathrm{m}$. Filmes de $0,5 \mu \mathrm{m}$ apresentaram fotocontração ligeiramente menor que a média apresentada pelas amostras. Em filmes muito espessos $(8,0$ e $9,7 \mu \mathrm{m})$ observa-se uma queda bastante acentuada do efeito de fotocontração.

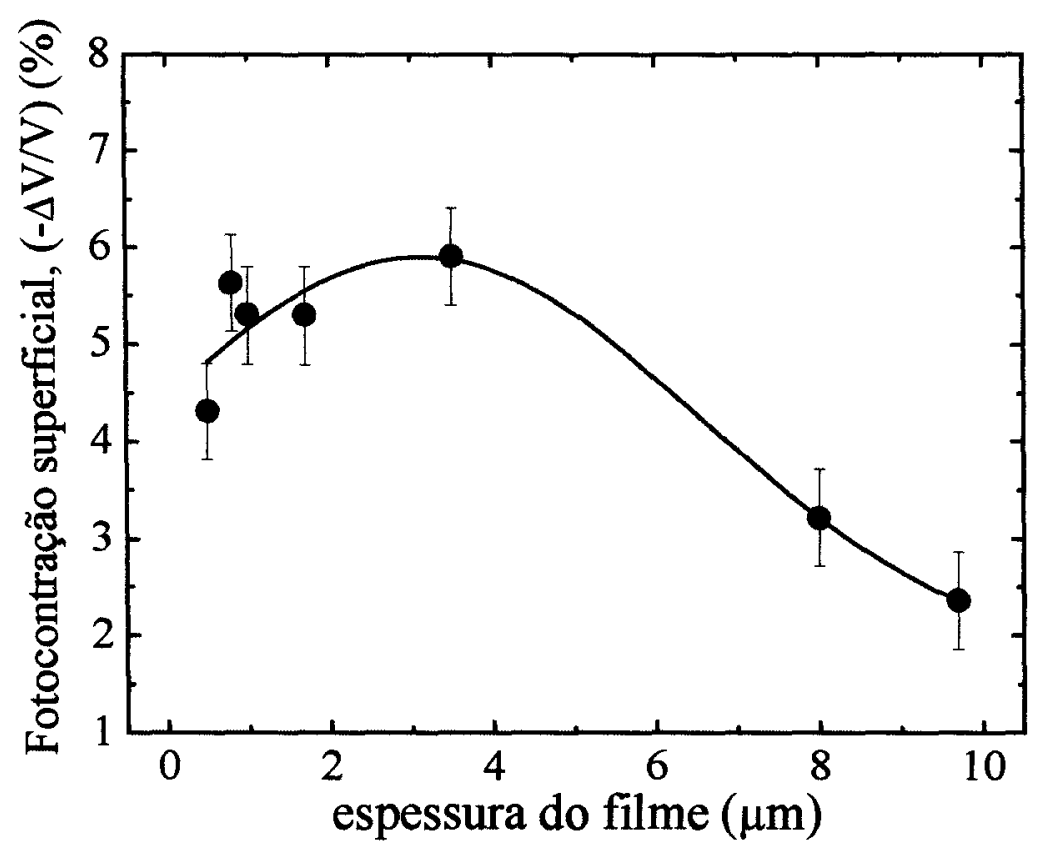

Figura 73 - Comportamento da fotocontração em função da espessura para filmes $20 \%$ $\left[\mathrm{Sb}\left(\mathrm{PO}_{3}\right)_{3}\right]_{n}-80 \% \mathrm{Sb}_{2} \mathrm{O}_{3}$, irradiados com laser $\mathrm{UV}(100 \mathrm{~mW} / 4$ horas $)$.

É esperado que em superficies muito finas (dezenas de nanômetros) os efeitos de mudança estrutural sejam diminuídos, pois finas camadas produzidas por evaporação térmica tendem a obter melhor arranjo estrutural sobre o substrato. Já em filmes muito espessos os efeitos de inomogeneidade composicional em função da espessura se tornam dominantes, e pode prejudicar a criação de efeitos fotoinduzidos. 


\section{CARACTERIZACÃO DO EFEITO DE FOTOCONTRACÃO POR ANÁLISES OUÍMICAS}

Nesta seção apresentamos resultados de análises químicas em filmes, obtidos pelas técnicas de RBS, WDX e XPS. As concentrações de elementos em filmes expostos e não expostos à irradiação UV foram obtidas.

\subsubsection{Retro-Espalhamento de Rutherford-RBS}

Apresentamos nesta seção resultados obtidos pela técnica de RetroEspalhamento de Rutherford (RBS), realizados no LAMFI - Laboratório de Análise de Materiais por Feixes Iônicos-IFUSP, coordenado pelo Professor Manfredo Tabaknics. Esta técnica permite a análise composicional em filmes, de forma que é possível observar pequenas variações na composição química ao longo da espessura de uma amostra em escala de dezenas de Ângstrons.

Inicialmente foi utilizada uma amostra ultrafina $(\sim 100 \mathrm{~nm})$ de TiAlTa utilizada para calibrar o equipamento. Essa medida fornece as posições dos picos em energia, e esses valores são utilizados para calibração. Através do programa RUMP (RBS Data Analisys, Simulation and Plotting) é possível obter simulações dos espectros extraindo parâmetros como concentração e espessura de camadas para cada elemento constituinte da amostra. Depois de obtido um espectro de simulação que se ajusta bem com o espectro experimental, se obtém do programa os valores relativos da concentração de cada elemento na amostra e a espessura da camada de material. Há simulações onde é necessário adicionar ao programa dados de várias camadas com diferentes espessuras e concentrações para obter um espectro que se ajuste bem com o experimental.

A Figura 74 mostra 2 exemplos de simulação para filme contendo antimônio, fósforo e oxigênio, com espessura de (a) 1000 e (b) 10000 ângstrons respectivamente. Essas simulações foram feitas para mostrar o efeito da espessura dos filmes nos espectros obtidos e também as posições dos picos. 

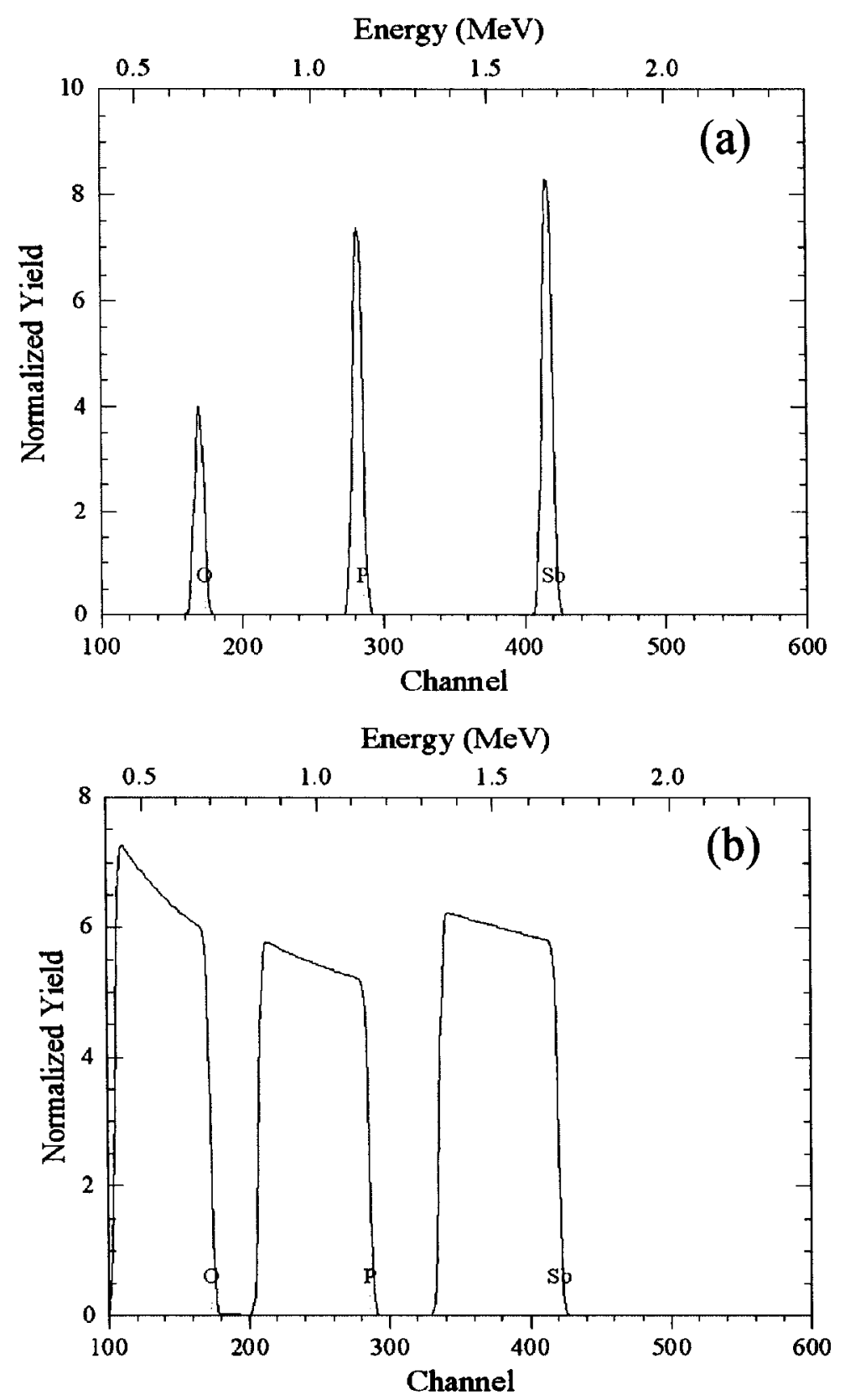

Figura 74 - Simulação do espectro de RBS para amostra composta por Sb, P, e O com (a) 1000 ângstrons e (b) com 10000 ângstrons de espessura.

Para se obter picos estreitos de RBS é necessário que a amostra possua de 0,01 a $0,1 \mu \mathrm{m}$ de espessura (100 a 1000 ângstrons), do contrário o feixe de íons retroespalhado pela amostra possui uma distribuição de energia muito grande, devido ao grande caminho que as partículas tem que percorrer até sair da amostra e atingir o detector. Esse efeito de alargamento pode ser observado na Figura 74 b. 


\subsubsection{Resultados de RBS para filmes de $\left[\mathrm{Sb}\left(\mathrm{PO}_{3}\right)_{3}\right]_{n}-\mathrm{Sb}_{2} \mathrm{O}_{3}$}

A seguir apresentamos os resultados de RBS obtidos para filmes com $5 \mu \mathrm{m}$ de espessura de $20 \%\left[\mathrm{Sb}\left(\mathrm{PO}_{3}\right)_{3}\right]_{\mathrm{n}}-80 \% \mathrm{Sb}_{2} \mathrm{O}_{3}$ não irradiados e irradiados com laser UV (5 $\mathrm{W} / \mathrm{cm}^{2}$ durante 6 horas). Na Figura 75 vemos os espectros de RBS para um filme não irradiado e outro irradiado. A única diferença perceptível entre os espectros está na região do canal do oxigênio (em torno do canal 150), mostrando um possível aumento na concentração desse elemento após a irradiação do filme com UV.

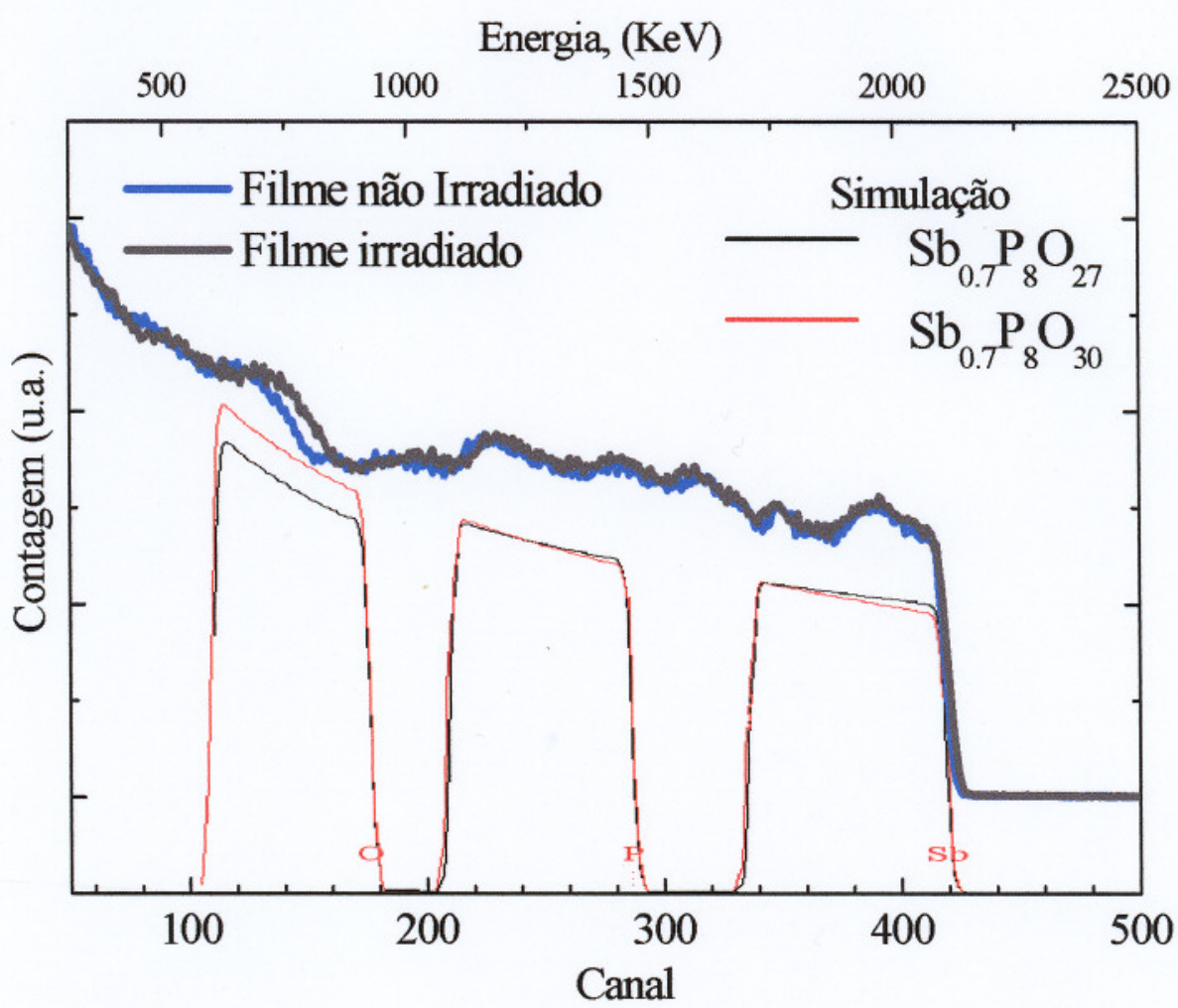

Figura 75 - Espectros de RBS obtido para os filmes de $20 \%\left[\mathrm{Sb}\left(\mathrm{PO}_{3}\right)_{3}\right]_{n}-80 \% \mathrm{Sb}_{2} \mathrm{O}_{3}$ (espessura: $5 \mu \mathrm{m}$ ) não irradiado e irradiado com $5 \mathrm{~W} / \mathrm{cm}^{2}$ durante 6 horas. As linhas sólidas (preta e vermelha) representam a simulação obtida pelo software RUMP.

Propusemos uma simulação do espectro de RBS introduzindo no programa RUMP um aumento na concentração do oxigênio, mostrado na Figura 75 como o aumento da intensidade das curvas de simulação (linhas sólidas vermelha e preta) na região do canal do oxigênio (em torno do canal 150). Nesta simulação consideramos quantidades estequiométricas (em at \%) de $\mathrm{Sb}_{0,7} \mathrm{P}_{8} \mathrm{O}_{27}$ para o filme não irradiado com $\mathrm{UV}$ e $\mathrm{Sb}_{0,7} \mathrm{P}_{8} \mathrm{O}_{30}$ para o filme após irradiação com UV. 


\subsubsection{Análises de WDX de Filmes de $\left[\mathrm{Sb}\left(\mathrm{PO}_{3}\right)_{3}\right]_{n}-\mathrm{Sb}_{2} \mathrm{O}_{3}$}

Através de medidas de composição por WDX (Wavelength Dispersive of X-ray) em filmes de $20 \%\left[\mathrm{Sb}\left(\mathrm{PO}_{3}\right)_{3}\right]_{n}-80 \% \mathrm{Sb}_{2} \mathrm{O}_{3}$, com $5 \mu \mathrm{m}$ de espessura observamos uma perda considerável de fósforo $(20 \%)$ após irradiação com $5 \mathrm{~W} / \mathrm{cm}^{2}(100 \mathrm{~mW}) \mathrm{de}$ potência de laser UV por até 6 horas. A variação nas composições de $\mathrm{Sb}, \mathrm{P}$ e $\mathrm{O}$ (em at \%) estão apresentadas na Figura 76.

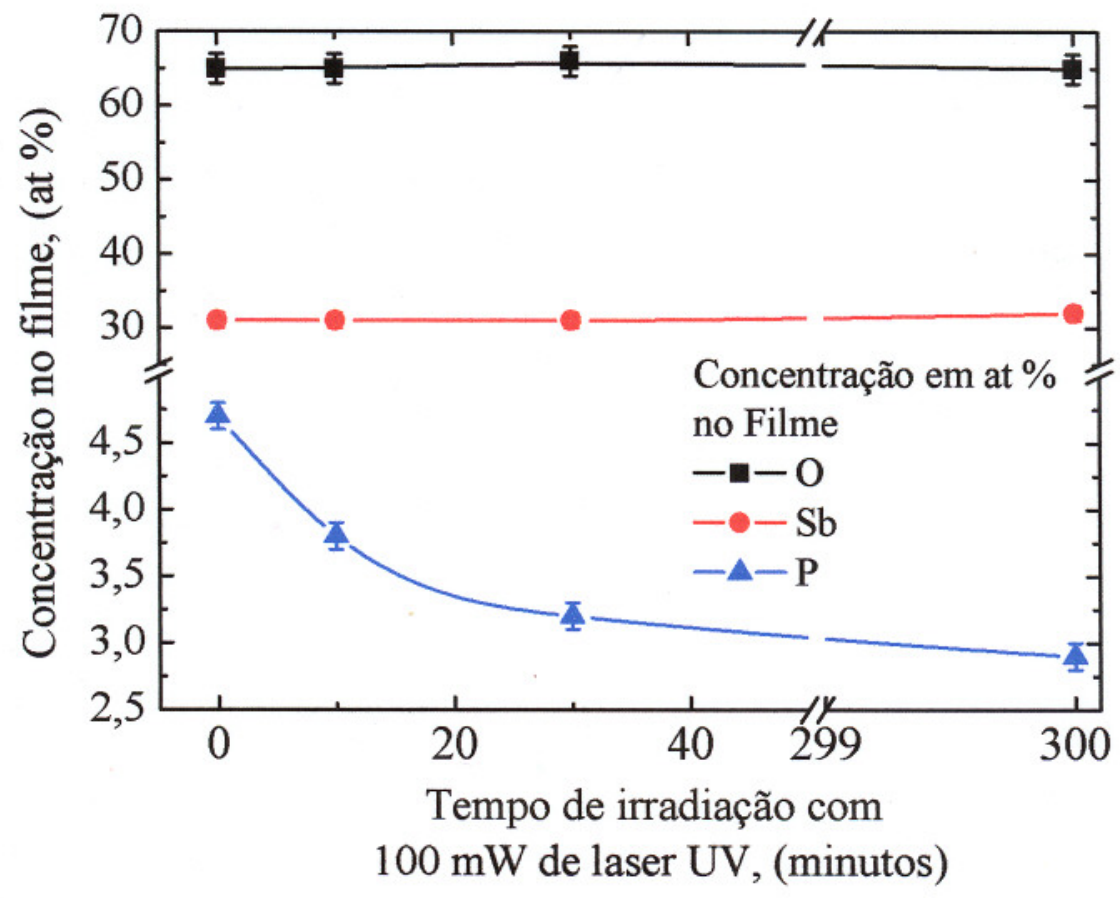

Figura 76 - Medida obtida por WDX, da composição de Sb, P e O em filme de $20 \%$ $\left[\mathrm{Sb}\left(\mathrm{PO}_{3}\right)_{3}\right]_{n}-80 \% \mathrm{Sb}_{2} \mathrm{O}_{3}$ (espessura:5 $\mu \mathrm{m}$ ), irradiado com diferentes tempos de exposição ao laser UV com $5 \mathrm{~W} / \mathrm{cm}^{2}(100 \mathrm{~mW})$.

Para comparação, a composição nominal (em at \%) de $\mathrm{Sb}, \mathrm{P}$ e $\mathrm{O}$ no sistema vítreo $x\left[\mathrm{Sb}\left(\mathrm{PO}_{3}\right)_{3}\right]_{n}-(100-x) \mathrm{Sb}_{2} \mathrm{O}_{3}$ é apresentada na Figura 77 , em função da quantidade, $x$, de formador vítreo $\left[\mathrm{Sb}\left(\mathrm{PO}_{3}\right)_{3}\right]_{n}$.

Para filmes produzidos a partir da evaporação de vidros com composição nominal de $x=20$ observa-se que as quantidades de O, Sb e P deveriam ser 63, 27 e 9 átomos \% respectivamente. Porém nestes filmes verificamos que as quantidades de $\mathrm{O}$, Sb e $\mathrm{P}$ são de 65, 30 e 4,7 átomos \% respectivamente. A perda de fósforo devido à preparação dos filmes por evaporação térmica já foi descrita em trabalho anterior [74]. 


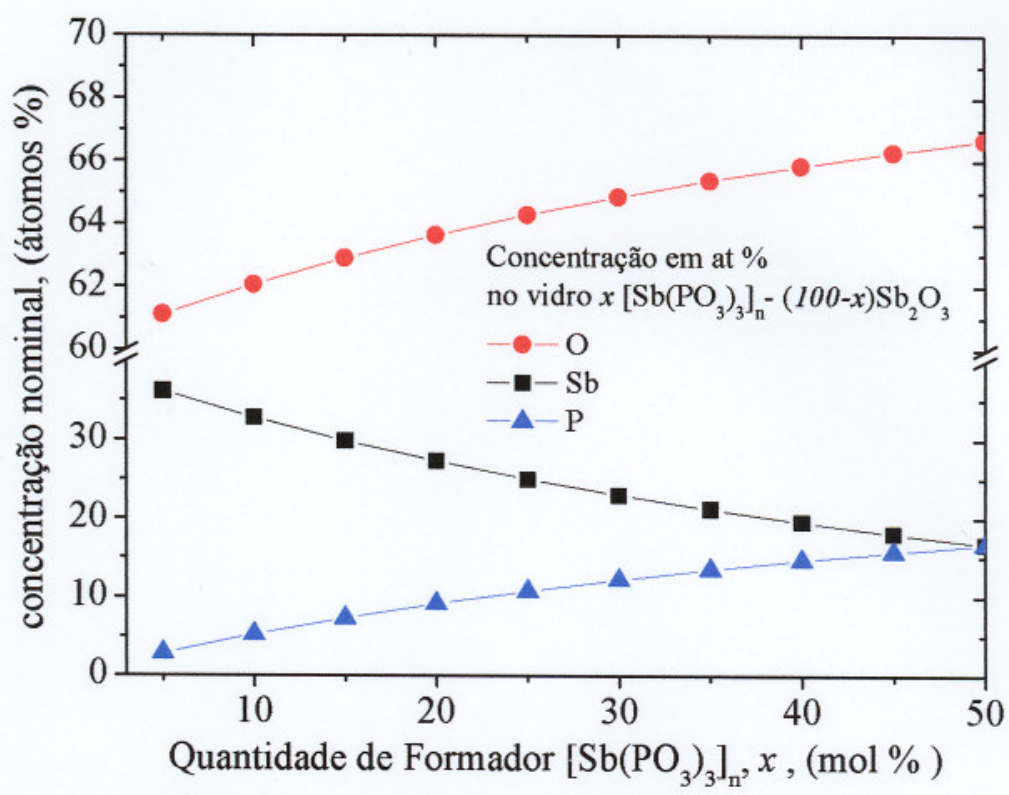

Figura 77 - Concentração nominal de Sb, $\mathrm{P}$ e $\mathrm{O}$ nos vidros de $x\left[\mathrm{Sb}\left(\mathrm{PO}_{3}\right)_{3}\right]_{n}-(100-x) \mathrm{Sb}_{2} \mathrm{O}_{3}$.

Entretanto é importante frisar que a irradiação UV também produz uma perda significativa de fósforo nos filmes, além das mudanças estruturais observadas por outras técnicas como XANES (seção 3.2.8). Como observa-se pela Figura 76, após 10 minutos de irradiação a quantidade de fósforo nos filme diminui de 4,7 para $\sim 3,8$ átomos $\%$ e após 30 minutos de exposição ao laser a quantidade de fósforo cai para $\sim 3,2$ at \%. Após exposição após 5 horas a concentração de fósforo está em torno de 2,8 at \% e esta perda parece estabilizar para longos tempos de irradiação analisando a forma da curva.

Por esse comportamento descrito acima podemos traçar um paralelo entre a evolução do efeito de fotocontração já estudado em função do tempo de exposição ao laser, correlacionando com a perda de fósforo como mostrado a seguir.

Pela Figura 78 nota-se que o comportamento da fotocontração é aproximadamente o inverso da curva de perda de fósforo com a exposição ao laser UV. Inclusive a região de saturação da fotocontração (após 100 minutos de irradiação) é próxima da região onde ocorre saturação na perda de fósforo, considerando-se o erro experimental na medida da concentração de fósforo por WDX que é maior do que a medida da fotocontração obtida por perfilometria. 


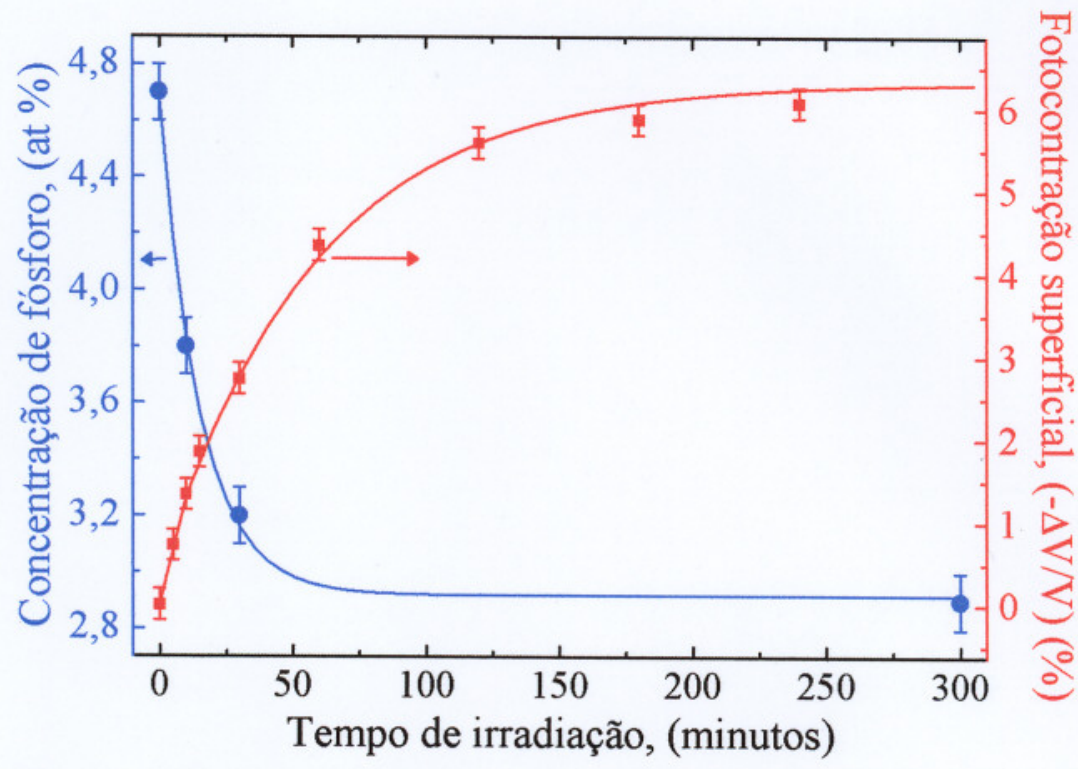

Figura 78 - Comparação da evolução da fotocontração com a perda de fósforo causada pela irradiação de Filmes de $20 \%\left[\mathrm{Sb}\left(\mathrm{PO}_{3}\right)_{3}\right]_{n}-80 \% \mathrm{Sb}_{2} \mathrm{O}_{3} \mathrm{com} 5 \mathrm{~W} / \mathrm{cm}^{2}(100 \mathrm{~mW})$ de laser UV.

Um efeito semelhante sobre perda de material em filmes irradiados com laser é reportado por Arun et al. [145-147] que trata da perda de até $40 \%$ de enxofre em filmes de $\mathrm{Sb}_{2} \mathrm{~S}_{3}$ por irradiação com laser contínuo de baixa potência $(100 \mathrm{~mW})$ e é denominado de efeito Fototérmico.

Nesse ponto podemos sugerir que o efeito de fotocontração nos filmes apresenta (além de mudanças estruturais intrínsecas com exposição ao UV), forte participação da componente térmica gerada pela irradiação com UV, ou seja, componente fototérmica induzida pela luz causando fotosublimação de fósforo.

\subsubsection{Análises de XPS de Filmes de $\left[\mathrm{Sb}\left(\mathrm{PO}_{3}\right)_{3}\right]_{n}-\mathrm{Sb}_{2} \mathrm{O}_{3}$}

As análises de XPS (X-ray Photoelectron Spectroscopy) foram realizadas no CCDM-UFSCAR em cooperação com o professor José Pedro Nascente.

Através das medidas por XPS das composições em filmes de $20 \%\left[\mathrm{Sb}\left(\mathrm{PO}_{3}\right)_{3}\right]_{n^{-}}$ $80 \% \mathrm{Sb}_{2} \mathrm{O}_{3}$ com $5,0 \mu \mathrm{m}$ de espessura irradiados por 6 horas com $5 \mathrm{~W} / \mathrm{cm}^{2}(100 \mathrm{~mW})$ pudemos obter a composição química dos filmes antes e depois da exposição ao laser. A Tabela 4 apresenta os resultados da análise química obtida para os elementos $\mathrm{Sb}, \mathrm{P}, \mathrm{O}$ e C (contaminante), bem como as posições dos picos relacionados com a energia de 
ligação de cada elemento. Antes da exposição ao UV a o filme apresenta concentrações de $\mathrm{Sb}, \mathrm{P}$, e $\mathrm{O}$ de 25,$67 ; 7,89$; e 55,71 em átomos \% respectivamente. Após a irradiação verifica-se que a concentração de fósforo cai drasticamente para 2,91 at $\%$ e a concentração de $\mathrm{O}$ aumenta de 55,71 para 58,42 at \%.

Tabela 4 - Resultados de XPS para filmes de 20\% $\left[\mathrm{Sb}\left(\mathrm{PO}_{3}\right)_{3}\right]_{n}-80 \% 20 \mathrm{Sb}_{2} \mathrm{O}_{3}$ (espessura:5 $\mu \mathrm{m}$ ) antes e após irradiação com laser UV.

\begin{tabular}{|c|c|c|c|}
\hline \multicolumn{4}{|c|}{ Filme não-irradiado } \\
\hline elemento & Posição do pico (eV) & $\begin{array}{c}\text { Ligações } \\
\text { envolvidas }\end{array}$ & $\begin{array}{c}\text { Concentração } \\
\text { (at \%) }\end{array}$ \\
\hline \multirow{2}{*}{$\mathrm{Sb}$} & $530,6(95 \%)$ & $\mathrm{Sb}_{2} \mathrm{O}_{3}$ & \multirow{2}{*}{25,67} \\
\hline & $528,4(5 \%)$ & $\mathrm{Sb}^{\circ}$ & \\
\hline \multirow{2}{*}{$\mathbf{P}$} & $133,4(82 \%)$ & P-O-P & \multirow{2}{*}{7,89} \\
\hline & $134,4(18 \%)$ & $\mathrm{P}-\mathrm{O}-\mathrm{Sb}$ & \\
\hline \multirow[t]{2}{*}{0} & $530,6(74 \%)$ & $\mathrm{O}_{\mathrm{NL}},(\mathrm{P}-\mathrm{O}-\mathrm{Sb})$ & \multirow{2}{*}{55,71} \\
\hline & $532,0(26 \%)$ & $\mathrm{O}_{\mathrm{L}},(\mathrm{P}-\mathrm{O}-\mathrm{P})$ & \\
\hline \multirow{3}{*}{ C } & $284,8(81 \%)$ & $\mathrm{C}-\mathrm{C}$ & \multirow{3}{*}{10,72} \\
\hline & $286,5(13 \%)$ & $\mathrm{C}-\mathrm{O}$ & \\
\hline & $288,8(6 \%)$ & $\mathrm{C}=\mathrm{O}$ & \\
\hline \multicolumn{4}{|c|}{ Filme Irradiado com laser UV (6 horas com $\left.5 \mathrm{~W} / \mathrm{cm}^{2}\right)$} \\
\hline \multirow{3}{*}{$\mathrm{Sb}$} & $530,6(81 \%)$ & $\mathrm{Sb}_{2} \mathrm{O}_{3}$ & 14,53 \\
\hline & - & $\mathrm{Sb}^{\circ}$ & - \\
\hline & $532,0(19 \%)$ & $\begin{array}{l}\text { Sobreposição } \\
\text { c/ pico do } \mathrm{O}\end{array}$ & - \\
\hline \multirow{2}{*}{$\mathbf{P}$} & $133,4(67 \%)$ & P-O-P & \multirow{2}{*}{2,91} \\
\hline & $134,4(33 \%)$ & $\mathrm{P}-\mathrm{O}-\mathrm{Sb}$ & \\
\hline \multirow{3}{*}{0} & $528,8(13 \%)$ & $\begin{array}{l}\text { Sobreposição } \\
\text { c/ pico do Sb }\end{array}$ & \multirow{3}{*}{$\mathbf{5 8 , 4 2}$} \\
\hline & $530,8(64 \%)$ & $\mathrm{O}_{\mathrm{NL}},(\mathrm{P}-\mathrm{O}-\mathrm{Sb})$ & \\
\hline & $532,4(23 \%)$ & $\mathrm{O}_{\mathrm{L}},(\mathrm{P}-\mathrm{O}-\mathrm{P})$ & \\
\hline \multirow{3}{*}{ C } & $284,8(49 \%)$ & & \multirow{3}{*}{24,15} \\
\hline & $286,5(35 \%)$ & $\begin{array}{ll}\mathrm{C}-\mathrm{C} \\
\mathrm{C}-\mathrm{O}\end{array}$ & \\
\hline & $288,8(16 \%)$ & $\mathrm{C}=\mathrm{O}$ & \\
\hline
\end{tabular}


Estes resultados são suportados pelas medidas de RBS e WDX que indicaram perda de fósforo e ganho de oxigênio após a irradiação. Estes efeitos foram extensivamente discutidos na introdução e são considerados efeitos de fotodesorção ou fotosublimação (no caso de perda de fósforo) e foto-oxidação (no caso de adsorção de oxigênio) como também reportado por vários autores [71,91,92,141,143].

Como a medida de XPS mostra uma fração de $5 \%$ de antimônio metálico $\left(\mathrm{Sb}^{\circ}\right)$ no filme, e após a irradiação com laser UV essa fração desaparece, deve-se considerar que o aumento na quantidade de oxigênio no filme está relacionado principalmente com a foto-oxidação de partículas de $\mathrm{Sb}^{\circ}$ sendo convertidas em $\mathrm{Sb}_{2} \mathrm{O}_{3}$ pela ação da irradiação UV.

Deve-se levar em conta que a produção dos filmes por evaporação com canhão de elétrons favoreça a formação de filmes deficientes em oxigênio, devido à dissociação do $\mathrm{Sb}_{2} \mathrm{O}_{3}$ durante o processo de aquecimento e evaporação do material durante a deposição, sendo a causa da formação de partículas de antimônio metálico dissolvidas na estrutura do filme.

Em relação à diminuição na quantidade de antimônio, o resultado de XPS indica também uma perda significativa (de 25,67 para 14,56 at \%). Já os resultados de RBS e WDX não confirmam a perda de antimônio, porem deve-se lembrar que ambas técnicas têm poder de penetração muito maior no filme $(\approx 5,0 \mu \mathrm{m})$ do que o XPS que é capaz de analisar com maior precisão camadas de poucos nanômetros de espessura [114].

Os espectros de XPS das linhas referentes aos elementos $\mathrm{Sb}(3 \mathrm{~d}), \mathrm{O}(1 \mathrm{~s}), \mathrm{P}(2 \mathrm{p})$, e $\mathrm{C}(1 \mathrm{~s})$ são apresentados nas figuras 81 e 82, respectivamente. A atribuição de posições aos picos de XPS em vidros a base de antimônio e fósforo e a definição de $\mathrm{O}_{\mathrm{L}} \mathrm{e} \mathrm{O}_{\mathrm{NL}} \mathrm{e}$ ligações P-O-Sb e P-O-P, baseado nas energias de ligação apresentadas pelos espectros de XPS e descritas na Tabela 4 foram estudadas recentemente e podem ser verificadas mais detalhadamente nas referências 148-150. 
a)

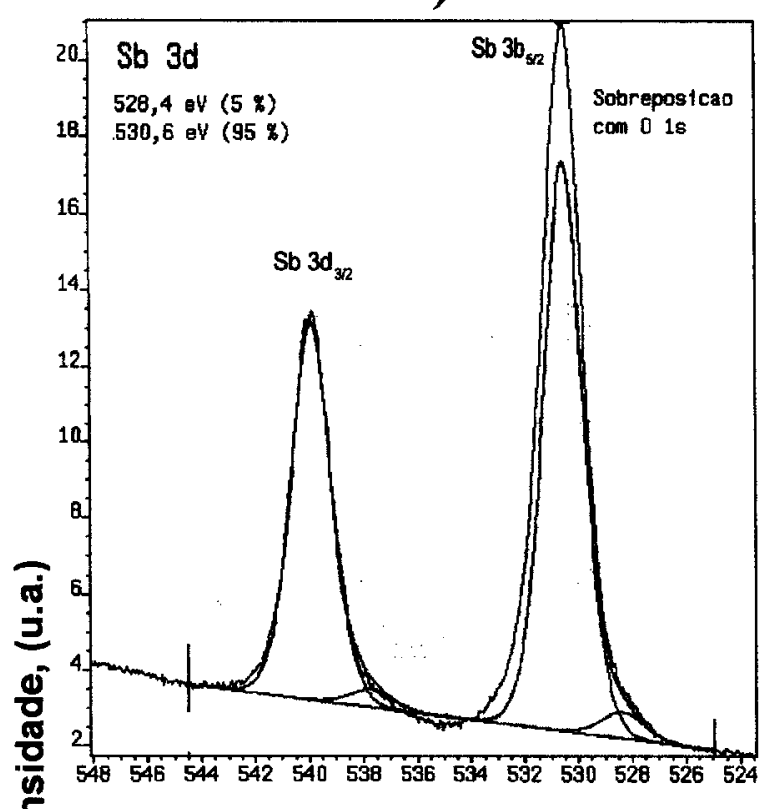

t.

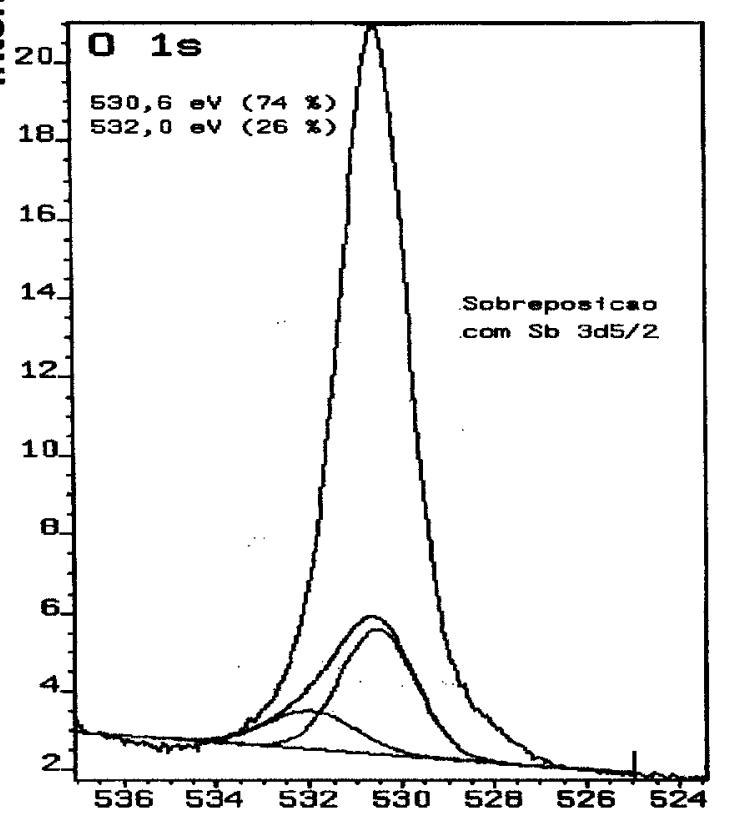

b)
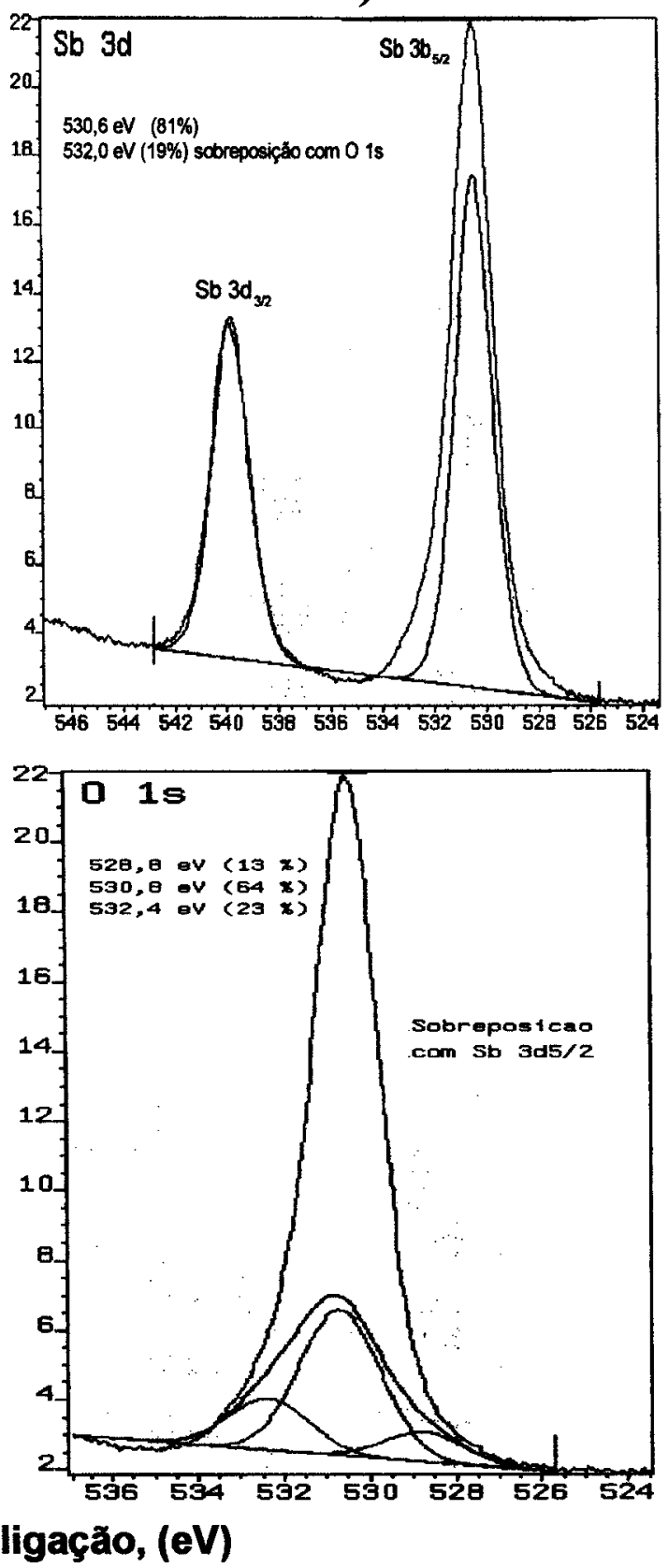

Figura 79 - Espectros de XPS das linhas do $\mathrm{Sb}(3 \mathrm{~d})$ e $\mathrm{O}(1 \mathrm{~s})$ para filmes de $20 \%\left[\mathrm{Sb}\left(\mathrm{PO}_{3}\right)_{3}\right]_{n}$ $80 \% 20 \mathrm{Sb}_{2} \mathrm{O}_{3}$ (espessura:5 $\mu \mathrm{m}$ ). a) filme não irradiado; b) filme após irradiação com laser UV (6 horas com $\left.5 \mathrm{~W} / \mathrm{cm}^{2}\right)$. 
a)

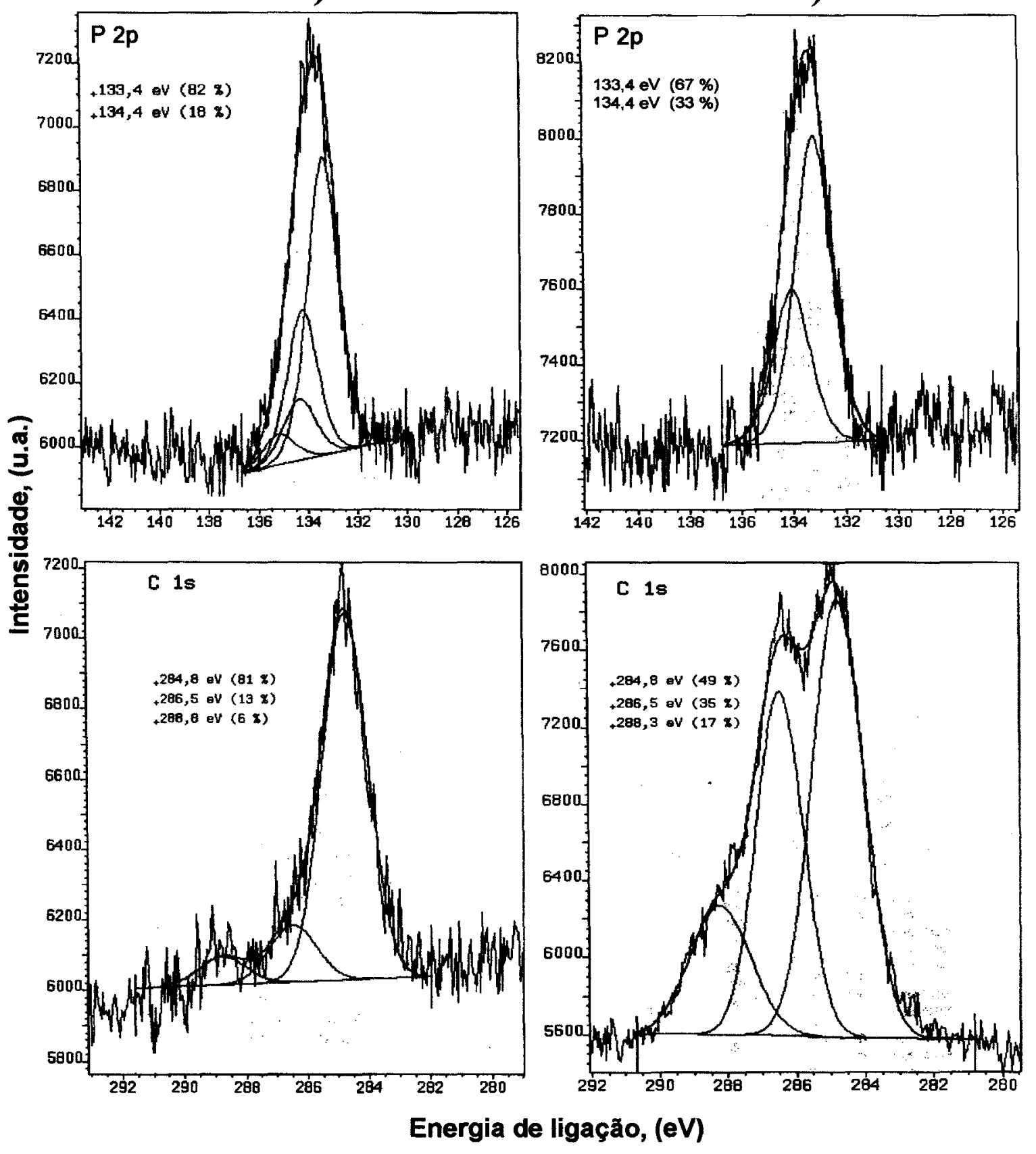

Figura 80 - Espectros de XPS das linhas do $\mathrm{P}(2 \mathrm{p})$ e e $\mathrm{C}(1 \mathrm{~s})$ para filmes de $20 \%\left[\mathrm{Sb}\left(\mathrm{PO}_{3}\right)_{3}\right]_{n}-80 \%$ $20 \mathrm{Sb}_{2} \mathrm{O}_{3}$ (espessura:5 $\mu \mathrm{m}$ ). a) filme não irradiado; b) filme após irradiação com laser UV (6 horas com $5 \mathrm{~W} / \mathrm{cm}^{2}$ ). 


\section{CARACTERIZACÃO A NÍVEL ESTRUTURAL DO EFEITO DE FOTOCONTRACÃO}

Nesta etapa do trabalho utilizamos técnicas como XANES, Difração de raios-X, FTIR, Luminescência, e RPE de filmes irradiados e não irradiados com laser UV com o objetivo de se extrair informações a respeito das mudanças estruturais a nível molecular induzidas pelo UV nas amostras. Os resultados são apresentados nas seções a seguir.

\subsubsection{Absorção de Raios-X próximo da Borda de Absorção (XANES)}

\subsubsection{XANES da borda $\mathrm{K}$ do fósforo de filmes}

Utilizamos a técnica de XANES para analisar a evolução da estrutura de filmes de $20 \%\left[\mathrm{Sb}\left(\mathrm{PO}_{3}\right)_{3}\right]_{n}-80 \% \mathrm{Sb}_{2} \mathrm{O}_{3} \quad(0,8 \mu \mathrm{m}$ de espessura) expostos ao UV e tratados termicamente. Na Figura 81 são mostrados os espectros de XANES para filmes irradiados e não irradiados e também para filmes tratados termicamente próximo a $\mathrm{T}_{\mathrm{g}}$ $\left(300{ }^{\circ} \mathrm{C} / 1 \mathrm{~h}\right)$. Podemos observar consideráveis mudanças tanto para os filmes irradiados com diferentes tempos de exposição ao laser, como para o filme tratado termicamente.

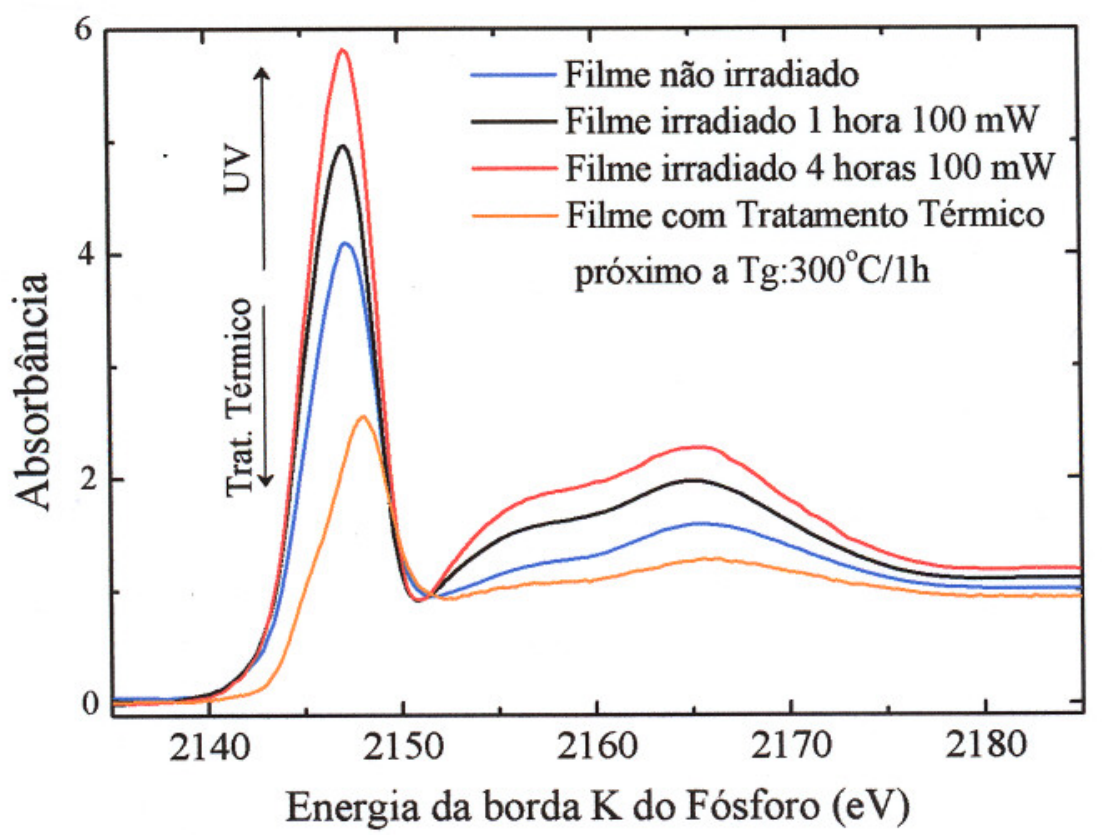

Figura 81 - XANES da borda $\mathrm{K}$ do fósforo para filmes de $20 \%\left[\mathrm{Sb}\left(\mathrm{PO}_{3}\right)_{3}\right]_{n}-80 \% \mathrm{Sb}_{2} \mathrm{O}_{3}$. 
O aumento na intensidade da linha branca dos espectros de filmes irradiados mostra que pode estar ocorrendo aumento no comprimento das cadeias de grupos fosfatos e/ou quebra de simetria entre grupos tetraédricos $\mathrm{PO}_{4}$, e esta mudança é mais acentuada quanto maior tempo de exposição ao laser. A interpretação de aumento de intensidade do pico de XANES estar relacionado com aumento no comprimento de cadeias de fosfatos (polimerização) foi proposta por Z. Yin et al. [137] em estudos sobre vidros fosfatos de sódio.

Esta interpretação está coerente com os espectros obtidos para o $\left.\left[\mathrm{SbPO}_{3}\right)_{3}\right]_{n}$ puro (Figura 59), pois a intensidade da linha branca obtida para este composto que possui estrutura polimérica é muito maior comparado com a intensidade da linha branca para $o$ $\mathrm{SbPO}_{4} \mathrm{e}$ o $\mathrm{NH}_{4} \mathrm{H}_{2} \mathrm{PO}_{4}$ que são formados por grupos $\mathrm{PO}_{4}$ isolados.

Para o filme tratado termicamente observamos uma diminuição drástica e também o deslocamento da linha branca para maior energia. Este comportamento é atribuído à relaxação de tensões e rearranjo estrutural no filme devido à temperatura.

\subsubsection{XANES de Filmes Tratados Termicamente}

Anteriormente mostramos resultados de XANES obtidos para filmes irradiados e não irradiados com laser UV. Nesta seção apresentamos resultados de XANES para filmes de $20 \%\left[\mathrm{Sb}\left(\mathrm{PO}_{3}\right)_{3}\right]_{n}-80 \% \mathrm{Sb}_{2} \mathrm{O}_{3}$ com diferentes tratamentos térmicos, de forma a analisar o efeito da temperatura na mudança estrutural causada em filmes com ou sem irradiação UV.

A Figura 82 apresenta resultados já mostrados anteriormente, porém incluindo a comparação entre espectros de filmes irradiados, tratado termicamente e vidro. Comparando os resultados nota-se que o espectro do filme é bastante diferente do espectro do vidro, e que após a irradiação com UV o espectro do filme evolui na mesma direção do espectro do formador vítreo, $\left[\mathrm{Sb}\left(\mathrm{PO}_{3}\right)_{3}\right]_{n}$, indicando possível efeito de polimerização entre grupos fosfato. Entretanto o espectro de um filme tratado termicamente próximo à temperatura de transição vítrea $\left(\mathrm{T}_{\mathrm{g}} \sim 300^{\circ} \mathrm{C}\right)$ por 1 hora se torna praticamente igual ao espectro do vidro. 


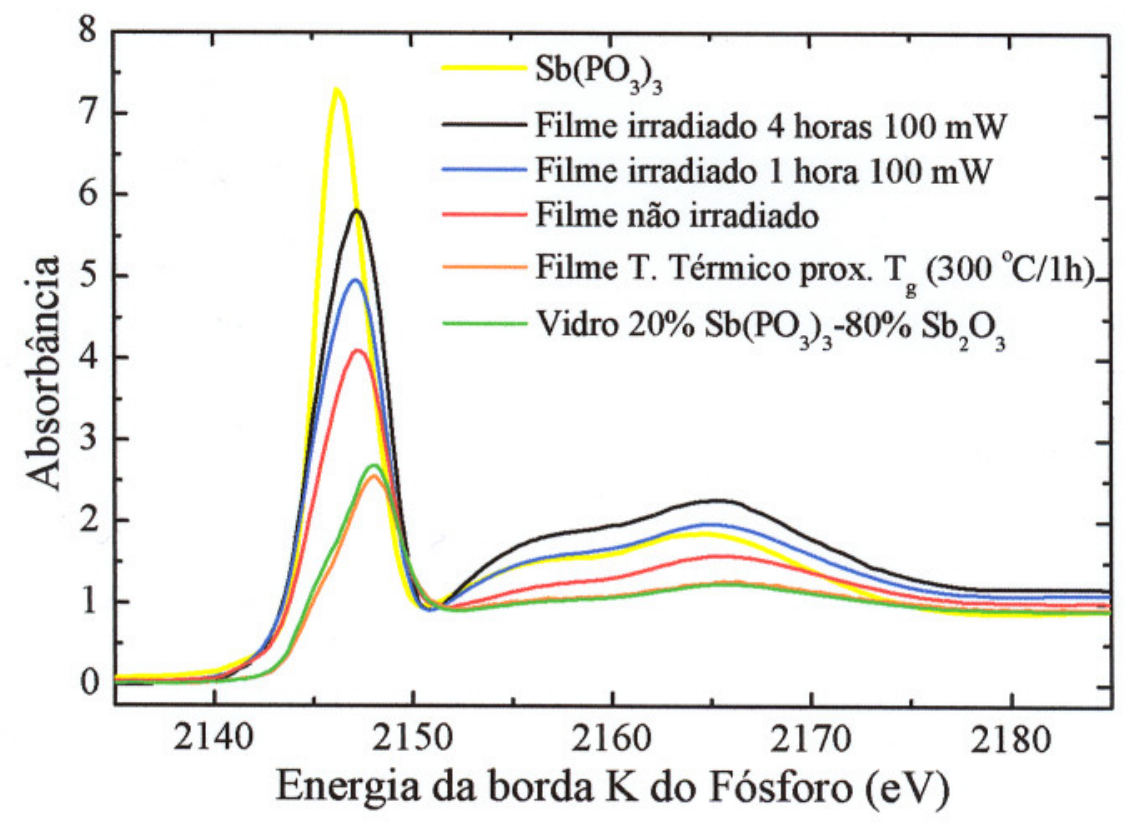

Figura 82 - Espectro de XANES da borda $\mathrm{K}$ do fósforo para filmes com composição $20 \%$ $\left[\mathrm{Sb}\left(\mathrm{PO}_{3}\right)_{3}\right]_{n}-80 \% \mathrm{Sb}_{2} \mathrm{O}_{3}$; Comparação entre filmes irradiados, tratados termicamente e vidro.

Isso nos leva a concluir os seguintes tópicos:

- A estrutura do material na forma de filme não possui o mesmo arranjo estrutural do que o vidro, embora ambos sejam amorfos como observado por difração de Raios-X.

- A temperatura induz alterações no filme de forma que a estrutura tende a retornar ao mesmo arranjo observado no vidro.

- Já o efeito da irradiação com laser UV provoca alterações no filme de forma que a estrutura tende a um rearranjo semelhante à estrutura do $\left[\mathrm{Sb}\left(\mathrm{PO}_{3}\right)_{3}\right]_{n}$. Este efeito pode ser compreendido como fotopolimerização.

- Além disso, devemos lembrar que o efeito fotoinduzido nos filmes também possui uma contribuição devido a efeito térmico induzido pela irradiação como foi observado devido a perda de fósforo no material irradiado e também reportado por outros autores como sendo um efeito fototérmico [145-147]. 
Para se compreender melhor o efeito térmico sobre a estrutura das amostras realizamos novas medidas de XANES para amostras de filmes não-irradiados, irradiados e também tratados termicamente. As medidas foram feitas nas seguintes amostras como mostra a Tabela 5 :

Tabela 5 - Seqüência e notação de amostras de filmes de $20 \%\left[\mathrm{Sb}\left(\mathrm{PO}_{3}\right)_{3}\right]_{n}-80 \% \mathrm{Sb}_{2} \mathrm{O}_{3}(0,8 \mu \mathrm{m}$ de espessura) preparados para medidas de XANES.

\begin{tabular}{ccccc}
\hline & Filme não-irradiado & $\begin{array}{c}\text { Filme irradiado/lhora- } \\
\text { 100mW UV }\end{array}$ & $\begin{array}{c}\text { Filme irradiado/4 horas- } \\
\text { 100mW UV }\end{array}$ & \\
\hline FNIR & FIR1h & FIR4h & \\
\hline FNIRT1 & FIR1hT1 & FIR4hT1 & $\mathrm{T} 1=250^{\circ} \mathrm{C} / 24$ horas \\
\hline & FIR1hT2 & FIR4hT2 & $\mathrm{T} 2=300^{\circ} \mathrm{C} / 1$ hora \\
\hline
\end{tabular}

Utilizamos a notação mostrada na Tabela 5 para identificar cada amostra e facilitar a descrição dos resultados no texto.

A Figura 83 mostra o efeito tanto da irradiação com UV como do tratamento térmico na forma dos espectros de XANES de filmes. O primeiro pico (denominado linha branca nos espectros de XANES) em torno de $2148 \mathrm{eV}$ nos traz informação sobre a estrutura do material a curto alcance ( $1^{\mathrm{a}}$. esfera de coordenação ao redor do fósforo) e as bandas após a linha branca dão informação a médio alcance (2a. e 3a. esferas de coordenação ao redor do fósforo). A irradiação da amostra com UV induz um aumento de intensidade tanto da linha branca como da banda posterior como já foi mencionado antes. Isso mostra que as mudanças estruturais ocorrem em curta e media distancias na estrutura ao redor do fósforo. $\mathrm{O}$ tratamento térmico causa diminuição de intensidades no espectro de XANES de forma que o filme passa a apresentar um espectro semelhante ao do vidro sugerindo reorganização e relaxação de tensões no filme. Podemos pensar que o tratamento térmico causa compactação ou relaxação da estrutura do filme e este se torna semelhante à estrutura do vidro. 


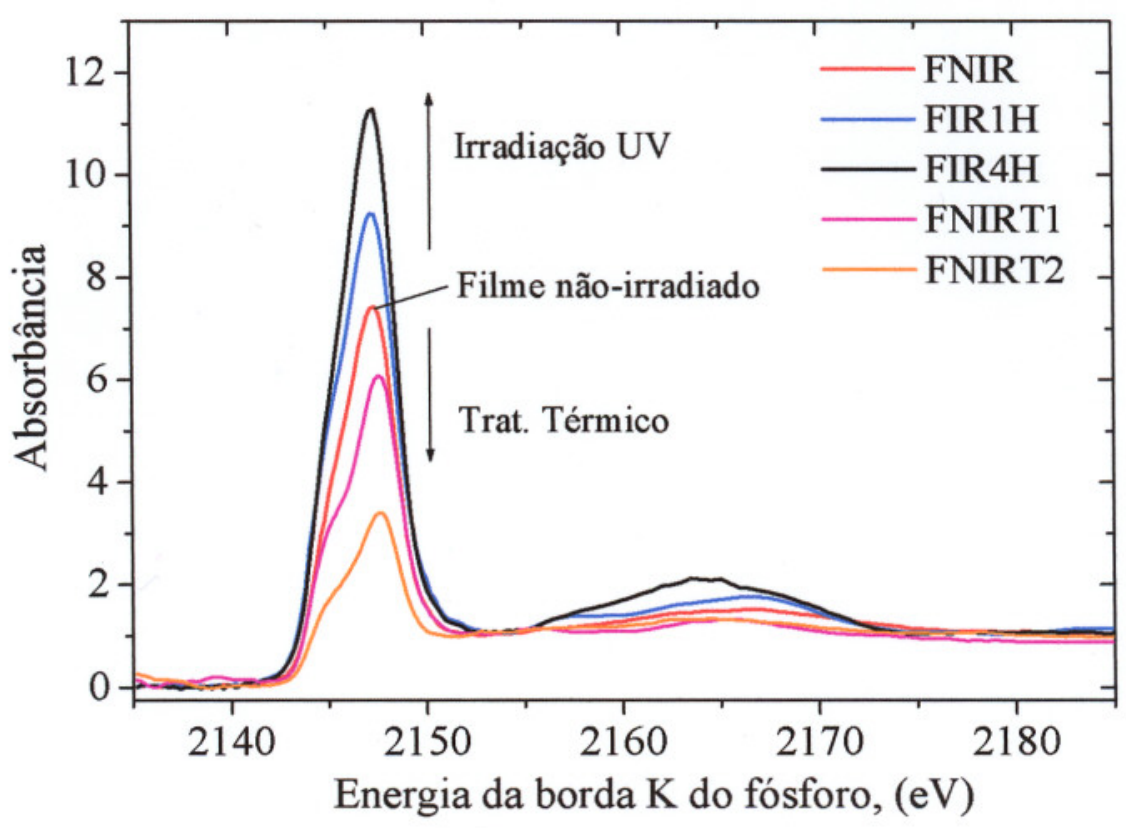

Figura 83 - Espectro de XANES da borda $\mathrm{K}$ do fósforo para Filmes de $20 \%\left[\mathrm{Sb}\left(\mathrm{PO}_{3}\right)_{3}\right]_{n}-80 \%$ $\mathrm{Sb}_{2} \mathrm{O}_{3}$ não-irradiado (FNIR), irradiado por $1 \mathrm{e} 4$ horas (FIR1h e FIR4h) e não-irradiados tratados termicamente (FNIRT1 e FNIRT2). (irradiação com $100 \mathrm{~mW}$ de laser UV $\left(5,0 \mathrm{~W} / \mathrm{cm}^{2}\right)$ ).

Porém a irradiação com UV também provoca uma compactação estrutural que é relacionada com a causa da fotocontração, mas ocasiona no filme um arranjo atômico diferente do vidro, pois os espectros de filme irradiado e filme tratado termicamente são completamente opostos. Isto é notado comparando-se as curvas relativas a FIR1H e FIR4H com as curvas relativas a FNIRT1 e FNIRT2. A semelhança entre os espectros relativos ao vidro e ao filme tratado termicamente $\left(300{ }^{\circ} \mathrm{C} / 1\right.$ hora $)$ pode ser observada pela Figura 82. 
Ao que tudo indica a temperatura afeta toda a estrutura (tanto nas ligações O-P como $\mathrm{Sb}-\mathrm{O}$ ) enquanto que a irradiação com UV parece agir mais diretamente nas ligações $\mathrm{P}-\mathrm{O}$ de forma a haver um arranjo estrutural entre esses grupos. Isso também é evidenciado pelos resultados de XANES da borda $\mathrm{L}_{3}$ do antimônio que mostra pouca variação nos espectros de filmes irradiados com UV como apresenta a Figura 84, indicando pouca variação estrutural no ambiente químico ao redor do $\mathrm{Sb}^{3+}$.

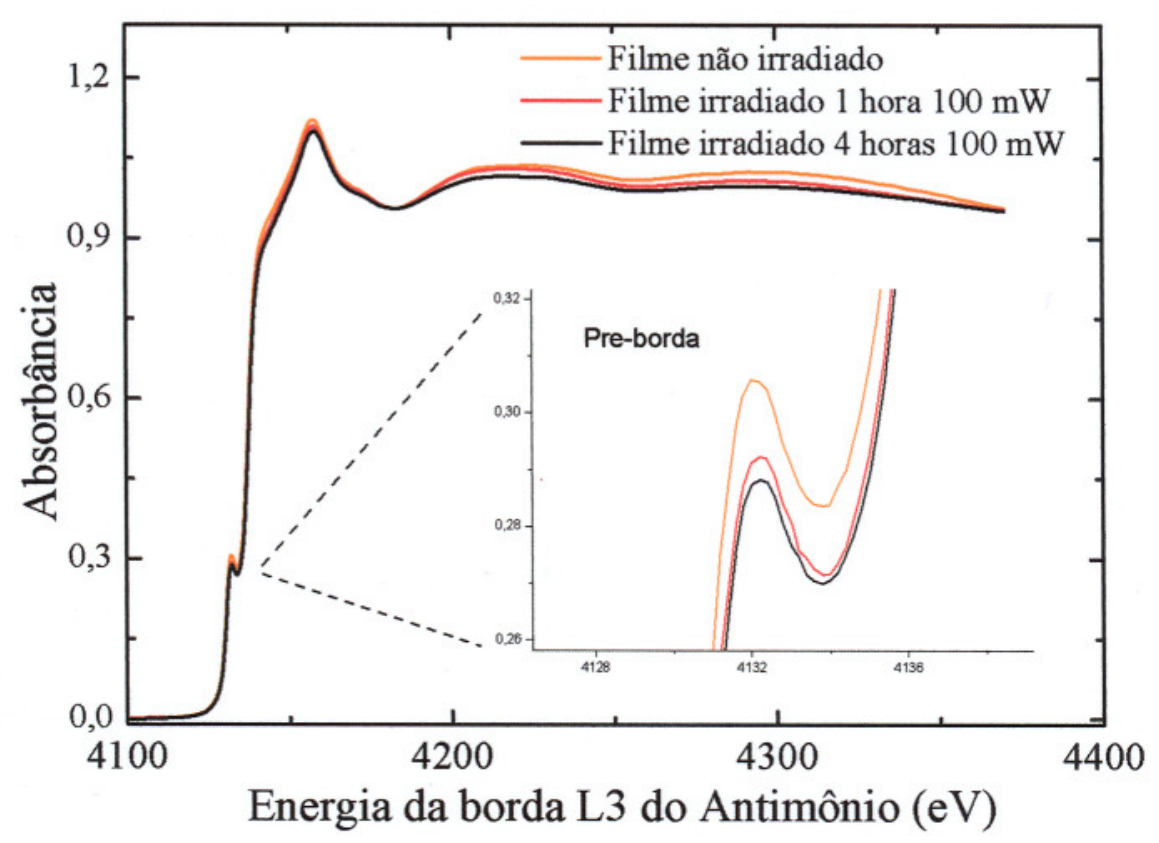

Figura 84 - Espectro de XANES da borda L3 do antimônio para Filmes de $20 \%\left[\mathrm{Sb}_{(}\left(\mathrm{PO}_{3}\right)_{3}\right]_{n}-80$ $\% \mathrm{Sb}_{2} \mathrm{O}_{3}$. 
$\mathrm{Na}$ Figura 85 podemos verificar o mesmo comportamento gerado pelo tratamento térmico de filmes irradiados por 1 hora com UV. A intensidade do espectro de XANES diminui com o tratamento térmico, mesmo para amostras irradiadas, porém é importante ressaltar que a intensidade do espectro de amostra irradiada e tratada termicamente é maior que o espectro da amostra apenas tratada termicamente.

Isso mostra que a irradiação induz um processo de mudança estrutural irreversível que não pode ser anulado com o tratamento térmico e também mostra que as mudanças estruturais introduzidas com tratamento térmico e com irradiação são de naturezas diferentes.

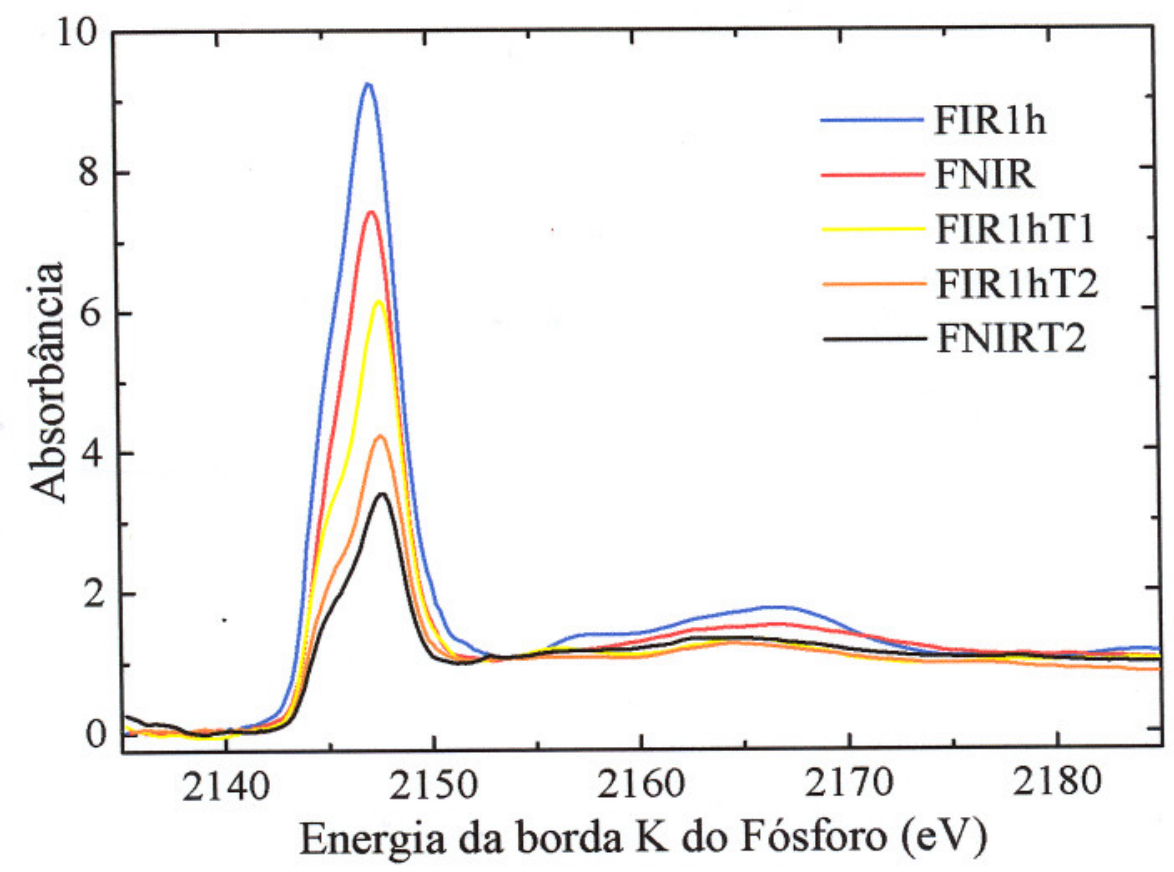

Figura 85 - Espectro de XANES da borda $\mathrm{K}$ do fósforo para Filmes de $20 \%\left[\mathrm{Sb}\left(\mathrm{PO}_{3}\right)_{3}\right]_{n}-80 \%$ $\mathrm{Sb}_{2} \mathrm{O}_{3}$ não-irradiado (FNIR), irradiado por 1 hora (FIR1h), irradiados tratados termicamente (FIR1hT1 e FIR1hT2) e não irradiados tratados termicamente (FNIRT2). (irradiação com 100 $\mathrm{mW}$ de laser UV $\left.\left(5,0 \mathrm{~W} / \mathrm{cm}^{2}\right)\right)$. 
A Figura 86 mostra a comparação de espectros de XANES de amostras irradiadas por 4 horas com laser UV e tratadas termicamente. A analise das intensidades e forma dos espectros mostra o mesmo comportamento observado nos resultados apresentados na Figura 85.

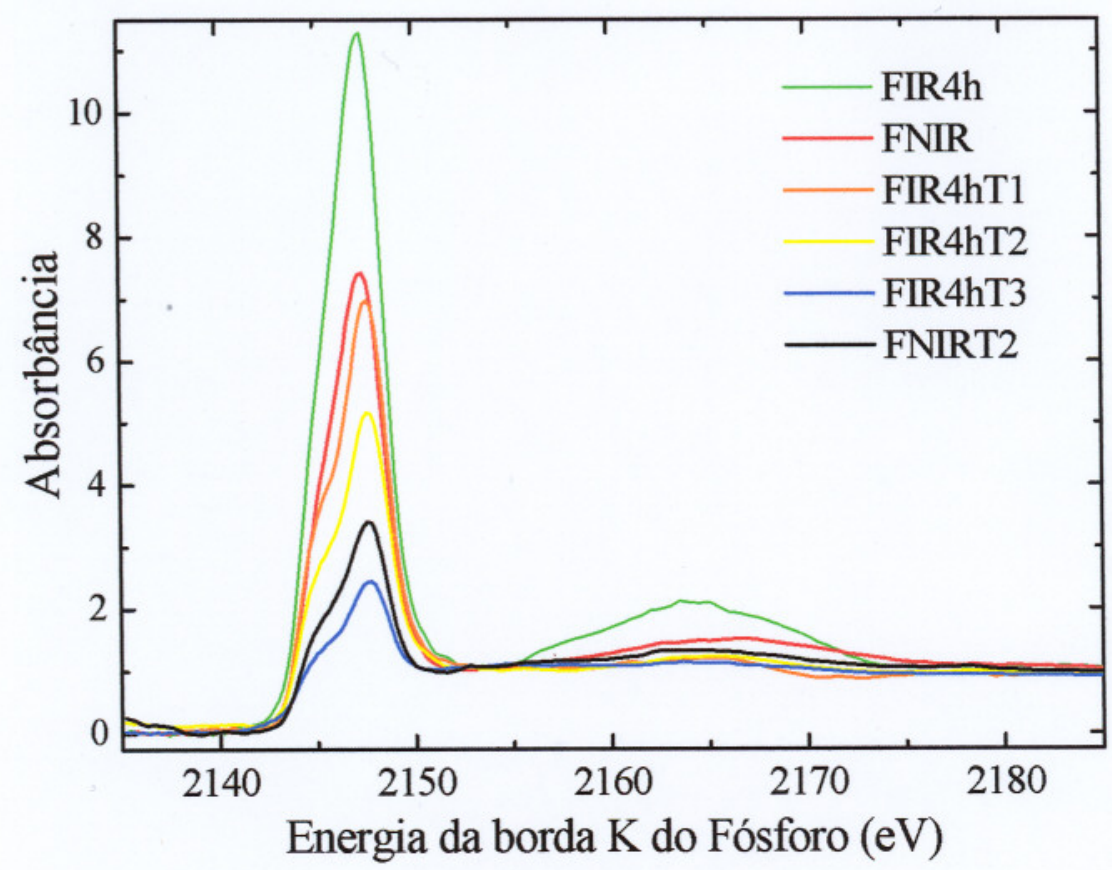

Figura 86 - Espectro de XANES da borda K do fósforo para Filmes de $20 \%\left[\mathrm{Sb}\left(\mathrm{PO}_{3}\right)_{3}\right]_{n}-80 \%$ $\mathrm{Sb}_{2} \mathrm{O}_{3}$ não-irradiado (FNIR), irradiado por 4 horas (FIR4h), irradiados tratados termicamente (FIR4hT1, FIR4hT2 e FIR4hT3) e não irradiado tratado termicamente (FNIRT2). (irradiação com $100 \mathrm{~mW}$ de laser UV $\left.\left(5,0 \mathrm{~W} / \mathrm{cm}^{2}\right)\right)$.

A Figura 87 apresenta um panorama geral da comparação das intensidades da linha branca dos espectros de XANES obtidos para todas amostras não-irradiadas, irradiadas e tratadas termicamente. Dessa forma é mais simples observar a comportamento e a evolução seqüencial das intensidades de XANES obtidos para cada amostra. 


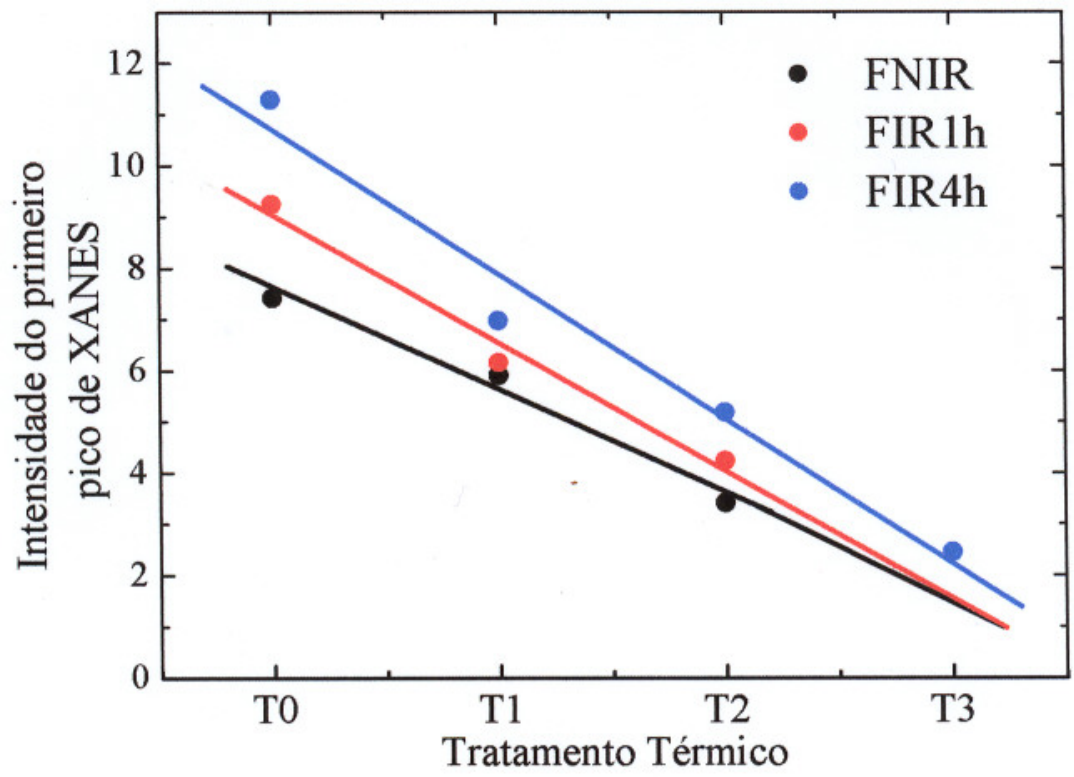

Figura 87 - Intensidade do primeiro pico de XANES (linha branca) de filmes de $20 \%$ $\left[\mathrm{Sb}\left(\mathrm{PO}_{3}\right)_{3}\right]_{n}-80 \% \mathrm{Sb}_{2} \mathrm{O}_{3}$ não-irradiado (FNIR), irradiado por 1 hora (FIRlh) e irradiado por 4 horas (FIR4h) sem tratamento térmico (T0) e para os tratamentos térmicos $\mathrm{T} 1: 250{ }^{\circ} \mathrm{C} / 24 \mathrm{~h}$, $\mathrm{T} 2: 300^{\circ} \mathrm{C} / 1 \mathrm{~h}$ e T $3: 30{ }^{\circ} \mathrm{C} / 6 \mathrm{~h}$.

Com o tratamento térmico a intensidade da linha branca diminui para todas amostras tanto não-irradiadas como irradiadas. E interessante notar que as intensidades seguem uma seqüência de evolução tanto no caso de irradiação UV como no caso de tratamento térmico, como já foi observado nos espectros de XANES.

- As amostras submetidas à irradiação UV apresentam maior intensidade XANES quanto maior o tempo de exposição à luz.

- As amostras tratadas termicamente apresentam queda linear na intensidade de XANES para os tratamentos térmicos T1, T2 e T3.

- As intensidades de XANES para as amostras não-irradiada, irradiada por 1 hora e 4 horas (FNIR, FIR1h e FIR4h) apresentam a seguinte seqüência:

$$
\text { FNIR }<\text { FIR1h }<\text { FIR4h }
$$

, e esta seqüência permanece mesmo após os tratamentos térmicos como ilustra a Figura 87. 
Isso mostra que mesmo após o tratamento térmico a mudança estrutural induzida pela irradiação permanece no material (efeito irreversível), pois a intensidade da linha branca ainda é maior do que da amostra que foi apenas tratada termicamente.

Outro dado interessante é que as intensidades de XANES das amostras após tratamento térmico parecem convergir para um mesmo ponto quanto maior o tempo de tratamento indicando uma possível degradação da amostra que pode ser devido à perda de fósforo ou cristalização.

\subsubsection{Difração de Raios-X, FTIR, e estrutura entre Vidros e Filmes}

A diferença de estrutura entre vidros e filmes citada anteriormente (1.4.1) e verificada pelas medidas de XANES (Figura 82) pode ser discutida em termos de quantidade de vazios intersticiais ao redor de unidades estruturais no filme, causados intrinsecamente devido ao processo de deposição de filmes por evaporação térmica, onde tais filmes exibem uma morfologia de crescimento colunar pronunciado que consiste de alta concentração de lacunas intermoleculares.

Essa diferença estrutural entre vidros e filmes pode ser verificada diretamente pelo primeiro pico estreito de difração (FSDP - First Sharp Difraction Peak), proposto por S. R. Elliot [151] que aparece no espectro de difração de Raios-X de materiais amorfos devido a vazios estruturais intersticiais. Em nosso caso este pico aparece em torno de 13,5 graus no espectro de raios-X de filmes de $20 \%\left[\mathrm{Sb}\left(\mathrm{PO}_{3}\right)_{3}\right]_{n}-80 \% \mathrm{Sb}_{2} \mathrm{O}_{3}$ como mostra a Figura 88. Para filmes após a irradiação com laser UV, percebe-se uma diminuição na intensidade do FSDP, para filmes irradiados por 1 e 2 horas com 100 $\mathrm{mW}$ de UV respectivamente. No espectro do vidro nota-se a ausência do pico de FSDP, como era esperado. Estes resultados sugerem uma diminuição no volume intersticial ao redor de unidades estruturais $\mathrm{PO}_{4}$ nos filmes. Um efeito similar foi observado em filmes de $\mathrm{As}_{40} \mathrm{~S}_{30} \mathrm{Se}_{30}$ [92]. As variações irreversíveis nestes materiais são associadas com o colapso fotoinduzido destas estruturas dispostas em lacunas, junto com a ruptura e formação de novas espécies moleculares do filme e originárias da fase de vapor. 


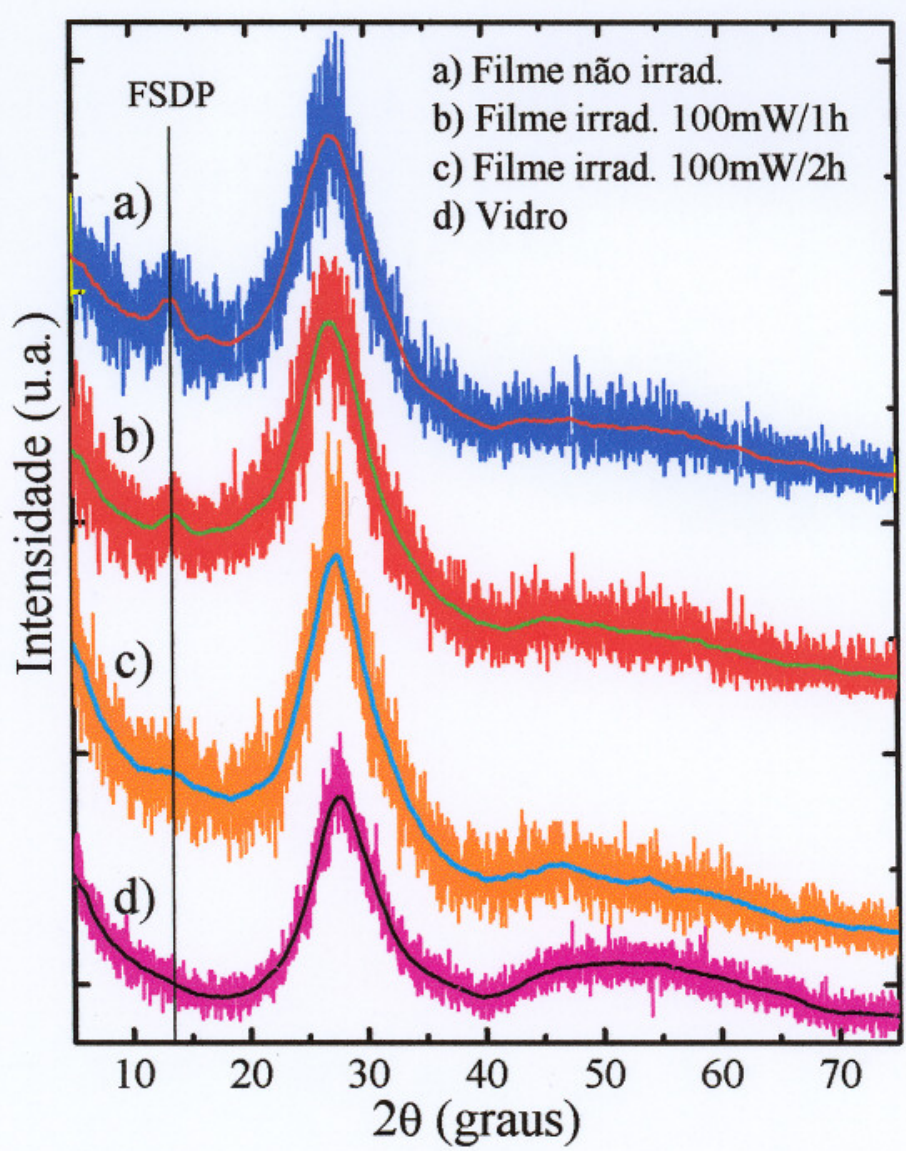

Figura 88 - Espectros de difração de raios-X para filmes não-irradiados, irradiados com UV e vidro do sistema $20 \%\left[\mathrm{Sb}\left(\mathrm{PO}_{3}\right)_{3}\right]_{n}-80 \% \mathrm{Sb}_{2} \mathrm{O}_{3}(0,8 \mu \mathrm{m}$ de espessura), mostrando o FSDP que representa o pré-pico relativo a vazios intersticiais ao redor de unidades estruturais em materiais amorfos.

Em casos onde os filmes possuem estrutura diferente do vidro originário, ocorre uma mudança estrutural irreversível denominada fotopolimerização em resposta a iluminação com energia próxima do bandgap. Este efeito de fotopolimerização, consiste na conexão de grupos fosfatos isolados formando cadeias maiores, devido à formação de novas ligações químicas com a irradiação UV, e causando aproximação entre cadeias e diminuição de vazios intermoleculares. A indicação desse efeito também foi observado através da interpretação de aumento de intensidade do pico de XANES, sendo relacionado com o aumento no comprimento de cadeias de fosfatos (polimerização) como proposto por Z. Yin et al. [137]. 
A Figura 89 apresenta os espectros de transmitância no IR para filmes de $20 \%$ $\left[\mathrm{Sb}\left(\mathrm{PO}_{3}\right)_{3}\right]_{n}-80 \% \mathrm{Sb}_{2} \mathrm{O}_{3}$ irradiados e não-irradiados com UV. A Figura 89-a) mostra o espectro de IR para região de 400 a $4000 \mathrm{~cm}^{-1}$, onde podemos visualizar as bandas referentes as ligações $\mathrm{P}-\mathrm{O}$ e Sb-O (região de 300 a $1300 \mathrm{~cm}^{-1}$ ), e também a região de interferência formando ondulações na região de 1300 a $4000 \mathrm{~cm}^{-1}$. O deslocamento dessas ondulações para maiores energias é relacionado com a diminuição na espessura do filmes causada pela irradiação UV. A Figura 89-b) mostra a região de 300 a 1300 $\mathrm{cm}^{-1}$, destacando as bandas referentes as ligações $\nu \mathrm{PO}_{3}, v_{\mathrm{s}} \mathrm{P}-\mathrm{O}-\mathrm{P}, \nu_{\mathrm{as}} \mathrm{P}-\mathrm{O}-\mathrm{P}$ e $\nu \mathrm{Sb}-\mathrm{O}$.

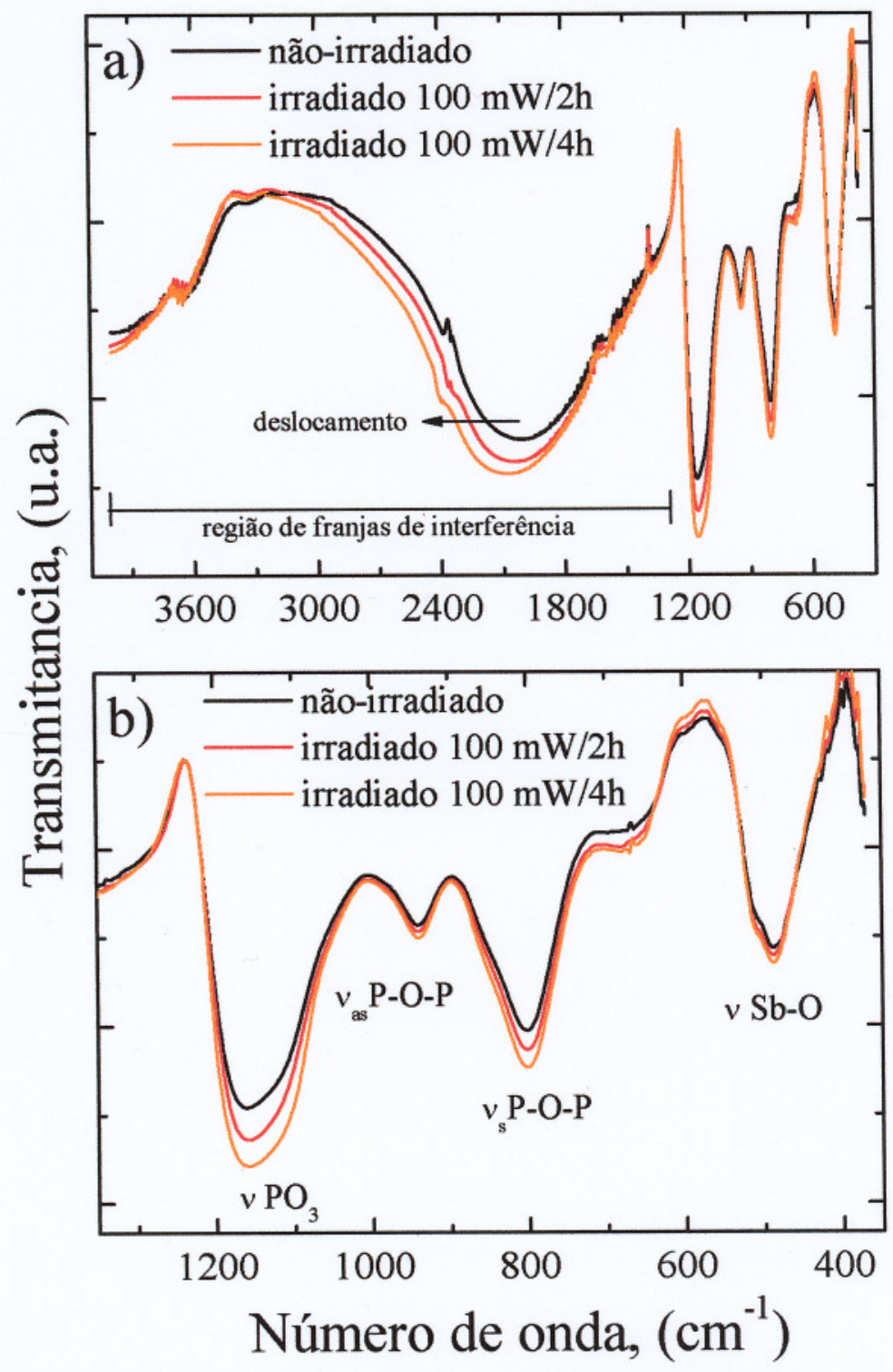

Figura 89 - Espectro de transmitância no IR para filmes $20 \%\left[\mathrm{Sb}\left(\mathrm{PO}_{3}\right)_{3}\right]_{n}-80 \% \mathrm{Sb}_{2} \mathrm{O}_{3}$ nãoirradiados e irradiados com UV. a) Região de $400 \mathrm{a} 4000 \mathrm{~cm}^{-1}$, b) Região das bandas relativas às freqüências das ligações $\mathrm{P}-\mathrm{O}$ e $\mathrm{Sb}-\mathrm{O}$ de $400 \mathrm{a} 1300 \mathrm{~cm}^{-1}$. 
Podemos verificar que após a irradiação dos filmes com UV as bandas em $800 \mathrm{e}$ $1150 \mathrm{~cm}^{-1}$ têm um aumento significativo de intensidade, referente à vibração das ligações P-O-P e $\mathrm{PO}_{3}$, respectivamente. Esse aumento sugere que a irradiação induz a formação de novas ligações químicas entre espécies de fosfatos, indicando um efeito de fotopolimerização estrutural. A banda em torno de $500 \mathrm{~cm}^{-1}$ relativa às ligações $\mathrm{Sb}-\mathrm{O}$ não apresenta alteração significativa após irradiação com UV. Resultado similar foi observado nos resultados de XANES da borda $\mathrm{L}_{3}$ do $\mathrm{Sb}^{3+}$, onde não foi observada alteração significativa no ambiente químico ao redor do antimônio (Figura 84).

3.2.10 Luminescência de Filmes de $\left[\mathrm{Sb}\left(\mathrm{PO}_{3}\right)_{3}\right]_{n}-\mathrm{Sb}_{2} \mathrm{O}_{3}$ dopados com $\mathrm{Cu}^{2+}$

Utilizamos a técnica de espectroscopia óptica com a finalidade de investigar as alterações a nível molecular nos filmes durante a irradiação com laser UV. Estudamos a luminescência do íon $\mathrm{Cu}^{2+}$ em filmes de $20 \%\left[\mathrm{Sb}\left(\mathrm{PO}_{3}\right)_{3}\right]_{n}-80 \% \mathrm{Sb}_{2} \mathrm{O}_{3}$, utilizando a emissão desse ín como sonda estrutural. Para estas medidas dopamos os vidros com $2,0 \%$ de óxido de cobre $(\mathrm{CuO})$ e preparamos filmes espessos $(\sim 8,0 \mu \mathrm{m})$ por evaporação por canhão de elétrons depositados sobre lâminas de vidro.

A coleta dos espectros de luminescência dos filmes foi feita simultaneamente durante a irradiação com laser UV, utilizando a montagem descrita na Figura 35. Cada espectro foi coletado em 30 segundos e mantivemos intervalos de 5, 10 e 60 minutos entre um espectro e outro para a mesma amostra. A Figura 90 mostra os espectros de luminescência de um filme de $20 \%\left[\mathrm{Sb}\left(\mathrm{PO}_{3}\right)_{3}\right]_{n}-80 \% \mathrm{Sb}_{2} \mathrm{O}_{3}$ com $2 \%$ de $\mathrm{CuO}$, irradiado com $50 \mathrm{~mW}$ de laser UV. $O$ espectro de luminescência apresenta duas bandas em torno de $430 \mathrm{~nm}$ e $525 \mathrm{~nm}$, com alargamento espectral característico do íon $\mathrm{Cu}^{2+}$ em matriz amorfa. 


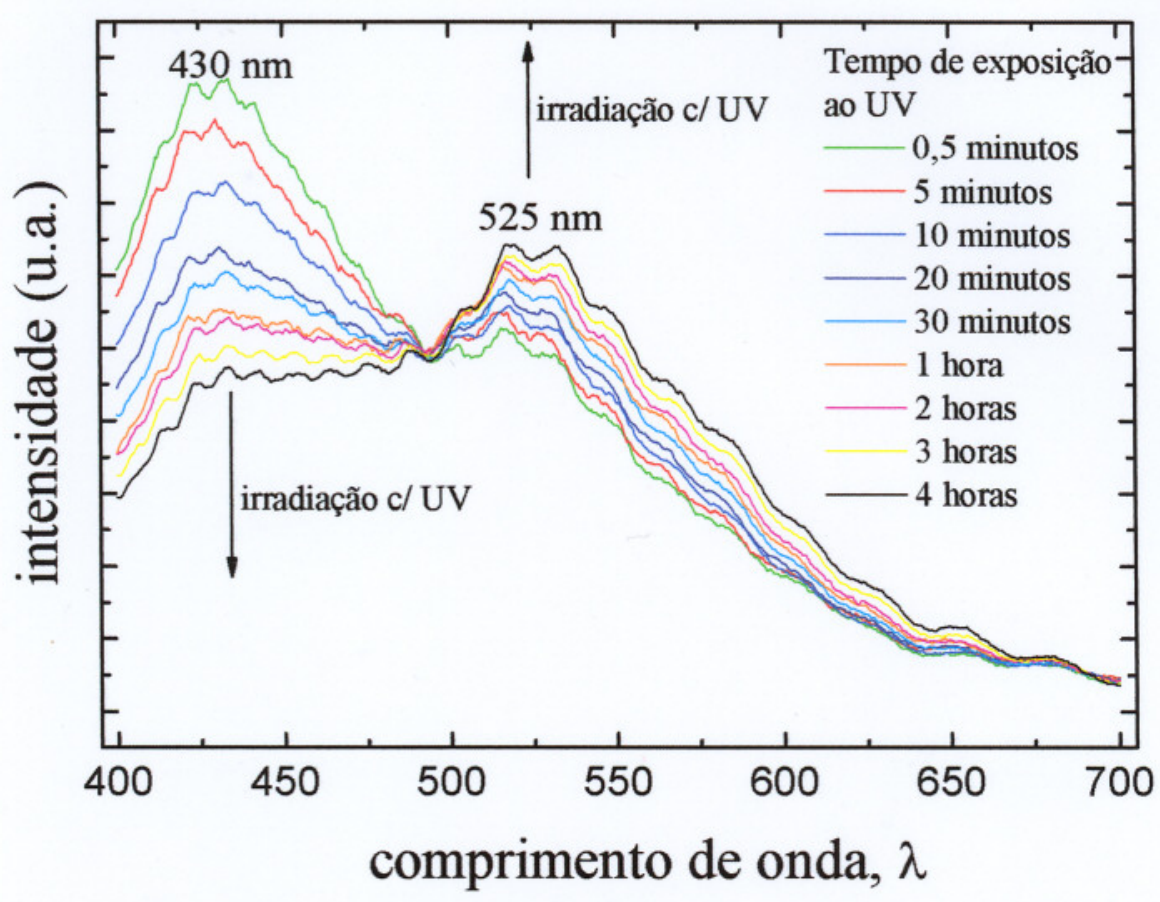

Figura 90 - Luminescência de filmes de $20 \%\left[\mathrm{Sb}\left(\mathrm{PO}_{3}\right)_{3}\right]_{n}-80 \% \mathrm{Sb}_{2} \mathrm{O}_{3}$ com $2 \%$ de $\mathrm{CuO}$, irradiados com $50 \mathrm{~mW}\left(2,5 \mathrm{~W} / \mathrm{cm}^{2}\right)$ de laser UV.

As ondulações observadas sobre todo o espectro são devidas ao fenômeno de interferência da luz no filme. As bandas de emissão em 430 e $525 \mathrm{~nm}$ do $\mathrm{Cu}^{2+}$ em vidros foram reportadas por B. Moine, P. Boutinaud, e E. Borsella, respectivamente [152-154].

A Figura 91-a) mostra a deconvolução dos espectros de luminescência através da soma de duas bandas gaussianas. Dessa forma podemos visualizar melhor a evolução das intensidades das duas bandas centradas em $430 \mathrm{~nm}$ e $525 \mathrm{~nm}$. Com o aumento do tempo de irradiação podemos observar que a banda em $430 \mathrm{~nm}$ diminui de intensidade em relação à banda em $525 \mathrm{~nm}$, que aumenta de intensidade. Além, disso a banda em torno de $515 \mathrm{~nm}$ se desloca de $511 \mathrm{~nm}$ para $525 \mathrm{~nm}$ com o aumento no tempo de exposição ao UV, sendo melhor visualizado na (Figura 91-b). 


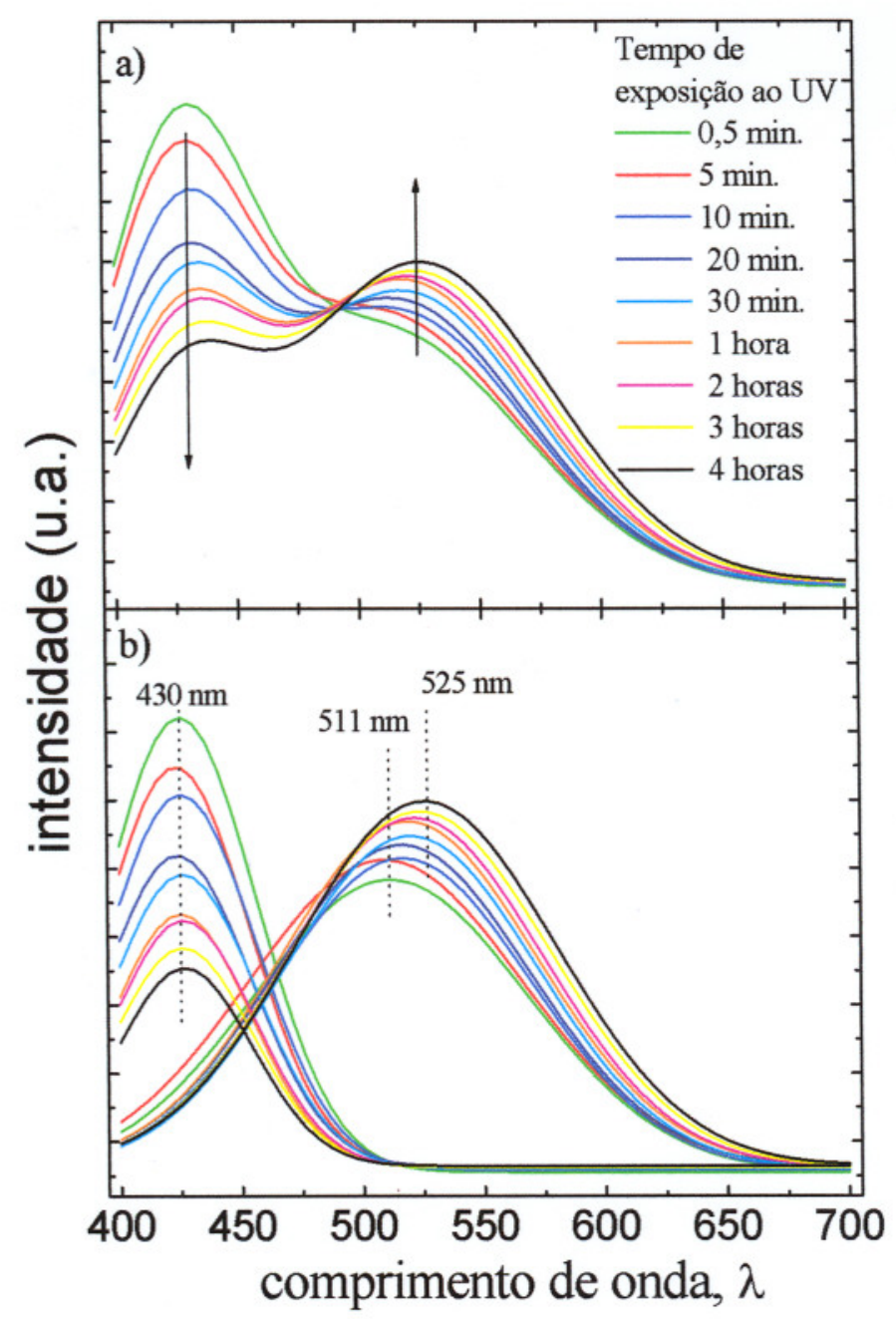

Figura 91 -Espectros de luminescência $\mathrm{Cu}^{2+}$ em filmes de $20 \%\left[\mathrm{Sb}\left(\mathrm{PO}_{3}\right)_{3}\right]_{n}-80 \% \mathrm{Sb}_{2} \mathrm{O}_{3}$ com 2 $\%$ de $\mathrm{CuO}$. a) Deconvolução gerada por duas curvas gaussianas b) Curvas gaussianas independentes em $430 \mathrm{~nm}$ e $\sim 520 \mathrm{~nm}$, utilizadas na deconvolução.

Mais especificamente, a banda de emissão em torno de $430 \mathrm{~nm}$ é atribuída a íns $\mathrm{Cu}^{2+}$ isolados enquanto que a banda em torno de $525 \mathrm{~nm}$ é atribuída a formação de pares $\left(\mathrm{Cu}^{2+}-\mathrm{Cu}^{2+}\right)$, como reportado para vidros fosfatos e também em compostos a base de fosfatos $\left(\mathrm{CuZr}_{2}\left(\mathrm{PO}_{4}\right)_{3}\right)[152,153]$. O deslocamento dessa banda de 511 para $527 \mathrm{~nm}$ está relacionado com uma compressão tetragonal do campo cristalino octaédrico ao redor do cobre, alterando a estrutura de níveis de energia desse íon.

Com estes resultados podemos verificar que a formação de pares $\mathrm{Cu}^{2+}-\mathrm{Cu}^{2+}$ durante a irradiação causando queda na intensidade de luminescência em $430 \mathrm{~nm}$ e aumento de intensidade da banda em $525 \mathrm{~nm}$, mostra que o efeito de fotocontração introduz mudanças na estrutura do material, e estas mudanças ocorrem a nível de campo 
cristalino local, como observado através das medidas de luminescência. A formação de pares $\mathrm{Cu}^{2+}-\mathrm{Cu}^{2+}$ também pode ser interpretada como a aproximação e aumento de interações dipolares entre estes íons na estrutura devido ao efeito de fotocontração, ou alterações estruturais em aglomerados pré-existentes de cobre. Este resultado pode ser discutido em termos de aproximação (formação de novas ligações químicas entre grupos fosfato) de cadeias de fosfatos após irradiação UV, causando uma aproximação de íons que estejam localizados intersticialmente.

\subsubsection{Ressonância Paramagnética Eletrônica-RPE}

Nessa etapa utilizamos a técnica de Ressonância Paramagnética Eletrônica (RPE) como ferramenta para investigar o efeito de fotocontração a nível de estrutura molecular em filmes de $20 \%\left[\mathrm{Sb}\left(\mathrm{PO}_{3}\right)_{3}\right]_{n}-80 \% \mathrm{Sb}_{2} \mathrm{O}_{3}$ dopados com $\mathrm{Cu}^{2+}$, antes a após irradiação com laser UV. Utilizamos o íon $\mathrm{Cu}^{2+}$ como sonda estrutural por apresentar o maior sinal de RPE dentre os testes que realizamos utilizando também íons $\mathrm{Cr}^{3+} \mathrm{e} \mathrm{Mn}^{2+}$. Realizamos experimentos de RPE-CW (contínuo) e RPE pulsado pela técnica de ESEEM (Electron Spin Echo Envelope Modulation). Para estas medidas dopamos os vidros com $0,2 \%, 0,5 \%, 1,0 \%, 1,5 \%$ e $2,0 \%$ de $\mathrm{CuO}$ e verificamos que as amostras com $2 \%$ apresentaram o melhor sinal de RPE durante as medidas. Assim sendo a partir dos vidros dopados com $2,0 \%$ de $\mathrm{CuO}$ preparamos filmes espessos $(\sim 8,0 \mu \mathrm{m})$, que foram irradiados com laser UV. Estas medidas e as análises de resultados foram desenvolvidas em cooperação com o grupo do Professor Cláudio Magon.

3.2.11.1 A técnica de RPE para análise estrutural em vidros

Nesta seção damos uma breve introdução sobre a utilização da técnica de RPE para estudo estrutural de vidros fotossensíveis dopados com íons paramagnéticos.

Efeitos induzidos por Laser como fotoescurecimento, fotoexpansão e fotocontração em vidros óxidos, calcogenetos e fosfatos têm sido investigados pela técnica de RPE [155] e vidros dopados com $\mathrm{Cu}^{2+}$ têm sido estudados devido ao forte sinal paramagnético apresentado por esse íon, favorecendo o estudo da estrutura vitrea através dos espectros obtidos [156,157]. 
A técnica de RPE é também utilizada na investigação a curto alcance das mudanças estruturais envolvidas em fenômenos fotoinduzidos em vidros dopados com íons paramagnéticos, pela observação do estreitamento dos espectros de RPE (Laser Induced EPR Narrowing) através dos quais é possível determinar o tipo de mudança estrutural relacionando com os estreitamentos espectrais devido às alterações nos níveis de energia do íon utilizado como sonda estrutural $[158,159]$.

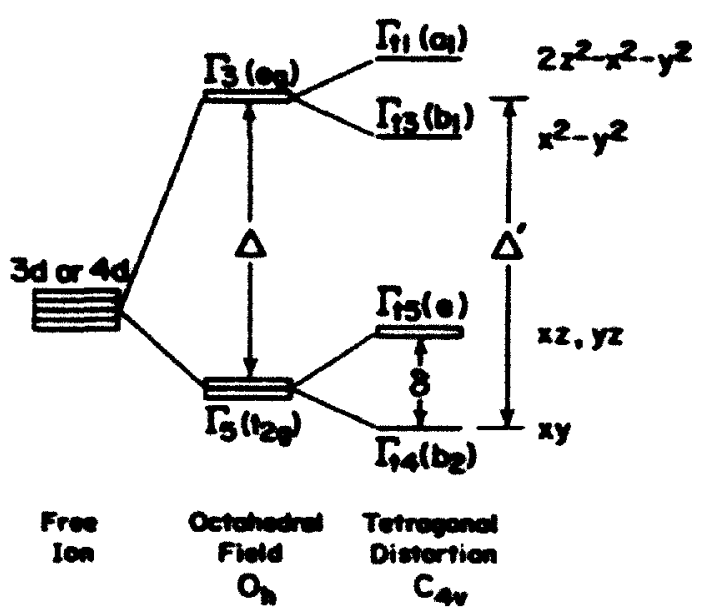

Figura 92 - Diagrama de energia do $\mathrm{Cu}^{2+}$ em um campo cristalino octaédrico e campo com distorção tetragonal em vidros óxidos. $\mathrm{A}$ ordem dos níveis e a designação das autofunções à direita indicam coordenação octaédrica com compressão tetragonal ao longo do eixo z como proposto por Griscom et al. [155].

A Figura 93 ilustra o tipo de alteração estrutural ao longo do eixo z, (compressão ou elongação tetragonal) em um complexo octaédrico ao redor de um íon paramagnético, que pode ser analisada a partir de medidas de RPE, relativo ao diagrama de níveis de energia apresentado acima (Figura 92).
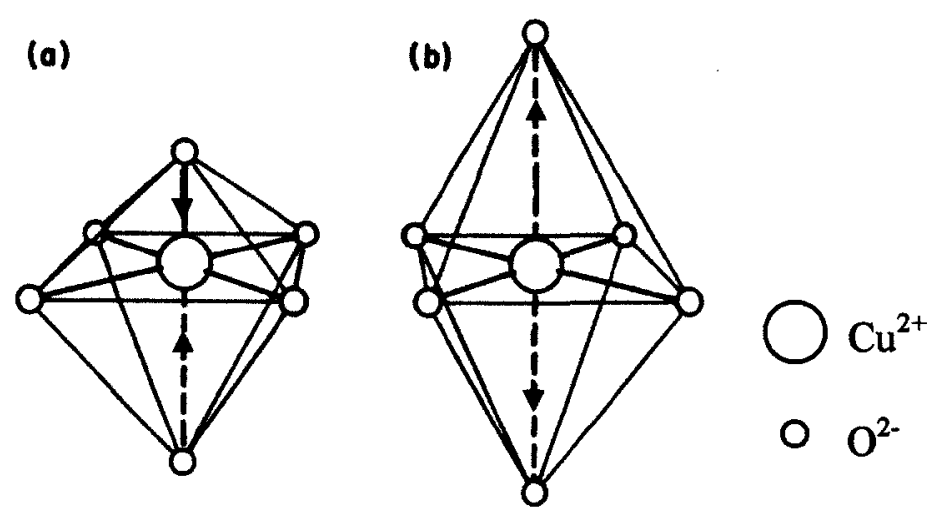

Figura 93 - Perspectiva de complexos octaédricos distorcidos ao longo do eixo $\mathrm{z}$, proposto a partir do diagrama de energia do $\mathrm{Cu}^{2+}$ em vidros óxidos; (a) compressão tetragonal, (b) elongação tetragonal [155]. 
A compressão ou elongação tetragonal é interpretada em termos de que uma das seis ligações $\mathrm{Cu}-\mathrm{O}$ se torna mais curta do que as outras cinco ligações fazendo com que ocorra uma mudança em apenas uma das direções cristalinas no sítio ocupado pelo íon paramagnético. A Figura 94 mostra os níveis de energia do ín $\mathrm{Cu}^{2+}$ em campo cristalino tetraédrico para vidros fosfato, com 2 distorções distintas observadas neste caso para o sítio do cobre na estrutura vítrea.

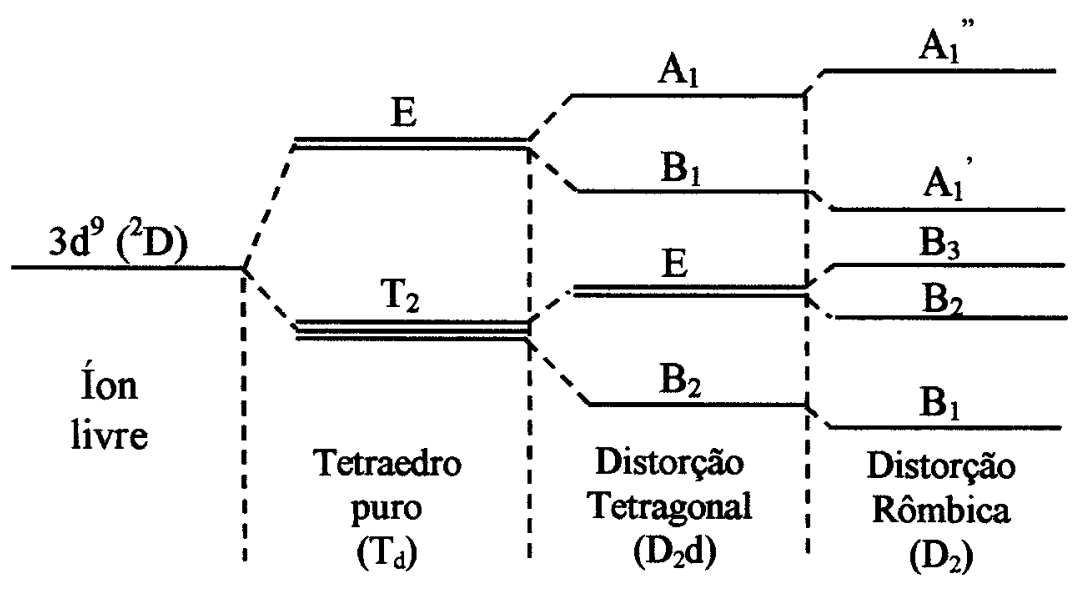

(a)

(b)

(c)

Figura 94 - Diagrama de energia do $\mathrm{Cu}^{2+}$ em campo cristalino em vidros fosfato: (a) tetraedro puro, (b) com distorção Tetragonal e (c) com distorção Rômbica (Cozar et al.) [160].

A Figura 95 apresenta espectros de RPE do $\mathrm{Cu}^{2+}$ em vidros fosfato com as típicas mudanças observadas nos espectros no caso de distorção tetragonal e rômbica ao redor do íon paramagnético.

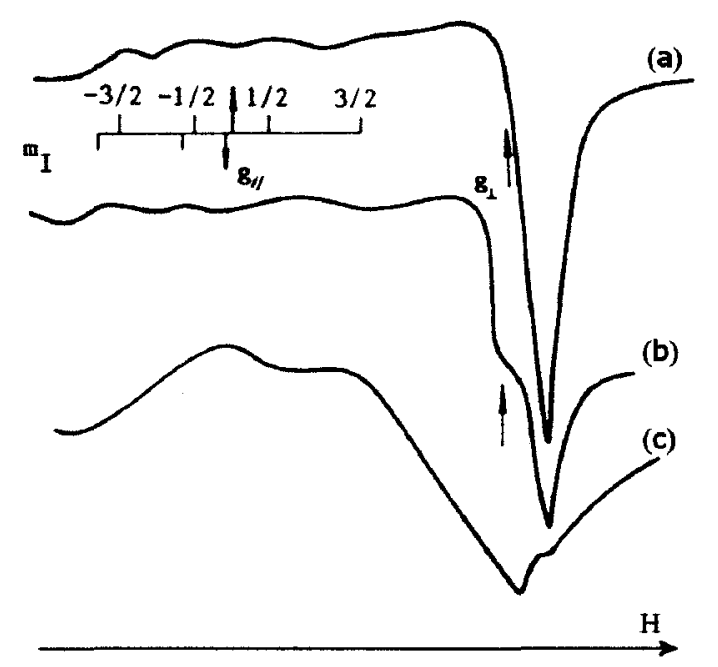

Figura 95 - Espectros de RPE onde o $\mathrm{Cu}^{2+}$ se apresenta em 3 simetrias diferentes para diferentes composições em vidros fosfato; (a) Tetraedro puro ,(b) Distorção tetragonal, (c) Distorção rômbica [160]. 


\subsubsection{Resultados de RPE para filmes dopados com $\mathrm{Cu}^{2+}$}

Para as medidas de RPE os vidros foram moídos e os filmes irradiados e nãoirradiados foram posteriormente raspados dos substratos e transformados em pó. Os filmes foram irradiados com laser UV durante 12 horas com feixe expandido a 1,0 $\mathrm{W} / \mathrm{cm}^{2}$, para garantir que todo o filme extraído da lâmina foi sensibilizado pelo laser. Os espectros a temperatura ambiente se apresentaram muito ruidosos no caso de filmes, dessa forma realizamos medidas a baixa temperatura.

A Figura 96 mostra o espectro de RPE-CW do vidro $20 \%\left[\mathrm{Sb}\left(\mathrm{PO}_{3}\right)_{3}\right]_{n}-$ $80 \% \mathrm{Sb}_{2} \mathrm{O}_{3}$ dopado com $2 \%$ de $\mathrm{CuO}$. Na região de $g$-paralelo, o espectro mostra uma estrutura hiperfina do cobre bem resolvida e com aumento na largura de linha proporcional ao número quântico magnético do spin nuclear MI. Baseado neste resultado, concluímos que em nossos vidros o $\mathrm{Cu}^{2+}$ está localizado em simetria axial octaédrica. Com base nessas informações e com os dados estruturais conhecidos para estes vidros e compostos similares temos indicações que o $\mathrm{Cu}^{2+}$ está substituindo o $\mathrm{Sb}^{3+}$ que também se situa em sítio octaédrico a curto alcance na estrutura do vidro, como ilustrado pela Figura 97. Outra possibilidade baseada na química de fosfatos, é que os íons de $\mathrm{Cu}^{2+}$ estejam coordenados por átomos de oxigênio terminais de grupos fosfatos.

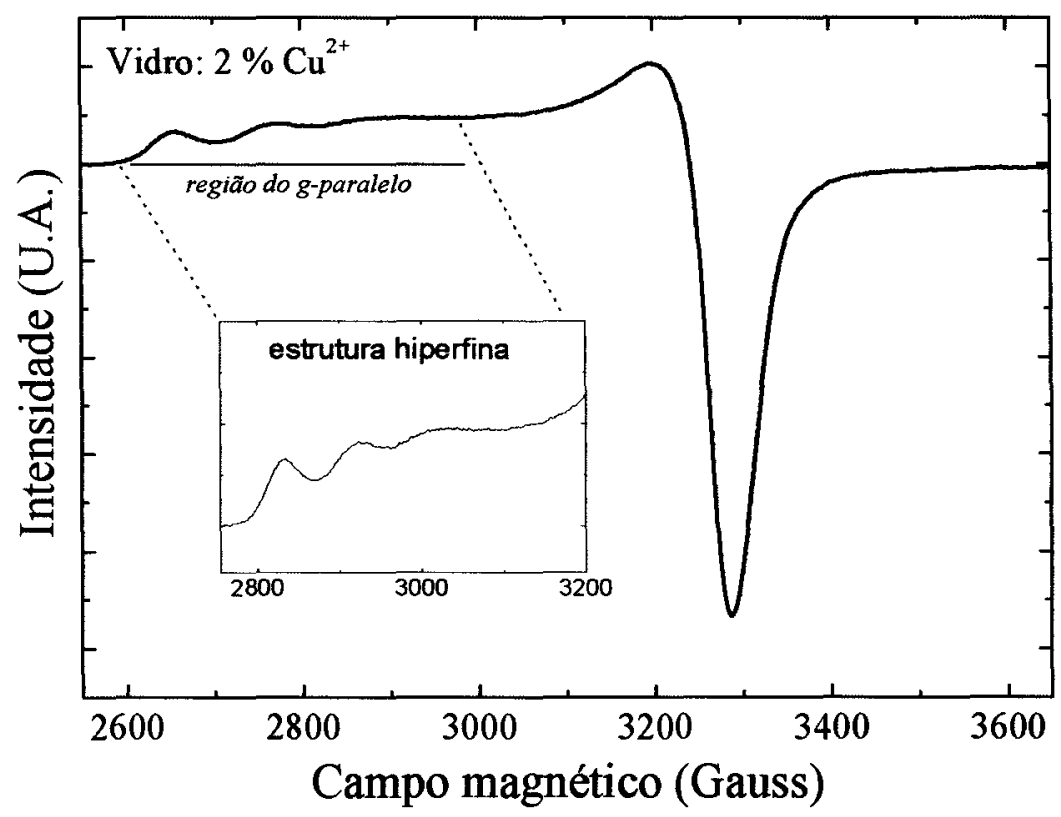

Figura 96 - Espectro de RPE para o vidro $20 \%\left[\mathrm{Sb}\left(\mathrm{PO}_{3}\right)_{3}\right]_{n}-80 \% \mathrm{Sb}_{2} \mathrm{O}_{3}$ com $2 \%$ de $\mathrm{CuO}$. 


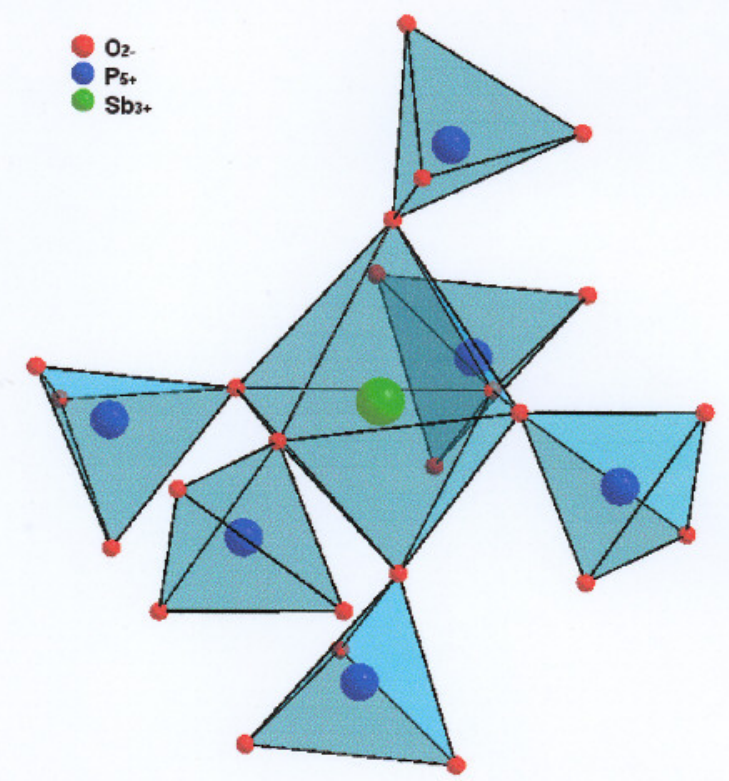

Figura 97 - Estrutura a curto alcance para os vidros de $\left[\mathrm{Sb}\left(\mathrm{PO}_{3}\right)_{3}\right]_{n}-\mathrm{Sb}_{2} \mathrm{O}_{3}$ mostrando um átomo de $\mathrm{Sb}$ em sítio octaédrico cercado por seis tetraedros $\mathrm{PO}_{4}$.

A Figura 98 mostra os espectros de RPE-CW para os vidros e filmes dopados com $\mathrm{Cu}^{2+}$. Através dos espectros pode-se observar que o filme e o vidro precursor apresentam a mesma simetria axial octaédrica ao redor do $\mathrm{Cu}^{2+}$, devido à estrutura hiperfina bem resolvida do cobre na região do $g$-paralelo. Após a irradiação o espectro do filme não perde a estrutura hiperfina e também apresenta o aparecimento de um pico intenso $\left({ }^{*}\right)$ na região do g-perpendicular. Estes resultados estão associados com uma compressão tetragonal do sítio do cobre, caracterizado por mudanças no comprimento das ligações químicas.

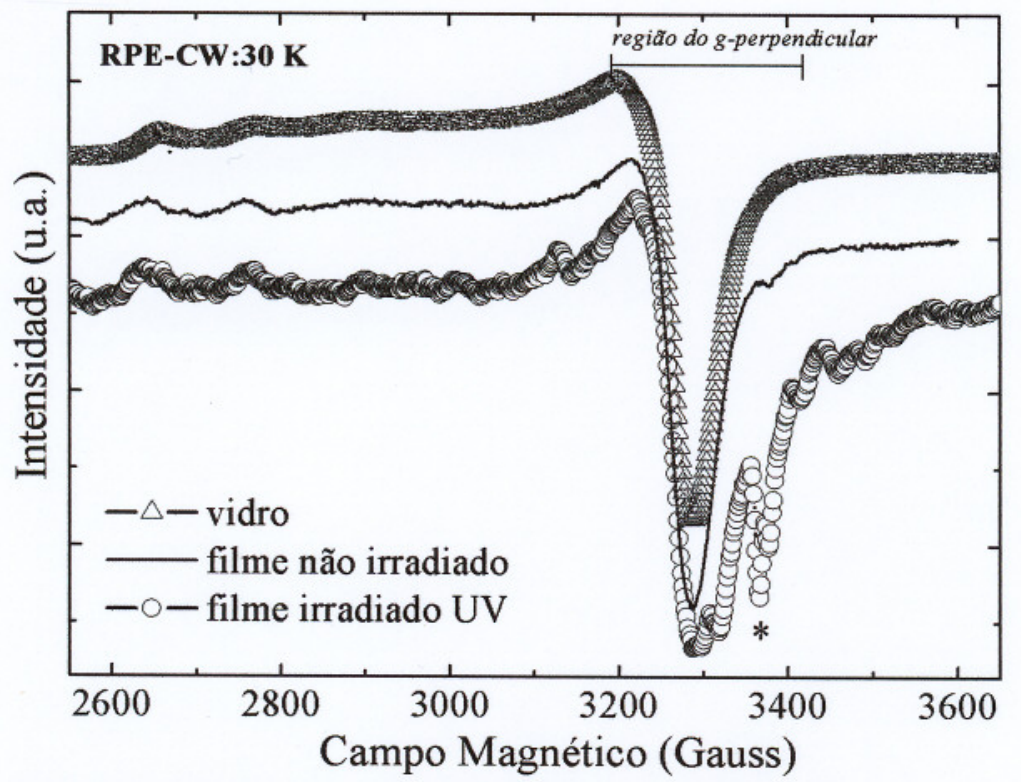

Figura 98 - Espectros de RPE obtidos para composição $20 \%\left[\mathrm{Sb}\left(\mathrm{PO}_{3}\right)_{3}\right]_{n}-80 \% \mathrm{Sb}_{2} \mathrm{O}_{3}$ com $2 \%$ de $\mathrm{Cu}^{2+}$, (a) vidro, (b) Filme não-irradiado, (c) Filme irradiado com UV. 
O experimento de modulação de eco de spins, (Electron Spin Echo Envelope Modulation-ESEEM), foi realizado com o intuito de se obter informações sobre a estrutura ao redor do $\mathrm{Cu}^{2+}$ a partir da resposta de núcleos de fósforo. Este método fornece informações a respeito das propriedades magnéticas dos núcleos de ${ }^{31} \mathrm{P}$ localizados fora da primeira esfera de coordenação do cobre. A Figura 99 mostra os espectros de ESEEM 2 e 3 Pulsos do filme irradiado por UV e do filme não irradiado.

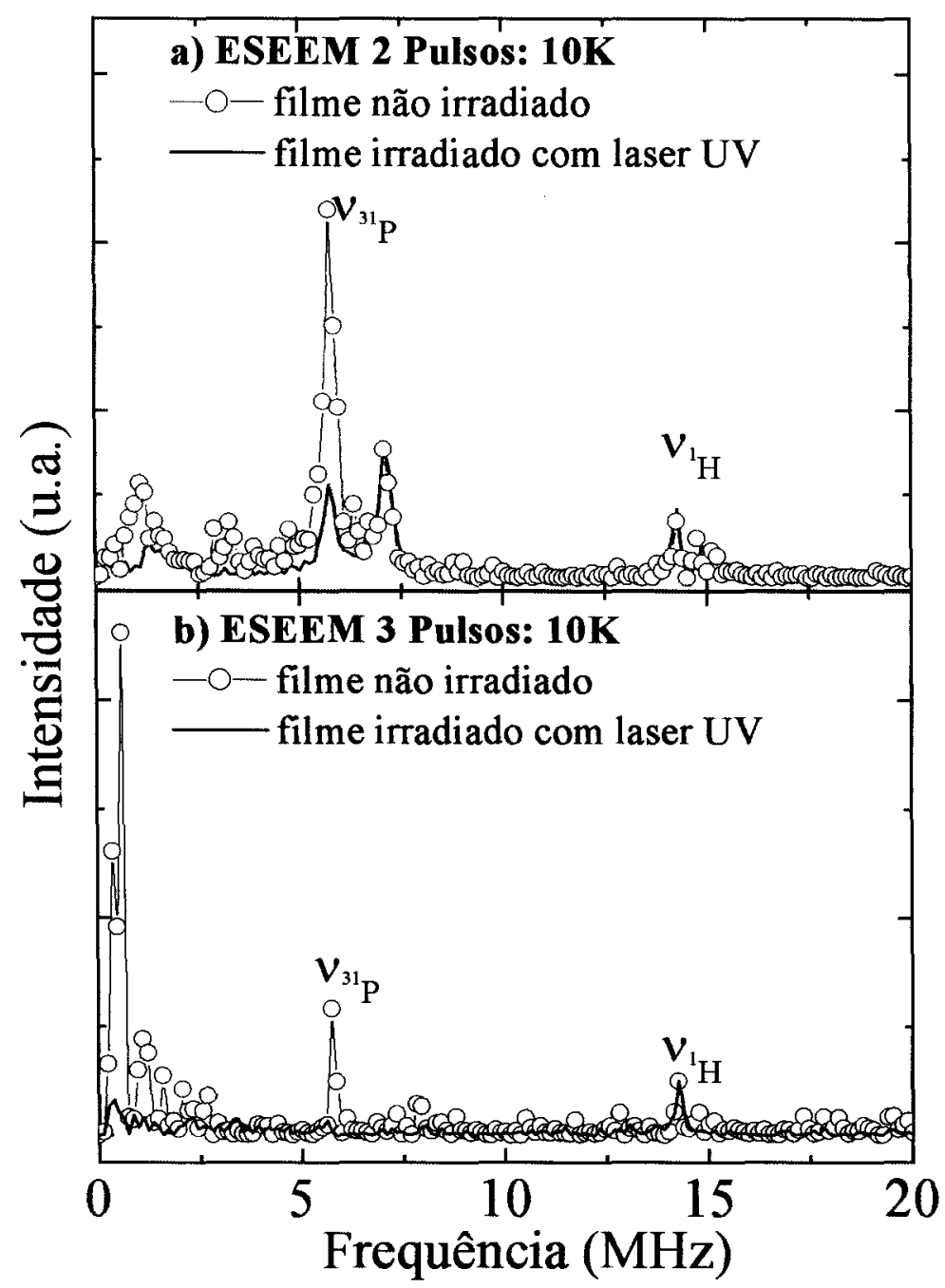

Figura 99 - Espectros de RPE obtidos a $10 \mathrm{~K}$ para Filme não-irradiado e Filme irradiado com laser UV (composição 20\% $\left[\mathrm{Sb}\left(\mathrm{PO}_{3}\right)_{3}\right]_{n}-80 \% \mathrm{Sb}_{2} \mathrm{O}_{3}$ com $2 \%$ de $\mathrm{Cu}^{2+}$ ); a) ESEEM 2 pulsos, b) ESEEM 3 pulsos.

Esses espectros mostram claramente uma diminuição na intensidade do pico referente à freqüência do ${ }^{31} \mathrm{P}$ nos filmes irradiados, o que indica diminuição do número desses núcleos após a irradiação com laser UV. Esses espectros também apresentam um pico correspondente ao ${ }^{1} \mathrm{H}$, devido à presença de $\mathrm{OH}$ na amostra. 
Também foi realizado o experimento de ESEEM 3 pulsos (Figura 99-b)), que proporciona linhas mais estreitas e uma resolução melhor que a apresentada no experimento de 2 pulsos, além de não apresentar picos referentes às freqüências harmônicas. Em concordância com o espectro de 2 pulsos, o espectro de ESEEM 3 pulsos referente ao filme irradiado por UV também apresenta uma queda drástica no sinal do núcleo de ${ }^{31} \mathrm{P}$, sinal este que é muito evidente no espectro do filme que não foi exposto à radiação. Esses espectros também mostram uma linha devido à contaminação por $\mathrm{OH}$.

Baseado nos resultados obtidos e nos modelos propostos em vários trabalhos encontrados na literatura, pode-se supor que as mudanças observadas nos espectros de RPE-CW para os filmes após irradiação com laser UV estão relacionadas com uma distorção tetragonal em apenas uma direção do sítio octaédrico ao redor do cobre, o que é bastante razoável uma vez que o efeito de fotocontração a nível estrutural pode ser explicado como um encurtamento das ligações químicas ao redor de um íon na estrutura vítrea. Outra interpretação que também é coerente com os resultados obtidos por luminescência em termos de aproximação de cadeias de fosfatos (fotopolimerização) após irradiação UV, causando uma aproximação de íons $\mathrm{Cu}^{2+}$ que estejam localizados intersticialmente.

A queda na amplitude da linha correspondente ao ${ }^{31} \mathrm{P}$ da amostra irradiada com relação à amostra não irradiada, obtido pelos espectros de ESEEM, indicam uma perda de fósforo induzida pela radiação UV, como observado também pelas técnicas de análise química apresentadas anteriormente. 


\section{MODELO PARA FOTOCONTRACÃO ESTRUTURAL}

\subsubsection{Modelo para Fotocontração baseado em centros de defeitos}

Como apresentado anteriormente (seção 1.4), alguns modelos sobre a natureza de fenômenos fotoinduzidos em vidros fotossensíveis foram propostos por vários autores na tentativa de explicar tais alterações a nível molecular [62,84,85].

Nesta seção apresentamos um modelo para o efeito de fotocontração estrutural observado nos filmes de $\left[\mathrm{Sb}\left(\mathrm{PO}_{3}\right)_{3}\right]_{n}-\mathrm{Sb}_{2} \mathrm{O}_{3}$ após irradiação com laser UV. Nosso modelo baseia-se nos resultados experimentais apresentados, que sugerem a presença de vazios estruturais intermoleculares em filmes, como proposto por Marquez [92] e Elliot [151], sendo relacionados com a existência de centros deficientes em oxigênio susceptíveis à excitação por fótons e na quebra de ligações instáveis e formação de novas espécies moleculares (fotopolimerização) [85].

$O$ efeito de fotopolimerização estrutural induzida por luz foi extensivamente estudado [95,143,161], além disso, Potter observou também que os efeitos fotoinduzidos são potencializados quando o material é irradiado em atmosfera de oxigênio, devido a adsorção de $\mathrm{O}^{2-}$ por centros deficientes em oxigênio e conseqüente formação de novas espécies moleculares causando polimerização estrutural. A Figura 100 ilustra um esquema proposto para os filmes estudados, em relação ao efeito de fotopolimerização de centros deficientes em oxigênio, $\left(\mathrm{PO}_{3}\right)^{+}$, pela reação com $\mathrm{O}^{2-}$ após irradiação com UV e formação de cadeias de grupos $\left(\mathrm{PO}_{3}\right)_{n}$.

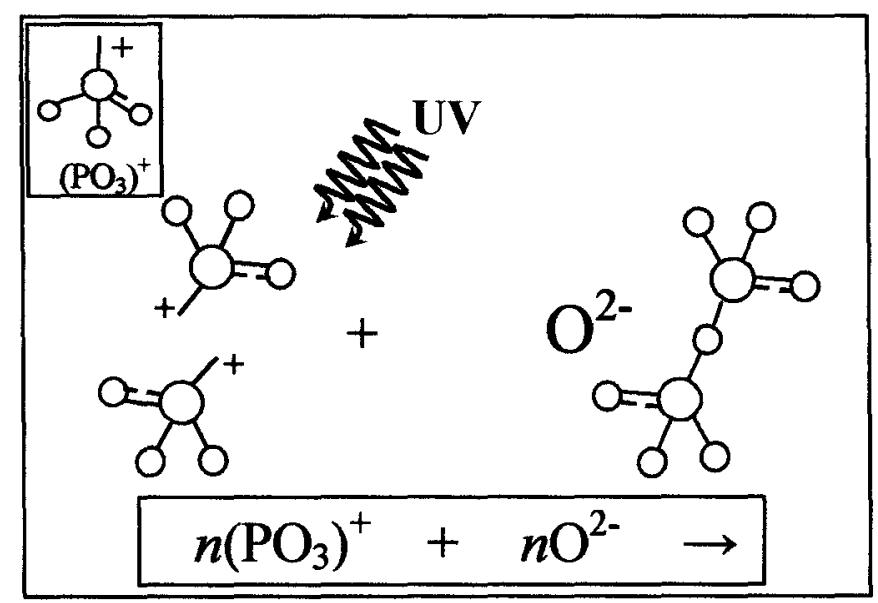

Figura 100 - Esquema ilustrativo do efeito de fotopolimerização de centros deficientes em oxigênio, $\left(\mathrm{PO}_{3}\right)^{+}$, pela reação com $\mathrm{O}^{2-}$ após irradiação com $\mathrm{UV}$ e formação de cadeias de $\left(\mathrm{PO}_{3}\right)_{n}$, em filmes de $\left[\mathrm{Sb}\left(\mathrm{PO}_{3}\right)_{3}\right]_{n}-\mathrm{Sb}_{2} \mathrm{O}_{3}$. 
A Figura 101 ilustra o modelo de forma mais abrangente para o efeito de fotocontração, considerando: a) a presença de centros deficientes em oxigênio e regiões de vazios estruturais; b) Adsorção de $\mathrm{O}_{2}$ seguido da fotopolimerização estrutural; c) conexão e aproximação entre cadeias de fosfatos; d) fotocontração estrutural.

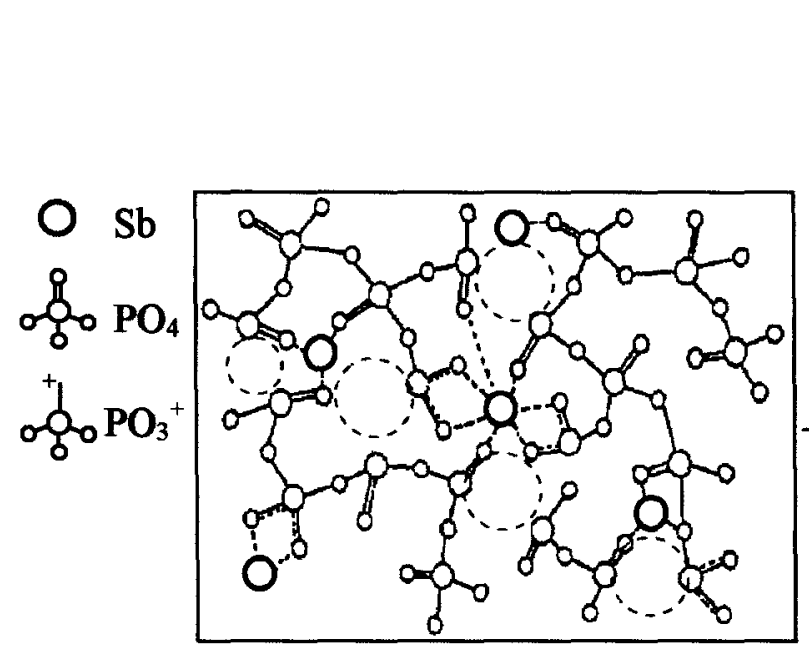

a) Centros deficientes em oxigênio e regiões de vazios estruturais

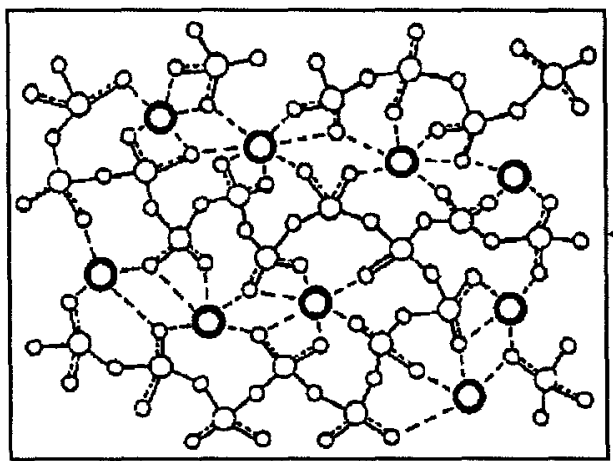

d) Fotocontração Estrutural

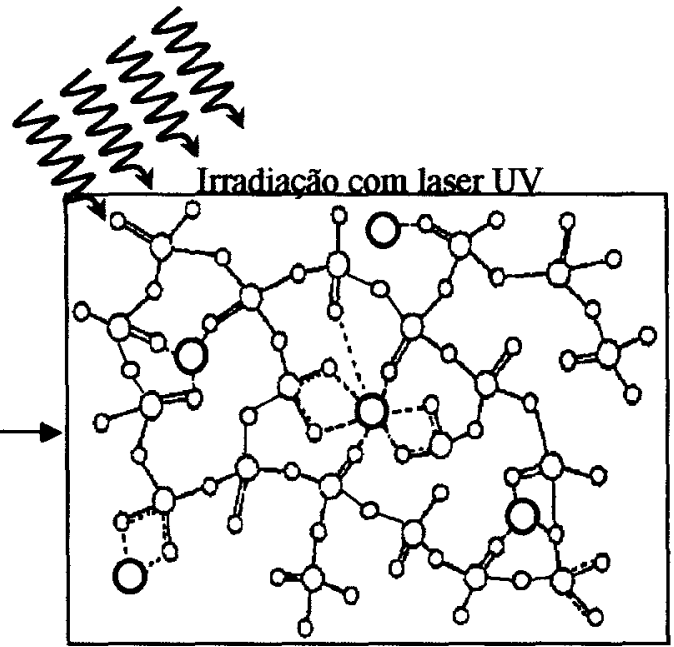

b) Adsorção de $\mathrm{O}_{2}$ seguido de fotopolimerização estrutural

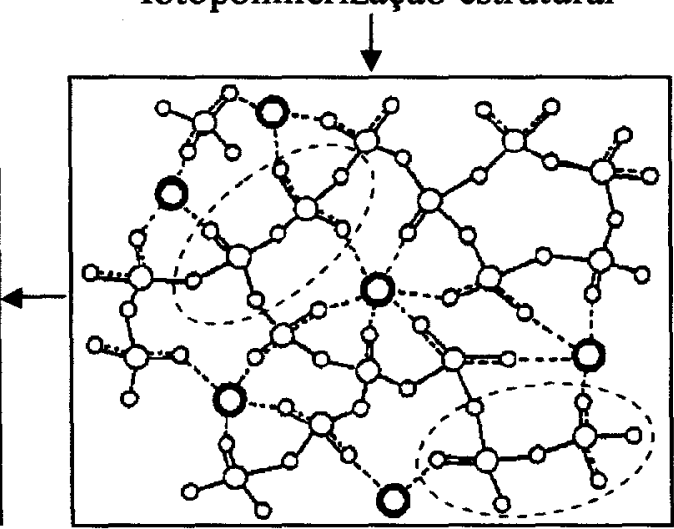

c) Conexão e aproximação entre cadeias de fosfatos

Figura 101 - Modelo ilustrativo para o Efeito de Fotocontração estrutural com irradiação UV (descrito no sentido horário) em filmes de $\left[\mathrm{Sb}\left(\mathrm{PO}_{3}\right)_{3}\right]_{n}-\mathrm{Sb}_{2} \mathrm{O}_{3}$, baseado em centros de defeitos deficientes em oxigênio e vazios estruturais na estrutura vítrea. 


\subsection{Aplicações do Efeito de Fotocontração para Holografia}

\subsubsection{Gravação de Redes Holográficas com Espelho de Lloyd}

Utilizamos o sistema baseado no Espelho de Lloyd para gravação de redes holográficas, através do qual foi possível obter padrões de interferência muito estáveis ao longo do tempo permitindo a gravação de redes com espaçamento de $20 \mu \mathrm{m}$ até 500 $\mathrm{nm}$, com período de exposição de várias horas sem interferência de vibrações mecânicas como ocorria com a montagem tradicional utilizada anteriormente para holografia. Através da mesma montagem registramos também as curvas de eficiência de difração das redes gravadas utilizando um laser de He-Ne como feixe de prova durante a gravação.

\subsubsection{Montagem e Cálculo do espaçamento das redes holográficas}

A montagem do espelho de Lloyd utilizado para gravação de redes holográficas e medidas de eficiência de difração em tempo real em filmes está descrita na seção 2.3.5 (Técnicas de Gravação Holográfica). $\mathrm{O}$ cálculo do espaçamento $\Lambda$ das franjas de interferência em função do ângulo $\theta \mathrm{e}$ do comprimento de onda $\lambda$ do laser de gravação pode ser obtido pela expressão $\lambda=2 \Lambda \operatorname{sen} \theta$, e está descrito de forma mais detalhada através das figuras a seguir.

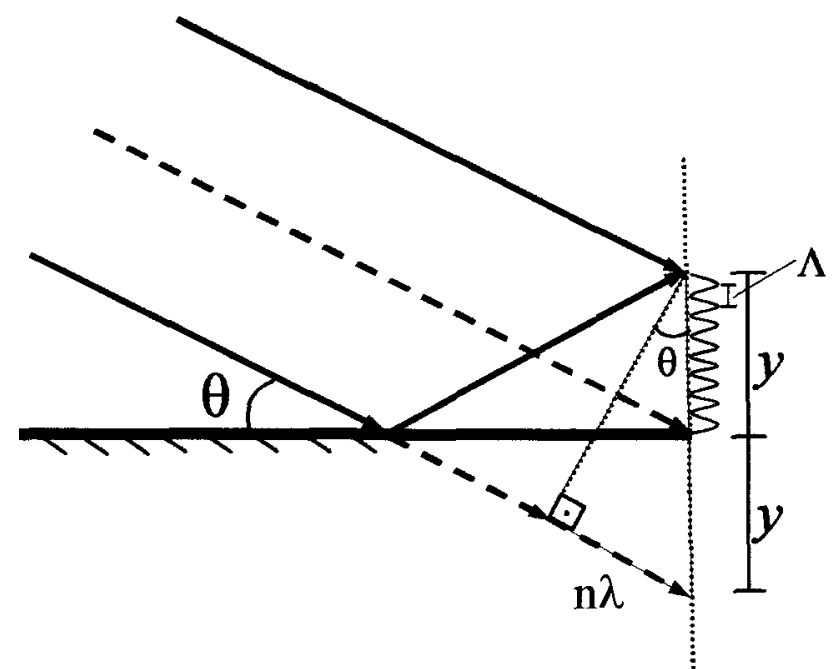

Figura 102 - Descrição da formação do padrão de interferência baseado no Espelho de Lloyd em função da dimensões mensuráveis. 
Na região de interferência " $y$ " se formarão " $n$ " franjas com espaçamento " $\Lambda$ " e para isto ocorrer é necessário que a diferença de caminho óptico entre os dois feixes seja igual a um múltiplo inteiro $(n \lambda)$ do comprimento de onda do laser de gravação. A diferença de caminho óptico entre os dois feixes que estão interferindo é igual a $(n \lambda)$ como pode-se observar pela Figura 102, e por simetria é possível obter a expressão que relaciona o ângulo entre os feixes que interferem e a região de formação do padrão de interferência " $y$ ", como ilustra a Figura 103 a seguir:

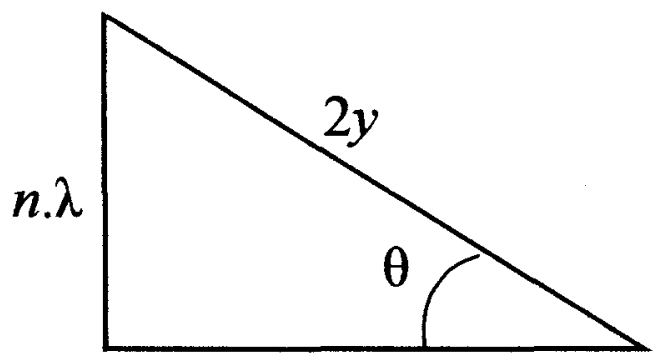

Figura 103 - Projeção por triangulação das dimensões mensuráveis derivadas do Espelho de Lloyd.

Da Figura 103 temos que $\operatorname{sen} \theta=n \lambda / 2 y$, onde $y=n . \Lambda$, portanto:

$$
\lambda=2 \Lambda \operatorname{sen} \theta
$$

onde $\lambda$ é o comprimento de onda do laser de gravação, $\Lambda$ o espaçamento das franjas de interferência e $\boldsymbol{\theta} \mathrm{o}$ ângulo entre o espelho de Lloyd e o feixe do laser de gravação.

A seguir apresentamos imagens de microscopia de força atômica (AFM) mostrando em detalhes as redes produzidas com diferentes espaçamentos e diferentes geometrias. 


\subsubsection{Redes em 1 direção}

Nesta seção apresentamos imagens de AFM de redes holográficas gravadas através da montagem de espelho de Lloyd, em filmes de $20 \%\left[\mathrm{Sb}\left(\mathrm{PO}_{3}\right)_{3}\right]_{n}-80 \% \mathrm{Sb}_{2} \mathrm{O}_{3}$ de 1,7 $\mu \mathrm{m}$ de espessura por exposição ao laser UV. Produzimos redes com ranhuras em apenas uma direção, variando o período das redes de $\sim 600 \mathrm{~nm}$ até $20 \mu \mathrm{m}$ para mostrar a sensibilidade do material e da montagem para gravações em diferentes ordens de grandeza de espaçamento. Para obtenção de imagens de AFM precisas utilizamos uma amostra padrão com $1,0 \mu \mathrm{m}$ de espaçamento. A Figura 104 mostra a imagem da amostra padrão e o perfil com as dimensões da amplitude e do período das ranhuras. Dessa imagem obtivemos que o período entre as ranhuras é de 1,004 $\mu \mathrm{m}$, ou seja, um erro de $0,4 \%$.

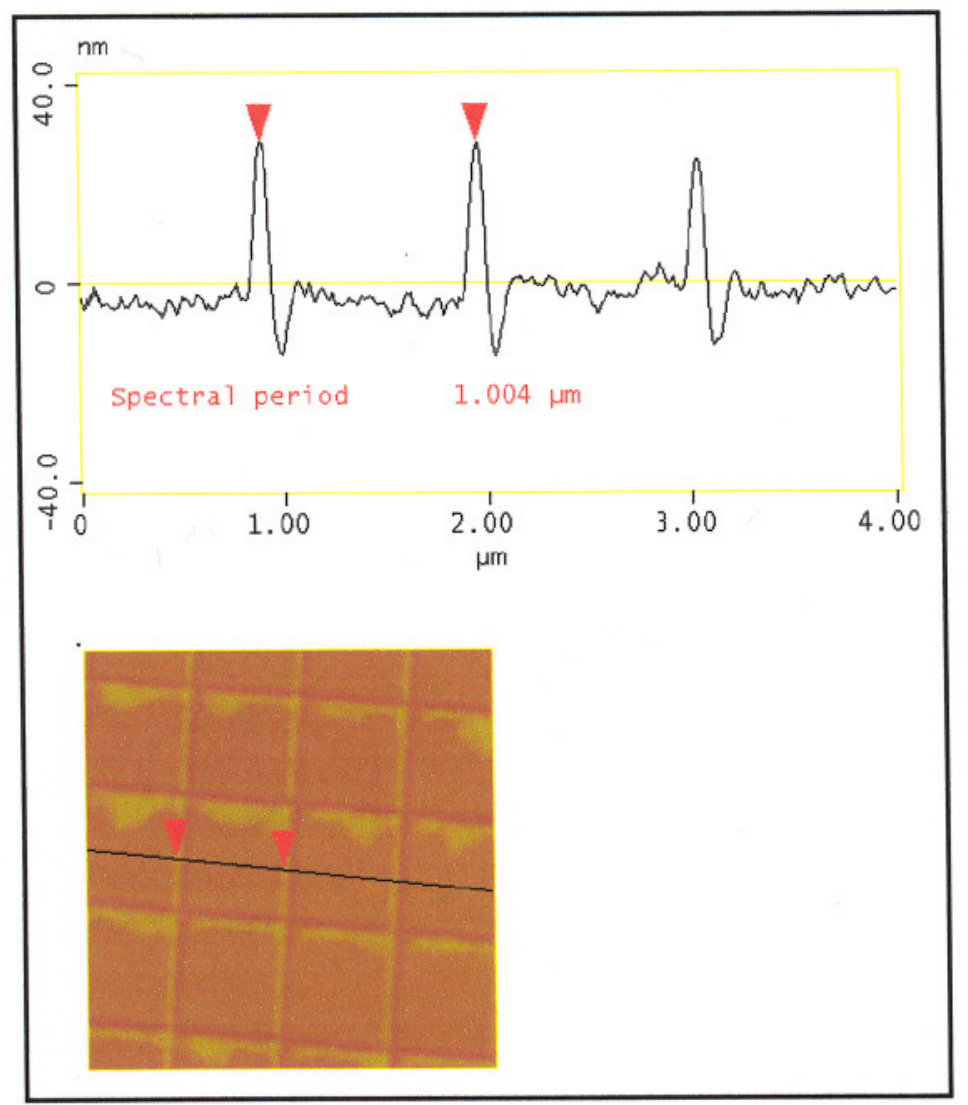

Figura 104 - Imagem de AFM de uma amostra padrão com $1 \mu \mathrm{m}$ de espaçamento, para calibração do microscópio de força atômica. 
A Figura 105 apresenta imagens de AFM para redes holográficas com diferentes períodos gravadas em filmes para diferentes tempos de exposição ao laser UV. A Figura 105-a) e b) mostra imagens de redes com perfil senoidal com período de $600 \mathrm{~nm}$ e 6,2 $\mu \mathrm{m}$ respectivamente, gravadas por exposição ao laser UV (100mW 1 hora). A Figura 105 -c) mostra imagens de redes com período de $20 \mu \mathrm{m}$, gravadas por exposição de 4 horas ao laser UV (100mW), formando relevo com perfil de "pontas" devido ao longo tempo de exposição.

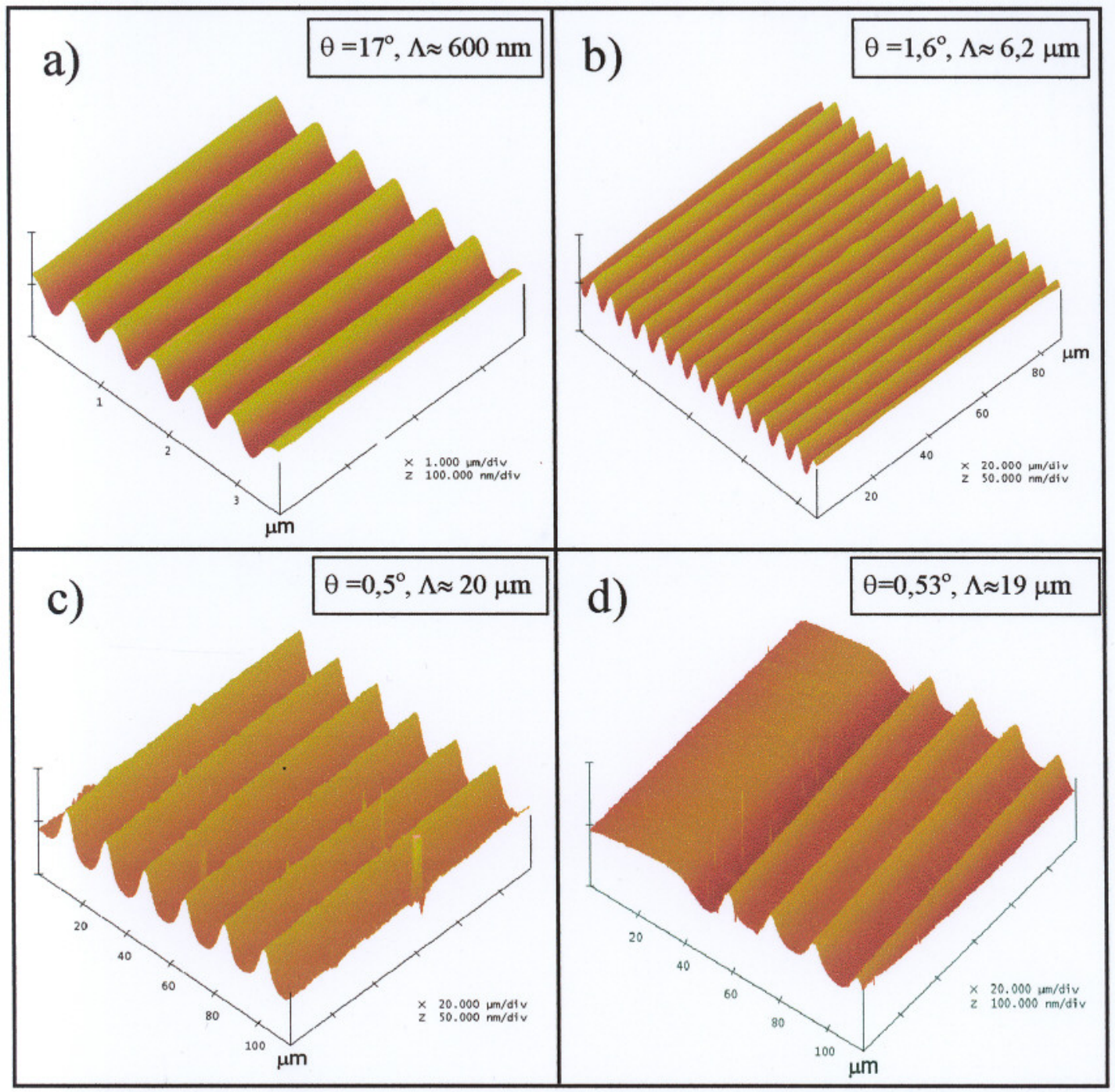

Figura 105 - Imagens de AFM do relevo de redes holográficas gravadas em filmes de $20 \%$ $\left[\mathrm{Sb}\left(\mathrm{PO}_{3}\right)_{3}\right]_{n}-80 \% \mathrm{Sb}_{2} \mathrm{O}_{3}$ com $1,7 \mu \mathrm{m}$ de espessura, após exposição ao laser $\mathrm{UV}$. a) $\Lambda \approx 600 \mathrm{~nm}$ (exposição de $100 \mathrm{~mW} / 1$ hora), b) $\Lambda \approx 6,2 \mu \mathrm{m}$ (exposição de $100 \mathrm{~mW} / 1$ hora) ,c) $\Lambda \approx 20 \mu \mathrm{m}$ (exposição de $100 \mathrm{~mW} / 4$ horas), d) $\Lambda \approx 19 \mu \mathrm{m}$ (exposição de $100 \mathrm{~mW} / 4$ horas). 
Na Figura 105-d), podemos visualizar a região da borda da gravação, mostrando o inicio da região de gravação. A região plana é a parte onde não há incidência do padrão de interferência do laser, e a parte onde começam as ondulações é a região onde há a incidência de luz. Pode-se ver também que a região sensibilizada pelo laser possui relevo abaixo da superficie do filme mostrando o efeito de fotocontração do material sensibilizado pelo laser.

A Figura 106 mostra imagens de AFM em corte, detalhando o perfil e a amplitude do relevo $(-\Delta \mathrm{V} / \mathrm{V})$ formado nas redes apresentadas na Figura 105.

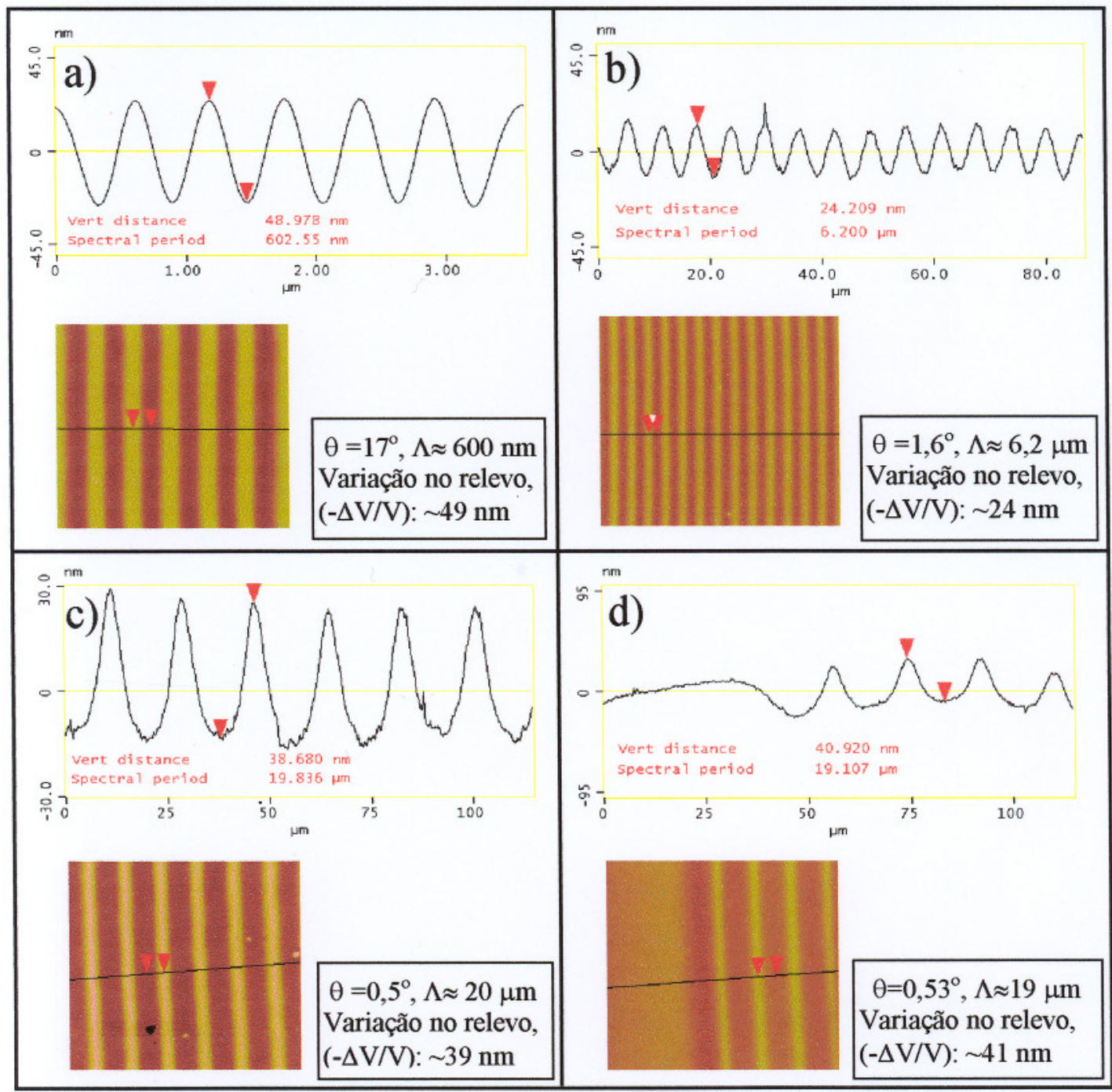

Figura 106 - Imagens de AFM do perfil de redes holográficas, mostrando as dimensões da amplitude e do período das ranhuras gravadas em filmes de $20 \%\left[\mathrm{Sb}\left(\mathrm{PO}_{3}\right)_{3}\right]_{n}-80 \% \mathrm{Sb}_{2} \mathrm{O}_{3} \mathrm{com}$ $1,7 \mu \mathrm{m}$ de espessura, após exposição ao laser UV. a) $\Lambda \approx 600 \mathrm{~nm}$ (exposição de $100 \mathrm{~mW} / 1$ hora), b) $\Lambda \approx 6,2 \mu \mathrm{m}$ (exposição de $100 \mathrm{~mW} / 1$ hora) ,c) $\Lambda \approx 20 \mu \mathrm{m}$ (exposição de $100 \mathrm{~mW} / 4$ horas), d) $\Lambda \approx 19 \mu \mathrm{m}$ (exposição de $100 \mathrm{~mW} / 4$ horas). 
As redes mostradas na Figura 106-a) e b) apresentam perfil senoidal com período de $600 \mathrm{~nm}$ e $\sim 6,2 \mu \mathrm{m}$ e amplitude de $\sim 49$ e $\sim 24 \mathrm{~nm}$, respectivamente. Já as redes apresentadas pela Figura 106-c) e d) apresentam perfil mais afilado em forma de "pontas", com período de $\sim 20 \mu \mathrm{m}$ e $19 \mu \mathrm{m}$, e amplitude de $\sim 39$ e $\sim 41 \mathrm{~nm}$, respectivamente.

O que se percebe nesse caso é que para tempos de exposição mais longos o perfil da rede começa a estreitar criando "pontas" que não acompanham mais o perfil senoidal de intensidades esperado para um padrão de interferência. Esse efeito é explicado, pois as franjas escuras em um padrão senoidal não apresentam intensidade zero de luz, mas sim regiões com intensidade muito baixa. Assim para longos tempos de exposição, a rede começa a ser apagada devido à influência da baixa intensidade de luz das regiões de mínimo de intensidade do padrão de interferência, gerando esse efeito de estreitamento do perfil da rede. $O$ efeito de apagamento das redes também pode ser atribuído à difusão da luz dentro do material, vibrações e deslocamentos devido a efeitos térmicos que interferem em variações de dimensões no sistema de gravação.

Devemos levar em conta a possibilidade do efeito de fotocontração estrutural ser causado por um efeito de temperatura gerado pelo feixe laser sobre o material, produzindo "ablação" na superficie do filme e conseqüente perda de material. Porém devemos salientar que seria impossivel a gravação de redes com períodos de $600 \mathrm{~nm}$ (Figura 105-a) levando em conta um efeito puramente térmico, pois efeitos de difusão de calor no material impediriam a gravação de uma rede bem definida considerando-se os longos tempos de exposição ( $>1$ hora) ao laser para gravação das redes. 


\subsubsection{Redes em 2 direções}

Nesta seção apresentamos imagens de AFM de algumas redes com ranhuras em 2 direções com período de $6 \mu \mathrm{m}$ aproximadamente, gravadas filmes $20 \%\left[\mathrm{Sb}\left(\mathrm{PO}_{3}\right)_{3}\right]_{n}{ }^{-}$ $80 \% \mathrm{Sb}_{2} \mathrm{O}_{3}$ de $1,7 \mu \mathrm{m}$ de espessura com exposição de 1,0 hora ao laser UV com $100 \mathrm{~mW}$ $\left(5,0 \mathrm{~W} / \mathrm{cm}^{2}\right)$. Estes resultados visam mostrar a sensibilidade do material para gravações mais complexas. Outro fator importante é a possibilidade de se produzir redes com perfis que se comportam como micro-lentes (Figura 107), área esta com grande aplicabilidade em dispositivos ópticos.

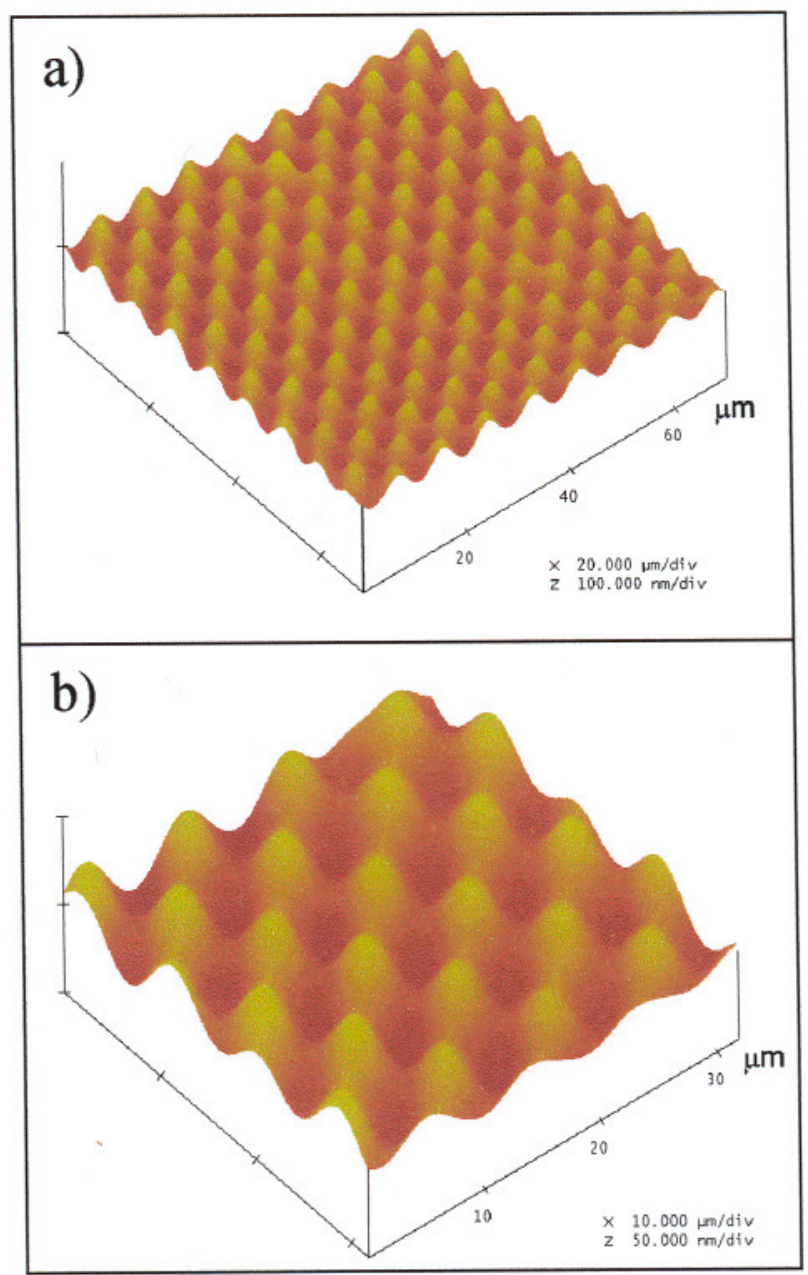

Figura 107 - Imagem de AFM mostrando detalhes das redes gravadas com ranhuras $(\Lambda \approx 6,4$ $\mu \mathrm{m})$ em duas direções em filmes de $20 \%\left[\mathrm{Sb}\left(\mathrm{PO}_{3}\right)_{3}\right]_{n}-80 \% \mathrm{Sb}_{2} \mathrm{O}_{3}$ com $1,7 \mu \mathrm{m}$ de espessura. (exposição 1,0 hora, UV com $100 \mathrm{~mW}$ ). a) região de $70 \times 70 \mu \mathrm{m}$; b) região de $30 \times 30 \mu \mathrm{m}$. 
Sabendo-se o índice de refração do filme obtido por um acoplador de prisma M-line ( $\mathrm{n}=1,87$ a $543 \mathrm{~nm}$ ) e o período das redes, calculamos o foco das micro-lentes através do programa OPTICAD. Obtivemos o valor de $300 \mu \mathrm{m}$ para o foco das microlentes. Para aplicação prática são necessárias redes de micro-lentes com foco da ordem de milímetros, e através de estimativas concluímos que é possível aumentar o foco das micro-lentes gravadas aumentando o período das redes.

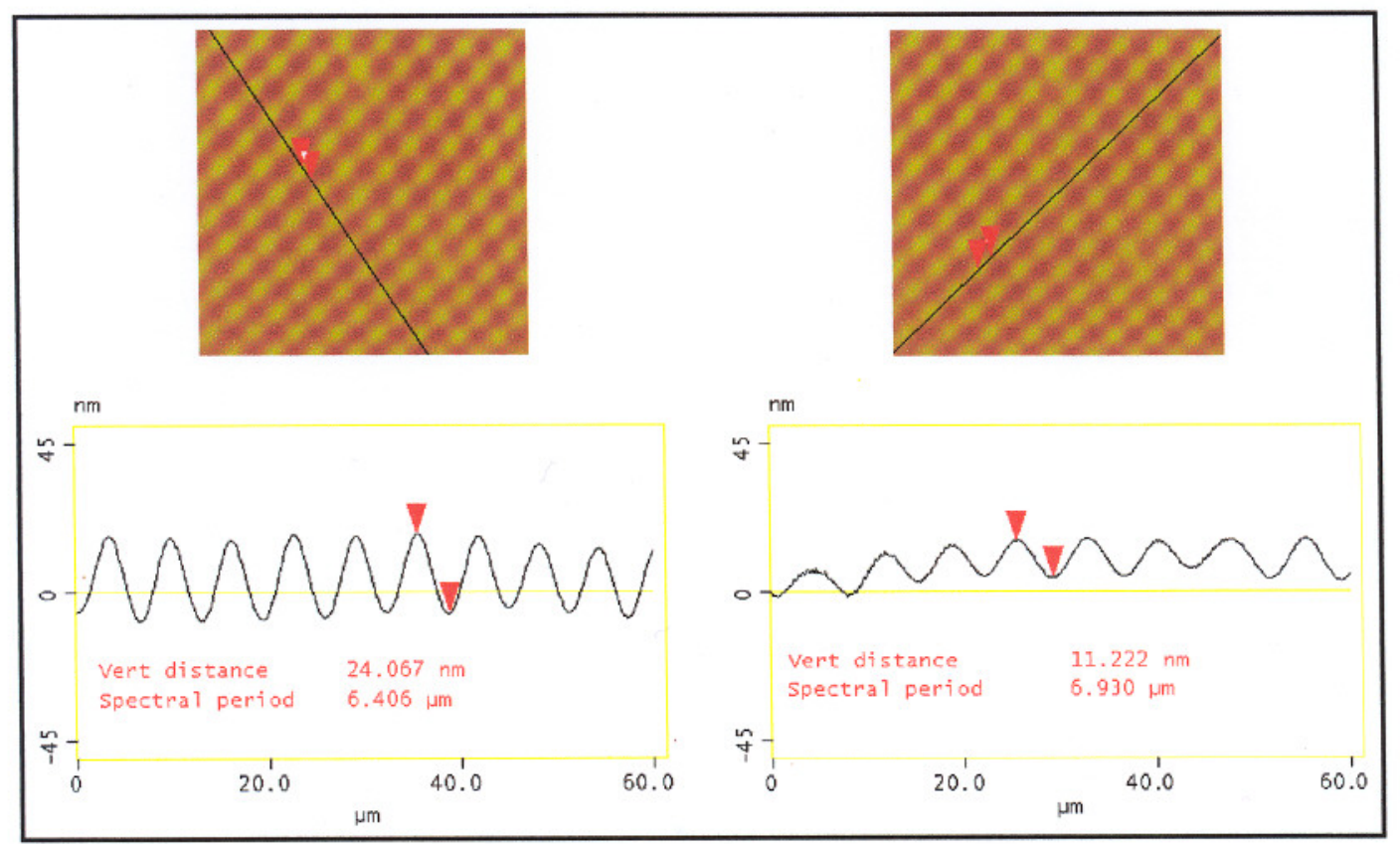

Figura 108 - Imagem de AFM do perfil de amplitude e período das ranhuras da amostra nas duas direções de gravação, para rede gravada com ranhuras em duas direções em filmes de $20 \%$ $\left[\mathrm{Sb}\left(\mathrm{PO}_{3}\right)_{3}\right]_{n}-80 \% \mathrm{Sb}_{2} \mathrm{O}_{3}$ (exposição de 1,0 hora ao laser UV com $100 \mathrm{~mW}$ ).

A Figura 108 apresenta imagens mostrando o perfil com as dimensões da amplitude e do período das ranhuras da rede nas duas direções de gravação. Neste caso vemos uma diferença no período e na amplitude da rede gravada, comparando os perfis apresentados para os cortes relativos a cada direção de gravação. Isto mostra que o filme foi exposto ao laser por mais tempo em uma direção de gravação do que na outra. Para gravação de redes em 2 direções há necessidade de uma sistematização precisa para alteração da posição da amostra e do tempo de exposição ao laser. 


\subsubsection{Medidas de Eficiência de Difração das redes}

Iniciamos as medidas de eficiência de difração das redes utilizando a montagem descrita na seção 2.3.5.1. Achamos interessante mostrar não só as curvas de eficiência, mas também a difração da luz em si, através das redes gravadas no material durante o processo de exposição ao laser como ilustra a Figura 109. Um anteparo de papel foi colocado atrás da amostra para refletir a luz difratada pela rede durante o processo de gravação. A imagem foi obtida por uma maquina fotográfica digital. Esta figura de difração é relativa a uma amostra com rede gravada em duas direções (Figura 107). É interessante notar que é observada até a $3^{\mathrm{a}}$ ordem de difração da luz pela rede.
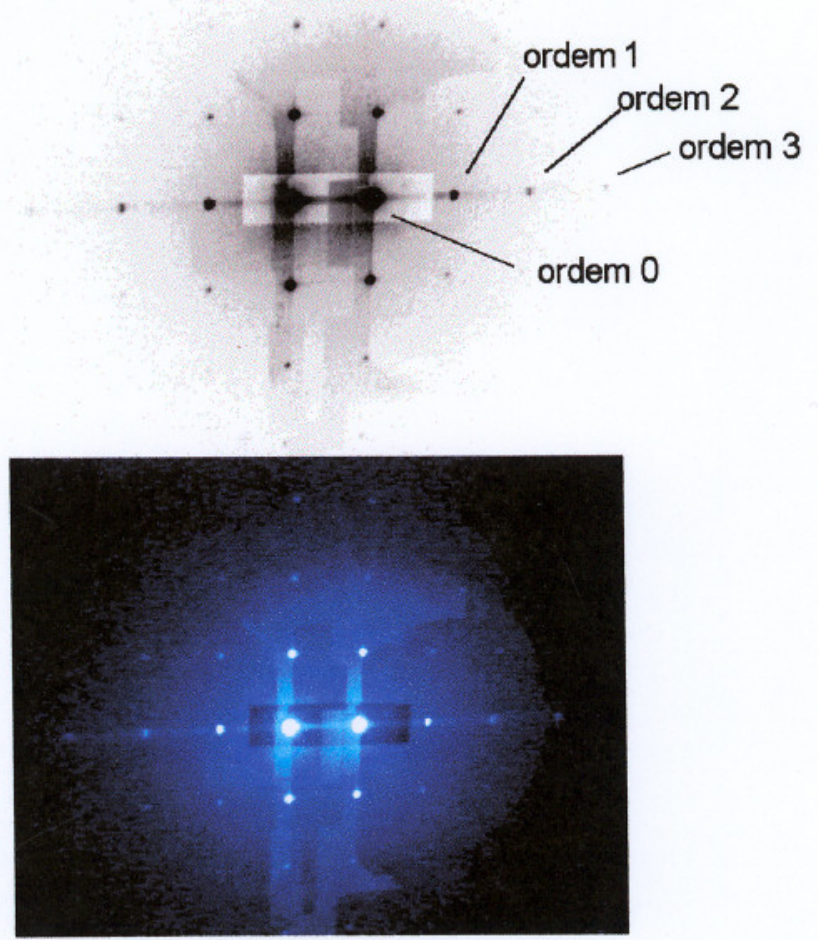

Figura 109 - Difração do laser durante a gravação das redes $(\Lambda \approx 6,4 \mu \mathrm{m})$ em filmes de $20 \%$ $\left[\mathrm{Sb}\left(\mathrm{PO}_{3}\right)_{3}\right]_{n}-80 \% \mathrm{Sb}_{2} \mathrm{O}_{3}$ de $1,7 \mu \mathrm{m}$ de espessura mostrando até a $3^{\mathrm{a}}$ ordem de difração (negativo e imagem real).

A eficiência de difração $(\eta)$ é definida como $\eta=I_{d} I_{t}$, onde $I_{d}$ é a intensidade do feixe do laser de He-Ne de primeira ordem difratado pela amostra e $I_{t}$ é a intensidade do feixe do laser He-Ne transmitido através do filme $[162,134]$. 
Na Figura 110 apresentamos as curvas de eficiência de difração para redes com período de $20 \mu \mathrm{m}$ gravadas em filmes de $20 \%\left[\mathrm{Sb}\left(\mathrm{PO}_{3}\right)_{3}\right]_{n}-80 \% \mathrm{Sb}_{2} \mathrm{O}_{3}$, com potencia do laser variando de 50 a $600 \mathrm{~mW}\left(2,5\right.$ a $\left.30 \mathrm{~W} / \mathrm{cm}^{2}\right)$. Obtivemos valores de eficiência de difração de 3 a 10,5 \% para aproximadamente 1 hora de gravação dependendo da potência do laser como mostram as curvas a seguir. As densidades de potência indicadas como 2,$5 ; 5,0 ; 10 ; 20$ e $30 \mathrm{~W} / \mathrm{cm}^{2}$ são respectivamente $50,100,200,400$, e $600 \mathrm{~mW}$.

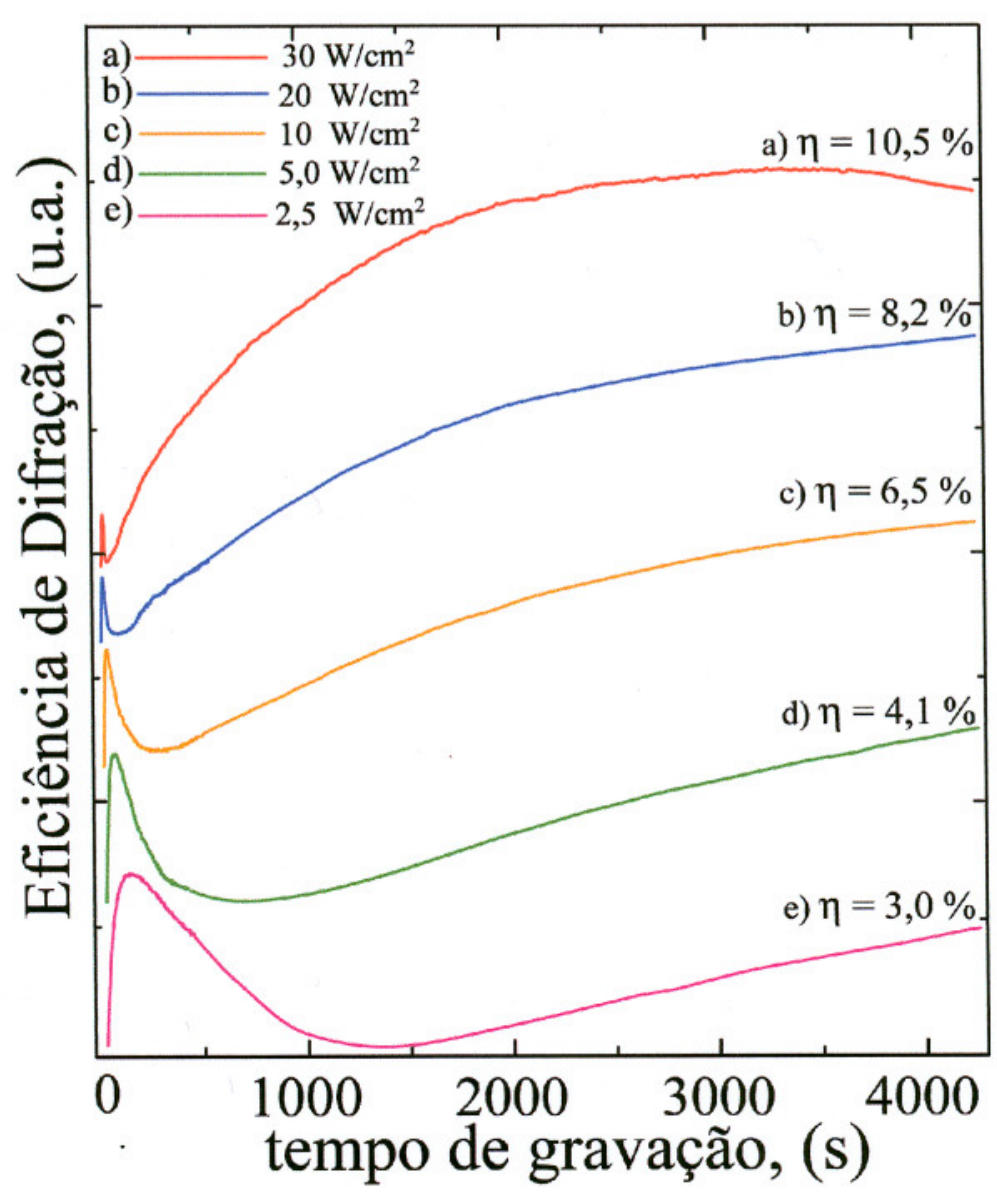

Figura 110 - Curvas de eficiência de difração obtida para redes com período de $20 \mu \mathrm{m}$ gravadas em filmes de $20 \%\left[\mathrm{Sb}\left(\mathrm{PO}_{3}\right)_{3}\right]_{n}-80 \% \mathrm{Sb}_{2} \mathrm{O}_{3}$ de $1,7 \mu \mathrm{m}$ de espessura, para potências de gravação de 50 a $600 \mathrm{~mW}\left(2,5\right.$ a $\left.30 \mathrm{~W} / \mathrm{cm}^{2}\right)$ e tempo de exposição de $\sim 1$ hora.

Durante as medidas observamos que a evolução do sinal de eficiência desaparecia para tempos de gravação curtos, e voltava a subir para tempos de exposição mais longos. Percebemos então que dois processos estão envolvidos na formação das redes. O primeiro processo é rápido e está ligado com o fotoclareamento (Figura 64) observado anteriormente nas amostras, que causa mudança da borda de absorção óptica para maiores energias e associado a este efeito ocorre mudança no índice de refração. $\mathrm{O}$ 
segundo processo é mais lento, sendo o efeito de fotocontração induzido por laser no material. Esta medida foi feita até se observar à saturação do efeito, atingindo eficiência de $\sim 10,5 \%$ após exposição maior que 1 hora para potência de $30 \mathrm{~W} / \mathrm{cm}^{2}(600 \mathrm{~mW})$.

A Figura 111 mostra com mais detalhes a evolução da eficiência de difração das redes e a evolução do sinal dos dois processos envolvidos (fotoclareamento e fotocontração). Para potências altas $30 \mathrm{~W} / \mathrm{cm}^{2}$ a rede de fotoclareamento é formada em alguns minutos e em seguida apagada, na seqüência começa a se formar a rede de relevo. Para potências baixas a formação da rede fotoclareamento é lenta e chega a durar 10 minutos para $2,5 \mathrm{~W} / \mathrm{cm}^{2}(50 \mathrm{~mW})$, após isso o processo de fotocontração tornase dominante.

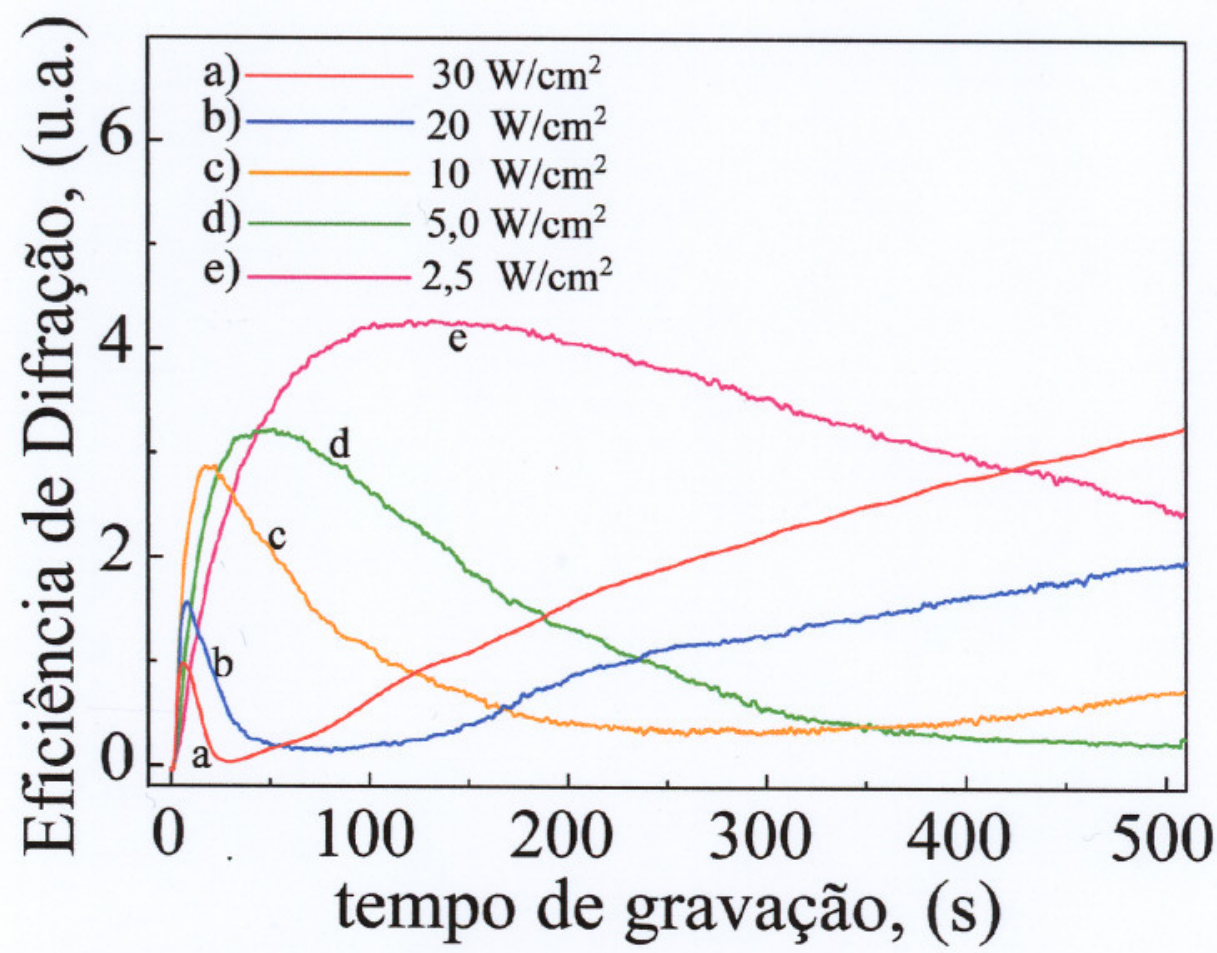

Figura 111 - Curvas de eficiência de difração obtida para redes com período de $20 \mu \mathrm{m}$ gravadas em filmes de $20 \%$ [ $\left.\mathrm{Sb}\left(\mathrm{PO}_{3}\right)_{3}\right]_{n}-80 \% \mathrm{Sb}_{2} \mathrm{O}_{3}$ de $1,7 \mu \mathrm{m}$ de espessura para potências de gravação de 50 a $600 \mathrm{~mW}\left(2,5\right.$ a $\left.30 \mathrm{~W} / \mathrm{cm}^{2}\right)$ e tempo de exposição de $\sim 10$ minutos.

A eficiência de difração no caso dos filmes estudados está associada ao fenômeno da fotocontração (mudança de volume) e fotoclareamento (alteração no índice de refração), ou seja, a difração ocorre devido à modulação do relevo na superfície e também devido à modulação do índice de refração do material [163]. A Figura 112 sintetiza os valores de eficiência de difração máxima obtida para redes formadas por: a) relevo e b) fotoclareamento. No caso das redes de relevo a eficiência 
de difração aumenta com o aumento da densidade de potência do laser de gravação. Já no caso das redes formadas por fotoclareamento a eficiência de difração tem seu máximo para baixas densidades de potência e diminui com o aumento da potência do laser de gravação, mostrando que a dinâmica de fotoclareamento nos filmes ocorre muito rapidamente e a rede é rapidamente apagada com o aumento do tempo de exposição.

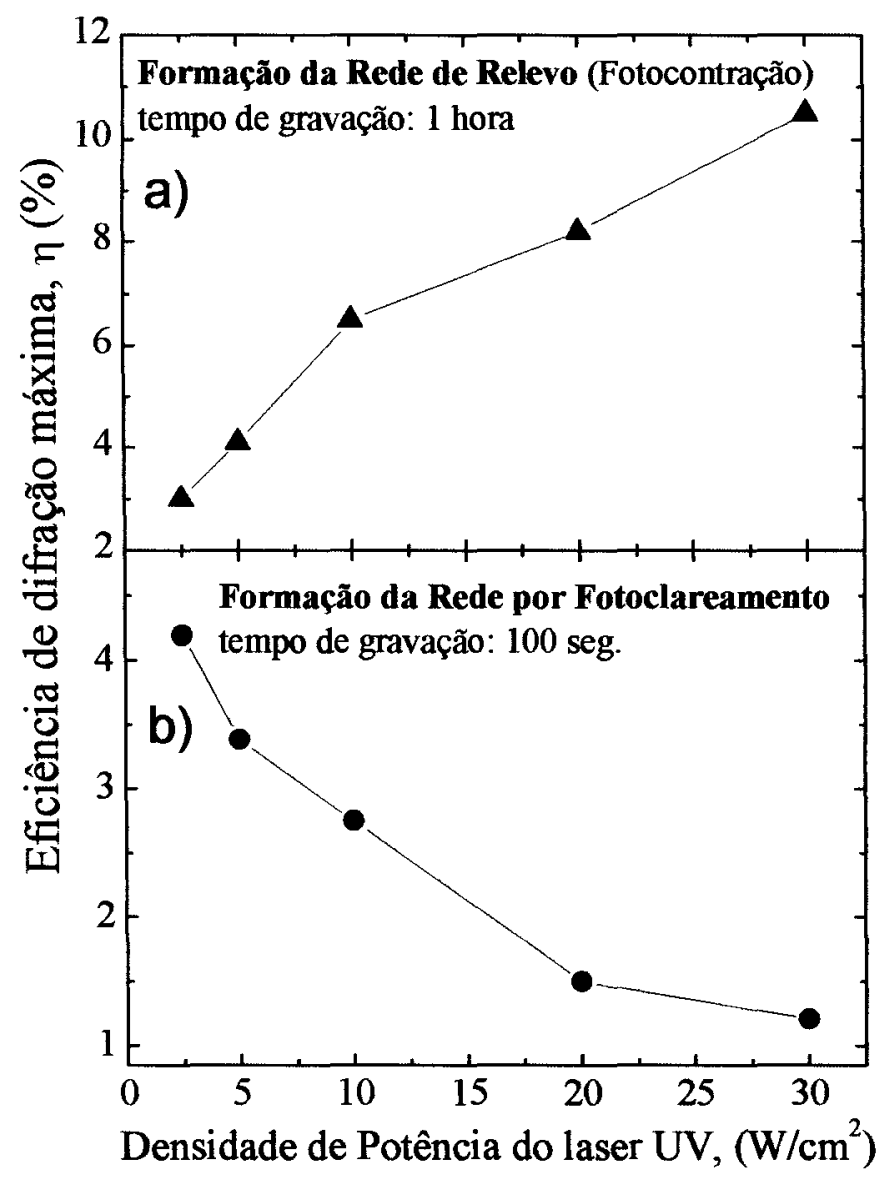

Figura 112 - Eficiência de difração máxima obtida para filmes de $20 \%\left[\mathrm{Sb}\left(\mathrm{PO}_{3}\right)_{3}\right]_{n}-80 \% \mathrm{Sb}_{2} \mathrm{O}_{3}$, em função da densidade de potência do laser UV para: a) Rede de Relevo gravada após 1 hora de exposição ao laser UV; b) Rede de Fotoclareamento após 1 hora de exposição ao laser UV.

As redes gravadas por holografia podem ser definidas como formadas por holograma espesso ou fino. Um holograma fino (ou plano) é aquele cuja espessura do meio de gravação (meio efetivamente sensibilizado pela luz) é pequena comparada com o espaçamento das franjas do padrão de interferência utilizado para gravação. Um holograma espesso (ou volumétrico) é aquele onde a espessura do meio de gravação é da mesma ordem ou mais espesso que o espaçamento das franjas da rede. A distinção 
entre holograma planar e de volume é geralmente feita com a ajuda do fator de Klein [164], $Q$, definido como:

$$
Q=2 \pi \lambda d /\left(\mathrm{n} \Lambda^{2}\right)
$$

onde $\lambda$ é o comprimento de onda da fonte de luz de gravação, $\mathrm{n}$ é o índice de refração do meio de gravação, $d$ é a espessura da porção de material sensibilizada pela luz, e $\Lambda$ o espaçamento das franjas. Um holograma é considerado planar se $Q \leq 10$, e caso contrário é considerado volumétrico.

Em nosso caso consideremos redes com ranhuras muito pequenas $(\Lambda=0,5 \mu \mathrm{m})$ gravadas por UV $(\lambda=350,7 \mathrm{~nm})$ e $\mathrm{n} \approx 2,0$ para o material, assim podemos calcular o valor de $Q \approx 5$, considerando que num caso extremo para um filme de $10 \mu \mathrm{m}$ de espessura, uma fração de $10 \%(\mathrm{~d}=1,0 \mu \mathrm{m})$ seja efetivamente sensibilizada pela luz. As curvas do fator Q vs. $\Lambda$ são apresentadas na Figura 113 para 3 diferentes espessuras de hologramas. Dessa maneira podemos verificar (como indicado pelas setas) que no caso de uma rede com período de $500 \mathrm{~nm}$, o valor máximo para o fator de Klein será $Q \approx 5$, ou seja, dentro do regime de holograma fino ou planar.

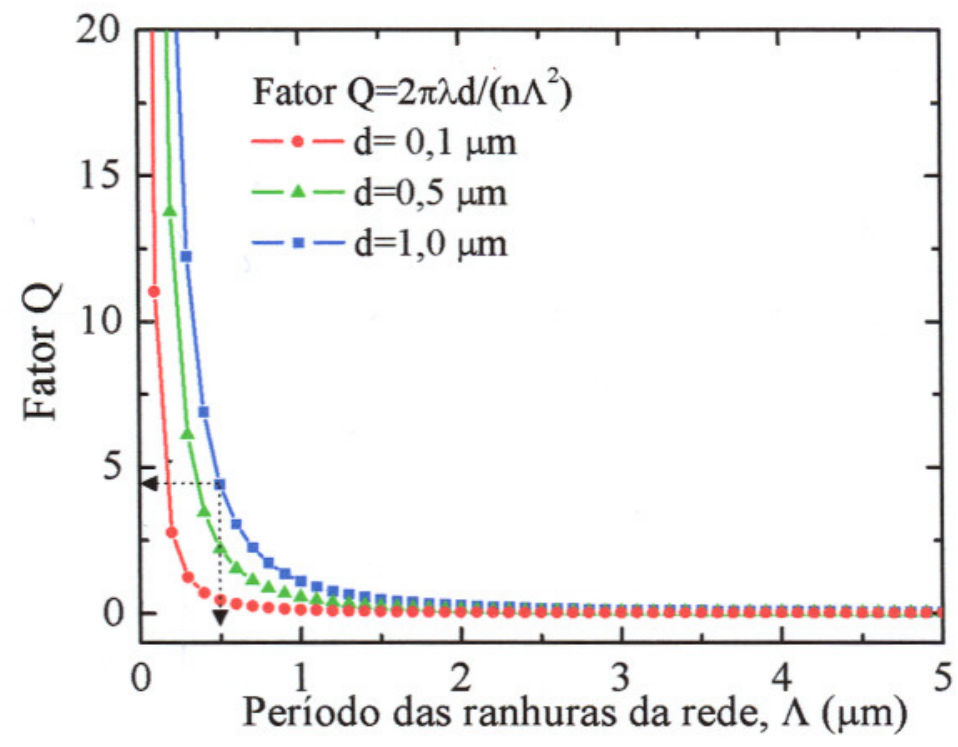

Figura 113 - Representação de $Q$ vs. $\Lambda$ para três espessuras de holograma. As setas indicam no gráfico o valor máximo para $Q$, obtido considerando $\mathrm{d}=1,0 \mu \mathrm{m}, \lambda=350,7 \mathrm{~nm}$, e $\mathrm{n} \approx 2,0$.

Finalmente, hologramas também são classificados segundo o mecanismo de difração da luz. Em um holograma de amplitude, por exemplo, uma rede gravada por fotoescurecimento, as franjas escuras causarão diminuição na intensidade da luz e uma variação na amplitude da onda eletromagnética. Hologramas de fase são aqueles cujas 
franjas causarão uma modulação na fase da onda, alterando o caminho óptico percorrido pela luz, gerando difração. Estas redes podem ser obtidas pela variação do relevo ou do índice de refração do material.

A eficiência de difração absoluta para redes de diffação de fase pode ser da ordem de $33 \%$, onde a razão entre a modulação do índice de refração complexo $(\Delta k)$ e real $(\Delta \mathrm{n})$ dado por $\Delta k \lambda \Delta \mathrm{n} 4 \pi$ esteja em torno de 0,1 ; ou será de $7 \%$ quando $\Delta k \lambda \Delta \mathrm{n} 4 \pi$ $\approx 1,0$. A eficiência de difração decresce também devido ao aumento no deslocamento de fase da onda que é dado por $2 \pi \Delta$ nd $/ \lambda$, ou seja, quanto maior a modulação no índice de refração real menor a eficiência da rede.

$\mathrm{Na}$ teoria mencionada acima, as propriedades ópticas variam lentamente em dimensões espaciais comparáveis ao comprimento de onda, tal que a aproximação para uma onda plana seja possível. Então se espera que a teoria mencionada seja válida somente para pequenas modulações do índice de refração.

Para entender as propriedades de difração de redes com uma alta modulação do índice, deve-se lembrar de redes de reflexão em superficie ondulada com um perfil senoidal. Uma onda plana refletida em tal superficie é fase-modulada como uma onda transmitida por uma rede de fase. Espera-se então, que as redes de transmissão de fase e redes de reflexão com superficie ondulada tenham propriedades similares.

A eficiência de difração de uma rede senoidal como função de $\boldsymbol{h} / \boldsymbol{\Lambda}$ depende da modulação da profundidade $\mu$, definida como:

$$
\mu=h / \Lambda
$$

onde $h$ é a profundidade do relevo e $\Lambda$ é o período da rede. É conveniente considerar cinco domínios de rede senoidal, que aumentam progressivamente a modulação de profundidade $\mu$ (Tabela 6).

Tabela 6 - Classificação dos domínios de rede em função da modulação de profundidade, $\mu$.

\begin{tabular}{cc}
\hline Domínio & Modulaçã o \\
\hline muito baixo & $\mu<0,05$ \\
baixo & $0,05<\mu<0,15$ \\
médio & $0,15<\mu<0,25$ \\
alto & $0,25<\mu<0,4$ \\
muito alto & $\mu>0,4$ \\
\hline
\end{tabular}


Pequenas modulações na profundidade $(h / \Lambda<0.05)$ podem ser tratados através de uma teoria escalar resultando em uma eficiência de difração de até $34 \%$, isto é, a mesma eficiência obtida para uma rede de transmissão de fase. Altos valores de modulação de profundidade $(h / \Lambda>0.1)$ não pertencem ao regime de difração escalar e nestes casos, as redes possuem eficiência de difração muito baixa.

Para uma rede como descrito pela Figura 106-a), com $\Lambda=600 \mathrm{~nm}$ e $h \approx 50 \mathrm{~nm}$, temos que $\mu=0,083$, ou seja esta rede pertence a domínio baixo de modulação de relevo. Para outro caso extremo (Figura 106-c) de uma rede com $\Lambda=20 \mu \mathrm{m}$ e $h \approx 40 \mathrm{~nm}$, temos que $\mu=0,002$, pertencente ao domínio muito baixo de modulação de relevo. Por outro lado devemos considerar uma forte modulação no índice de refração do material exposto ao UV, como mostra a Figura 114, para um filme $20 \%\left[\mathrm{Sb}\left(\mathrm{PO}_{3}\right)_{3}\right]_{n}-80 \% \mathrm{Sb}_{2} \mathrm{O}_{3}$ irradiado com $2.5 \mathrm{~W} / \mathrm{cm}^{2}$ para tempos de exposição variando de 1 a 30 minutos.

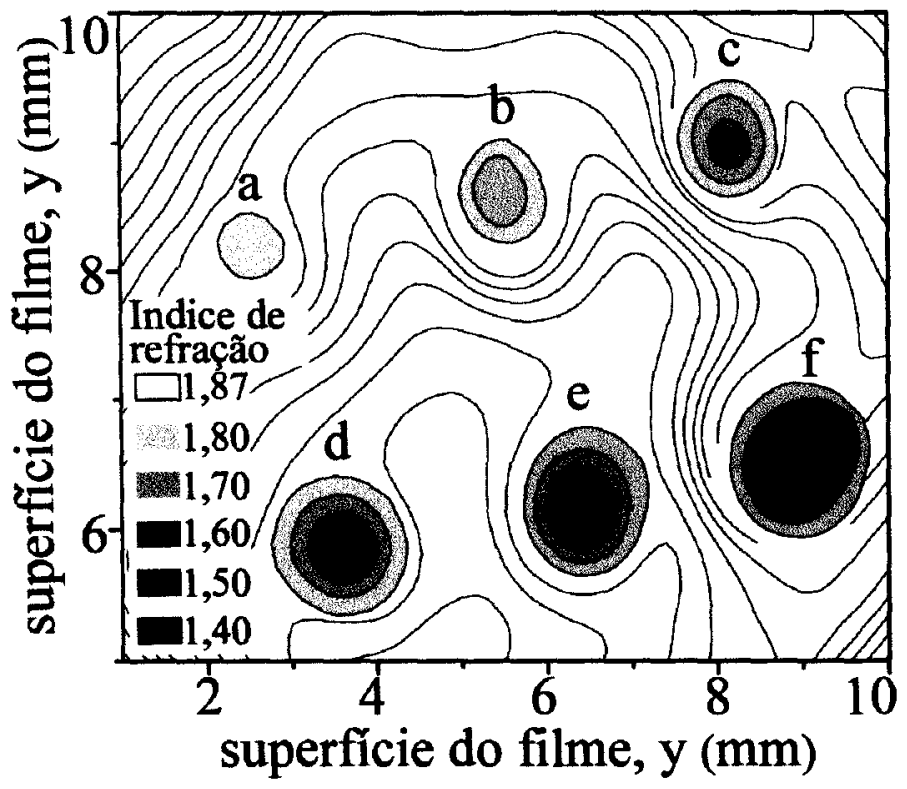

Figura 114 - Alteração no índice de refração em vários pontos do filme $20 \%\left[\mathrm{Sb}\left(\mathrm{PO}_{3}\right)_{3}\right]_{n}-$ $80 \% \mathrm{Sb}_{2} \mathrm{O}_{3}$ irradiado com $50 \mathrm{~mW}\left(2.5 \mathrm{~W} / \mathrm{cm}^{2}\right)$ por diferentes períodos de tempo. a) $\left.1, \mathrm{~b}\right) 5$, c) 10 , d) 15 , e) 20 , e f) 30 minutos, respectivamente, medido por elipsometria $(633 \mathrm{~nm})$.

Verifica-se que o índice de refração decresce com o aumento do tempo de irradiação UV e a máxima variação de índice de refração $(-\Delta \mathrm{n} / \mathrm{n})$ é de $\sim 25 \%$ para exposição de 30 minutos a $50 \mathrm{~mW}$. No caso das redes a eficiência de difração está associada ao fenômeno da fotocontração e do fotoclareamento (variação no índice de refração), ou seja, a difração ocorre devido aos efeitos de modulação do relevo na superficie do filme e também devido à modulação no índice de refração. 
A variação negativa no índice de refração $(\Delta n<0)$ gerada por efeitos fotoinduzidos em filmes é relacionada com o deslocamento do bandgap para maiores energias (fotoclareamento), como descrito pelas relações de Kramers-Kronig [85,165].

Além disso, modelos de centros deficientes em oxigênio e estrutura de defeitos sensíveis ao UV foram propostos para explicar variação negativa no índice de refração $[166,167]$, e em conjunto com este modelo, efeitos de aquecimento local e processos de absorção de alta ordem $[168,169]$. Popesco et al. verificou queda no índice de refração seguida de fotocontração devido à perda de enxofre em filmes de GeAsS [170]. Semelhante fenômeno foi reportado por Petrov et al. em filmes de GeAsS e GeAsBi [171].

Em nosso caso podemos atribuir esta variação negativa no índice de refração a perda de fósforo com a irradiação como foi descrito anteriormente. Associado a este efeito temos o aumento na quantidade de oxigênio nas camadas superficiais do filme, observado por RBS e XPS, sugerindo que o modelo de centros deficientes em oxigênio reportado por K.D. Simmons et al. e D.P. Hand et al. $[166,167]$ também seja aplicável neste caso. 


\section{CONCLUSÕES}

Estudamos os fenômenos de Mudanças Estruturais Fotoinduzidas (principalmente o efeito de fotocontração e fotoclareamento) gerados por irradiação com laser UV (350,7 nm) em filmes do sistema vítreo a base de antimônio, $\left[\mathrm{Sb}\left(\mathrm{PO}_{3}\right)_{3}\right]_{n}-\mathrm{Sb}_{2} \mathrm{O}_{3}$. Os filmes foram produzidos por deposição por canhão de elétrons através da evaporação de vidros do sistema $\left[\mathrm{Sb}\left(\mathrm{PO}_{3}\right)_{3}\right]_{\mathrm{n}}-\mathrm{Sb}_{2} \mathrm{O}_{3}$.

\section{Estudo do sistema vítreo $x\left[\mathrm{Sb}\left(\mathrm{PO}_{3}\right)_{3}\right]_{n}-(100-x) \mathrm{Sb}_{2} \mathrm{O}_{3}$}

Para preparação dos filmes do sistema $\left[\mathrm{Sb}\left(\mathrm{PO}_{3}\right)_{3}\right]_{n}-\mathrm{Sb}_{2} \mathrm{O}_{3}$, foi necessário a produção e caracterização deste sistema vítreo. Dessa forma produzimos vidros de $x\left[\mathrm{Sb}\left(\mathrm{PO}_{3}\right)_{3}\right]_{n}-(100-x) \mathrm{Sb}_{2} \mathrm{O}_{3}$ com concentrações de formador $\left[\mathrm{Sb}\left(\mathrm{PO}_{3}\right)_{3}\right]_{n}$ variando de 5 $\leq x \leq 40$, e caracterizamos o sistema utilizando técnicas tradicionais para caracterização de vidros (DSC, XRD, FTIR) e também técnicas mais específicas como MAS-NMR. Dessa forma obtivemos o diagrama de formação vítrea para esse sistema (Figura 52). Observamos a formação de microcristalinidade nos vidros $x\left[\mathrm{Sb}\left(\mathrm{PO}_{3}\right)_{3}\right]_{n}-(100-x) \mathrm{Sb}_{2} \mathrm{O}_{3}$ para $x \leq 5$ e $x \geq 30$. A verificação de formação fase microcristalina para composições de $x \geq 30$ só foi possível com a técnica de MAS-RMN do ${ }^{31} \mathrm{P}$, que é muito sensível a variações no ambiente químico ao redor do fósforo, pois contrariamente, os espectros de XRD mostravam fase amorfa para a composição $x \geq 30$. A região de formação vítrea ocorre para composições entre $10 \leq x \leq 25$ sendo que para $x=5, x=30$, e $x=35$ formase um vidro com pequena fração de microcristalinidade que apresenta coloração amarelada porém é visualmente transparente, já para $x=40$ forma-se um vidro com maior fração de microcristalinidade sendo visualmente opaco.

Apresentamos também através de medidas de XANES (seção 3.1.8) do sistema vítreo, resultados sobre a evolução estrutural dos grupos $\mathrm{PO}_{4}$ na estrutura a curto alcance dos vidros em função da concentração de formador $\left[\mathrm{Sb}\left(\mathrm{PO}_{3}\right)_{3}\right]_{n}$ variando de $5 \leq$ $x \leq 40$. Verificamos também a formação de partículas de antimônio metálico dissolvido em vidros fundidos a temperaturas acima de $930{ }^{\circ} \mathrm{C}$. Este efeito ocorre devido à formação de uma atmosfera altamente redutora pela degradação do cadinho de carbono vítreo e deve ser levado em consideração durante a preparação de vidros deste sistema (seção 3.1.9). 


\section{Estudo dos efeitos fotoinduzidos em Filmes de $\left[\mathrm{Sb}\left(\mathrm{PO}_{3}\right)_{3}\right]_{n} \underline{\mathrm{Sb}_{2}} \underline{\mathrm{O}_{3}}$}

Os vidros deste sistema não apresentam efeito de fotocontração como observado para os filmes do mesmo sistema, e isto está relacionado com diferenças estruturais geradas pelos métodos de preparação; fusão no caso dos vidros e deposição por evaporação térmica no caso de filmes. Porém estes vidros apresentam efeitos fotoinduzidos como fotoescurecimento devido à formação de centros de defeitos e mudança de estados de oxidação do antimônio $\left(\mathrm{Sb}^{3+}-\mathrm{Sb}^{5+}\right)$ como reportado anteriormente [73].

Apesar de se partir da evaporação dos vidros para produção dos filmes, a principal diferença de estrutura entre vidro e filme é que estes últimos apresentam estrutura com grande número de vazios intersticiais ao redor de unidades estruturais, 0 que não ocorre para os vidros. Este fato foi confirmado pela observação de um pico estreito observado em espectros de difração de raios-X (Figura 88), denominado de FSDP (First Sharp Diffraction Peak) segundo a definição de S. R. Elliot [151]. Além disso esta diferença nos fenômenos fotoinduzidos entre vidros e filmes pode ser relacionada com diversos fatores que são geralmente mais pronunciados em filmes como: efeitos fototérmicos [71-73,91,92] (perda de material por aquecimento); efeitos fotoquímicos de superfícies [93-95] (fotoadsorção, fotodesorção); estrutura colunar e efeitos de interfaces em filmes [96]; e amplificação de efeitos fotoinduzidos em superficies com imperfeições nanométricas $[97,103,104]$. Nossos resultados mostraram efetivamente que o efeito de fotocontração em filmes irradiados com UV está relacionado com mudanças de estrutura de grupos fosfatos e efeitos fototérmicos cooperativos, como detalhado a seguir.

\section{Evolução do efeito de fotocontração}

$O$ efeito de fotocontração nos filmes foi notado primeiro devido ao fotoclareamento observado visualmente após a exposição ao UV e foi confirmado por medidas de perfilometria da região irradiada com UV. O efeito de fotoclareamento ocorre gerando deslocamento de $\sim 30 \mathrm{~nm}$ do bandgap $(3,58 \mathrm{eV}, 347 \mathrm{~nm})$ para maiores energias $(4,01 \mathrm{eV}, 310 \mathrm{~nm})$ como apresentado na Figura 64 . Também observamos um pequeno deslocamento do bandgap para irradiações com $\lambda=482$ e $460 \mathrm{~nm}$. No caso de um filme tratado termicamente verificamos um efeito contrário (fotoescurecimento), 
com deslocamento do bandgap para menores energias. Nesses últimos casos não foi observado efeito de fotocontração nos filmes.

A fotocontração evolui não linearmente com o tempo e potência de irradiação (Figura 70). Depende também do tempo de exposição e da potência do laser, tendendo a saturação após 4 horas de exposição a $5 \mathrm{~W} / \mathrm{cm}^{2}$ (100 mW) (Figura 69) ou 2 horas de exposição a $15 \mathrm{~W} / \mathrm{cm}^{2}$ (300 mw) (Figura 70 ).

A fotocontração tem forte dependência com a concentração de polifosfato de antimônio na composição dos filmes do sistema vítreo $x\left[\mathrm{Sb}\left(\mathrm{PO}_{3}\right)_{3}\right]_{n}-(100-x) \mathrm{Sb}_{2} \mathrm{O}_{3}$. Filmes de $1,0 \mu \mathrm{m}$ de espessura irradiados com $100 \mathrm{~mW}\left(5,0 \mathrm{~W} / \mathrm{cm}^{2}\right)$ por 4 horas (região de saturação) apresentam fotocontração $(-\Delta \mathrm{V} / \mathrm{V})$ de até $8,0 \%$ da espessura do filme (para $x=25)$ quando irradiados com laser UV $(\lambda=350 \mathrm{~nm})$. Para $x=10$ a contração é menor que $2,0 \%$. Para concentrações de polifosfato acima de $25 \%$ efeito é diminuído drasticamente, provavelmente devido aos efeitos de cristalização das amostras como mostrado para vidros desta composição ( Figura 71).

A atmosfera na qual o filme é irradiado tem grande influência no efeito de fotocontração. Filmes de $20 \%\left[\mathrm{Sb}\left(\mathrm{PO}_{3}\right)_{3}\right]_{n}-80 \% \mathrm{Sb}_{2} \mathrm{O}_{3}$ (espessura:1,0 $\mu \mathrm{m}$ ) irradiado com laser UV por 4 horas a $100 \mathrm{~mW}\left(5,0 \mathrm{~W} / \mathrm{cm}^{2}\right)$ apresentaram fotocontração $(-\Delta \mathrm{V} / \mathrm{V})$ de $\sim 8 \%$ ( $50 \%$ maior) em atmosfera de $\mathrm{O}_{2}, 5 \%$ no ar, e menor que $2 \%$ para o vácuo, $\mathrm{N}_{2}$ e He (Figura 72).

Filmes muito espessos $(8,0$ e $9,7 \mu \mathrm{m})$ apresentaram fotocontração $(-\Delta \mathrm{V} / \mathrm{V})$ de 3 e $2,5 \%$, respectivamente, obtido para filmes de $20 \%\left[\mathrm{Sb}\left(\mathrm{PO}_{3}\right)_{3}\right]_{n}-80 \% \mathrm{Sb}_{2} \mathrm{O}_{3}$, irradiados com laser UV (100 mW / 4 horas), (Figura 73). Essa queda na fotocontração para filmes muito espessos pode estar relacionada com inomogeneidade composicional em função da espessura.

\section{Caracterização química de filmes irradiados e não-irradiados}

Através de medidas de RBS e XPS observamos um aumento na concentração de oxigênio na superficie de filmes irradiados com UV e acreditamos que seja um processo de foto-oxidação participativo com outros processos como fotoadsorção. Observamos também por WDX, uma perda de fósforo de 4,7 para 2,9 at \% ( 38\%) em filmes de 5 $\mu \mathrm{m}$ irradiados com laser UV com $5 \mathrm{~W} / \mathrm{cm}^{2}(100 \mathrm{~mW}$ ) por 5 horas (Figura 76). Este processo é denominado por alguns autores como fotosublimação ou fotodesorção. 


\section{Caracterização Estrutural de filmes irradiados e não-irradiados}

Pela análise dos dados de XANES (seção 3.2.8), verificou-se que o aumento na intensidade da linha branca dos espectros de filmes irradiados mostra que pode estar ocorrendo aumento no comprimento das cadeias de grupos fosfatos, e esta mudança é mais acentuada quanto maior tempo de exposição ao laser. A interpretação de aumento de intensidade do pico de XANES estar relacionado com aumento no comprimento de cadeias de fosfatos (polimerização) foi proposta por Z. Yin et al. [137].

As medidas de XANES mostraram que a fotocontração não é devido à relaxação de tensões do filme e que a estrutura do filme após irradiação com laser UV é diferente da estrutura do filme após tratamento térmico, e além disso as mudanças estruturais induzidas por irradiação UV permanecem no filme mesmo após tratamento térmico de 1 hora a $300^{\circ} \mathrm{C}$ indicando uma mudança estrutural irreversível (Figura 87). Em filmes apenas tratados termicamente, a temperatura induz alterações no filme de forma que a estrutura tende a retornar ao mesmo arranjo observado no vidro. Já o efeito da irradiação com laser UV provoca alterações no filme de forma que a estrutura tende a um rearranjo semelhante à estrutura do $\left[\mathrm{Sb}\left(\mathrm{PO}_{3}\right)_{3}\right]_{n}$. Este efeito pode ser compreendido como fotopolimerização.

As medidas de luminescência (seção 3.2.10) mostraram que após a irradiação com UV ocorre a formação de pares $\mathrm{Cu}^{2+}-\mathrm{Cu}^{2+}$, podendo ser interpretada como a aproximação destes íons na estrutura devido ao efeito de fotocontração. Este resultado pode ser discutido em termos de aproximação de cadeias de fosfatos (formação de novas ligações químicas entre grupos fosfato) após irradiação UV, causando uma aproximação de íons que estejam localizados intersticialmente na estrutura.

As mudanças observadas nos espectros de RPE-CW (seção 3.2.11) para os filmes após irradiação com laser UV estão relacionadas com uma distorção tetragonal em apenas uma direção do sítio octaédrico ao redor do cobre, o que é bastante razoável uma vez que o efeito de fotocontração a nível estrutural pode ser explicado como um encurtamento das ligações químicas ao redor de um íon na estrutura vítrea. Outra interpretação que também é coerente com os resultados obtidos por luminescência em termos de aproximação de cadeias de fosfatos (fotopolimerização) após irradiação UV, causando uma aproximação de íons $\mathrm{Cu}^{2+}$ que estejam localizados intersticialmente.

Os espectros de RPE-ESEEM mostraram uma queda na amplitude da linha correspondente ao ${ }^{31} \mathrm{P}$ da amostra irradiada com relação à amostra não irradiada, 
indicando uma perda de fósforo induzida pela radiação UV, como observado também pelas técnicas de análise química.

Dessa forma podemos atribuir a fotocontração nos filmes após irradiação UV devido a fotopolimerização (diminuição de vazios intersticiais pela conexão entre grupos moleculares fosfatos), fotosublimação (perda superficial de fósforo) e fotooxidação (devido à adsorção de oxigênio).

\section{Gravação de Redes Holográficas}

$\mathrm{Na}$ parte de aplicações gravamos redes holográficas de relevo nos filmes estudados. Utilizando uma montagem tipo espelho de Lloyd para holografia foi possível gravar redes com período de $600 \mathrm{~nm}$ até $20 \mu \mathrm{m}$ e medimos a eficiência de difração em tempo real utilizando um feixe de prova de laser He-Ne. As redes gravadas em filmes de filmes de $20 \%\left[\mathrm{Sb}\left(\mathrm{PO}_{3}\right)_{3}\right]_{n}-80 \% \mathrm{Sb}_{2} \mathrm{O}_{3}$ com período de $20 \mu \mathrm{m}$ de espessura apresentam eficiência de difração de 3 a $10,5 \%$ para aproximadamente 1 hora de gravação e potencia variando de 50 a $600 \mathrm{~mW}\left(2,5 \mathrm{a} 30 \mathrm{~W} / \mathrm{cm}^{2}\right)$, respectivamente (Figura 110).

Dois processos estão envolvidos na formação das redes. $O$ primeiro processo é rápido e está ligado com o fotoclareamento e mudança de índice de refração. O segundo processo é mais lento, sendo o efeito de fotocontração induzido por laser gerando mudança de relevo na superfície do filme, ou seja, a difração ocorre devido à modulação do relevo na superfície e também devido à modulação do índice de refração do material

Verificamos por medidas de elipsometria que o índice de refração de filmes decresce com o aumento do tempo de irradiação UV e a máxima variação de índice de refração $(-\Delta n / n)$ é de $\sim 25 \%$ para exposição de 30 minutos. A variação negativa no índice de refração $(\Delta n<0)$ gerada por efeitos fotoinduzidos em filmes é relacionada com o deslocamento do bandgap para maiores energias (fotoclareamento), como descrito pelas relações de Kramers-Kronig e por modelos de centros deficientes em oxigênio e estrutura de defeitos sensiveis ao UV. Em nosso caso podemos atribuir esta variação negativa no índice de refração a perda de fósforo com a irradiação com o foi descrito anteriormente. Associado a este efeito temos o aumento na quantidade de oxigênio nas camadas superficiais do filme, observado por RBS e XPS. 


\section{SUGESTÕES PARA TRABALHOS FUTUROS}

- Sugerimos como trabalhos complementares para melhor compreensão da incorporação e localização dos íons na matriz vítrea medidas de absorção de raios-X (EXAFS) da borda $\mathrm{K}$ do $\mathrm{Sb}^{3+}$ de filmes antes e depois de processos de irradiação com UV. Estas medidas apresentam uma limitação devido à borda de absorção de raios-X do $\mathrm{Sb}^{3+}$ estar localizada em faixa de energia muito alta (em torno de $30 \mathrm{KeV}$ ), e esta faixa de operação de aceleradores síncrotron por enquanto só é encontrada em aceleradores no exterior.

- Outro experimento interessante seria medidas de absorção de raios-X (XAS) das bordas $\mathrm{L}_{1}$ e $\mathrm{L}_{3}$ do $\mathrm{Sb}^{3+}$ com irradiação de UV in-situ para observação dos fenômenos fotoinduzidos em filmes. Atualmente foi implementada uma linha de XAS no LNLS com detector CCD com capacidade de captação de espectros em milisegundos. Dessa forma a evolução das mudanças estruturais poderiam ser observadas simultaneamente durante a irradiação com UV, onde a única limitação para tais medidas seria a obtenção de uma fonte de UV com intensidade razoável.

- Produção de filmes ultrafinos, na faixa de 10 a $100 \mathrm{~nm}$ para estudo de efeitos fotoinduzidos por espectroscopia de elétrons (como RBS e XPS) em função da profundidade de penetração. 


\section{TRABALHOS PUBLICADOS}

\subsection{Publicą̧̃̃es em Artigos Cientificos}

6.1.1 F. S. De Vicente, M. Siu Li, Y. Messaddeq, "Holographic Recording in $\left[\mathrm{Sb}\left(\mathrm{PO}_{3}\right)_{3}\right]_{n}-\mathrm{Sb}_{2} \mathrm{O}_{3}$ Glassy Films by Photoinduced Volume and Refraction Index Changes", Journal of Non-Crystalline Solids, (in press) set (2004).

6.1.2 F. S. De Vicente, E. A. A. Rubo, M. S. Li, "Construction of an Evaporation System for Film Deposition via Resistive and Electron Beam Sources", Revista Brasileira de Aplicações de Vácuo, 23 (1) (2004).

6.1.3 F. S. De Vicente, M. Siu Li, M. Nalin, Y. Messaddeq, "Photoinduced Structural Changes in Antimony Polyphosphate Based Glasses", Journal of Non Crystalline Solids, 330 (2003)168-173.

6.1.4 F. S. De Vicente, E. R. De Azevedo, Y. Messaddeq, M. Siu Li, T. J. Bonagamba, "Structural Characterization and Formation of the $\left[\mathrm{Sb}\left(\mathrm{PO}_{3}\right)_{3}\right]_{n^{-}}$ $\mathrm{Sb}_{2} \mathrm{O}_{3}$ Glass System", Journal of Materials Chemistry (submetido) nov. (2003).

\subsection{Participações em Congressos}

Participações em eventos/Congressos Nacionais

6.2.1 XXVII Encontro Nacional de Física da Matéria Condensada, Poços de Caldas-MG 2004, "Mudança estrutural foto-induzida em filmes do sistema vitreo $\left[\mathrm{Sb}\left(\mathrm{PO}_{3}\right)_{3}\right]_{n}-\mathrm{Sb}_{2} \mathrm{O}_{3}: \mathrm{Cu}^{2+}$ observada por RPE', J. F. Lima, F. S. De Vicente, M. Siu Li ,C. J. Magon.

6.2.2 XXIV Congresso Brasileiro de Aplicações de Vácuo na Indústria e na Ciência, IF-UNESP-Bauru 2003, "Construction of an Evaporation System for Film Deposition via Resistive and Electron Beam Sources", F. S. De Vicente, E. A. A. Rubo, M. Siu Li.

6.2.3 XIII RAU - Reunião Anual de Usuários do LNLS, LNLS-Campinas 2003, "Estudo da fotocontração induzida por laser UV em filmes e vidros de $\left[\mathrm{Sb}\left(\mathrm{PO}_{3}\right)_{3}\right]_{\mathrm{n}}-\mathrm{Sb}_{2} \mathrm{O}_{3}$ por $\mathrm{SXS}$ e XAS das bordas $\mathrm{K} \mathrm{e}_{3}$ do fósforo e antimônio", F. S. De Vicente, M. Siu Li, M. Nalin, S. L. J. Ribeiro, Y. Messaddeq. 
6.2.4 VI SICEM - Simpósio de Ciência e Engenharia de Materiais. USP-São Carlos, 2003, “Gravação de Redes Holográficas com Laser UV em Filmes de $\mathrm{Sb}\left(\mathrm{PO}_{3}\right)_{3}-\mathrm{Sb}_{2} \mathrm{O}_{3}$ depositados por Evaporação por Canhão de Elétrons", F. S. De Vicente, M. Siu Li, Y. Messaddeq.

6.2.5 XXV Encontro Nacional de Física da Matéria Condensada, Caxambu-MG 2002, "Redes de Difração Holográficas em Filmes Amorfos de $\mathrm{Sb}_{2} \mathrm{~S}_{3}-\mathrm{Sb}_{2} \mathrm{O}_{3}$ depositados por Evaporação por Canhão de Elétrons”. F. S. De Vicente, M. Siu Li, M. Nalin, Y. Messaddeq.

Participações em eventos/Congressos Internacionais

6.2.6 Second International Symposium on Non-Crystalline Solids in Brazil and Sixth Brazilian Symposium on Glass and Related Materials, Campos do Jordão 2003, "Holographic recording in $\left[\mathrm{Sb}\left(\mathrm{PO}_{3}\right)_{3}\right]_{n}-\mathrm{Sb}_{2} \mathrm{O}_{3}$ glassy films by photoinduced volume changes”, F. S. De Vicente, M. Siu Li, Y. Messaddeq

6.2.7 First International Symposium on Non-Crystalline Solids in Brazil and Fifth Brazilian Symposium on Glass and Related Materials, Foz do Iguaçu 2001, "Photoinduced Structural Changes In Antimony Polyphosphate Based Glasses”, F. S. De Vicente, M. Siu Li, M. Nalin, Y. Messaddeq. 


\section{REFERÊNCIAS}

[1] W. H. Zachariansen, “Atomic Arrangements in Glass", J. Am. Ceram. Soc. 54(10), (1932) 3841.

[2] P. K. Gupta, J. Non-Cryst. Solids 195 (1996) 158.

[3] O. L. Alves, I. F. Gimenez, I. O. Mazali, "Vidros", Cadernos Temáticos - Química Nova na Escola, Edição especial, fev. 2001.

[4] N.J. Kreidl, W.A. Weyl, J. Am. Ceram. Soc. 24 (11) (1941) 372.

[5] J.R. Van Wazer, "Phosphorus and its Compounds", vol. 1, Interscience, New York, (1958).

[6] E. Kordes, W. Vogel, R. Feterowsky, Z. Elektrochem. 57 (1953) 282.

[7] E. Kordes, R. Nieder, Glastechn. Ber. 41 (1968) 41.

[8] M.J. Weber, J. Non-Cryst. Solids 123 (1990) 208.

[9] R.K. Brow, L. Kovacic, R.E. Loehman, Ceram. Trans. 70 (1996) 177.

[10] C.J. Quinn, G.H. Bell, J.E. Dickinson, in: Proceedings of the XVIth International Congress on Glass, vol. 4,1992 , p. 79.

[11] D.E. Day, Z. Wu, C.S. Ray, P. Hrma, J. Non-Cryst. Solids 241 (1998) 1.

[12] J. Vogel, P. Wange, P. Hartmann, Glastech. Ber. 70 (1997) 23.

[13] J. Fu, J. Mater. Sci. 33 (6) (1998) 1549.

[14] J.B. Bates, N.J. Dudney, G.R. Gruzalski, R.A. Zuhr, A. Choudhury, C.F. Luck, J.D. Robertson, Solid State Ionics 53 (1992) 647.

[15] Y. Abe, in: M. Grayson, "Topics in Phosphorus Chemistry", E.J. Griath (Ed.) vol. 11, Wiley, New York, 1983, p. 19.

[16] S.W. Martin, Eur. J. Solid State Chem. 28 (1991) 163.

[17] O. Lamm, "Measurement and Calculation of equilibrium of high-molecular metaphosphates", Arkiv fur Kemi Mineralogi ach Geologi, 17A (1944) 25.

[18] O. Sammuelson, "The constitution of Graham 's salt", Svensk Kem. Tid., 56 (1944) 343.

[19] J. R. Van Wazer, "Structure and properties of condensed phosphates II-A theory of the molecular structure of Sodium Phosphate Glasses", Journal of American Chemical Society, 72 (1950) 644.

[20] P. J. Flory, "Statistical Mechanics of chain Molecules", Wiley-Interscience, New York (1969).

[21] T. Uchino, Y. Ogata, J. Non-Cryst. Solids, 181 (1995) 175.

[22] D. E. C. Corbridge, "Phosphorus: An outline of its chemistry, biochemistry, and technology", 4th edn. Elsevier, Amesterdam (1990).

[23] J. R. Parks, J. R. Van Wazer, "Structure and properties of the condensed phosphates VII Reorganization theory and some applications", Journal of American Chemical Society, 79 (1957) 4890.

[24] R. K. Brow, C. A. Click, T. M. Alam, Journal of Non-Crystalline Solids 274 (2000) 9.

[25] G. Hägg, J. Chem. Phys. 3 (1935) 42.

[26] J. R. Van Wazer, C. F. Callis, "Metal complexing by phosphates", Chemical Review, 58 (1958) 1011.

[27] R. K. Brow, Journal of Non-Crystalline Solids 263\&264 (2000) 1.

[28] V. Dimitrov, S. Sakka, J. Appl. Phys. 79 (1996) 1736. 
[29] J. Gally, O. Lindquist, J. Solid State Chem. 27 (1979) 279.

[30] C.K. Loong, K. Suzuya, D.L. Price, B.C. Sales, L.A. Boatner, Physica B 241-243 (1998) 890.

[31] H. Eckert, "NMR - Basic Principles and Progress", vol. 33, Springer, Berlin, (1994), p. 127.

[32] B. C. Sales, R. S. Ramsey, J. B. Bates, and L. A. Boatner, J. Non-Cryst. Solids 87 (1986) 137.

[33] I. Haiduc, D.B. Sowerby, Polyhedron 15 (1995) 2469.

[34] A. Shishkov, D. Atanasova, Nauchni Tr. Plovdivski Univ. 13 (1975) 209; Chem. Abstr., 89 (1978) 36020 .

[35] H.H. Farmer, B.W.Malone, H.F. Tompkis, Lubric. Eng. 23 (1967) 57.

[36] R.H. Neilsen, D.L. Mckay, G.H. Dale, Ger. Pat. 2,808,103 (1978); Chem. Abstr., 90 (1979) 154.

[37] E. Kordes, Phys. Chem., B43 (1939) 173.

[38] H. Hasegawa, Phys. Chem. Glasses, 19 (1978) 28.

[39] A. J. G. Ellison, S. Sen, Phys. Rev., B 67 (2003) 52203.

[40] J. F. Bednarik, J. A. Neely, Phys. and Chem. of Glasses, 23(6) (1982) 204.

[41] Ernst Leitz G. M. B. H., Company, no. 76, 07712, 17 março de 1976.

[42] P. Melnikov, Y. Messadeq, M. Poulain, S. J. L. Ribeiro, D. Grando, "Nouveau Procédé de Synthése $d u\left[\ln \left(\mathrm{PO}_{3}\right)_{3}\right]_{n}$ à haute degré de pureté" Brevet deposé dans CE, N91-11722, (1997).

[43] Z. Ling, Z. Jiashen, L. Qirong, J. Non-Cryst. Solids, 256-257 (1999) 396.

[44] A. Paul. U. S. Ghosh, C. Basu, J. Non-Cryst. Solids, 221 (1997) 265.

[45] M. Fadel, Vacuum, 52 (1999) 277.

[46] J. M. Durand, P. E. Lippens, J. Olivier-Fourcades, J. C. Jumas, J. Non-Cryst. Solids, 192-193 (1995) 364.

[47] S.E. Paje, M.A. Garcia, M.A. Villegas, J. Llopis, J. Non-Cryst. Solids, 278 (2000) 128.

[48] Y. Guimond, J. L. Adam, A. M. Jurdyc, H. L. Ma, J. Mugnier, B. Jacquier, J. Non-Cryst. Solids, 256-257 (1999) 378.

[49] P. Predeep, N. S. Saxena, A. Kumar, J. Phys. Chem. Sol., 58(3) (1997) 385.

[50] I. Ardelean, H. Qiu, H. Sakata, Mat. Lett., 32 (1997) 335.

[51] K. Terashima, T. Hashimoto, T. Uchino, S.H. Kim, T. Yoko, J. Ceram. Soc. Jap., 104 (1996) 1008.

[52] A. Datta, A. K. Giri, D. Chakravorty, Phys Rev B, 47 (1993) 16242.

[53] K. Terashima, J. Ceram. Soc. Jpn., 104 (1996) 1008.

[54] M. Shimizu, Y. Ohmori, J. Lightwave Technol. LT-5 (1987) 763.

[55] John Minelly nd Adam Ellison, "Applications of antimony-silicate glasses for fiber optic amplifiers", Optical Fiber Technology, 8 (2002) 123-138.

[56] P. A Tick, Phys. Chem. Glass., 25 (1984) 149.

[57] B. C. Sales, R. S. Ramsey, J. B. Bates, and L. A. Boatner, J. Non-Cryst. Solids, 87 (1986) 137.

[58] Y. Messaddeq, D. Grando, P. Melnikov, S. J. L. Ribeiro, L. F. C. Oliveira, J. of alloys and Comp., 275-277 (1998) 81.

[59] D. Ehrt, C. Fuchs, V. Vogel, Silikattechnik, 35 (1984) 6.

[60] W. K. Tredway, S. H. Risbud, in S. Hampshire (Ed.), "Non-Oxide Technical and Engineering Ceramics", Elsevier, Amsterdam, (1987), p. 203. 
[61] K. Schwartz, "The Physics of Optical Recording" (Springer, Berlin, 1993 ).

[62] S.R. Elliott, "A unified model for reversible photostructural effects in chalcogenide glasses", J. NonCryst. Solids 81, (1986) 71.

[63] J. Feinleib, J. deNeufville, S.C. Moss, and S.R. Ovshinky, Appl. Phys. Lett. 18, (1971) 254.

[64] M. Terao. K. Shigemalsu, M. Ojima, Y. Taniguchi, S. Horigome, and S, Yonezawa, J. Appl. Phys. 50 (1979) 6881.

[65] B. Singh, S. Rajagopalan, P. K. Bhat, D. K. Pandya, and K. L. Chopra, Sol. Sta. Comum. 29 (1979) 167.

[66] P. Arun, and A. G. Vedeshwar, J. Appl. Phys. 79(8) (1996) 4029.

[67] T. Aoki, H. Shimada, N. Hirao, N. Yoshida, K. Shimakawa, and S.R. Elliott, Phys. Rev. B. 59(3) (1999) 1579.

[68] O. Salminem, N. Nordman, P. Riihola, A. Ozols, Opt. Comun. 116 (1995) 310.

[69] R. Barton, Ch. R. Davis, K. Rubin, and G. Lim, Appl. Phys. Lett. 48 (1986) 1255.

[70] P. Arun, and A. G. Vedeshwar, J. Appl. Phys 79(8), (1996) 4029.

[71] P. Arun, A. G. Vedeshwar, J. Non-Cryst. Solids 220, (1997) 63.

[72] P. Arun, A. G. Vedeshwar and N. C. Mehra, Mat. Res. Bull. 32 (7) (1997) 907.

[73] M. Nalin, Y. Messaddeq, S. L. J. Ribeiro, M. Poulain, V. Briois, J. Optoelectronics Adv. Mat. 3 (2) (2001) 553.

[74] F. S. De Vicente, M. Siu Li, M. Nalin, Y. Messaddeq, J. Non-cryst. Solids 330 (2003) 168.

[75] Y. Y. Gurerich, Y. Pleskov, "Semiconductors and Semimetals", vol. 19, ed. R. K. Willardson and A. C. Beer (New York: Academic), (1983) p 255.

[76] B. Kranentler, A. J. Bard, J. Am. Chem. Soc., 100 (1978) 2239.

[77] R. M. Osgood, S. R. J. Brneck, H. R.Schlossberg, "Proc. Materials Res. Soc. Conf. Laser Diagnostics and Photochemical Proc. for Semicondutor Devices", vol. 17 (New York: Elsevier) (1983).

[78] D. J. Ehrlich, J. Y. Tsao, J. Vac. Sci. Technol., B 1 (1983) 969.

[79] Xin Xu, J. I. Steinfeld, Appl. Surf. Sci., 45 (1990) 281.

[80] R. M. Osgood, H. H. Gilgen, Ann. Rev. Mater. Sci., 15 (1985) 549.

[81] Z. Ying, W. Ho, Phys. Rev. Lett., 60 (1988) 57.

[82] W. Hoheisel, K. Jungmann, M. Vollmer, R. Weidenauer, F. Träger, Phys. Rev. Lett., 60 (1988) 1649.

[83] P. M. Ferm, S. R. Kurtz, K. A. Pearlstine, G. M. McClelland, Phys. Rev. Lett., 58 (1987) 2602.

[84] H. Harada, K. Tanaka, J. Non-cryst. Solids 246 (1999) 189-196.

[85] B.G. Potter Jr., K. Simmons-Potter, Nuc. Instr. Meth. in Phys. Res. B 166\&167 (2000) 771.

[86] S.R. Elliot, Advanced in Physics, 44 (1995) 475

[87] R.M. Martin, G. Lucovsky, and K. Helliwell, Phys. Rev. B 13 (1976)1383

[88] O. Salminen, N. Nordman, P. Riihola and A. Ozols, Opt. Commun. 116 (1995) 310.

[89] A. Ozols, O. Salminen, M. Reinfeld, J. Appl. Phys. 75 (1994) 3326.

[90] F. Gan, Journal of Non-Crystalline Solids 256\&257 (1999) 176.

[91] M. Popescu, F. Sava, A. Lorinczi, E. Skordeva, P.-J. Koch, H. Bradaczek, J. Non-cryst. Solids 227230 (1998) 719. 
[92] E. Marquez, J. M. Gonzalez-Leal, R. Jimenez-Garay, M. Vlcek, Thin Solid Films 396 (2001) 183.

[93] T. J. Chuang, Surf. Sci. Rep. 3 (1983) 1.

[94] R. B. Hall, J. Phys. Chem. 91 (1987) 1007.

[95] R. Franchy, "Surface and bulk photochemistry of solids", Rep. Prog. Phys. 61 (1998) 691.

[96] A. J. Pedraza, "Interaction of UV laser light with wide band gap materials: Mechanisms and effects", Nuc. Instr. Meth. in Phys. Res. B 141 (1998) 709.

[97] A. S. Epifanov, Soviet Phys. JETP 40 (1974) 897.

[98] W. L. Smith, Op. Eng. 17 (1978) 489.

[99] A. Schmidt, P. Braunlich, P. Kelly, Phys. Rev. B 16 (1977) 4569.

[100] X. A. Shen, P. Braunlich, S. C. Jones, P. Kelly, Phys. Rev. Lett. 59 (1987) 1605.

[101] S. C. Jones, A. H. Fischer, P. Braunlich, P. Kelly, Phys. Rev. B 37 (1988) 755.

[102] X. A. Shen, S. C. Jones, P. Braunlich, Phys. Rev. Lett. 62 (1989) 2711.

[103] M. A. Schilbach, A. V. Hamza, Phys. Rev. B 45 (1992) 6197.

[104] N. Bloembergen, IEEE J. Quantum Electron. 10 (1974) 375.

[105] M. Nalim, Tese de Doutorado, Instituto de Química-UNESP/Araraquara, 2003.

[106] A.Wagendristel and Y.Wang, "An Introduction to Physics and Technology of Thin Films", World Scientific, Singapore (1994.)

[107] R.S.Hiratsuka (in memoriam), C.V. Santilli e S.H. Pulcinelli, Química Nova 18 (2) (1995) 171.

[108] L. Eckertová, "Physics of Thin Films", 2nd. ed. Plenum Press, New York, London (1986).

[109] Model ST-Electron Beam Gun - Power Supply/Instruction Manual, TFI TELEMARK, 1996.

[110] Sycon Instruments STM - 100/MF - Users Manual, 1994.

[111] P. S. P. Herrmann, M. A. P. da Silva, R. B. Filho, A. E. Job, L. A. Colnago, J. E. Frommer and L. H. C. Mattoso, Polímeros:Ciência e Tecnologia, Out-Dez (1997) pg. 51-61.

[112] J.I. Goldstein, D. E. Newbury, P. Echlin, D. C. Joy, A. D. Romig Jr., C. E. Lyman, C. Fiori, and E Lifshin, "Scanning Electron Microscopy and X-Ray Microanalysis", 2nd. Ed. (Plenun Press 1992).

[113] Wei-Kan Chu, J. W. Mayer, M. A. Nicolet, "BackScattering Spectrometry", (Ac. Press. Inc., Harcourt Brace Janovich, Publishers) 1993.

[114] M. P. Seah and W. A. Dench, Surf. Interface Anal. 1 (1979) 2.

[115] L. E. Davis, "Modern Surface Analysis - Metallurgical Applications", ATMS-AIME Short Course, Las Vegas, Nevada, February pp 23, 1980.

[116] D. Briggs and M. P. Seah; "Pratical Surface Analisys (second edition), V.1:Auger and X-ray Photoelectron Spectroscopy"; (John Wiley \& Sons, Chichester, 1990).

[117] M. D. Lumb, “Luminescence Spectroscopy”, (Academic Press 1978).

[118] B. D. Cullity, "Elements of X-Ray Diffraction", (Addison-Wesley Series in Metallurgy and Materials) Ed Addison-Wesley Publishing Company (Philippines Copyright, 1978).

[119] H.P. Klug and L.E. Alexander, "X-Ray Diffraction Procedure for Polycrystalline and Amorphous Materials", Vol. 2, 791-859, John Wiley and Sons, N.Y. (1974).

[120] G. Margaritondo, "Introduction to Synchrotron Radiation", Oxford University Press, (1988).

[121] P.A. Lee, P. Citrin, P. Eisenberg, B. Kincaid, Rev. Mod. Phys. 53, 769 (1981). 
[122] B.K. Teo, D.C. Joy, "EXAFS Spectroscopy, Techniques and Applications", Plenum, N.Y., (1981).

[123] Matthew Newville, "Fundamentals of XAFS", Consortium for Advanced Radiation Sources University of Chicago, Chicago, IL Revision 1.2 Sept 15 (2002).

[124] V. M. S. Gil e C. F. G. C. Geraldes, "Ressonância Magnética" (Fundação Calouste Gulbenkian 1987).

[125] C. P. Slichter, "Principles of Magnetic Resonance" (CLAS), 3rd ed., (Springer-Verlag, 1992 and Harper \& Row, 1963), p. 65.

[126] S. M. Kirkpatrick, J. W. Baur, C. M. Clark, L. R. Denny, D. W. Tomlin, B. R. Reinhardt, R. Kannan, M. O. Stone, Appl. Phys. A 69, (1999) 461.

[127] C. J. Barrett, A. L. Natansohn, P. L. Rochon, J. Phys. Chem. 100 (1996) 8836.

[128] R. V. Ramaswamy, R. Srivastava, J. Lightwave Technol. 6 (1988) 225.

[129] C.V. Poulsen, J. Huebner, T. Rasmussen, L.U.A. Andersen, M. Kristensen, Electron. Lett. 31 (1995) 1437.

[130] G.D. Maxwell, R. Kashyap, B.J. Ainslie, D.L. Williams, J.R. Armitage, Electron. Lett. 28 (1992) 2106.

[131] V. Mizrahi, P.J. Lemaire, T. Erdgan, W.A. Reed, D.J. DiGiovanni, Appl. Phys. Lett. 63 (1993) 1727.

[132] M. Svalgaard, C.V. Poulsen, A. Bjarklev, O. Poulsen, Electron Lett. 30 (1994) 1401.

[133] A. B. Seddon, J. Non-cryst. Sol., 184 (1995) 44.

[134] Jean-Pierre Fonassier \& Jan F. Rabek, "Lasers in Polymer Science and Technology: Applications", (CRC Press, Boca Raton, Fla), v. 3 (1989).

[135] O. V. Mazurin, M. V. Streltsina, and Shvaikovskaya (Eds.), Handbook of glass data, Part E, (Single-component, binary, and ternary oxide glasses) Elsevier, Amsterdam, 1985.

[136] A. Michalowicz, "EXAFS pous lê Mac" (Societé Française de Chimie, Paris, 1991) p.102.

[137] Z. Yin, M. Kasrai, G. M. Bancroft, "X-Ray Absorption spectroscopic studies of sodium polyphosphate glasses", Phys Rev B, 51 (1995) 742.

[138] A. Bianconi, M Dell'Ariccia, A. Gargano, C. R. Natoli, "EXAFS Near Edge Structure", Springer Ser. Chem. Phys. 27 (1983) 57.

[139] R. Balda , L.M. Lacha , A. Mendioroz , M. Sanz , J. Fernandez , J.-L. Adam , M.A. Arriandiaga, J. Alloys Comp., 323-324 (2001) 255.

[140] K. Tanaka, Y. Kasanuki and A. Odajima, Thin Solids Films 117 (1984) 251.

[141] L. Ticky, A.Trista, H. Ticha and M. Frumar, Phylosophical Magazine B, 54 (1986) 219.

[142] S. H. Messaddeq, Tese de Doutorado, Instituto de Física - USP/São Carlos, 2003.

[143] T. Kawaguchi and S. Maruno, Jap. Appl. Phys. 27 (1988) 2199.

[144] K.S. Harshavardhan ans m.S. Hedge, solid state Commun. 69 (1989)117.

[145] P. Arun, A. G. Vedeshwar, J. Appl. Phys. 79 (8) (1996) 4029.

[146] P. Arun, A. G. Vedeshwar, J. Non-Cryst. Sol. 220 (1997) 63.

[147] P. Arun, A. G. Vedeshwar and N. C. Mehra, Mat. Res. Bull. 32 (7) (1997) 907.

[148] M. Nocun, J. Non-Cryst. Sol. 333 (2004) 90. 
[149] P. Y. Shih, Materials Chemistry and Physics 80 (2004) 151.

[150] T. Honma, R. Sato, Y. Benino, T. Komatsu, V. Dimitrov, J. Non-Cryst. Sol. 272 (2000) 1.

[151] S. R. Elliot, Nature 354 (1991).

[152] B. Moine, C. Pedrini, E. Duloisy, P. Boutinald, C. Parent, G. Leflem, J. Physique IV 1 (C1) (1991) 289.

[153] P. Boutinaud, D. Garcia, C. Parent, M. Faucher, G. Le Flem, J. Phys. Chem. Sol. 56 (9) (1995) 1147.

[154] E. Borsella, A. Dal Vecchio, M. A. Garcia, C. Sada, F. Gonella, R. Polloni, A. Quaranta, L. J. G. W. Van Wilderen, J. Appl. Phys. 91 (1) (2002) 90.

[155] D. L. Griscom, "Electron Spin Ressonance in Glasses", J. of Non-Cryst. Sol., 40 (1980) 211.

[156] M. V. Ramana, P. S. Lakshmi, S. Rahman, K. Sivakumar, G. S. Sastry, Mat. Sci. and Eng. B10 (1991) 25.

[157] H. Imagawa, Phys. Stat. Sol., 30 (1968) 469.

[158] L. D. Bogomolova, T. F. Dolgolenko, V. A. Jachkin, V. N. Lazukin, J. of Mag. Resson. 15 (1974) 283.

[159] G. Fuxi, "Optical and Spectroscopic properties of glass", pp. 127-147 (Springer-Verlag, 1992).

[160] O. Cozar and I. Ardelean, J. of Non-Cryst. Sol., 92 (1981) 278.

[161] O. I. Shpotyuk, Opto-Electronics Review 11(1).

[162] K. Schwartz, "The Physics of Optical Recording" (Springer, Berlin, 1993).

[163] H.J. Eichler, P. Gunter, D.W. Pohl, "Laser Induced Dynamic Gratings", Springer Verlag, vol 50, pag 99 (1998).

[164] P. Hariharan, in P. L. Knight and S. D. Smith, (eds.), “Optical Holography: Principle, Techniques, and Applications", Cambridge Studies in Modern Optics, Cambridge, 1987, p 85.

[165] K. Simmons-Potter, B.G. Potter Jr., Journal of Non-Crystalline Solids 239 (1998) 96.

[166] K.D. Simmons, S. LaRochelle, V. Mizrahi, G.I. Stegeman, D.L. Griscom, Opt. Lett. 16 (1991) 141. [167] D.P. Hand, P.St.J. Russell, Opt. Lett. 15 (1990) 102.

[168] R.M. Atkins, V. Mizrahi, T. Erdogan, Elec. Lett. 29 (1993) 385.

[169] K.D. Simmons, G.I. Stegeman, B.G. Potter Jr., J.H. Simmons, J. Non-Cryst. Solids 179 (1994) 254.

[170] M. Popescu, F. Sava, A. Lorinczi, E. Skordeva, P.J. Koch, H. Bradaczek, Journal of NonCrystalline Solids 227-230 (1998) 719.

[171] K. Petrov, P. J. S. Ewen, J. Non-cryst. Sol. 249 (1999) 150. 